\title{
Environmental Chamber Studies of Atmospheric Reactivities of Volatile Organic Compounds: Effects of Varying Chamber and Light Source
}

W. Carter, D. Luo, I. Malkina, and

J. Pierce

University of California

Riverside, $C A$

NREL technical monitor:

B. Bailey
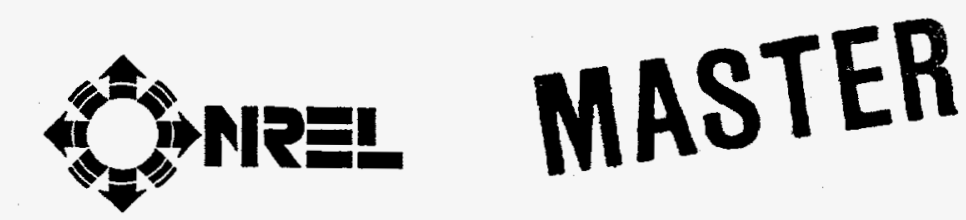

National Renewable Energy Laboratory 1617 Cole Boulevard Golden, Colorado 80401-3393

A national laboratory of the U.S. Department of Energy Managed by Midwest Research Institute for the U.S. Department of Energy

Under Contract No. DE-AC36-83CH10093

Prepared under Subcontract Number XZ-2120751

May 1995 


\section{NOTICE}

This report was prepared as an account of work sponsored by an agency of the United States government. Neither the United States government nor any agency thereof, nor any of their employees, makes any warranty, express or implied, or assumes any legal liability or responsibility for the accuracy, completeness, or usefulness of any information, apparatus, product, or process disclosed, or represents that its use would not infringe privately owned rights. Reference herein to any specific commercial product, process, or service by trade name, trademark, manufacturer, or otherwise does not necessarily constitute or imply its endorsement, recommendation, or favoring by the United States government or any agency thereof. The views and opinions of authors expressed herein do not necessarily state or reflect those of the United States government or any agency thereof.

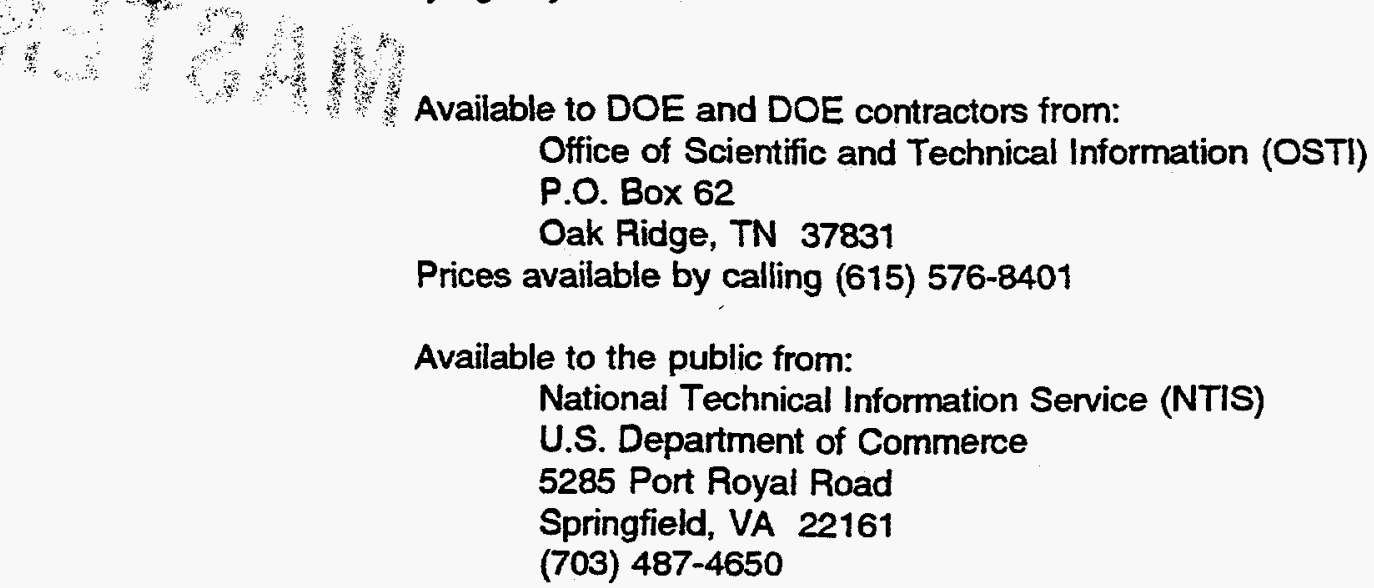




\section{DISCLAIMER}

Portions of this document may be illegible in electronic image products. Images are produced from the best available original document. 


\section{PREFACE}

This report describes work carried out at the University of California under funding from the National Renewable Energy Laboratory (NREL) through Contract no. Xz-2-12075, the California Air Resources Board (CARB) through contract number A032-0962, the Coordinating Research Council, Inc. (CRC) through project number ME-9, and the California South Coast Air Quality Management District (SCAQMD) through contract no. C91323. NREL funded the construction and evaluation of the xenon arc light source. CARB, CRC and NREL funded most of the experimental work, and the SCAQMD funded the building where the experiments were conducted

The opinions and conclusions in this document are entirely those of the authors. Mention of trade names and commercial products does not constitute endorsement or recommendation for use. 


\begin{abstract}
An experimental and modeling study was conducted to assess how chemical mechanism evaluations using environmental chamber data are affected by the light source and other chamber characteristics. Xenon arc light lights appear to give the best artificial representation of sunlight currently available, and experiments were conducted in a new Teflon chamber constructed using such a light source. Experiments were also conducted in an Outdoor Teflon Chamber using new procedures to improve the light characterization, and in Teflon chambers using blacklights. These results, and results of previous runs other chambers, were compared with model predictions using an updated detailed chemical mechanism. The magnitude of the chamber radical source assumed when modeling the previous runs were found to be too high; this has implications in previous mechanism evaluations. Temperature dependencies of chamber effects can explain temperature dependencies in chamber experiments when $\mathrm{T} z \sim 300^{\circ} \mathrm{K}$, but not at temperatures below that. The model performance had no consistent dependence on light source for experiments not containing aromatics, but the model tended to underpredict $\mathrm{O}_{3}$ in the new xenon arc and blacklight chamber runs. This is despite the fact that such biases are not seen in modeling runs in the older xenon arc chamber or in preliminary modeling of University of North Carolina outdoor chamber runs. The reasons for this are not clear, and additional studies are planned as part of our ongoing program.
\end{abstract}




\section{ACKNOWLEDGEMENTS}

The authors wish to acknowledge and thank Mr Bart Croes of the CARB, Mr. Tim Belian of the CRC, Dr. Alan Lloyd of the SCAQMD, Mr. Brent Bailey of NREL, and the members of the CRC/APRAC reactivity committee for their support of this project and their patience with the delays in completing this report. We also gratefully acknowledge Dr. Joseph Norbeck, Director of the University of California, Riverside's College of Engineering Center for Environmental Research and Technology (CE-CERT) for providing significant salary support and equipment used in this project.

Mr. Robert walters made major contributions to the specification, design, and construction of the xenon arc light source, and assisted in improvements to the pure air and temperature control system used in this project. Mr. Ken Sazaki did most of the work in developing and adapting the Jeffires light model for use in calculating photolysis rates for the outdoor chamber, and assisted in other ways in the light characterization efforts. Dr. Harvey Jeffries of the University of North Carolina provided very important and helpful assistance to Mr. Sazaki in developing the model, and provided the Teflon characterization data and model needed to adapt the light model to our chamber. Valuable assistance in constructing the chamber facility and conducting the experiments for this program was provided by Mr William D. Long. Mr Kurt Bumiller assisted in conducting some of the xenon arc light characterization experiments. Mr. Dennis Fitz assisted in the preparation of this report. Assistance in conducting the experimental runs was provided by MS. Kathalena M. Smihula and Mr. Armando D. Avallone. 


\section{EXECUTIVE SUMMARY}

\section{Background}

Photochemical oxidant models are essential tools for assessing effects of emissions changes on ground-level ozone formation. Such models are needed for predicting the ozone impacts of increased alternative fuel use. The gas-phase photochemical mechanism is an important component of these models because ozone is not emitted directly, but is formed from the gas-phase photochemical reactions of the emitted volatile organic compounds (VOCs) and oxides of nitrogen ( $\mathrm{NO}_{x}$ ) in air. The chemistry of ground level ozone formation is complex; hundreds of types of vocs being emitted into the atmosphere, and most of their atmospheric reactions are not completely understood. Because of this, no chemical model can be relied upon to give even approximately accurate predictions unless it has been evaluated by comparing its predictions with experimental data.

The primary means for evaluating chemical mechanisms for use in airshed models is to determine if they can correctly simulate the results of environmental chamber experiments. If a mechanism cannot successfully predict ozone under well characterized conditions, it certainly can not be relied upon to do so in the atmosphere. If the model can successfully predict the gas-phase transformations under a range of conditions reflecting the variability in the atmosphere, one has at least some basis to expect that it might give appropriate predictions in ambient simulations, if provided with the appropriate input data.

Unfortunately, the use of environmental chamber data to evaluate mechanisms has its own set of difficulties. To successfully use such data for this purpose, the uncertainties in characterizing the conditions of the experiments, including chamber effects as well as light intensity and spectrum, temperature, reactant levels, etc., must be less than the uncertainties in the mechanism being evaluated. Otherwise, errors in the chamber or experimental characterization assumptions will result in a correct mechanism giving predictions which are inconsistent with the data or, worse, an erroneous mechanism appearing to be "validated" by the data because of compensating errors. In principle, the differences between these light sources and sunlight can be corrected for when modeling the chamber experiments, but this requires a knowledge if the absorption cross sections and times quantum yields of all the important photolysis reactions, which in many cases, particularly for aromatic products, are uncertain.

Among the various factors distinguishing different types of chambers, the nature of the light source is perhaps the most important. This is because light provides the energy which drives the entire photochemical smog formation process. The light source must approximate both the intensity and spectrum of sunlight if it is to provide an appropriate simulation of atmospheric chemistry. The use of outdoor chambers and natural sunlight is one way to address this, but outdoor 
chamber experiments are much more difficult to control and characterize for modeling, and are also more expensive. Indoor chambers allow for conditions to be more controlled and better characterized, but require the use of artificial light sources whose spectrum can only approximate that of sunlight.

Various alternatives for indoor chamber lighting are discussed in detail in this report. The major practical options are blacklights for blacklights combined with sunlight) and xenon arc lights. Blacklights have been widely used but have an unnatural spectrum in the higher wavelength region which affects photolyses of $\mathrm{NO}_{3}$ radicals and certain aromatic products. Xenon arc lights provide a much better simulation of sunlight in that wavelength region, though they have their own difficulties, the principal ones being that they are much more expensive and that their spectra are much more variable.

The nature of the chamber walls is an additional factor which must be considered. Different assumptions concerning the chamber radical source and other chamber-dependent effects have been used when modeling data from these various types of chambers.

There is already a fairly extensive data base of environmental chamber experiments for mechanism evaluation. However, this data set has limitations. For example, there are many important types of vocs for which the available mechanism evaluation data are limited or of low quality. While there are now a number of VOC reactivity experiments with indoor chambers using blacklights, there is relatively little information concerning whether the use of this unnatural light source may be affecting reactivities in ways which are not understood. Perhaps more significantly in terms of the overall mechanism evaluation process, this data set is not adequate to systematically assess how the major chamber characteristics (e.g., light source, surface type, operating procedures) affect mechanism evaluation results.

\section{Objectives and scope}

The objectives of this study is to systematically assess how the nature of the environmental chamber and light source affects mechanism evaluation results. The scope of this effort included both modeling comparable experiments in the available data base carried out in different types of chambers, and conducting new experiments to provide the additional data needed for a systematic assessment. To address the need for well-characterized data concerning the effects of alternative light sources, we constructed a new Teflon environmental chamber utilizing a xenon arc light source, we developed an improved method to characterize light intensity in outdoor chamber experiments, and we conducted a number of experiments with representative compounds and mixtures using these chambers. Experiments were also carried out in blacklight irradiated chambers to fill in additional gaps in the data base needed for this study. The results of these new and selected previous experiments were then used to determine if 
they were consistent with our current understanding of atmospheric chemistry and of chamber and light source characteristics.

The types of experiments which were used to evaluate chamber and light source effects for this program are summarized in Table EX-1. The new experiments conducted especially for this study are shown in bold. The table also includes a qualitative summary of the performance of the model in simulating these runs, which is discussed in the following section.

\section{Results and Conclusions}

Performance Evaluation of Alternative Light Sources. Xenon arc lights were found to give a better representation of sunlight for use in indoor chamber experiments than the other alternatives which were examined. A commerciallyavailable system consisting of four $6.5 \mathrm{~kW}$ xenon arc lights was installed in a room with reflective surfaces and was found to give acceptable light intensity and uniformity for irradiating a 2000 -liter Teflon film chamber. The lights decline slowly in intensity with time, particularly in the UV portion of the spectrum. However, in terms of spectral stability and representativeness of ground-level sunlight in the far UV region the well-conditioned or aged xenon arc lights are actually more suitable for environmental chamber studies than newly conditioned ones. The light was found to give photolysis rates which correspond to sunlight as well as can reasonably be expected, given the fact that ratios of photolysis rates can vary by a factor of two or more in the atmosphere, depending on conditions. This is definitely superior to the performance of blacklights in this regard.

However, since the match between xenon arc lights and sunlight is not exact, outdoor chamber runs are still necessary to verify that we can accurately model the important photoreactive processes in the atmosphere. They are also necessary to verify the performance of the xenon arc system in simulating photochemical reactions in sunlight. To provide data useful for this, we developed an improved method for deriving outdoor chamber light spectra. This is based on direct measurements of sunlight spectra during the runs, and on utilizing a light model to correct for differences between the measured spectra and intensities and spectra and intensities in the chamber. The method gave good predictions of $\mathrm{NO}_{2}$ photolysis rates measured in and out of the chamber, though a $\sim 7 \%$ correction, presumably to account for albedo effects, had to be applied. Although only applicable for modeling runs carried out under clear sky conditions, we were able to carry out a sufficient number of outdoor runs under such conditions to provide a useful comparison with the xenon arc and other experiments.

As shown on Table EX-1, The results of the outdoor chamber and xenon arc runs were generally consistent in terms of model performance when simulating comparable runs. With the possible exception of the outdoor chamber ethene runs, where inexplicably variable results were obtained, the types of runs which 
Table EX-1. Summary of types of chamber runs used to assess the effects of chamber and light source on mechanism evaluation results.

\begin{tabular}{lcccccccc}
\hline Chamber & ITC & ETC & DTC & DTC & EC & XTC & OTC & UNC \\
Light Source & BL & BL & BL & BL & Xen & Xen & Sun & Sun \\
Humidityb & Wet & Dry & Dry & Wet & Wet & Dry & Dry & Wet \\
Surface $^{\text {C }}$ & TF & TF & TF & TF & TCA & TF & TF & TF \\
\hline
\end{tabular}

\section{Run Type}

Formaldehyde

Acetaldehyde

Ethene

Propene

Toluene

m-XYlene

135-Trimethylbenzene

Surrogate Mixtures

Run Type

Formaldehyde

Acetaldehyde

Ethene

Propene

Toluene

m-Xylene

135-Trimethylbenzene

Surrogate Mixtures
Number of Experiments Modeled ${ }^{d}$

$\begin{array}{cccccccc} & 2 & & & 4 & 3 & 2 & \\ 3 & 17 & 10 & & 2 & 2 & 4 & \\ 13 & 3 & 5 & 2 & 5 & 3 & 7 & \\ 2 & & 2 & & 9 & 1 & 6 & 20 \\ 1 & 1 & 2 & & 2 & 1 & 4 & \\ 3 & & & 2 & 1 & & \\ 18 & 35 & 33 & & 10 & 2 & 7 & 20\end{array}$

Qualitative Model Performance ${ }^{e}$

ok

ok

ok

var

ok fair

var ok

ok

ok

ok

ok ok

ok

ok

ok

ok

ok

\section{fair}

fair

var ok ok

var ok

var low

ok low

ok low

ok low var

ok ok-var

low-var

low

low ok

a $\mathrm{BL}=\mathrm{blacklights;}$ Xen = xenon arc; Sun = sunlight

b Wet $=\sim 50 \% \mathrm{RH}$ or (for UNC) variable $\mathrm{RH} ;$ Dry $=55 \% \mathrm{RH}$

c $T F=$ FEP Teflon film; TCA = Teflon coated aluminum with quartz end windows.

d New experiments not reported previously are shown in bold.

- Codes for the performance of the model in simulation $\mathrm{O}_{3}$ formation and No oxidation rates are as follows. Low temperature UNC or ETC surrogate runs, where the model consistently overpredicted, are not included.

ok Agreement within $\pm 30 \%$ with no consistent bias

fair Agreement within $\pm 30 \%$ with some variability or bias that may be due to uncertainty in the radical source.

var Significant run-to-run variability that cannot be attributed to uncertainty in the radical source. More extreme cases shown in bold.

low The model has a definite bias for underprediction that cannot be attributed to the radical source.

were simulated reasonably well in the XTC were also simulated reasonably well in the OTC. Where there were biases in the model performance results, they were generally the same for both chambers. This indicates that modeling runs using the xenon arc light source gives a good indication of how well the model will perform simulating runs using real sunlight, provided that other conditions are comparable. The consistency in the OTC and XTC results also provides indirect evidence to support the light characterization method developed for the outdoor chamber. 
Chamber Effects. Chamber effects represent a significant factor which must be taken into account when comparing data from different chambers. The differences in mechanism evaluation results between the SAPRC EC and the new XTC, which have essentially the same type of light source but quite different types of walls (and operated at different humidities), indicate the potential importance of chamber effects.

The most important known chamber effect is the chamber radical source. This can be a significant factor affecting model biases when assessing model performance using environmental chamber data. This is particularly important when looking for trends and biases on the order of 25-50\%, which is the case for most of the groups of runs modeled in this work. Uncertainties and variabilities in the radical source have the greatest effect under low ROG/NO $\mathrm{N}_{x}$ conditions. (Note that these are also conditions where vocs have their largest incremental effect on ozone formation.) Therefore, the sensitivity of the model simulations to this effect decreases as $\mathrm{ROG} / \mathrm{NO}_{\mathrm{x}}$ increases. This means that an inappropriate radical source assignment could cause apparent $\mathrm{ROG} / \mathrm{NO}_{\mathrm{x}}$ dependencies in model biases. Because of this, and the uncertainties and variabilities in the radical source, we find that the that model performance generally improves as $\mathrm{ROG} / \mathrm{NO}_{x}$ increases.

The radical source assignments which have been used in previous mechanism evaluations using SAPRC chamber data were re-evaluated for this study, and were revised downward significantly. Using the tracer- $\mathrm{NO}_{x}$ method for deriving radical source parameters is apparently not as reliable as modeling $\mathrm{n}$-butane- $\mathrm{NO}_{\mathrm{x}}$ or $\mathrm{CO}$ $\mathrm{NO}_{\mathrm{x}}$ experiments, particularly for Teflon film chambers. This revision of our radical source assignments has implications concerning previous SAPRC mechanism evaluations, and is probably the reason we found that the performance of the SAPRC-90 mechanism in simulating SAPRC chamber data deteriorated when it was updated based on new laboratory kinetic data. This indicates the importance of appropriate and consistent radical source assignments when evaluating mechanisms using chamber data. The implications this may have in atmospheric predictions of updated mechanisms evaluated using chamber data have not yet been determined.

The results of this work confirmed earlier studies that the chamber radical source is temperature dependent, and improved the data base necessary to quantify it. A single Arrhenius-type temperature dependence expression was found to fit the results of the $n$-butane runs carried out in all the Teflon film chambers where dry air was used, regardless of light source. This is based primarily on data from the outdoor chamber, where the average temperature ranged from $310-$ $319 .{ }^{\circ} \mathrm{K}$, combined with the indoor runs where the temperature was typically $\sim 300^{\circ} \mathrm{K}$. The temperature dependence corresponds to an apparent activation energy of $\sim 20$ $\mathrm{kcal} / \mathrm{mole}$. The radical sources are higher in chambers using humidified air and in the SAPRC EC, which has different types of walls (see Table EX-1). 
The dependence of the radical source on temperature explains some but not all of the temperature dependence observed in previous chamber runs. The temperature dependence of the radical source derived in this work explains the temperature dependencies observed in the replicate ETC mini-surrogate experiments used in our previous reactivity studies, but only when the average temperatures was higher than $\sim 301^{\circ} \mathrm{K}$. The model still overpredicted $\mathrm{O}_{3}$ formation in the runs at lower temperatures, and also in UNC chamber runs at temperatures below $\sim 295^{\circ} \mathrm{K}$. It is probable that either the current gas-phase mechanisms are not accurate for lower temperature conditions, or that there is some low-temperature chamber artifact that is not currently recognized. More controlled experiments, both for chamber characterization and for mechanism evaluation, are needed for lower temperature conditions.

Effect of Chamber and Light Source on Mechanism Evaluations. The results of this study indicate no significant light source effect in the mechanisms evaluation results for runs which do not contain aromatics. The model performed well in simulating the aldehyde runs in chambers with the different light sources. This is significant because these compounds are photoreactive and experiments with them should be highly sensitive to the light source. The model is apparently appropriately representing the differences in light spectra between blacklights, xenon arcs, and sunlight, at least for the photolysis reactions which are important in runs which do not contain aromatics.

There was variability in the model performance in the simulations of the propene and even more in the simulations of the ethene runs, in some of the chambers. In the case of propene the variability may be a humidity effect, though additional experiments are needed to confirm this. In the case of ethene, the variability was observed in experiments using sunlight and some of the runs using the xenon arc light source, but not in the runs with blacklights. There may be something in ethene's chemistry which is not being well represented in the model, though ethene has been thought to be the best understood of all the reactive VOCs. More ethene runs in the XTC, at variable $\mathrm{ROG} / \mathrm{NO}_{\mathrm{x}}$ and temperatures, are needed to determine what experimental variables affect model performance for this important compound. Such experiments are being included in the next phase of our experimental chamber studies.

The model simulations of the aromatic and surrogate mixture runs suggest that there may be a problem either in the gas-phase mechanisms for aromatic compounds, or some chamber or humidity effect involving aromatics which has not been identified. The model gives fair to good performances in simulating the aromatic and mixture runs in the blacklight chambers and the EC, but has a bias towards underpredicting ozone formation in aromatic or mixture runs in the XTC and the OTC. This is not simply a light source effect because such biases are not seen in the EC or UNC experiments, and not simply a humidity effect since such biases are not seen in the DTC or ETC. This result is difficult to understand unless there are compensating errors in the model involving both 
humidity and light source effects in the chambers where the unbiased fits are observed. We are planning to carry out an extensive series of additional aromatic experiments in the xenon arc chamber, and the study of the effects of humidity on these experiments, as part of the next phase of our experimental environmental chamber programs.

As a whole, this study has provided useful information concerning the current status of chemical mechanism evaluation using environmental chamber data. To our knowledge, this is the first attempt to systematically evaluate the effect of changing the nature of the light source on the ability of a state-of-the-art chemical mechanism to simulate environmental chamber results. Although the results were not completely conclusive because of inconsistencies between new xenon arc chamber runs and previous runs in a different type of chamber using a similar light source, we believe that significant progress has been made. Additional work is clearly needed, some of which is underway in our laboratories. 
xii 


\section{TABLE OF CONTENTS}

Section

Page

PREFACE

ABSTRACT

ACKNOWIEDGEMENTS

EXECUTIVE SUMMMARY

I. INTRODUCTION

A. Background

B. Available Chamber Data Base

C. Objectives and scope of this study

II. ANALYSIS OF ALTERNATIVE LIGHT SOURCES

FOR ENVIRONMENTAL CHAMBER STUDIES
A. Specification of Requirements
B. Alternative light sources
1. Spectra of Representative Light Sources. . . * .
2. Photolysis Rate Constant Ratios for Representative Light Sources.
c. Assessments of Iight Intensity, uniformity, and cost consider- ations
D. Acquisition and Initial Testing of Xenon Arc Iights.

III. EXPERIMENTAI METHODS . . . . . . . . . . . . . . . . . . . . . . . 23

A. Chambers . . . . . . . . . . . . . . . . . . . . . . . . . . 23

1. Indoor Teflon Chamber \#2 (ETC) . . . . . . . . . . . . . . . . 23

2. Dividable Teflon Chamber (DTC) . . . . . . . . . . . . 23

3. Xenon Teflon Chamber (XTC) . . . . . . . . . . . . . . 24

4. Outdoor Teflon Chamber . . . . . . . . . . . . . . . 25

B. Experimental Procedures . . . . . . . . . . . . . . . . . . . 27

C. Analytical Methods . . . . . . . . . . . . . . . . . . . 27

D. Iight Source Characterization . . . . . . . . . . . . . . . 28

1. Indoor Chambers . . . . . . . . . . . . . . . . . . . . 28

2. Outdoor Chamber... . . . . . . . . . . . . . . . 29

E. Other Characterization Data . . . . . . . . . . . . . . . . . 30

1. Temperature . . . . . . . . . . . . . . . . . . . 30

2. Dilution . . . . . . . . . . . . . . . . . . 31

3. Control Experiments . . . . . . . . . . . . . . . 32

IV. MODEL SIMULATION METHODS . . . . . . . . . . . . . . . . . . . . . . 33

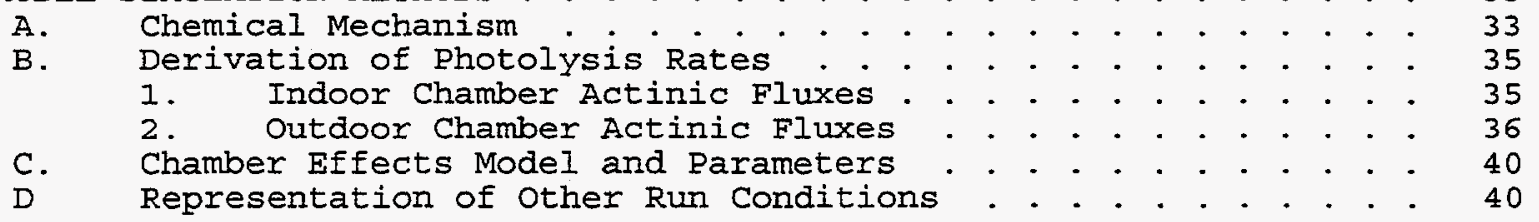

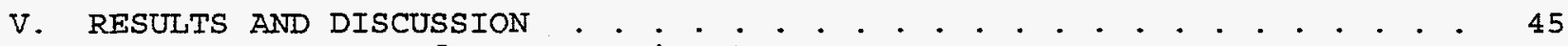

A. Summary of New Experiments . . . . . . . . . . . . . . . . . 45

B. Xenon Arc Light Evaluation Results . . . . . . . . . . . . . . . . . . 49

1. Light Intensity . . . . . . . . . . . . . . . . . . . . 49

2. Light Uniformity . . . . . . . . . . . . . . . . . . . 51

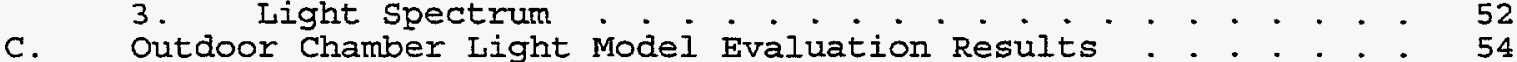


D. Evaluation of Chamber Radical Source Assignments . . . . . . 55 1. Re-Evaluation of Previous Radical Source Assignments . 58 2. Radical Source Assignments for Dry Teflon Chamber Experiments . . . . . . . . . . . . . . . . . . . . . 63

E. Effect of Light Source and Chamber on Mechanism Evaluation Results . . . . . . . . . . . . . . . . . . . . . . 66 1. Formaldehyde and Acetaldehyde . . . . . . . . . . . . . 68

2. Ethene .. . . . . . . . . . . . . . . . . . . 76

3. Propene . . . . . . . . . . . . . . . . . . . 80

4. Aromatics .. . . . . . . . . . . . . . . . . . 80

5. Surrogate Experiments . . . . . . . . . . . . . . . . 887

5. UNC Outdoor Chamber Experiments . . . . . . . . . . . . 92

VI. CONCLUSIONS • . . . . . . . . . . . . . . . . . . . . . . . . . . . 95

VII. REFERENCES . . . . . . . . . . . . . . . . . . . . . . . . . . . . 101 
1. Calculated Ratios of Rate Constants for Photolysis Reactions used in a Photochemical Smog Reaction for Selected Light sources.

2. Reactions and parameters used to represent chamber wall processes

and contaminant effects. . . . . . . . . . . . . . . . . . . . . .

3. Values of chamber wall and contaminant effects parameters used when modeling runs in this work.

4. Listing of new environmental chamber experiments relevant to this report. . . . . . . . . . . . . . . . . . . . . . . . . .

5. Summary of results of $\mathrm{NO}_{2}$ actinometry experiments in the Xenon Teflon Chamber. . . . . . . . . . . . . . . . . . . . . . . . . .

6. Calculated ratios of photolysis rate constants relative to $\mathrm{NO}_{2}$ for the XTC or blacklight chambers, relative to ratios calculated for solar zenith angles of $0^{\circ}$ and $60^{\circ}$.

7. Results of $\mathrm{NO}_{2}$ actinometry experiments in the outdoor chamber. . . 56

8. Summary of radical source values which best fit data in model simulations of ETC, DTC, XTC, and OTC n-butane experiments. . . .

9. Summary of types of chamber runs used to assess the effects of chamber and light source on mechanism evaluation results. . . . .

10. Summary of conditions and experimental and calculated $d\left(O_{3}-\mathrm{NO}\right)$ results for all environmental chamber experiments modeled for this program. 
$x v i$ 


\section{LIST OF FIGURES}

Number

page

1. Spectra of representative light sources in the 300-700 nm region. . 9

2. Spectra of representative light sources in the $280-350 \mathrm{~nm}$ region. . 10

3. Plots of Action Spectra for the Photolysis Reactions in the Carter (1990) Atmospheric Photochemical Mechanism for Solar ( $\mathrm{z}=0)$ Irradia-

tion. . . . . . . . . . . . . . . . . . . . . . . . . . .

4. Plots of Relative Differences in Photolysis Rate Constant Ratios for Various Light Sources, Compared with $\mathrm{Z}=0$ Sunlight. . . . . . . . . 16

5. Side view of Xenon Teflon Chamber. . . . . . . . . . . . . . . . . 25

6. Diagram of the SAPRC Outdoor Teflon Chamber (OTC). . . . . . . . 26

7. Examples of fits of adjusted solar light model to light characterization data for two outdoor chamber runs. Top plots: fits to direct and diffuse spectral data. Bottom plots: fits to changes with time in the data from the UV and broadband radiometers.

8. Plots of $\mathrm{NO}_{2}$ photolysis rates in the XTC chamber against XTC run number. . . . . . . . . . . . . . . . . . . . . . . . . .

9. Summary of results of light uniformity measurements in the XTC. . .

10. Representative XTC spectra compared with solar spectra for zenith angles of $0^{\circ}$ and $60^{\circ}$. . . . . . . . . . . . . . . . . . . . . . . . . .

11. (A) Ratio of spectrum of run XTC120 relative to that of run XTC08I against wavelength, showing the decline of spectral intensity as a function of wavelength during the experiments for this program. plot of relative intensity at $300 \mathrm{~nm}$ against XTC run number.

12. Plots of experimental $\mathrm{Vs}$ calculated $\mathrm{NO}_{2}$ photolysis rates measured in or around the Outside Teflon Chamber. . . . . . . . . . . . . . . .

13. Results of model simulations of $d\left(O_{3}-N O\right)$ of the $n$-butane - NO ethene - $\mathrm{NO}_{\mathrm{x}}$ and propene - $\mathrm{NO}_{\mathrm{x}}$ experiments carried out in the SAPRC ITC, where the model used the radical source assignments used in the SAPRC-90 and RADM-2 mechanism evaluations.

14. Results of model simulations of $d\left(\mathrm{O}_{3}-\mathrm{NO}\right)$ of the $n$-butane - $\mathrm{NO}_{x}$, ethene - $\mathrm{NO}_{x}$ and propene - $\mathrm{NO}_{x}$ experiments carried out in the SAPRC ITC, where the model used the radical source assignments adjusted to fit the n-butane runs.

15. Experimental and calculated concentration - time profiles for $\mathrm{d}\left(\mathrm{O}_{3}-\mathrm{NO}\right)$ and propene and $\mathrm{n}$-butane tracers in the tracer $-\mathrm{NO}_{\mathrm{x}}+$ added $\mathrm{CO}$ experiment ITC625.

16. Results of model simulations of $d\left(\mathrm{O}_{3}-\mathrm{NO}\right)$ in the $\mathrm{EC} \mathrm{n}$-butane - $\mathrm{NO}_{x}$ runs using the previous and the adjusted radical source assignments.

17. Results of model simulations of $\mathrm{d}\left(\mathrm{O}_{3}-\mathrm{NO}\right)$ in $\mathrm{ETC} \mathrm{n}$-butane - $\mathrm{NO}_{x}$ and in selected set 3 mini-surrogate - NO experiments using the radical source assignment of Carter et. al (1993a). 
18. Arrhenius plot showing the temperature dependence of radical source input parameters which fit the ETC, DTC, XTC, and OTC n-butane runs.

19. Results of model simulations of the ETC, DTC, XTC, and OTC n-butane - $\mathrm{NO}_{x}$ experiments using the radical source assignment given in Equation (IV)

20. Results of model simulations of $d\left(\mathrm{O}_{3}-\mathrm{NO}\right)$ in the formaldehyde - $\mathrm{NO}_{\mathrm{x}}$ and the acetaldehyde - $\mathrm{NO}_{x}$ experiments.

21. Results of model simulations of $d\left(\mathrm{O}_{3}-\mathrm{NO}\right)$ in the ethene - $\mathrm{NO}_{x}$ experiments carried out in the blacklight chambers. . . . . . . . .

22. Results of model simulations of $d\left(\mathrm{O}_{3}-\mathrm{NO}\right)$ in the ethene - $\mathrm{NO}_{x}$ experiment carried out in the xenon arc or outdoor chambers. . . .

23. Plots of model bias for hour $3 \mathrm{~d}\left(\mathrm{O}_{3}-\mathrm{NO}\right)$ against initial $\mathrm{ROG} / \mathrm{NO}_{\mathrm{x}}$ ratio for the ethene - $\mathrm{NO}_{\mathrm{x}}$ experiments.

24. Results of model simulations of $d\left(\mathrm{O}_{3}-\mathrm{NO}\right)$ in the propene - $\mathrm{NO}_{x}$ experiments carried out in the blacklight chambers. . . . . . . . .

25. Results of model simulations of $d\left(\mathrm{O}_{3}-\mathrm{NO}\right)$ in the propene - $\mathrm{NO}_{\mathrm{x}}$ experiment carried out in the xenon arc or outdoor chambers.

26. Plots of model bias for hour $3 \mathrm{~d}\left(\mathrm{O}_{3}-\mathrm{NO}\right)$ against initial $\mathrm{ROG} / \mathrm{NO}_{\mathrm{x}} \mathrm{ratio}$ for the propene - NO, experiments.

27. Results of model simulations of $d\left(\mathrm{O}_{3}-\mathrm{NO}\right)$ in the toluene - $\mathrm{NO}_{\mathrm{x}}$ experiments. . . . . . . . . . . . . . . . . . . . . . .

28. Plots of model bias for hour $3 \mathrm{~d}\left(\mathrm{O}_{3}-\mathrm{NO}\right)$ against initial $\mathrm{ROG} / \mathrm{NO}_{\mathrm{x}} \mathrm{ratio}$ for the toluene - $\mathrm{NO}_{\mathrm{x}}$ experiments.

29. Results of model simulations of $d\left(\mathrm{O}_{3}-\mathrm{NO}\right)$ in the m-xylene - $\mathrm{NO}_{x}$ and $1,3,5$-trimethylbenzene - $\mathrm{NO}_{\mathrm{x}}$ experiments. . . . . . . . . . . . . . .

30. Plots of model bias for hour $3 \mathrm{~d}\left(\mathrm{O}_{3}-\mathrm{NO}\right)$ against initial $\mathrm{ROG} / \mathrm{NO}_{x} \mathrm{ratio}$ for the m-xylene - $\mathrm{NO}_{x}$ and 1,3,5-trimethylbenzene - $\mathrm{NO}_{\mathrm{x}}$ experiments.

31. Results of model simulations of $\mathrm{d}\left(\mathrm{O}_{3}-\mathrm{NO}\right)$ in surrogate - $\mathrm{NO}_{\mathrm{x}}$ experiments carried out in the ETC and the DTC. . . . . . . . . . . . .

32. Results of model simulations of $d\left(\mathrm{O}_{3}-\mathrm{NO}\right)$ in surrogate - $\mathrm{NO}_{\mathrm{x}}$ experiments carried out in the ITC and the EC.

33. Results of model simulations of $d\left(\mathrm{O}_{3}-\mathrm{NO}\right)$ in surrogate - $\mathrm{NO}_{x}$ experiments carried out in the XTC and the OTC.

34. Plots of model bias for hour $3 \mathrm{~d}\left(\mathrm{O}_{3}-\mathrm{NO}\right)$ against initial $\mathrm{ROG} / \mathrm{NO}_{\mathrm{x}}$ ratio for the surrogate - NO experiments.

35. Results of model simulations of $d\left(\mathrm{O}_{3}-\mathrm{NO}\right)$ in propene - NO and surrogate - $\mathrm{NO}_{\mathrm{x}}$ experiments carried out in the UNC outdoor chamber. 


\section{INTRODUCTION}

\section{A. Background}

Photochemical oxidant models are essential tools for assessing effects of emissions changes on ground-level ozone formation. Such models are needed for predicting the ozone impacts of increased alternative fuel use. The gas-phase photochemical mechanism is an important component of these models because ozone is not emitted directly, but is formed from the gas-phase photochemical reactions

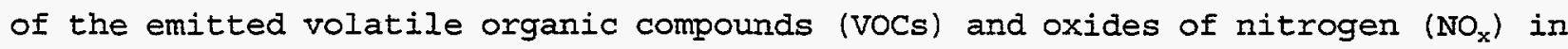
air. The chemistry of ground level ozone formation is complex; hundreds of types of VoCs being emitted into the atmosphere, and most of their atmospheric reactions are not completely understood. Because of this, no chemical model can be relied upon to give even approximately accurate predictions unless it has been evaluated by comparing its predictions with experimental data.

The primary means for evaluating chemical mechanisms for use in airshed models is to determine if they can correctly simulate the results of environmental chamber experiments. If a mechanism cannot successfully predict ozone under well characterized conditions, it certainly can not be relied upon to do so in the atmosphere. If the model can successfully predict the gas-phase transformations under a range of conditions reflecting the variability in the atmosphere, one has at least some basis to expect that it might give appropriate predictions in ambient simulations, if provided with the appropriate input data.

Unfortunately, the use of environmental chamber data to evaluate mechanisms has its own set of difficulties. To successfully use such data for this purpose, the uncertainties in characterizing the conditions of the experiments, including chamber effects as well as light intensity and spectrum, temperature, reactant levels, etc., must be less than the uncertainties in the mechanism being evaluated. Otherwise, errors in the chamber or experimental characterization assumptions will result in a correct mechanism giving predictions which are inconsistent with the data or, worse, an erroneous mechanism appearing to be "validated" by the data because of compensating errors. These problems have been discussed by Jeffries et al. (1992a), who concluded that it is essential that mechanisms be evaluated using data from a variety of different types of chambers. This would minimize (though not entirely eliminate) the chance of compensating errors due to mis-characterizing the conditions of any particular type of chamber.

Among the various factors distinguishing different types of chambers, the nature of the light source is perhaps the most important. This is because light provides the energy which drives the entire photochemical smog formation process. The light source must approximate both the intensity and spectrum of sunlight if it is to provide an appropriate simulation of atmospheric chemistry. The use of outdoor chambers and natural sunlight is one obvious means to address this 
requirement. However, conditions in the current generation of outdoor chambers are much more difficult to control and, more importantly for mechanism evaluation, the time-varying intensity and spectrum of the sunlight are much more uncertain to characterize for modeling. This makes outdoor chamber data a somewhat imprecise test of the mechanism, since poor fits of the model to the data can, at least to some extent, be blamed on characterization uncertainties. In addition, outdoor chamber experiments are more expensive and difficult to carry out, and can only provide useful data on days with favorable weather conditions. Indoor chambers allow for conditions to be more controlled and better characterized (including especially the intensity and spectrum of the light source), but require the use of artificial light sources whose spectrum can only approximate that of sunlight.

The various alternatives for indoor chamber lighting are discussed in detail in section II of this report. As indicated there, the major options in practice are either blacklights (or blacklights combined with sunlights) or xenon arc lights. Blacklights have been widely used because they are inexpensive and easy to use, and can provide the appropriate intensity in the ultraviolet (UV) region which promotes most photochemical reactions. However, they have unnaturally low relative intensities in the visible region, and have sharp spectral lines in the wavelength regions affecting photolysis reactions which are not present in natural sunlight. Xenon arc lights provide a much better simulation of sunlight in the longer wavelength region, though the match with sunlight is not exact, and the UV intensity is variable, depending on the age of the lamp and the spectral filter(s) employed.

In principle, the differences between these light sources and sunlight can be corrected for when modeling the chamber experiments, but this requires a knowledge of the action spectra (absorption cross sections times quantum yields) of all the important photolyzing species and reactions. In many cases these action spectra are uncertain, particularly for the unidentified aromatic ring fragmentation products.

The nature of the chamber walls is an additional factor which must be considered. This can affect heterogeneous reactions such as the "chamber radical source" (Carter et al., 1982; Carter and Lurmann, 1990, 1991) which are believed to significantly affect environmental chamber results. Basically there are two types of surfaces which have been used to generate chamber data considered to be sufficiently well characterized for mechanism evaluation: heat-sealable FEP Teflon film such as used for the University of North Carolina (UNC) and Statewide Air Pollution Research Center (SAPRC) outdoor chambers and for most of the SAPRC indoor chambers, and Teflon coated aluminum such as used in the SAPRC evacuable chamber. Different assumptions concerning the chamber radical source and other chamber-dependent effects have been used when modeling data from these various types of chambers (e.g., Gery et al., 1988; Carter and Lurmann, 1990, 1991; Carter et al., 1995a). 
The data base of potentially useful chamber experiments which have been reported and are currently available to us are briefly summarized below. There may be additional chamber runs from other laboratories, but they have either not yet been made generally available in a form suitable for use in mechanism evaluation, or are not considered to be sufficiently well characterized for this purpose.

SAPRC Evacuable Chamber (EC) Experiments. The SAPRC EC is a r $6000-1$ iter Teflon-coated aluminum chamber with a xenon arc light source. Although over 100 potentially useful single compound and mixture - $\mathrm{NO}_{\mathbf{x}}$ - air runs have been conducted in this chamber between 1975 and 1983, it has not been used for mechanism evaluation experiments since 1983. Runs in this chamber were usually carried out at 50\% RH. Data are available to test mechanisms for many types of VOCs, though some VOCs of significance to alternative fuel use have not been studied, and only limited data are available to test model predictions of incremental reactivities*. As indicated above, this chamber has a different type of surface than the other chambers used for mechanism evaluation. The data from this chamber has recently been extensively reviewed and in some cases corrected, and have been incorporated in the current SAPRC chamber data base for mechanism evaluation (Carter et al., 1995a). Data from this chamber has been used in the development and evaluation of the SAPRC-90 (Carter, 1990), Carbon Bond IV (Gery et al., 1988) and Radm-II (Stockwell et al., 1992; Carter and Lurmann, 1990) mechanisms.

SAPRC Indoor Teflon Chamber \#1 (ITC) Experiments. The SAPRC ITC is a -6000-liter Teflon film reactor with a blacklight light source. The Teflon film reactor is periodically replaced. A number of potentially useful single compound and mixture - $\mathrm{NO}_{x}$ experiments have been carried out in this reactor since 1982 . The data from this chamber have also been reviewed and corrected, and they are included in the current SAPRC chamber data base (Carter et al., 1995a). The feature distinguishing data from this chamber from data from the ETC or DTC chambers discussed below is that runs in this chamber were carried out at $50 \%$ RH. Data from this chamber has been used in the development and evaluation of the SAPRC-90 (Carter, 1990) and RADM-II (Stockwell et al., 1992; Carter and Lurmann, 1990) mechanisms, and a limited number of mixture runs from this chamber were used in the evaluation of Carbon Bond IV (Gery et al., 1988).

SAPRC Indoor Teflon Chamber \#2 (ETC) Reactivity Assessment Experiments. The SAPRC ETC consists of a $\sim 4000$-liter FEP Teflon reactor with blacklights, and is similar to the SAPRC ITC except that all experiments were carried out using

"The incremental reactivity of a VOC is a measure of its effect on ozone formation when added to an already polluted air mass (see Carter, 1994, and references therein). Incremental reactivity scales have been adopted as a means to compare ozone impacts of different exhaust mixtures (CARB, 1990). 
dry ( $55 \% \mathrm{RH}$ ) air. It was used for an extensive series of incremental reactivity experiments where the effects of adding a number of individual compounds to a simple reactive organic gas (ROG) - NO surrogate was determined under low ROG $/ \mathrm{NO}_{x}$ conditions (Carter et al., 1993a). The data were not available when the current mechanisms used in airshed models were developed and initially evaluated, though they are being used to evaluate the updated SAPRC detailed mechanism which is being developed (Carter et al., 1993a). This is the largest data base of reactivity experiments for single compounds currently available for mechanism evaluation. More recently, additional reactivity experiments have been carried out in this chamber using an ROG surrogate consisting of ethylene alone, to provide reactivity data in more chemically simplified system (Carter et al., 1995b). The data from this chamber is now included in the SAPRC chamber data base for mechanism evaluation (Carter et al., 1995a).

SAPRC Dividable Tefion Chamber (DTC) Reactivity Assessment Experiments. The SAPRC DTC consists of two connected $\sim 5000$-liter reactors with a blacklight light source, specifically designed and optimized for conducting incremental reactivity experiments. Like the ETC only dry purified air is used. This chamber has been used to conduct incremental reactivity experiments with more

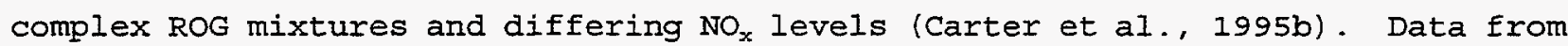
this chamber complement and serve as an extension of the ETC reactivity data base. They also provide more precise incremental reactivity measurements because the design of the chamber assures that the "base case" experiment is carried out under the same conditions, and with same base case reactant concentrations, as the added VOC "test" experiment (Carter et al., 1995b). These data have been used to evaluate the current version of the updated SAPRC mechanism. The data from this chamber is now included in the SAPRC chamber data base for mechanism evaluation (Carter et al., 1995a).

UNC Outdoor Chamber Experiments. The UNC outdoor is a very large pair of matched reactors with FEP teflon walls and which uses natural sunlight. The Teflon film is not replaced. Filtered rural air is used (with some drying for more recent experiments) and reactants are injected prior to sunrise with the irradiation beginning as the sun rises. This has been used for a number of years for a wide variety of single compound and mixture - $\mathrm{NO}_{\mathrm{x}}$ experiments (e.g., Jeffries et al., 1982, 1985a-c, 1990, 1992b). UNC chamber experiments have been the primary data set used in the development and evaluation of the Carbon Bond IV mechanism (Gery et al., 1988), and have been used in the evaluation (though not development) of the SAPRC-90 and RADM-2 mechanisms (Carter and Lurmann, 1990, 1991). Jeffries and co-workers are now in the process of evaluating, correcting, and documenting these data for a UNC standard chamber data base for mechanism evaluation, but the corrected and evaluated data, and the results of the most recent experiments, are not yet available outside UNC. We do have data for number of UNC runs prior to 1985 which we have used for the SAPRC-90 and RADM-2 evaluations (Carter and Lurmann, 1990, 1991), Jeffries (private communication) 
considers this data set to have a number of errors, which presumably are being corrected as part of the data base preparation. For this reason, it is probably not worthwhile to use UNC chamber data for mechanism evaluation until the evaluated and documented UNC chamber data base is available. Although light intensity and spectrum are difficult to characterize in outdoor chambers, Jeffries (1988, 1989, 1991, personal communication) has done a considerable amount of work in developing and evaluating a model for UNC light characteristics to make these runs suitable for mechanism evaluation.

SAPRC Outdoor Teflon Chamber (OTC) Experiments. The SAPRC outdoor chamber consists of a dividable $40,000-1$ iter FEP Teflon reaction bag located on a framework outdoors. This differs from the UNC chamber in that (I) a cover is used when the reactants are injected, and the irradiation is begun (usually around 0900 local standard time) by opening the cover, (2) dry purified air is used, and (3) the reaction bag is periodically replaced. Also, unlike the UNC chamber, data are available primarily for mixture - $\mathrm{NO}_{x}$ irradiations, and up to 1992 only a limited number of runs suitable for evaluating mechanisms for individual runs have been conducted in this chamber. Data from this chamber have been used in evaluating the SAPRC-90 and RADM-2 mechanisms (Carter and Lurmann, 1990, 1991), but not in the evaluation of Carbon Bond IV (Gery et al., 1988). Unfortunately, a model for the light characteristics of this chamber is not as well developed as for the UNC chamber, and we now believe that additional work is needed before the light intensity and spectrum of these past OTC runs is sufficiently well characterized for mechanism evaluation.

This data set, though extensive, has limitations. As discussed by Carter and Lurmann (1990, 1991), there are many important types of vocs for which the available mechanism evaluation data are limited or of low quality. While there are now a number of VOC reactivity experiments with indoor chambers using blacklights, there is relatively little information concerning whether the use of this unnatural light source may be affecting reactivities in ways which are not understood. Perhaps more significantly in terms of the overall mechanism evaluation process, this data set is not adequate to systematically assess how the major chamber characteristics (e.g., light source, surface type, operating procedures) affect mechanism evaluation results.

For example, while there are indoor chamber runs with two differing types of surfaces (Teflon coated aluminum and FEP Teflon film) and two differing artificial light sources (xenon arcs and blacklights), there are no sets of runs where the effect of changing only one of these factors can be assessed. The procedures, chamber characteristics, and air purification systems at SAPRC and UNC are sufficiently different that comparisons of SAPRC and UNC chamber data do not give an unambiguous assessment of differences between using sunlight vs artificial light sources. Furthermore, the large number of single- and mixture$\mathrm{NO}_{x}$-air runs in the ITC blacklight/Teflon chamber (Carter et al., I995a and references therein) were carried out at different humidity levels than the large 
number of reactivity experiments carried out in the ETC and DTC (Carter et al., 1993a, 1995a,b). Data are needed to provide linkages between the various data sets, so we can assess whether we are appropriately representing their characteristics in when we use these data in mechanism evaluations.

\section{c. Objectives and scope of this study}

In view of the considerations discussed above, and as a part of our ongoing experimental programs to develop an environmental chamber data base for evaluating chemical mechanisms and voc reactivity scales (Carter, 1993a, 1995b), we carried out assessment of how mechanism evaluation results depend on the nature of the environmental chamber and light source. The scope of this effort included both modeling comparable experiments in the available data base carried out in the different chambers, and constructing a new chamber and generating new data to provide the linkages needed for a more comprehensive assessment. To address the need for data concerning the effects of alternative light sources on experiments carried out under controlled conditions, we constructed a new environmental chamber and lighting system. IN this chamber a xenon arc light source, such as used in the SAPRC EC, was interfaced to a FEP Teflon reactor such as used in all other chambers generating the current available data base. In addition, a new series of outdoor chamber experiments were carried out with special efforts made to characterize the time-varying spectra and intensity of the photolyzing light. New experiments were also carried out in the SAPRC blacklight Teflon chambers to fill in additional gaps in the data base needed for this study. The results of these new and selected previous experiments were then used to determine if they were consistent with our current understanding of atmospheric chemistry and of chamber and light source characteristics. 


\section{ANALYSIS OF ALTERNATIVE LIGHT SOURCES FOR ENVIRONMENTAL CHAMBER STUDIES}

\section{A. Specification of Requirements}

The gas-phase processes which cause ozone formation in photochemical smog are driven to a large extent by a series of photolysis reactions by which various pollutants interact with light and break apart forming reactive intermediates. To accurately simulate these processes in an environmental chamber experiment, it is necessary that all of these reactions occur at approximately the same rate as they do in the atmosphere. The intensity of the light source affects each of the rate constants equally, but does not affect their values relative to each other (their ratios). These are determined by the light spectrum in the wavelength regions which affect these photolysis reactions. If the light source in a chamber experiment does not have a spectrum which is sufficiently close to that of sunlight, the relative importance of some of the reactions may differ significantly in the experiment compared to the atmosphere. This may lead to inappropriate conclusions concerning the implications of the results of these experiments on atmospheric processes, unless these differences can be corrected for. Such corrections can be made if we know exactly how all the important photolysis reactions depend on the light spectrum. However, in many cases this is uncertain, and thus we cannot always have confidence that the light spectrum corrections being made when interpreting the experiments are appropriate. For this reason, it is important that the spectrum of the chamber light source be as close as possible to that of natural sunlight in the wavelength region which affects the photolysis reactions.

To be suitable for use in such studies, the light source must satisfy the following requirements:

Light spectrum. The light source should have a spectrum which can produce ratios of photolysis rate constants which approximate those of mid-day, clear-sky sunlight at ground level. In this context, the proper range of ambient conditions refers to clear sky, ground level, mid-day sunlight. If this is not achievable, the light source must be at least equal in this regard to any other known existing indoor environmental chamber light source.

Light Intensity. The light source must consistently and reproducibly produce a uniform intensity which is comparable to that of sunlight throughout a Teflon Bag chamber which is at least 4000 -liters in volume. The ideal design goal calls for the light intensity to correspond to an $\mathrm{NO}_{2}$ photolysis rate of at least $0.3 \mathrm{~min}^{-1}$, which is approximately half the maximum photolysis rate on a clear day with direct overhead sunlight. In addition, the light intensity should also have a spacial uniformity of better than $\pm 10 \%$ for at least $90 \%$ of the volume of the chamber. The total light intensity should be sufficiently controllable 
that it vary by less than 5\% during a one-day (up to 8-hour) run, and such that the day-to-day variation is less than $5 \%$

Temperature control. The light source and chamber facility must be such that the operating temperature during an experiment using the lights at maximum intensity can be consistently and reproducibly maintained to within $\pm 1^{\circ} \mathrm{K}$ with an operating temperature between $295^{\circ}$ and $305^{\circ} \mathrm{K}$. Ideally, the operating temperature should be reproducible from day to day to within $a \pm 10 \mathrm{~K}$ range. Ability to maintain $\pm 1^{\circ} \mathrm{K}$ temperature control over a more extended range is desirable, but funds to pursue this option are not yet available.

Cost. The cost of acquiring the lights and the necessary light and temperature control system must be within the budget currently available for this purpose.

\section{B. Alternative Iight Sources}

Outdoor chambers obviously satisfy the requirement that the light spectrum approximate that of sunlight, but fail to satisfy the requirements regarding consistency and reproducibility of light intensity and temperature control. However, indoor chambers require artificial light sources, and thus satisfying the spectral characteristics requirement is much more difficult. As discussed below, xenon arc lights, such as used in the SAPRC evacuable chamber (Beauchene et. al., 1973; Winer et al. 1980) appear to be the best option in this regard, and should satisfy the requirement that the light spectrum approximate that of natural sunlight and represent a. significant improvement over light sources in indoor chambers presently used for reactivity research. However, they present greater problems than other light sources with regard to the criteria of light intensity and uniformity, temperature control, and cost. In this section, we discuss the alternatives and the reason why xenon arc lights were chosen as the solution.

1. Spectra of Representative light Sources.

A qualitative indication of how closely the spectrum of a light source resembles that of sunlight can be obtained by a visual comparison of the spectra. Examples of spectra of natural sunlight and various light sources which have been or might be used in environmental chambers are shown on Figure $I$ and 2. These are as follows:

- The tropospheric solar spectrum calculated by Peterson (1976) for direct overhead sun $(Z=0)$ and a zenith angle $(Z)$ of 60 degrees, respectively;

- The spectrum of a $6.5 \mathrm{~kW}$ xenon arc lamp with borosilicate inner and outer filters (provided by Atlas Electric)

- The spectrum of the blacklight light source presently used at in the SAPRC indoor Teflon chambers, including the indoor chamber currently used to assess VOC reactivities; 

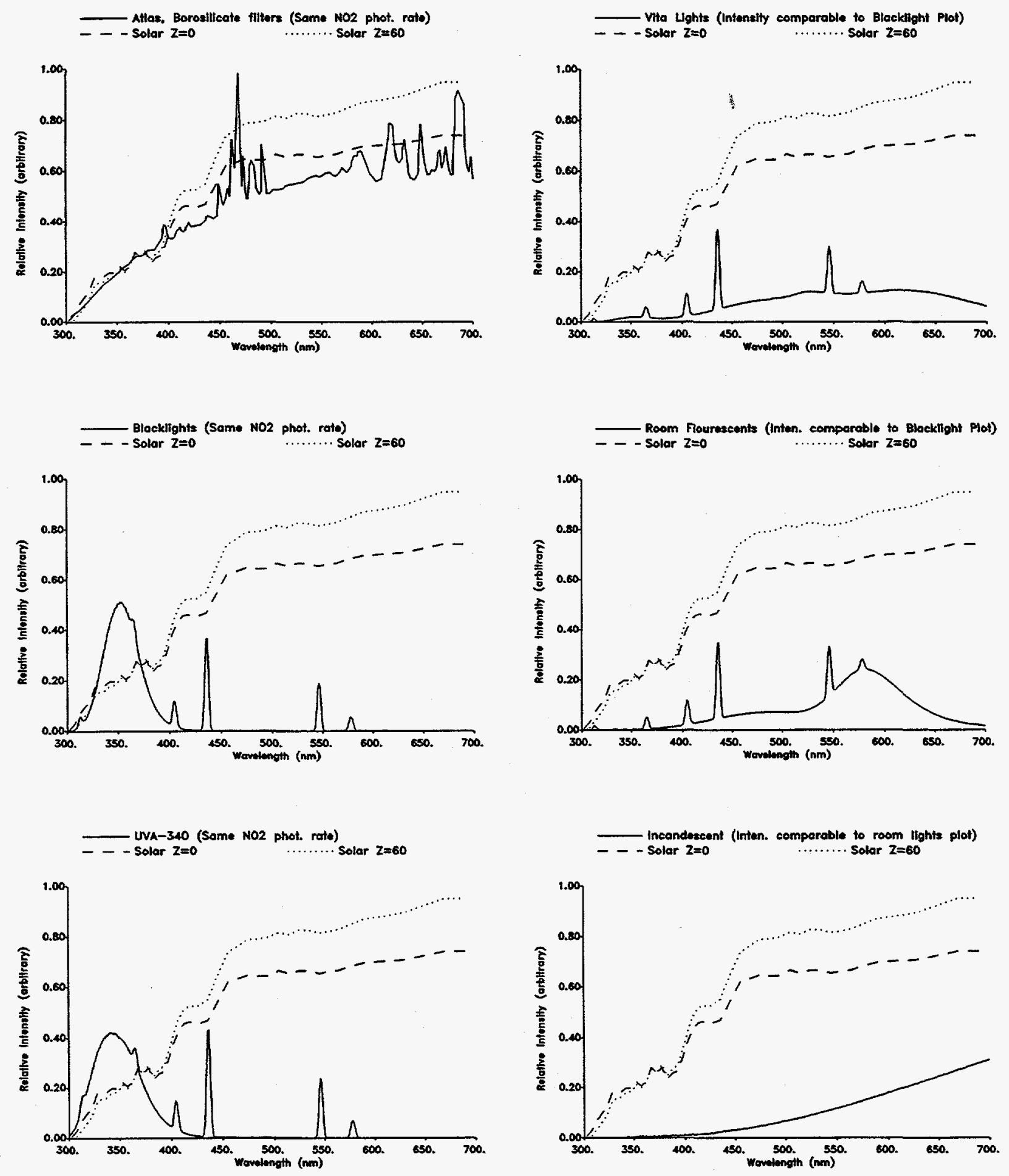

Figure 1. Spectra of representative light sources in the 300-700 nm region. Iight intensities were normalized to yield the same $\mathrm{NO}_{2}$ photolysis rate or to yield comparable intensity to the black lights. 
- Allas, Borositileate filter (Same NO2 phot. rate)

- - Solar $\mathrm{Z}=0 \quad \ldots \ldots \ldots$. Solar $\mathrm{Z}=60$

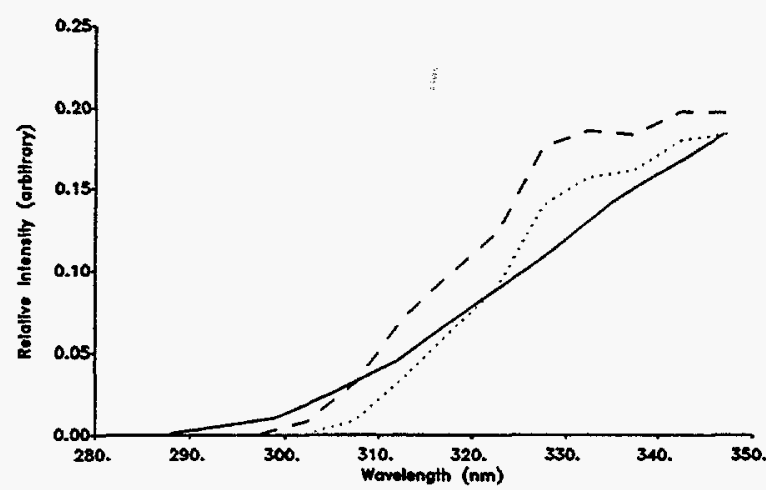

- Blacklights (Same NO2 phot. rote)

- - Solar $z=0$....... Solar $z=60$

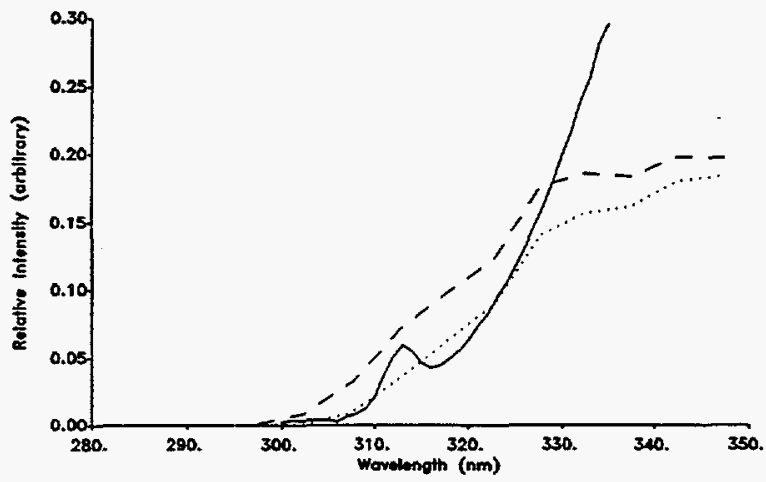

- UVA-340 (Same NO2 phot. rote)

- - Solar $\mathrm{z}=0$ (S...... Solar $\mathrm{z}=60$

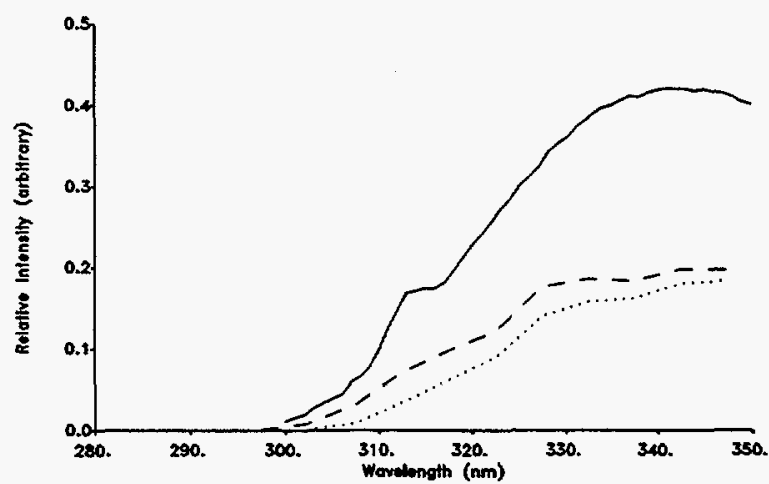

- SAPRC EC (Same N02. phot rete)

- - Solar $z=0$......... Solar $z=60$

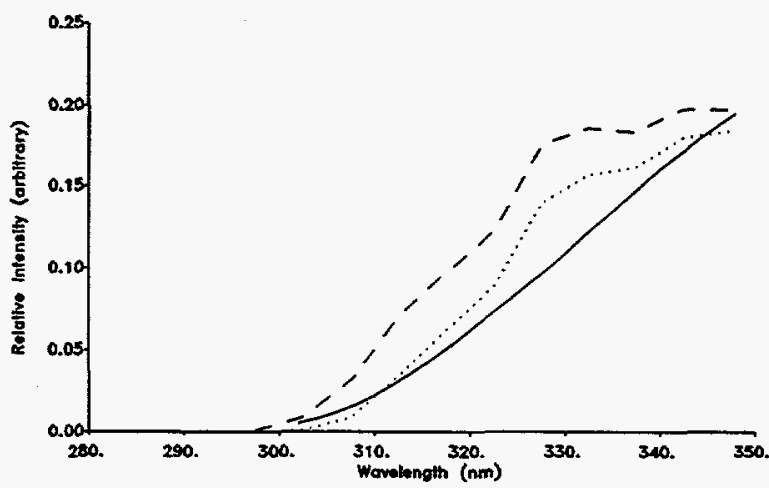

Attos, Sodalime fitters (Some NO2 phot. rote)
- - Solar $z=0$

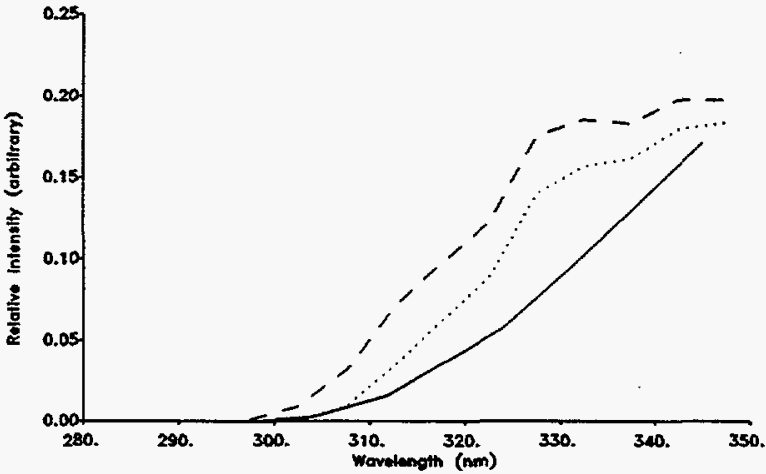

- Vita Ughts (Same NO2. phot rate)

- - Solar $2=0 \quad \ldots \ldots$. Solar $2=60$

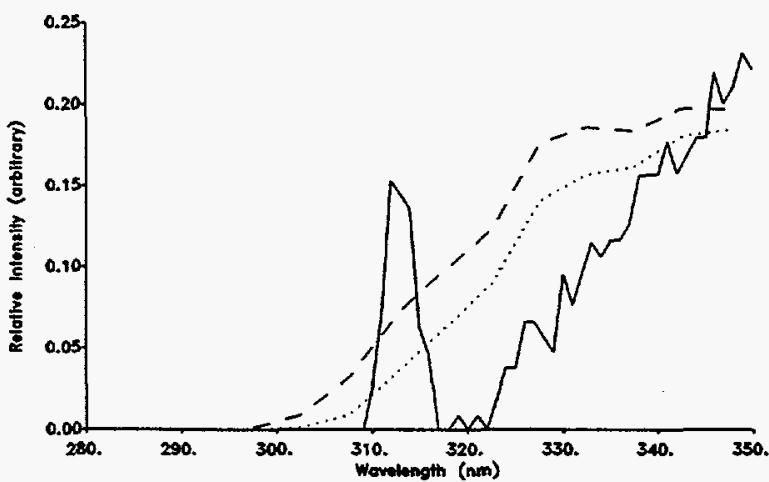

Figure 2. Spectra of representative light sources in the 280-350 nm region. Light intensities were normalized to yield the same $\mathrm{NO}_{2}$ photolysis rate. 
- UV-A lights or "sunlamps", which can be used to enhance the UV intensity of blacklights;

- "Vita" lights, which we had considered for use as a supplement to blacklights to enhance the intensity in the longer wavelength region;

- The spectrum of a fluorescent lamp used for office and home lighting (Sylvania "Super Saver" model); and

- A high intensity (tungsten halogen) incandescent light.

Other light sources, such as sodium, mercury, or metal halide lamps, are not shown because their spectra are not considered acceptable because they are characterized by discrete atomic lines rather than a continuous spectrum such as sunlight. The solar, xenon, blacklight, and UV-A spectra are all scaled on Figures 1 and 2 to yield the same photolysis rate for $\mathrm{NO}_{2}$, which is commonly used as the standard against which other photolysis rates are compared (see below). The "Vita" and "Room" lights are scaled so they correspond to the same approximate number of lights and distance from the detector as the blacklights. The scale of the incandescent light spectrum is arbitrary.

Figure 1 shows the full spectral region which affects known photolysis reactions in the lower troposphere. Sunlight at the earth's surface has no intensity below $\sim 290 \mathrm{~nm}$, and no known photolysis reaction in air pollution is affected by wavelengths above $\sim 900 \mathrm{~nm}$. Figure 2 gives a closeup of the spectra of selected light sources in the $s 350 \mathrm{~nm}$ region, which as discussed below is particularly important in affecting some photolysis reactions. It includes all the light sources above except for room florescent and incandescent spectra, which (as can be seen from Figure 1) have low or negligible intensity in this region. (The intensity of the "Vita" light spectrum on Figure 2 is increased so it gives the same $\mathrm{NO}_{2}$ photolysis rate as the other spectra on this figure. The jagged nature of the spectrum above $324 \mathrm{~nm}$ is due to noise, since the spectrometer is measuring a relatively low intensity.) spectra from several other xenon arc light sources are also shown, including $6.5 \mathrm{~kW}$ Atlas lights with sodalime outer filters, and a spectrum recently taken of the $20 \mathrm{~kW}$ xenon arc in the solar Simulator used with the SAPRC evacuable chamber (Beauchene et al., 1973; Winer et al. 1980), filtered by a I/4" Pyrex pane. Note that the spectra of the xenon lights are very similar in the longer (>350 $\mathrm{nm}$ ) wavelength region, and thus the spectrum shown on Figure 1 is representative of the other xenon arc light sources.

It is clear from the figures that in terms of the overall appearance of the spectrum the xenon arc lights are far superior to any of the other indoor light sources which are shown. Only xenon lights have intensity similar to sunlight throughout the $300-800 \mathrm{~nm}$ spectral region. In addition, although xenon lights have some sharp atomic emission lines in their spectra which are not present in sunlight, these lines are far less important than is the case of all the fluorescent lights, where the mercury emission lines are dominant features in 
their spectra. The blacklights give a good representation of the solar spectrum in the low wavelength region, but overestimate the relative intensity in the $320-$ $360 \mathrm{~nm}$ region, and have essentially no intensity above $400 \mathrm{~nm}$, except for the mercury lines. The other fluorescent light spectra are similar to the blacklights except that the continuous part is shifted either to slightly lower (for UVA) or to much higher (for "Vita" or room lights) wavelength regions. The "Vita" lights actually have the best spectrum of all the florescent sources in terms of continuous portion having a shape similar to that of sunlight over a wide wavelength region, but the intensity in the UV and near-UV is far lower than those of blacklights or UVA. (The spectral shown for the various florescent lights on Figure 1 all correspond to similar power levels.) The incandescent light source is unsatisfactory because it has essentially no intensity in the UV region.

However, the xenon arc lights are not perfect matches of the solar spectra. Figure 1 shows that the xenon lights have somewhat lower intensities in the $>400$ $\mathrm{nm}$ region relative to their intensities in the 320-400 $\mathrm{nm}$ region than do the sunlight spectra, and Figure 2 shows they have variable cutoffs in the short wavelength region, depending on what type of short wavelength cutoff filter is used. Unfiltered xenon arc lights have very high intensity in the UV, being more representative of the solar spectrum in deep space than at ground level. For this reason, xenon arc lights always have to be used with UV cutoff filters when simulating ground level sunlight. As shown on Figure 2, Pyrex or borosilicate glass has the cutoff in the appropriate spectral region for this purpose.

2. Photolysis Rate Constant Ratios for Representative Light Sources. Although Figures 1 and 2 provide a visual comparison of the spectra, they do not provide quantitative measure of how well the light sources will actually perform in producing ratios of photolysis rates which approximate those of natural sunlight. To assess this, it is necessary to calculate and compare rates of photolysis for relevant reactions for the various light sources. Photolysis rate ratios relative to that of $\mathrm{NO}_{2}$ are appropriate for this purpose because (1) $\mathrm{NO}_{2}$ photolysis is the reaction directly responsible for ozone formation in the atmosphere; (2) the $\mathrm{NO}_{2}$ photolysis rate (also called " $\mathrm{k}_{1}$ ") is a common way of measuring light intensity in both the atmosphere and in environmental chamber experiments; and (3) because the photolysis of $\mathrm{NO}_{2}$ is affected by a spectral region which is intermediate in the range established by the various photolysis reactions.

For light source " $j "$, the ratio of the rate constant for photolysis reaction " $i$ " relative to the photolysis of $\mathrm{NO}_{2}$ is given by:

$$
k_{i, j}^{r e l}=\frac{\int J_{j, \lambda} \sigma_{i, \lambda} \Phi_{i, \lambda} d \lambda}{\int J_{j, \lambda} \sigma_{\mathrm{NO}_{2}, \lambda} \Phi_{\mathrm{NO}_{2}, \lambda} \mathrm{d} \lambda}
$$


where $J_{j, \lambda}$ is the intensity of the light source $j$ at wavelength $\lambda$, and $\sigma_{i, \lambda}$ and $\Phi_{i, \lambda}$ are the absorption cross sections and quantum yields for the photolysis reaction $i$, and $\sigma_{\mathrm{NO} 2, \lambda}, \Phi_{\mathrm{NO} 2, \lambda}$ are the absorption cross sections and quantum yields for the photolysis of $\mathrm{NO}_{2}$. Note that since Equation (I) gives a ratio of rate constants, $\mathrm{k}^{\mathrm{rel}}$ is affected only by the shape of the spectral distributions, and not the absolute light intensities. Note also that the $\sigma$ and $\Phi$ values are independent of the light source and are considered part of the chemical mechanism. In this discussion, the $\sigma$ and $\Phi$ values from the SAPRC gas-phase photochemical mechanism are used (Carter, 1990), but the conclusions would be the same regardless of which mechanism were used, assuming that it included specifications of these values. (Mechanisms which lack such specifications in their documentation are not suitable for use in airshed models because they are incompletely formulated.)

Table 1 lists all the photochemical reactions which are represented in the SAPRC mechanism for photochemical smog chemistry (Carter, 1990; Carter et al., 1993b), given in order of increasing wavelength region which affects their rates. The wavelength region which affects any photolysis reaction is determined by the product $J \sigma \Phi$ (see Equation $I$ ), which we refer to as the "action spectrum" of the reaction/light source combination. The "characteristic wavelength" is the average wavelength weighted by the action spectrum for $\mathrm{Z}=0$ sunlight,

$$
\lambda_{i}^{\operatorname{char}}=\frac{\int \lambda J_{z=0, \lambda} \sigma_{i, \lambda} \Phi_{i, \lambda} d \lambda}{\int J_{z=0, \lambda} \sigma_{i, \lambda} \Phi_{i, \lambda} d \lambda}
$$

and provides a means to order the photolysis reactions by wavelength region affecting their rates. Figure 3 shows plots of action spectra for representative examples of the reactions listed on Table 1 with $z=0$ sunlight (Peterson, 1976), where they can be compared with the light source spectra on Figure 1 . It can be seen that most of the reactions, including the photolysis of $\mathrm{NO}_{2}$ and all those above it on the list in Table 1, are affected primarily by the $<400 \mathrm{~nm}$ wavelength region. This is why blacklights, which have reasonably representative intensities in this region, are often used for tropospheric simulations despite their poor representation of the solar spectrum at longer wavelengths. The photolysis of $\mathrm{NO}_{3}$ radicals and of $O_{3}$ to $O\left({ }^{3} \mathrm{P}\right)$ are affected by the longer wavelength regions, but these reactions are relatively less important than most of the others in the overall photochemical smog system. On the other hand, the photolysis of methyl glyoxal is also affected by the longer wavelength region (though not as much so as $\mathrm{NO}_{3}$ or $\mathrm{O}_{3} \rightarrow O\left({ }^{3} \mathrm{P}\right)$, and this is representative of an important class of reactions affecting the reactivity of aromatic hydrocarbons.

The rightmost seven columns on Table 1 give the photolysis rate ratios for the various light sources $\left(\mathrm{k}^{\mathrm{rel}}{ }_{\mathrm{i}, j}\right)$ relative to those calculated for direct overhead sunlight $\left(\mathrm{k}^{\mathrm{rel}}{ }_{i, z=0}\right)$. Note that the numbers are multiplied by 100 , so a "100" means that the photolysis rate ratio is the same as for overhead sunlight. Thus the extent to which the ratios for the various reactions approach 100 provides a measure of how well the light source simulates the solar spectrum in 
Table 1. Calculated Ratios of Rate Constants for Photolysis Reactions used in a Photochemical Smog Reaction for selected Light Sources. The wavelength regions affecting the various photolysis reactions are also shown.

\begin{tabular}{|c|c|c|c|c|c|c|c|c|c|c|}
\hline \multirow[t]{2}{*}{ Reaction or Species [a] } & \multirow{2}{*}{$\begin{array}{l}k^{r e l}(z=0) \\
{[b]}\end{array}$} & \multirow{2}{*}{$\begin{array}{l}\lambda^{\max } \\
{[c]}\end{array}$} & \multirow{2}{*}{$\begin{array}{l}\lambda^{\text {char }} \\
\text { [d] }\end{array}$} & \multicolumn{7}{|c|}{$\mathrm{k}^{r e l} / \mathrm{k}^{\mathrm{rel}}(\mathrm{z}=0) \quad[\mathrm{e}]$} \\
\hline & & & & $\mathrm{Z}=60$ & $\mathrm{Xe}-\mathrm{EC}$ & $\mathrm{Xe}-\mathrm{AB}$ & Xe-As & Black & UVA & Vita \\
\hline$O_{3} \rightarrow O_{2}+O^{1} D$ & 0.43 & 320 & 304 & 28 & 43 & 264 & 22 & 33 & 189 & 32 \\
\hline $\mathrm{CH}_{3} \mathrm{CHO} \rightarrow \mathrm{CH}_{3}+\mathrm{HCO}$ & 0.067 & 330 & 310 & 46 & 45 & 117 & 28 & 49 & 200 & 54 \\
\hline $\mathrm{CH}_{3} \mathrm{COCH}_{3} \rightarrow$ Products & 0.0093 & 335 & 310 & 43 & 45 & 179 & 28 & 49 & 195 & 42 \\
\hline Higher Ketones $\rightarrow$ Prod's & 0.018 & 340 & 313 & 53 & 47 & 106 & 33 & 60 & 201 & 52 \\
\hline Higher Aldehydes $\rightarrow$ Prod's & 0.24 & 345 & 313 & 53 & 47 & 99 & 32 & 60 & 202 & 54 \\
\hline $\mathrm{HCHO} \rightarrow \mathrm{H}+\mathrm{HCO}$ & 0.33 & 340 & 317 & 62 & 48 & 79 & 37 & 68 & 200 & 44 \\
\hline $\mathrm{H}_{2} \mathrm{O}_{2} \rightarrow 2 \mathrm{OH}$ & 0.084 & 355 & 322 & 69 & 56 & 91 & 47 & 104 & 205 & 57 \\
\hline $\mathrm{CH}_{3} \mathrm{OOH}$ (absorp.) & 0.082 & 360 & 324 & 70 & 58 & 89 & 49 & 109 & 204 & 59 \\
\hline $\mathrm{HCHO} \rightarrow \mathrm{H}_{2}+\mathrm{CO}$ & 0.48 & 360 & 329 & 80 & 52 & 76 & 57 & 133 & 204 & 59 \\
\hline Acrolein (absorp.) & 5.2 & 380 & 339 & 87 & 77 & 85 & 74 & 165 & 190 & 90 \\
\hline Benzaldehyde $\rightarrow$ Prod's & 0.48 & 385 & 345 & 89 & 83 & 89 & 81 & 159 & 173 & 92 \\
\hline $\mathrm{CH}_{3}$ ONO (absorp.) & 24. & 410 & 350 & 93 & 88 & 92 & 87 & 157 & 161 & 97 \\
\hline HONO $\rightarrow \mathrm{OH}+\mathrm{NO}$ & 18. & 390 & 356 & 97 & 95 & 96 & 95 & 156 & 143 & 107 \\
\hline $\mathrm{NO}_{2} \rightarrow \mathrm{NO}+\mathrm{O}^{3} \mathrm{P}$ & 100. & 425 & 369 & 100 & 100 & 100 & 100 & 100 & 100 & 100 \\
\hline Glyoxal $\rightarrow$ Prod's & 1.23 & 460 & 383 & 95 & 72 & 83 & 68 & 37 & 91 & 123 \\
\hline Methyl Glyoxal $\rightarrow$ Prod's & 1.7 & 470 & 417 & 112 & 87 & 87 & 88 & 15 & 25 & 185 \\
\hline $\mathrm{NO}_{3} \rightarrow \mathrm{NO}_{2}+\mathrm{O}^{3} \mathrm{P}$ & 1900 & 635 & 548 & 124 & 88 & 89 & 93 & 2 & 2 & 215 \\
\hline $\mathrm{NO}_{3} \rightarrow \mathrm{NO}+\mathrm{O}_{2}$ & 207. & 640 & 592 & 126 & 89 & 91 & 95. & 0 & 0 & 209 \\
\hline $\mathrm{O}_{3} \rightarrow \mathrm{O}_{2}+\mathrm{O}^{3} \mathrm{P}$ & 5.2 & 900 & 647 & 114 & 88 & 95 & 91 & 13 & 32 & 186 \\
\hline
\end{tabular}

[a] Absorption cross sections and quantum yields as used in mechanism of Carter (1990). Acrolein absorption cross sections from Gardner et al. (1987).

[b] Photolysis rates relative to NO2, expressed as $\mathrm{k}^{\mathrm{rel}}=100 \mathrm{x}$ (Photolysis rate for reaction) / (photolysis rate for NO2).

[c] Longest wavelength where product of absorption cross sections and quantum yields are nonzero.

[d] Average wavelength weighed by $J_{\lambda} \sigma_{\lambda} \Phi_{\lambda}$. (Equation II).

[e] Ratios of $\mathrm{k}^{\mathrm{rel}}$ calculated for the spectral distribution indicated to the $\mathrm{k}^{\text {rel }}$ calculated using the ground level solar spectral distribution calculated by Peterson (1976) for zenith angle of zero. Codes for spectral distributions are as follows:

$\mathrm{Z}=60$ : Ground level solar spectral calculated by Peterson (1976) for a zenith angle of 60 degrees.

Xe-EC: $20 \mathrm{~kW}$ Xenon arc light source of the SAPRC Evacuable Chamber.

Xe-AB: Atlas $6.5 \mathrm{kw}$ Xenon arc light with newly conditions borosilicate inner and outer filters.

Xe-AS: Atlas $6.5 \mathrm{~kW}$ Xenon arc light with newly conditions borosilicate inner and sodalime outer filters.

Black: Blacklights

UVA: UV-A lights (sunlights)

Vita: "Vita" lights.

[f] Only absorption cross sections used, i.e., photolysis rate calculated assuming unit quantum yields at all wavelengths. 


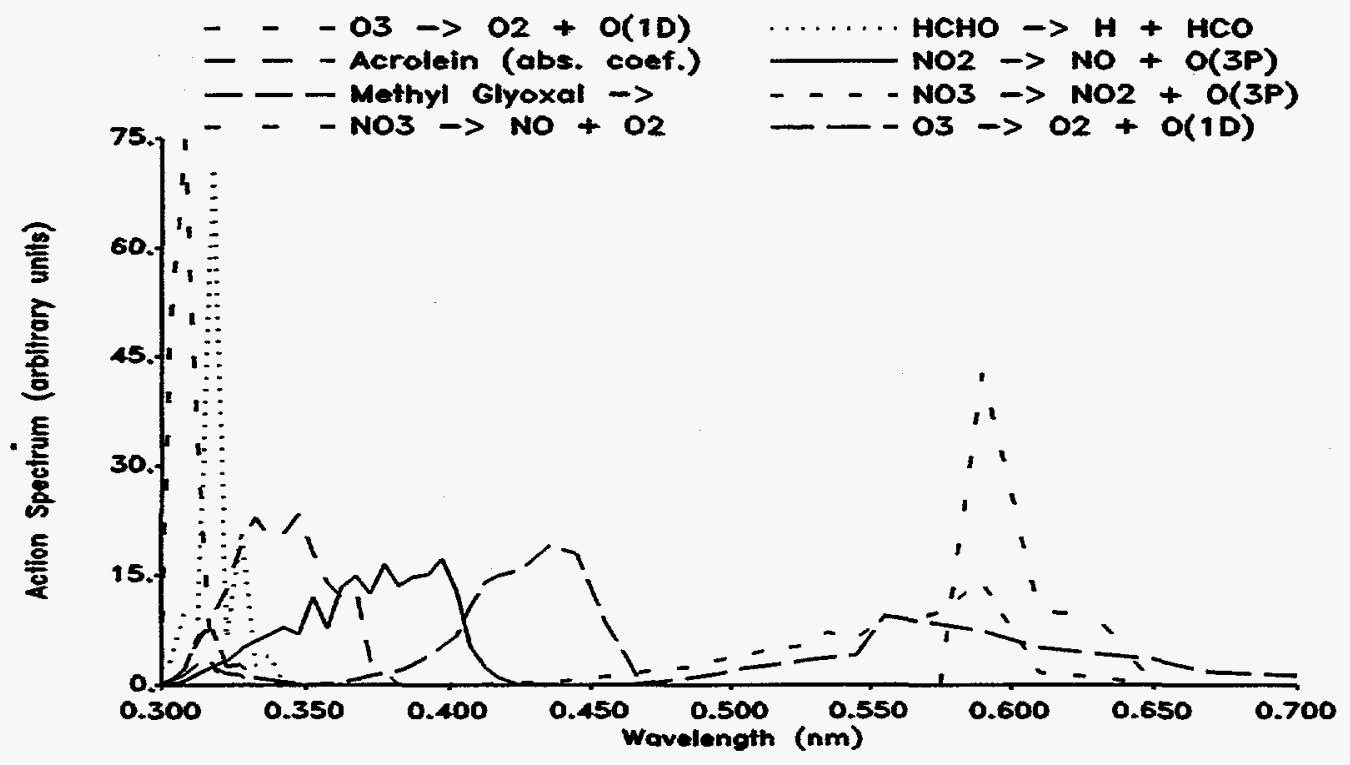

Figure 3. Plots of Action Spectra for the Photolysis Reactions in the Carter (1990) Atmospheric Photochemical Mechanism for Solar $(\mathrm{Z}=0)$ Irradiation.

the wavelength regions of these reactions. The relative differences in the rate constant ratios for the light sources compared with $\mathrm{z}=0$ sunlight are plotted against characteristic wavelength on Figure 4. For each reaction $i$, the "relative difference" in rate constant ratio for light source $j$ compared with $z=0$ sunlight is quantified by,

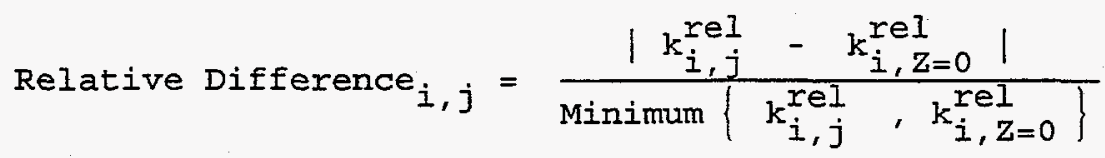

where $k^{\text {rel }}$ is calculated as shown in Equation (I). In this case, a "relative difference" of zero means that the ratio agrees with that of sunlight when $\mathrm{z}=0$. It can be seen from Figure 4 that the extent to which the light source can reproduce solar $\mathrm{z}=0$ photolysis rate ratios is a relatively smooth function of the characteristic wavelength, and thus can be used to give an indication of the other photolysis reactions, given their characteristic wavelength.

Note that as the solar zenith angle increases the UV becomes attenuated more rapidly than the longer wavelengths of sunlight. Thus the photolysis reactions which are most affected by the UV intensity decrease the most rapidly as $z$ increases, with the aldehyde photolyses rates being reduced by a factor of 2 as the zenith angle increases from 0 to 60 degrees, and the reactions affected by the shortest wavelengths being reduced by over a factor of 3 . A zenith angle of 60 degrees is approximately that in Los Angeles in mid-winter at midday, or 


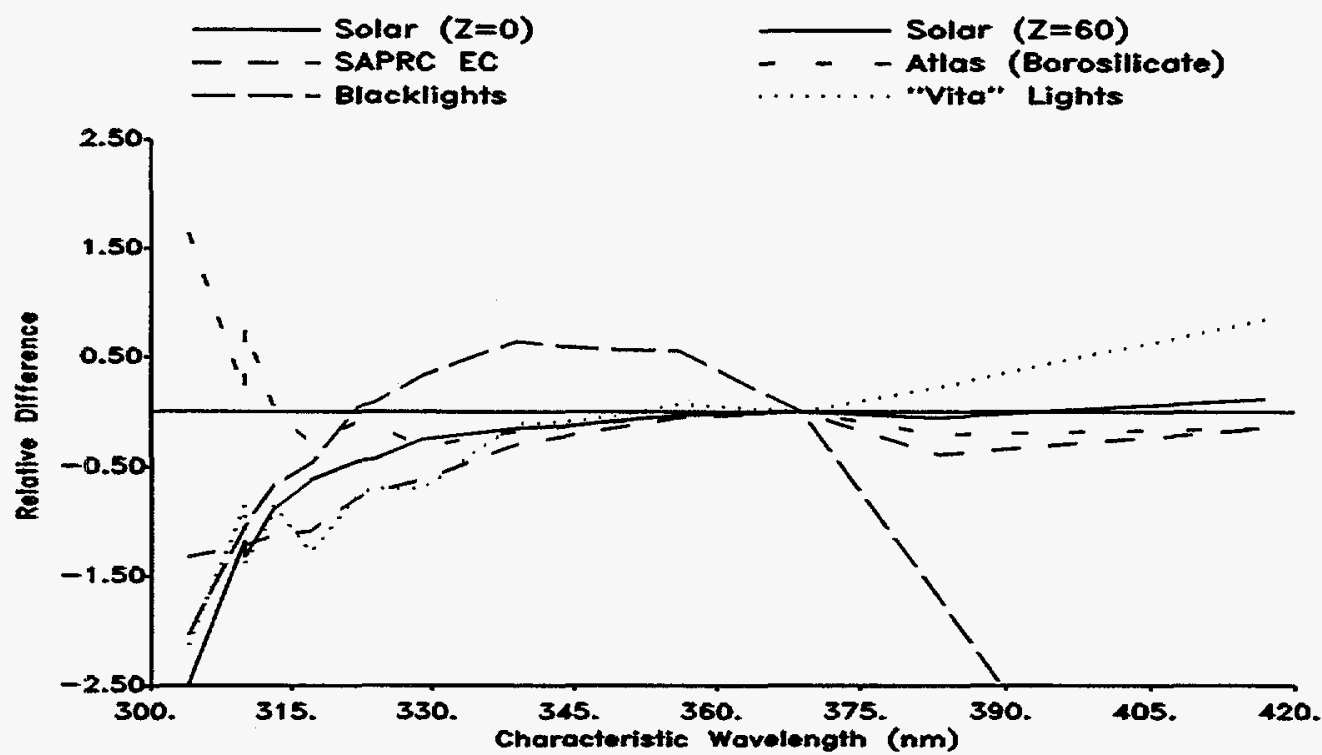

Figure 4. Plots of Relative Differences in Photolysis Rate Constant Ratios for Various Light Sources, Compared with $\mathrm{z}=0$ sunlight. (Relative Differences Computed Using Equation II.)

that at 4:00 PM on the equator. Thus in general there is no single set of photolysis rate ratios which characterize sunlight. The rate constant ratios for the $\mathrm{Z}=0$ and the $\mathrm{Z}=60$ spectral distributions are taken as bounds for acceptable ranges of rate constant ratios for artificial light sources.

Discussions of the implications of these results concerning the suitability of the various light sources for environmental chamber experiments are given below. Blacklights, UV-A lights and xenon arc lights are given particular emphasis because the former two are low-cost options which are frequently used in environmental chamber experiments (including at our laboratories), and because the latter gives the spectrum which most closely resembles sunlight.

Blacklights. Table 1 shows that blacklights give relative photolysis rates for aldehydes and $\mathrm{O}_{3} \rightarrow 0\left({ }^{3} \mathrm{P}\right)$ which are comparable to that of sunlight at zenith angle of 60 , and that a combination of blacklights with some UVA lights should give a good simulation of ratios for overhead sunlight for these reactions. However, the relative rate constants for the photolysis of acrolein, benzaldehyde, and nitrites are somewhat higher than they are under sunlight, because these reactions are influenced by the wavelength region where blacklights are most intense. On the other hand, the photolysis rates for glyoxal and methyl glyoxal are significantly lower with blacklights than sunlight, and the $\mathrm{NO}_{3}$ photolysis hardly occurs at all. 
Some of the differences in photolysis rate ratios are not particularly significant in terms of the effect on the overall photochemical smog process, and thus do not, by themselves, present a significant concern for use of blacklights. The exact magnitude of the nitrite photolyses rates are not particularly important because nitrite photolysis is a rapid process for any light source which has intensity in the spectral region where $\mathrm{NO}_{2}$ photolyzes, and its rate only affects the photostationary state levels of these rapidly photolyzing compounds. Photolysis does not appear to be major factor affecting benzaldehyde reactivity (Carter, 1990), since its major consumption process is reaction with $\mathrm{OH}$ radicals. In addition, reactions of benzaldehyde do not appear to have a significant affect on photooxidations of complex mixtures, and they are often not included in the more condensed atmospheric photochemical models (Lurmann et al., 1987; Gery et al., 1988). The photolysis of ozone to $O\left({ }^{3} \mathrm{P}\right)$ is not important as a sink for ozone because most of the $O\left({ }^{3} \mathrm{P}\right)$ which is formed reacts with $\mathrm{O}_{2}$ to reform ozone, and is not important as a source of $O\left({ }^{3} \mathrm{P}\right)$ in systems where $\mathrm{NO}_{2}$ is present.

The significant differences in $\mathrm{NO}_{3}$ photolysis rates might be a somewhat greater concern, though this is probably not an important factor under many conditions. $\mathrm{NO}_{3}$ radicals are formed by reaction of $\mathrm{O}_{3}$ with $\mathrm{NO}_{2}$, exist in thermal equilibrium with $\mathrm{N}_{2} \mathrm{O}_{5}$, and they are removed mostly either by reaction with No or by photolysis. The photolysis reactions are not highly important under conditions where NO is in excess, but may affect $\mathrm{NO}_{x}$ cycle processes when NO levels are low. However, since the rate constants for most of these $\mathrm{NO}_{x}$ cycle reactions are reasonably well known [except perhaps the $\mathrm{N}_{2} \mathrm{O}_{5}$ hydrolysis, which is relatively slow in environmental chambers made of Teflon film and is probably usually slow (though not negligible) in the atmosphere], and since the photolysis rates of $\mathrm{NO}_{3}$ radicals can be calculated for various light sources, the differences in the $\mathrm{NO}_{\mathrm{x}}$ cycle reactions can be taken into account in model simulations of the experiments. Of greater concern is the fact that reactions of $\mathrm{NO}_{3}$ radicals with alkenes will be more important in chamber irradiations with blacklights than in the atmosphere, because of the higher $\mathrm{NO}_{3}$ radical levels. (In the atmosphere, the $\mathrm{NO}_{3}+$ alkene reaction is mainly important at nighttime, when $\mathrm{NO}_{3}$ cannot photolyze.) The rate constants for the $\mathrm{NO}_{3}$ reactions of most of the alkenes are known or can be estimated (Atkinson, 1991), and thus if the mechanism of these reactions are known, this also can be taken into account in model simulations of the experiments. This can be considered to be the case for the simpler alkenes such as ethene and propene. However, the mechanisms for the $\mathrm{NO}_{3}$ reactions for isoprene and the terpenes have major uncertainties, and this complicates use of blacklight chamber experiments to evaluate mechanisms for these important biogenic alkenes.

Perhaps the greatest problem area with the use of blacklights concerns photolysis rate ratios for the types of compounds which we believe account for the reactivities of aromatic compounds. The aromatics have much higher impacts on ozone formation than other compounds with similar atmospheric reaction rates, 
and models can only simulate this if they assume that they form significant yields of highly photoreactive products. The highly photoreactive $\alpha$-dicarbonyls such as methyl glyoxal are known products from aromatics, but their known yields are such that they can only account for part of the high aromatic reactivity. $A$ variety of other ring fragmentation products have been observed from aromatics but never quantified (e.g., Shepson et al., 1984, Dumdei and O'Brien, 1984), including unsaturated carbonyls which might have action spectra similar to acrolein. The action spectra of these products are unknown, and thus we have no reliable way to account for any differences in their photolysis rates when using data from blacklight-irradiated chamber experiments to test photochemical models which will then be applied to the atmosphere. These differences may well be significant. If the unknown products have action spectra similar to the $\alpha$ dicarbonyls (as is implicitly assumed in the Carbon Bond IV mechanism (Gery et al. 1988), then the photolysis rate ratios with blacklights will be much lower in the chamber than in the atmosphere. However, if the unknown products have action spectra more like that of acrolein - which is a reasonable simplified model compound for many of the types of aromatic fragmentation products which have been identified, then the blacklight photolysis rate ratios will be higher than in the atmosphere. The SAPRC mechanism (Carter, 1990) assumes that the latter is the case because this can yield reasonably good simulations of aromatic reactivity in experiments employing blacklights as well as those using xenon arc lights or sunlight. Nevertheless, this must be considered to be a major uncertainty.

Thus we conclude that while blacklight spectra may not look much like that of sunlight, they may provide a reasonably good representation of rate constant ratios for chemical systems which are driven by photolysis of simple aldehydes and ketones, and where any differences in $\mathrm{NO}_{3}$ photolysis rates can be corrected for by model calculations. However, they present a complication in using chamber data to test mechanisms for biogenic alkenes, and introduce major uncertainties in using such data to test mechanisms for aromatics. The latter is of particular concern since photolysis of species which respond to spectral regions where blacklights and sunlight are significantly different is a major factor affecting aromatic reactivity. This means that while chamber experiments with aromatics using blacklights provide a valuable supplement to experiments with more representative light sources in testing details of models, they cannot, by themselves, be considered sufficient for evaluating aromatic reactivity.

UV-A Lights. UV-A lights by themselves are not suitable for environmental chamber experiments because they produce unnaturally high relative photolysis rates for species which are sensitive to the UV end of the spectra, and they have all the deficiencies of blacklights in the longer wavelength region (see Table 1 and Figure 4). They could be used in combination with blacklights to provide UV levels which are more representative of direct overhead sunlight. However, use of UV-A lights would not solve the problems of unrepresentative rate constant ratios for $\mathrm{NO}_{3}$ and aromatic product photolyses which were discussed above. 
Vita Liqhts. Vita lights (also called "grow lights", since they are designed to be a light source for growing plants indoors) produce the best approximation to sunlight spectra of all the florescent light sources we have investigated. Table $I$ and Figure 4 show that they give ratios of rate constants which are remarkably close to the $\mathrm{Z}=60$ solar spectrum, and in theory using them in combination with UV-A lights could correct to a large extent both for their deficiencies in the UV end relative to overhead sunlight, and for their slight excesses in the high wavelength end.

However, the mercury emissions lines have a much higher relative contribution to the total spectral output than is the case for blacklights. See, for example, the relative importance of the mercury emission line at $312.6 \mathrm{~nm}$ in the Vita lights compared to the blacklight or UV-A lights as shown on Figure 2, where the intensities are normalized to yield the same $\mathrm{NO}_{2}$ photolysis rates. The mercury lines at the higher wavelengths (see Figure 1) give concern that an unknown aromatic product might have a coincidental absorbance band at one of these mercury lines, giving rise to an unnaturally high photolysis rate which (since the compound is unknown) would not be corrected for in model simulations of the experiments. However, the data on Figure 4 suggest that such a coincidental absorbance is not occurring with the photolysis reactions presently in the model, since the dependence of reaction rate constants on $\lambda^{\text {char }}$ appear to be relatively smooth.

The greatest problem with Vita lights is not their spectrum but their intensity. Because of their favorable spectral characteristics, and because they can be used in the same fixtures as blacklights, we had investigated their use as an alternative or supplement to blacklights. Unfortunately, we found that when operated under the same conditions, they give $\mathrm{NO}_{2}$ photolyses rates which are only $210 \%$ those of blacklights. This means that to obtain the same overall intensity, 10 times more Vita lights are required than we presently use for blacklights. To obtain sufficient intensity with blacklights it is necessary that the chamber be almost completely surrounded with the lights, and be backed with efficient reflectors. Thus, increasing the number of lights 10-fold with commercially available fittings and lights is not physically possible. It may be possible that with sufficient research and effort that a modified arrangement or lights which can provide the necessary intensity can be developed. However, the possibility of success is uncertain, and the cost may well exceed that of xenon lights, which have superior spectra and which, though expensive, are commercially available. For this reason, we ruled out vita lights as a viable alternative to blacklights and xenon arc lights.

Xenon Arc Lights. A $20-\mathrm{kW}$ xenon arc light is presently employed in the Solar Simulator used with the SAPRC evacuable chamber (Beauchene et al. 1973; winer et al. 1980), and $6.5 \mathrm{~kW}$ lights are available from Atlas Electric Co. The spectra of these two types of xenon arc lights do not appear to be significantly different except in the shorter $(<350 \mathrm{~nm})$ wavelength region, where the spectrum 
is determined primarily by the spectral filtex used. (Xenon arc lights are much more intense in the UV than sunlight at ground level, and filters are required to remove the UV below $290 \mathrm{~nm}$.) The $6.5 \mathrm{kw}$ lamps from Atlas come with various types of replaceable filters which surround the lamp, with separate "inner" and "outer" filter being used for each lamp. The SAPRC solar simulator has no internal filters, and $0.25 "$ Pyrex panes are used to filter out the extreme UV light before it enters the chamber. Figure 2 shows the effects of these different filters on the light spectrum.

Table 1 and Figure 4 show that the xenon arc light sources give photolysis rate ratios which are within $\pm \sim 25 \%$ those of sunlight for the reactions with characteristic wavelengths greater than $\sim 340 \mathrm{~nm}$, or that or acrolein. Thus use of this light source in chamber experiments should produce realistic relative photolysis rates for $\mathrm{NO}_{3}$ radicals and probably most of the aromatic ring fragmentation products. However, the extent to which a xenon arc light produces realistic rate constant ratios for reactions with lower characteristic wavelengths, such as aldehydes and $O_{3} \rightarrow O\left({ }^{1} D\right)$, is dependent on the nature of the spectral filter used.

The best spectral filter of those shown appears to be the 0.25 " Pyrex pane used with the SAPRC EC, which gives photolysis rate ratios closely resembling those for solar $Z=60$, except for reactions with very low $\lambda^{\text {char }}$, where the ratios are roughly halfway between those of $z=0$ and $z=60$. The dual borosilicate filter system for the Atlas system performs even better for reactions with $\lambda^{\text {char }} \geq \sim 310$ $\mathrm{nm}$, but gives photolysis rates for very low $\lambda^{\text {char }}$ reactions which are almost three times those predicted to occur in natural sunlight. This is due to the fact that the borosilicate filter does not sufficiently remove light below $300 \mathrm{~nm}$ (see Figure 2. However, the short wavelength spectra of borosilicate or Pyrexfiltered xenon arc light are not constant over time, since the filter glass will "solarize" over time, which will increase the cutoff wavelength. Thus an aged lamp would be expected to give lower rate constants for reactions with $\lambda^{\text {char }} z$ $-310 \mathrm{~nm}$, relative to those with higher $\lambda^{\text {char}}$, than shown on Table 1 or Figure 4 .

\section{Assessments of Iight Intensity, Uniformity, and Cost Considerations}

Based on the considerations discussed in the previous section, we concluded

that a xenon arc lighting system has the best potential for satisfying the requirements of our specification concerning light spectrum. In terms of the cost required to achieve the desired intensity with reasonable uniformity in a 4000-6000 liter chamber, we concluded that a system based on four Atlas Electric RM-65A $5.6 \mathrm{KW}$ xenon arc lights and associated power supplies, could be obtained within the budget of this program, could satisfy our requirements. This conclusion was based on estimates discussed in detail by Carter and walters (1992), who used two methods to estimate the likely light intensity achievable with such a system. The more conservative estimate is based on the specifications for the Atlas XR260 "Large Component Xenon Exposure System" (Carter and Walters, 1992), which uses four RM-65A-type $5.6 \mathrm{~kW}$ lights to irradiate a volume 
which is $\sim 4$ times smaller than desired for our application, but with a maximum light intensity which is $\sim 4$ times higher than required. The other estimation method was based on information in an Atlas brochure giving the light intensity a stated distance away from the a lamp, and gave a maximum light intensity which was $\sim 50 \%$ higher than estimated based on the XR260 specifications.

An analysis of light uniformity considerations was also made prior to ordering the system (Carter and Walters, 1992). Using a two-dimensional light reflectance model, we estimated that satisfactory uniformity could be obtained if the chamber and lights were located in a room with reflective floor, ceiling, and walls, with the chamber located in one half of the room, and the four lights mounted on the wall farthest from the chamber. The multiple reflections of the light off the wall, and the distance between the chamber and the lights, were sufficient to yield an estimated uniformity of within $\pm 5 \%$ (Carter and walters, 1992). The design of the system actually constructed, discussed in the Experimental section, was based on these analyses.

D. Acquisition and Initial Testing of Xenon Arc Lights.

The order for the four Atlas RM-65A lighting system, together with burner tubes and borosilicate inner and outer filters was placed in october of 1992. After the system became operational, a small one-light temporary chamber enclosure was constructed to evaluate the accuracy of the light intensity and uniformity predictions discussed in the previous section. The temporary chamber consisted of an $\sim 4^{\prime} \times 4^{\prime} \times 8^{\prime}$ enclosure constructed of reflective aluminum panels, with the light at one end. This is approximately a $1 / 4$ scale model of the full-size chamber enclosure which was planned.

The light intensity was measured at various positions in the small enclosure using the quartz tube $\mathrm{NO}_{2}$ actinometry method discussed in section III.D. The quartz tube actinometer measures light integrated along the line of the actinometer tube, while photolysis rates are determined by spherically integrated light intensities. However, a reasonable estimate of the spherically integrated light intensity can be obtained by averaging the line measurements made at right angles to each other. Measurements were made with the tube 2 25-30" from the lamp, one with the actinometer tube perpendicular to the lamp burner tube, one with it parallel to the burner tube, and one with the actinometer tube facing the burner tube. The $\mathrm{NO}_{2}$ photolysis rates in these three positions were $0.40,0.32$, and $0.26 \mathrm{~min}^{-1}$, respectively, with the lamp power at $4.0 \mathrm{kw}$. The estimated spherically integrated $\mathrm{NO}_{2}$ photolysis rate would then be $0.33 \mathrm{~min}^{-1}$, which meets the design goal of $0.3 \mathrm{~min}^{-1}$. Higher photolysis rates could be obtained with higher power settings (up to the maximum of $6.5 \mathrm{kw}$ ), though at the cost of increased rate of change of $U V$ intensity and reduced lamp lifetime.

The differences in the $\mathrm{NO}_{2}$ photolysis rates measured in the three perpendicular positions were as expected based on geometrical considerations. The highest $\mathrm{NO}_{2}$ photolysis rates were observed when the actinometer and burner 
tube are parallel, with the tube receiving the greatest amount of direct radiation from the lamp. The intensity was the least when the actinometer tube was positioned so it received very little direct radiation from the burner tube, but the fact that it was still $\sim 65 \%$ of the maximum indicates the importance of the light reflected from the reflective aluminum walls. This high contribution of reflected light is consistent with the predictions of our two-dimensional light reflectance model, and indicates that spherically integrated light intensity should be reasonably uniform throughout the chamber. However, the test chamber was too small to make useful measurements of light intensity as a function of position.

The light intensity was monitored using both an Eppley UV radiometer and an Eppley Model PSP broadband pyranometer to determine consistency of light intensity with time. Spectra were also taken of the light during this initial period, and were as expected based on the spectra we obtained previously from the manufacturer. The spectra, and how they vary with time, will be discussed in the Results section. The broadband readings were essentially constant immediately after the lights were turned on, but the UV readings tended to decrease slightly (by $15 \%$ ) during an initial warm-up period, and take approximately 20-30 minutes to stabilize. For this reason, we decided to constructed a shutter system for the chamber to allow the lights to warm up and stabilize before beginning the irradiation of the chamber contents.

The tests with the scale model chamber indicated that the initial estimates of light intensity and uniformity given by Carter and walters (1992) were reasonably accurate, and we could proceed with the construction of the xenon arc lighting system for the full size chamber as originally planned. The resulting chamber, which is designated the Xenon Teflon Chamber (XTC) is described in the following section. 


\section{EXPERIMENTAI METHODS}

The facility and experimental methods for the new experiments discussed in this report are described in this section. The model simulations also used data from SAPRC and ITC experiments. The facility and experimental methods for those earlier runs are described in detail elsewhere (Carter et al., 1995a, and references therein.)

A. Chambers

1. Indoor Teflon Chamber \#2 (ETC)

The Indoor Teflon Chamber \#2, which is called the "ETC", was described in our previous report (Carter et al., 1993a). Briefly, it consisted of a 2-mil thick FEP Teflon reaction bag fitted inside an aluminum frame of dimensions of $8 \mathrm{ft} \times 4 \mathrm{ft} \times 4 \mathrm{ft}$. The light source for the chamber consisted of two diametrically opposed banks of 30 sylvania $40-\mathrm{W}$ BL blacklights, one above and the other below the chamber. Dry purified air was provided by an AADCO air purification system. Later in the program, when larger volume chambers were employed a second AADCO was added to provide greater air flow. The chamber was located in the main laboratory in the modular building immediately adjacent to the site of the outdoor chamber (Carter et al., 1995b).

\section{Dividable Teflon Chamber (DTC)}

The Dividable Teflon Chamber (DTC), which was designed to allow irradiations of two separate mixtures at the same time and under the same reaction conditions, is described in a separate report (Carter et al., 1995b). Briefly, it consists of two $~ 5000$-liter FEP Teflon (2 mil) reaction bags located adjacent to each other, and fitted inside an 8' cubic framework. The chamber enclosure was in a specially prepared room in the modular building adjacent to the site of the outdoor chamber. The light source consisted of two diametrically opposed banks of 32 sylvania 40-W BL blacklights, whose intensity can be controlled by separate switches. The lights are backed by aluminum-coated plastic reflectors which are molded into the same shape as the Alzak reflectors in the SAPRC ITC (Carter et al., 1995a). The other surfaces are covered with polished aluminum panels, except for a window which is used for sample probes, reactant injections, etc. A specially constructed system of two Teflon-coated fans and blowers was used to rapidly exchange and mix the contents of the two reaction bags. Pure, dry air for this chamber was provided by the same AADCO air purification system which served the ETC. The chamber was operated at $50 \%$ the maximum light intensity for comparable conditions to runs in other SAPRC indoor chambers.

The two Teflon reaction bags are designated as sides "A" and "B". Because two separate mixtures are being irradiated simultaneously, each DTC run consists 
of two separate experiments. These are designated as runs DTCnnnA and DTCnnnB, where nnn is the run number.

\section{Xenon Teflon Chamber (XTC)}

As discussed in section II, as a part of this program we acquired a xenon arc light source for use in indoor environmental chamber experiments. After all the experiments with the DTC were completed, and after the initial testing with the xenon arc lights (discussed in section II.D), we reconfigured the DTC chamber enclosure to incorporate these xenon arc lights, and designated the resulting chamber the Xenon Teflon Chamber (XTC). A diagram of the XTC is shown on Figure 5. For the XTC configuration, the fluorescent lights used for the DTC were removed and the aluminized reflective panels remained, to reflect and diffuse the light. Since the space was limited, only a single reactor bag for the XTC was constructed by heat-sealing five foot wide 2mil FEP Teflon film to form a $5 \mathrm{~m}^{3}$ chamber. (A single reaction bag was used rather than multiple smaller bags for comparability with surface/volume conditions in other SAPRC chambers, and to allow adequate volume for continuous sampling.) The top and bottom of the chamber were lined with Everbright reflective aluminum panel that had been perforated with 1/16-1/8 inch holes at $1 / 4$ inch center-to-center spacing. All other surfaces exposed by the light source were solid Everbright. An Everbright panel was set up as a shutter, sliding in and out approximately one foot in front of the light source. Based on visual observation, we believe that when closed this shutter prevented all but an insignificant amount of light into the chamber. A Teflon coated mixing fan in the reactor bag was powered by an electric motor through a vacuum-tight shaft seal. The fan was normally used only for initially mixing the contents after reactant injection. Quarter inch (OD) sample lines were installed by means of stainless steel tubing union with Teflon washers. A PVC gate valve with a Teflon slider was installed on the reactor bag for emptying the contents of the chamber with a squirrel cage blower exhausted to the outside.

The four $6.5 \mathrm{kw}$ xenon arc lamps (Atlas model RM-65) were evenly spaced on one end of the chamber. The power supplies were located in the same room, six to ten feet away. Potable water was attached to the power supplies for cooling the lamp assemblies. The radiative power per lamp using borosilicate inner and outer lamp filters was stated as 114,350 microwatta per square centimeter at $48 \mathrm{~cm}$ from the light. Assuming spherical symmetry, the total radiative output is $3.3 \mathrm{kw}$. The lamps were operated at a constant power setting of $4.0 \mathrm{kw}$ for all experiments discussed here, which is $\sim 60 \%$ of maximum.

A temperature control system was constructed to control the chamber temperature to within $\pm 1 \mathrm{C}$. A six inch thick plenum was constructed over the top of the chamber. Four 1/4 HP squirrel cage blowers were used to force air into the plenum. The air exited the plenum through the perforated Everbright sheets covering the top of the chamber enclosure, and then streamed evenly past the Teflon chamber and exited at gaps at three sides along the bottom. The 


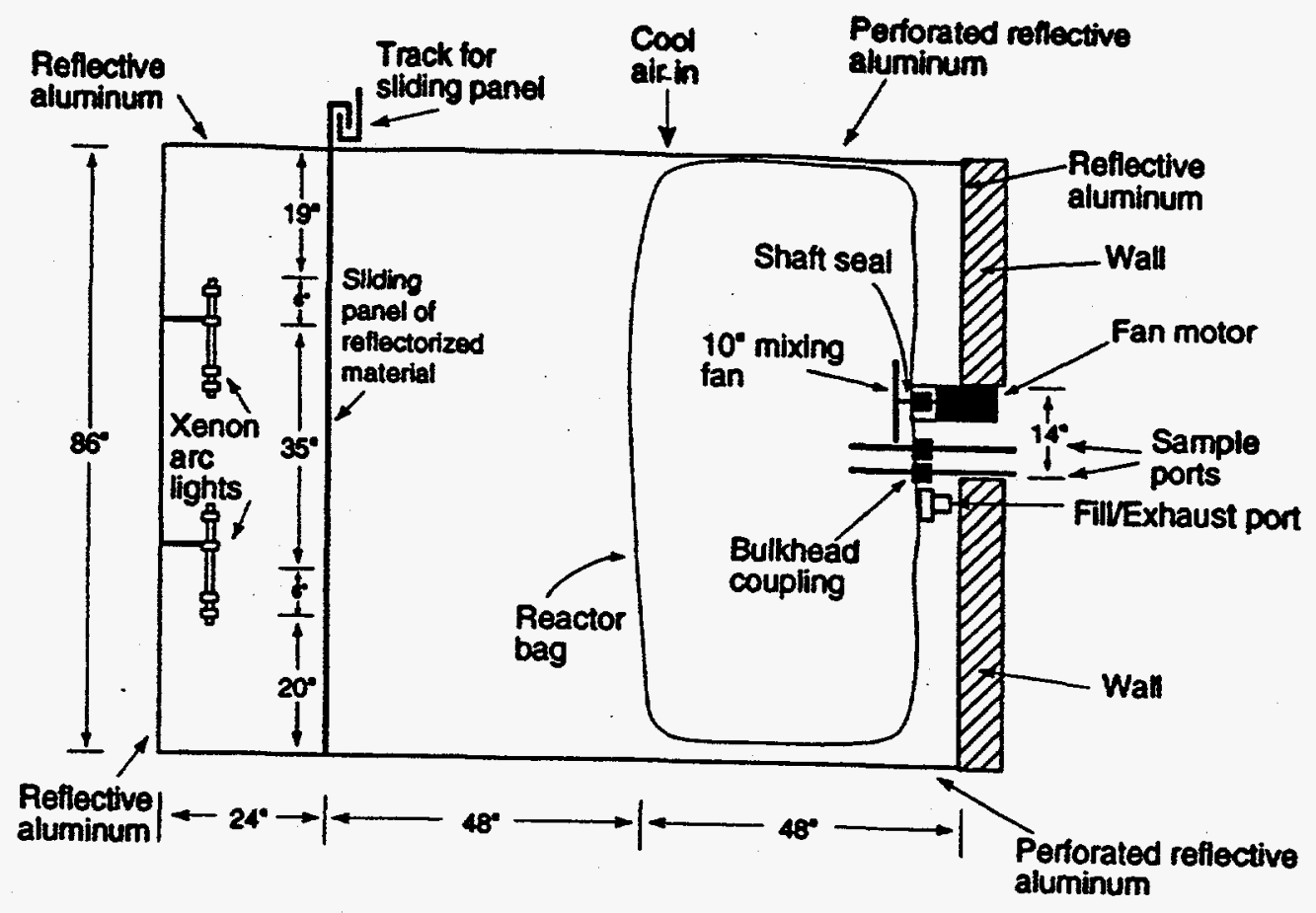

Figure 5. Side view of Xenon Teflon Chamber.

blowers received temperature controlled air from a plenum (this plenum was actually the two foot high space between the roof and the false ceiling) that was feed by the shelter air conditioning system and a dedicated 24,000 BTU air conditioner equipped with two $3.6 \mathrm{kw}$ heater strips. The dedicated air conditioner was constantly in the cooling mode. One heater strip was on at all times, but with the power level adjusted with a rheostat. A proportional temperature controller sensed the temperature in the plenum and set the powerlevel of the second heater strip as necessary depending on the temperature set point.

\section{Outdoor Teflon Chamber}

The SAPRC Outdoor Teflon Chamber (OTC) is shown schematically on Figure 6. The chamber consists of a $\sim 40,000-1$ iter, 2-mil thick FEP Teflon, pillow-shaped reaction bag located outdoors immediately adjacent to the indoor chamber laboratory. The reaction bag is supported by nylon ropes on a framework and held 2.5 feet off the ground to allow air circulation under the chamber. A green indoor-outdoor carpet is located under the chamber. When the chamber contents are not being irradiated, the reaction bag is covered by an opaque trap which is removed to begin the irradiation. An AADCO air purification system supplies pure dry air for this chamber. All OTC runs employed dry ( 5\%) air. The OTC chamber is described in more detail elsewhere (Carter, et al., 1984, 1986). 


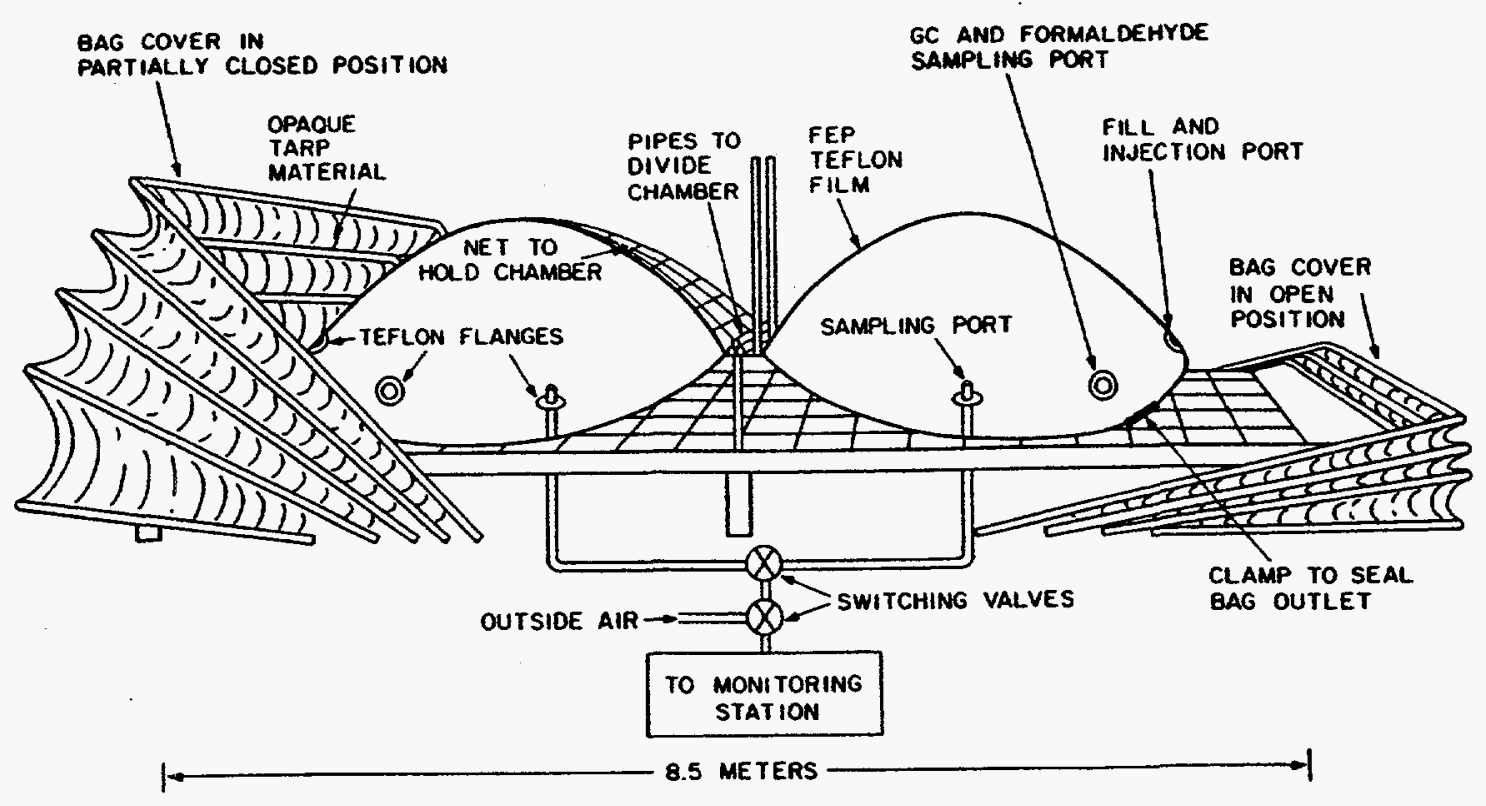

Figure 6. Diagram of the SAPRC Outdoor Teflon Chamber (OTC).

This chamber can be operated in a dual mode to allow two parallel experiments under the same lighting and temperature conditions. This division of the chamber into two separate reactors, which can be done after reactants common to both chamber sides are injected and mixed, is accomplished by means of three 1 1/4-in diameter cast-iron pipes, which are surrounded by foam to protect the Teflon reactor. The reaction bag is divided by raising the lower pipe and placing it tightly between the upper pipes, then rotating them by 180 degrees. Previous tests have shown that this. forms a tight seal, with the exchange between the chamber sides being less than $0.1 \%$ per hour (Carter et al., 1981). The chamber is oriented such that the pipes dividing the chamber run in a north-south direction, with side $A$, by convention, always being on the eastern half of the chamber. All OTC experiments discussed here were conducted with the chamber in the divided mode.

The sampling to the continuous monitors were controlled by computeractivated solenoid valves. The sampling to the GCs were taken from the outside bags directly because our sampling comparison study indicated there was a little difference between the sample taken from outside bag and indoor manifold, though sampling air to the indoor manifold was being drawn during the experiments. 
The chambers were flushed with dry purified air for 6-9 hours on the nights before the experiments. The monitors were connected prior to reactant injection and the data system began logging data from the continuous monitoring systems. The reactants were injected as described previously (Carter et al, 1993a). For dual chamber (DTC or OTC) runs, the common reactants were injected in both sides simultaneously (using a "T" in the injection line) and were well mixed before the chamber was divided. In the case of the OTC, the reactants were mixed by manual agitation of the reaction bag, while with the DTC the contents of side A were blown into side $B$ and vise-versa using two separate blowers. Fans were used to mix the reactants in the indoor chambers during the injection period, but these were turned off prior to the irradiation. Dividing the OTC consisted of clamping the reaction bag in two using pipes, while "dividing" the DTC consisted of closing the ports which connected the two reaction sides. After the OTC or DTC was divided, the reactants for specific sides were injected and mixed. The irradiation began by turning on the lights (for the blacklight chambers), opening the cover (for the OTC), or sliding back the panels in front of the xenon lights (which were turned on 230 minutes previously). The irradiation proceeded for 6 hours. Periodic spectral measurements were taken during XTC and OTC runs, as discussed in section $D$, below. After the run, the contents of the chamber(s) were emptied (by allowing the bag to collapse) and flushed with purified air. A heater was turned on to preheat the ETC chamber to reach the experimental temperature desired and turned off when the irradiation began, as described in previous report (Carter et al, 1993a). Preheat for the DTC and XTC chambers was accomplished by turning on the temperature control system $\sim 2$ hours prior to the irradiation.

\section{c. Analytical Methods}

Ozone and nitrogen oxides were continuously monitored using commercially available continuous analyzers with Teflon and borosilicate glass sample lines inserted directly into the chambers (ca 18 in.). For DTC and OTC chamber runs, the sampling lines from each half of the chamber were connected to solenoids which switched from side to side every 10 minutes, so the instruments alternately collected data from each side. Ozone was monitored using a Dasibi Model 1003AH UV photometric ozone analyzer and $\mathrm{NO}$ and total oxides of nitrogen (including $\mathrm{HNO}_{3}$ and organic nitrates) were monitored using either a Columbia Model 1600 or a Teco Model $14 \mathrm{~B}$ or 43 chemiluminescent $\mathrm{NO} / \mathrm{NO}_{x}$ monitor. The output of these instruments, along with that from the temperature and (for OTC and XTC runs) light sensors were attached to a computer data acquisition system, which recorded the data at periodical intervals, using 30 second averaging times. For single mode (ETC or XTC) chamber runs, the $\mathrm{O}_{3}, \mathrm{NO}_{x}$, and other continuous data recorded every 15 minutes; for the divided chamber (DTC or OTC) runs, the data was collected every 10 minutes, yielding a sampling interval of 20 minutes for taking data from each side. 
Organic reactants other than formaldehyde were measured by gas chromatography with FID detection as described elsewhere (Carter et al., 1993a). GC samples were taken for analysis at intervals from fifteen minutes to one hour using 100 $\mathrm{ml}$ gas-tight glass syringes. These samples were taken from ports directly connected to the chamber. The syringes were flushed with the chamber contents several times before taking the sample for analysis. The various analysis systems, and their calibration data, are described in more detail elsewhere (Carter et al., 1995a).

Although we made numerous attempts to obtain a good analysis for PAN using the GC-ECD instrument acquired for this purpose (Carter et al., 1995a), we were not successful in obtaining reproducible data until after the experiments discussed in this report were completed. Therefore, useable PAN data are not available for any of the new experiments discussed in this report.

Formaldehyde was monitored using a diffusion scrubber system based on the design of Dasgupta and co-workers (Dasgupta et al, 1988, 1990; Dong and Dasgupta, 1987), as described elsewhere (Carter et al., 1993a). This system alternately collected data in sample ( 30 minutes), zero ( 15 minutes), and calibrate mode ( 15 minutes), for a one hour cycle time. The readings at the end of the time period for each mode, averaged for 30 seconds, were recorded on the computer data acquisition system, which subsequently processed the data to apply the calibration and zero corrections. A separate sampling line from the chamber was used for the formaldehyde analysis. For the DTC or OTC, a solenoid, which was separate from the one used for $\mathrm{O}_{3}$ and $\mathrm{NO}_{x}$ sampling, was used to select the chamber side from which the formaldehyde sample was withdrawn, which alternated every 15 minutes. This yielded formaldehyde data as frequently as every 15 minutes for single chamber (ETC and XTC) runs, and every 30 minutes for each side of DTC and OTC runs. The calibration data for this instrument are discussed elsewhere (Carter et al., 1995a).

\section{Light source Characterization 1. Indoor Chambers}

$\mathrm{NO}_{2}$ Actinometry. The absolute light intensity in the DTC and XTC was determined by conducting periodic $\mathrm{NO}_{2}$ actinometry experiments using the quartz tube method as employed previousiy (Carter et al, 1993a), except that the "effective quantum yield" factor, $\Phi$, was changed from 1.75 to 1.66 based on computer model simulations of a large number of such experiments as discussed in detail elsewhere (Carter et al., 1995a). In the actinometry runs for the DTC, the quartz tube usually was located between the reaction bags and at about mid height, and parallel with the walls with the lights and the ceiling and the floor. In the case of the XTC, unless noted differently the tube was located inside the reaction bag, and parallel with the wall with the lights and the ceiling and the floor. Some XTC experiments were done with the tube in different positions, as discussed in the Results section. 
One $\mathrm{NO}_{2}$ actinometry experiment was conducted in the XTC using the $\mathrm{NO}, \mathrm{NO}_{2}$, $\mathrm{O}_{3}$ steady state method. In this method, $50 \mathrm{ppb}$ of $\mathrm{NO}_{2}$ was added to the chamber in air in the absence of other reactants, and the steady state levels of $\mathrm{NO}, \mathrm{NO}_{2}$ and $\mathrm{O}_{3}$ were monitored when the chamber was irradiated. The $\mathrm{NO}_{2}$ photolysis rate is then given by

$$
k_{1}=\frac{k\left(\mathrm{O}_{3}+\mathrm{NO}\right)\left[\mathrm{O}_{3}\right][\mathrm{NO}]}{\left[\mathrm{NO}_{2}\right]}
$$

where $\mathrm{k}\left(\mathrm{O}_{3}+\mathrm{NO}\right)=27.6 \mathrm{ppm}^{-1} \mathrm{~min}^{-1}$ at $\sim 300 \mathrm{~K}$ (Carter, 1990). Short reaction lines and a rapid response ethylene chemiluminescence $O_{3}$ monitor was used to minimize reactions of $\mathrm{O}_{3}$ and NO in the sample lines. Relatively low concentrations of $\mathrm{NO}_{2}$ were employed to also minimize this dark sample line reaction, since the reaction rate increases with concentration. Measurements were made with incremental amounts of $\mathrm{NO}_{2}$ added to determine the level where this sample line reaction affected the results, and the $\mathrm{k}_{1}$ was found to be unaffected by the $\mathrm{NO}_{x}$ levels when $\mathrm{NO}_{\mathrm{x}} \leq \sim 150 \mathrm{ppb}$.

Spectral Measurements - ETC and DTC. The spectral measurements for the ETC and DTC chambers were taken periodically using a LiCor Li-1800 portable spectraradiometer. There was found to be no significant difference between the spectrum of this chamber and any other SAPRC blacklight chamber. As discussed elsewhere (Carter et al., 1995a) a composite spectrum was developed, based on spectral measurements using several spectraradiometers, for use in modeling experiments in all SAPRC blacklight chambers. That spectrum, which gives a better representation of the sharp Hg lines than the lower resolution spectrum used previously (Carter et al., 1993a; Carter and Lurmann, 1991) was used in this work.

Spectral Measurements - XTC. The spectrum of the light source in the XTC chamber was usually measured five times during each experiment using the Licor Li-1800 portable spectraradiometer. A shelf for the Li-1800, which held it in the same location for every XTC run, was cut in one of the side walls approximately 5 feet from the light bank, with the sensor pointing at the midpoint between the lights. The instrument was held in the same position during these measurements so that it could provide information of the change in absolute intensities with time, as well as changes in the spectra. This provided a more precise measure of the gradual decay in light intensity with time than was possible using the more infrequent, and generally less precise, $\mathrm{NO}_{2}$ actinometry runs.

\section{Outdoor Chamber}

The light intensity for all outdoor runs for this program was monitored continuously using both an Eppley UV radiometer and an Eppley model PSP precision broadband pyranometer. These sensors were located on the roof of the 
laboratory building next to the OTC. These data were recorded on strip charts and $30-$ second averages were stored on the run data sets every 10 minutes.

The spectral characteristics of the sunlight runs was measured at approximately hourly intervals during the outdoor chamber runs using the Li-1800. The instrument was located on a table beside the OTC at approximately the same height as the chamber framework, and approximately the same distance from the laboratory building as the center of the OTC. The sensor head (cosine response) pointed straight up. Spectra were taken with both the unshaded sensor and with the sensor shaded with a $10.0 \mathrm{~cm}$ disk held $90 \mathrm{~cm}$ from the sensor, positioned so that the shadow of the disk covered the sensor. The former was used to obtain information about the total (direct + diffuse) solar irriadiance, while the latter provided data on the diffuse irriadiance alone. These were used to derive parameters for the solar radiation model which in turn was used to calculate the photolysis rates as a function of time, as discussed later in this report. (The $90 \mathrm{~cm}$ length for the disk from the sensor head was used based on the advice of Jeffries [private communication], who stated this was the practice used when developing the UNC solar radiation models [Jeffries, 1991]. This distance is enough for the disk to just shade the LiCor sensor head.)

Several $\mathrm{NO}_{2}$ actinometry experiments were conducted outdoors for the purpose of evaluating the solar radiation and chamber light transmission models. The same quartz tube method as employed with the indoor runs was used. The tube was directed North-East or South-West and was positioned in the open air next to the chamber with a similar indoor-outdoor carpet under it as the chamber, or inside the chamber, or in the reaction bag area in which bag was removed. A Columbia NO-NO2-NO analyzer and high temperature stainless steel converter were used and placed inside the module building. It was zeroed with zero air and calibrated with No span gas before the actinometry experiment. All the sampling lines were covered with black electrical tape. $\mathrm{An} \mathrm{NO}_{2}$ cylinder was placed outside close to quartz tube. Initial concentrations of $\mathrm{NO}, \mathrm{NO}_{2}$ and $\mathrm{NO}_{x}$ from the $\mathrm{NO}_{2}$ cylinder were checked by connecting the inlet and outlet without the quartz tube. The $\mathrm{NO}_{2}$ was then turned on at approximately 1 liter/min and flowed into the quartz tube which was exposed to sunlight. The outlet of quartz was connected to the columbia analyzer with a " $\mathrm{T}$ ', one of which was used as a vent for the $\mathrm{NO}_{2}$ overflow. The concentrations of $\mathrm{NO}, \mathrm{NO}_{2}$ and $\mathrm{NO}_{x}$ were obtained when photochemical equivalence was reached and then used to calculate $\mathrm{NO}_{2}$ photolysis rate as discussed previously (Carter et al., 1995a).

\section{E. Other Characterization Data \\ 1. Temperature}

Iron-Constantan thermocouples, interfaced directly to a temperature sensor board in the Keithly data system, were used to monitor the temperature as a function of time in these experiments. The probes were calibrated as discussed elsewhere (Carter et al., 1993a). Some additional corrections are needed to the temperature data for the individual chambers, as discussed below. 
ETC and DTC. One temperature sensor was located in each of the reaction bags for the ETC and DTC chambers. No shielding was used for the probes because at the time it was believed that radiative heating by the blacklights was believed to be minor. However, subsequent comparison of temperatures monitored with this method with simultaneous readings using an aspirated temperature probe indicated that temperatures measured using this method need to be corrected by $\sim 2^{\circ} \mathrm{C}$ (Carter et al., 1995a).

XTC. For the XTC runs after XTC91, the temperature was monitored with the thermocouple inside an opaque 1/4" OD sample line inside the chamber, with air being drawn through at a rate of $2 \mathrm{l} / \mathrm{min}$. This is referred to as the aspirated temperature probe. Provided that the flow rate past the sensor is sufficient, this method is considered to give the more accurate temperature reading, and data obtained using this method were used without correction. Tests showed that a flow rate of be at least $2 \mathrm{l} / \mathrm{min}$ was required for the measured temperature to be independent of the flow. For almost all XTC runs, the temperature was also monitored with a probe inside the chamber with an aluminum shield keeping the probe from being directly illuminated. A comparison of data when both methods were used suggested that the data from the unaspirated probe might have to be corrected by as much as $-6.5^{\circ} \mathrm{C}$. However, if this correction was made for the earlier runs where only the unaspirated probe was used, the average temperature in the experiments was found to be significantly lower than the subsequent experiments where the more reliable method was used. Therefore, all temperature data using this method were rejected. Since there was no reason to believe the temperature range was different in the earlier runs, for modeling purposes we decided not to use the corrected temperature data for these runs, but to estimate the temperature based on averages of temperature for subsequent runs. The runs with the uncertain temperature data are indicated on the results tabulation (see also Carter et al. [1995a]).

OTC. Temperature was monitored by shielded thermocouple probes installed in the sample port for each side to measure the air temperature immediately as it flowed out of the chamber. The probes were located slightly outside and underneath the chamber, and were shaded by the Teflon "T"'s used to interface them to the sample line. A separate probe, located underneath the laboratory building, was used to monitor the ambient temperature in the shade. No corrections were made to the temperature data for this chamber.

\section{Dilution}

Dilution due to sampling was expected to be small because the flexible reaction bags can collapse as sample is withdrawn for analysis. However, some dilution occasionally occurred because of small leaks, and several runs had larger than usual dilution due to a larger leak which was subsequently found and repaired. Information concerning dilution in an experiment can be obtained from relative rates of decay of added vocs which react with oH radicals with differing rate constants (Carter et al., 1993a). All experiments had a more 
reactive compound (such as m-xylene or n-octane) present either as a reactant or added in trace amounts to monitor of radical levels. Trace amounts ( 0.1 ppm) of $n$-butane was added to experiments if needed to provide a less reactive compound for the purposes of monitoring dilution. In many experiments, dilution rates were zero within the uncertainties of the determinations.

\section{Control Experiments}

Several types of control experiments were conducted to characterize chamber conditions. Ozone decay rate measurements were conducted with new reactors, and the results were generally consistent with ozone decays observed in other Teflon bag reactors (Carter et. al. 1984, 1986). NO -air irradiations with trace amounts of propene or isobutene, or n-butane-NO $\mathrm{N}_{\mathrm{x}}$-air experiments, were conducted to characterize the chamber radical source (Carter et al., 1982). The specific types of experiments are discussed where relevant in the results or model simulation methods sections. 


\section{MODEL SIMULATION METHODS}

A.

\section{Chemical Mechanism}

The chemical mechanism employed in this work has been documented in the report on our study of the reactivity of acetone (Carter et al., 1993b), and is the same as the mechanism used in our recent report on the dependencies of voc reactivities on ROG surrogate and $\mathrm{NO}_{x}$ (Carter et al., 1995b). The starting point for this mechanism was the "SAPRC-91" mechanism used by Carter et al. (1993a), which in turn is an updated version of the "SAPRC-90" mechanism documented by Carter (1990). The differences between the current mechanism, which can be referred to as "SAPRC-93" (Carter et al., 1995b) the earlier versions of the SAPRC detailed mechanisms are summarized below. Note that some of the changes are not relevant to the specific simulations in this report, but are included in the discussion below for completeness.

(1) The updates to the formaldehyde absorption cross-sections and the kinetics of PAN formation incorporated in the SAPRC-91 mechanism were also incorporated in this mechanism. The changes in PAN kinetics cause the model to predict somewhat higher ozone formation rates than the SAPRC-90 mechanism.

(2) The SAPRC mechanisms use model species whose photolysis rates are adjusted to fit aromatic-NO $\mathrm{N}_{\mathrm{x}}$-air chamber experiments to represent the unknown photoreactive aromatic fragmentation products (Carter, 1990). In the SAPRC-91 and the current mechanisms, the action spectra (absorption coefficients $x$ quantum yields) for these products were assumed to be proportional to the absorption cross section for acrolein (Gardner et al., 1987), rather than using the somewhat arbitrary action spectrum in the SAPRC-90 mechanism. The yields of these products were reoptimized based on the simulations of the available chamber data using the updated mechanism. In the SAPRC-91 mechanism, different optimizations were used for m-xylene, depending on which experiments were being simulated (Carter et al., 1993a). In this work, the same m-xylene mechanism was used in all simulations, with the parameters optimized to fit m-xylene - $\mathrm{NO}_{\mathrm{x}}$ - air experiments. This resulted in a mechanism which somewhat underpredicted the results of many of the Phase I mini-surrogate experiments, though it performed much better than did the "unadjusted SAPRC-91" mechanism used in the Phase I report, and it performed reasonably well in simulating the base case experiments in the phase II study (Carter et al., 1995b, see also below). The calibration and zero errors found in the $\mathrm{NO}_{x}$ data for all the relevant aromatic experiments were corrected as discussed by Carter et al. (1995a) prior to reoptimizing the aromatic product yield parameters.

(3) The mechanisms for the reactions of ozone with alkenes were modified to be consistent with the data of Atkinson and Aschmann (1993), who observed much higher yields of $O H$ radicals than predicted by the SAPRC-90 and SAPRC-91 mechanisms. To account for these data, it was assumed that (1) the formation of 
$\mathrm{OH}$ radicals dominates over other radical-forming fragmentation processes, and (2) in the reactions of unsymmetrical alkenes, the more substituted Criegee biradical, which forms higher $O H$ yields, are formed in relatively higher yields than the less substituted biradicals. The ozone reactions for the alkenes discussed in this paper are:

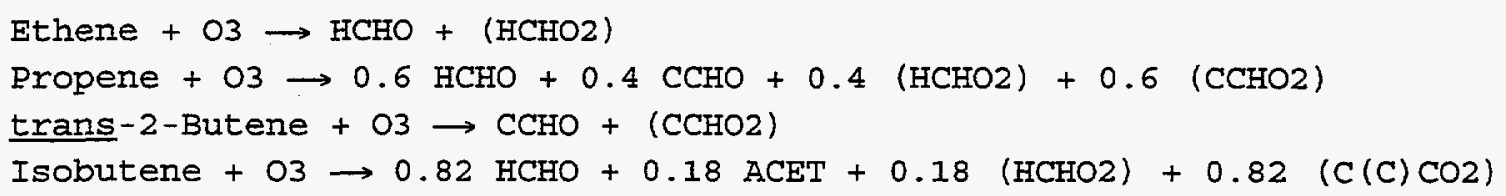

where CCHO and ACET represent acetaldehyde and acetone, and (HCHO2), etc., represent the excited Criegee biradicals, which are represented as reacting as follows :

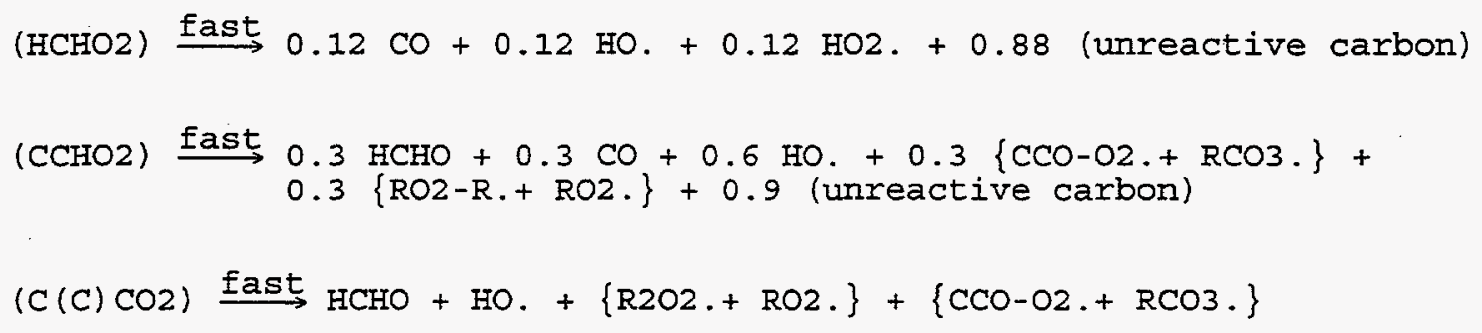

[See Carter (1990) for a description of the model species and the methods used to represent peroxy radical reactions.] This is clearly an oversimplification of this complex system (e.g., see Atkinson, 1990, 1994), but is intended to account for the observed $O H$ radical yields and represent the major features affecting these compounds' reactivities. Note that this new mechanism gives substantially higher radical yields in the ozone + alkene systems than the SAPRC90 mechanism, particularly for internal alkenes.

(4) The reaction of No with the peroxy radical formed in the reaction of OH radicals with isobutene was assumed to form the corresponding hydroxyalkyl nitrate 108 of the time. This assumption resulted in significant improvements to the fit of model simulations to ozone and PAN yields in isobutene - $\mathrm{NO}_{x}$ - air chamber experiments. Without this assumption, the model with the of yields indicated by the $\mathrm{O}_{3}+$ isobutene data of Atkinson and Aschmann (1993) significantly overpredicts $\mathrm{O}_{3}$ formation rates. If lower radical yields in the $\mathrm{O}_{3}+$ isobutene reaction are assumed, the model significantly underpredicts, PAN (unpublished results from this laboratory).

(5) The mechanistic parameters used in the model for isooctane were modified to improve the model simulations of its reactivity (Carter et al., 1993a). 
(6) Several changes were made to the mechanism for acetone. These are documented elsewhere (Carter et al., 1993b.) Note that the mechanism used in this work employed the acetone quantum yields based on the corrected data of Meyrahn et al (1986), and not the values adjusted to fit our recent chamber experiments (Carter et al., 1993b), which predict somewhat lower reactivities for this compound. Although this is a potential source of bias, it only affects predictions of acetone's reactivity, and has no substantial effect on any of the simulations discussed in this report.

A listing of the SAPRC-93 mechanism is given by Carter et al. (1993b). Further updates to this mechanism are planned, and the process of evaluating it against the full data base of chamber experiments (Carter and Lurmann, 1991; Carter et al., 1995a,b) is underway. However, it was evaluated in model simulations of the results of the extensive set of Phase I and II reactivity experiments (Carter et al, 1993c, 1995b), and was found to perform somewhat better than the SAPRC-90 and SAPRC-91 mechanisms in simulating these data.

\section{B. Derivation of Photolysis Rates}

The rate constant for photolysis reactions are calculated from the wavelength-dependent absorption cross sections $\left(\sigma_{\lambda}\right)$ and quantum yields $\Phi_{\lambda}$ for the photolyzing species and reactions, and the spherically integrated actinic fluxes of the light source $\left(J_{\lambda}\right)$. The absorption cross sections and quantum yields are given with the documentation of the mechanism (Carter et al., 1993b). The derivation of the actinic fluxes depended on the type of light source, as discussed below.

1. Indoor Chamber Actinic Fluxes

For indoor chamber runs, the actinic flux is calculated from the $\mathrm{NO}_{2}$ photolysis rate $\left(k_{1}\right)$ and the relative spectral distribution $\left(J_{\lambda}{ }^{\text {rel }}\right)$ for the experiment as follows,

$$
J_{\lambda}=J_{\lambda}{ }^{\mathrm{rel}} \frac{k_{1}}{\sum J_{\lambda}{ }^{\mathrm{rel}} \sigma_{\lambda}^{\mathrm{NO2}} \Phi_{\lambda}{ }^{\mathrm{NO2}}}
$$

where $\sigma_{\lambda}{ }^{\mathrm{NO} 2}$ and $\Phi_{\lambda}{ }^{\mathrm{NO2}}$ are the $\mathrm{NO}_{2}$ absorption cross sections and photolysis quantum yields for $\mathrm{NO}_{2}$ in the gas-phase mechanism. The sources for the $\mathrm{NO}_{2}$ photolysis rates for the indoor chamber experiments modeled in this work are as follows:

\begin{tabular}{lll} 
Chamber & Derivation Method & Values \\
\cline { 2 - 2 } & Carter et al. (1995a) & Varied. See Carter et al. (1995a) \\
ITC & Carter et al. (1995a) & Varied. See Carter et al. (1995a) \\
ETC $(<370)$ & Carter et al. (1993a) & Varied. Carter et al. (1993a) x 1.05 \\
ETC $(>370)$ & Carter et al. (1995a) & $0.351 \mathrm{~min}^{-1}$ see Carter et al. (1993a) \\
DTC & Carter et al. (1995a) & $0.388 \mathrm{~min}^{-1}$ (This work) \\
XTC & this work & Varied. See Results section.
\end{tabular}


The spectral distributions used when simulating the EC and ITC experiments are given by Carter et al. (1995a). Note that the spectral distribution for the EC experiments vary with experiment. (Runs after EC650 have significantly lower UV intensity than earlier EC runs [Carter et al., 1995a], but these runs were not modeled in this work). Measurements indicate that the spectral distributions for the ETC and DTC are the same as for the ITC, so the same spectral distribution is used when modeling all SAPRC blacklight chambers.

Note that the EC and ITC $k_{1}^{\prime}$ s and spectral distributions given by Carter et al. (1995a) are a result of a complete re-evaluation of the available relevant data, and in general are somewhat differ from those used in previous mechanism evaluations using those experiments (e.g., Gery et al., 1988, Carter and Lurmann, 1990, 1991). All the $\mathrm{NO}_{2}$ photolysis rates were recalculated using updated rate constants and analysis methods, and $k_{1}$ values and EC spectral distributions were reassigned for the individual runs based on the overall data set. Some corrections were made to the spectral radiometer data used to measure the EC spectral distributions. A new blacklight spectrum, which is significantly better in representing the many mercury emission lines, was derived based on a composite of different spectra. The effects of these changes in light characterization assignments relative to those used in previous evaluations on model simulations have not yet been investigated.

\section{Outdoor Chamber Actinic Fluxes}

The light characterization data for the outdoor chamber runs consist of continuous UV and broadband radiometer data, and approximately hourly global and diffuse solar spectra taken using the LI-1800 spectrometer. The global and diffuse spectra, along with the JSPECTRA solar light model developed by Jeffries (1988, 1989, 1991) and adapted for use in this work as discussed below, were used as the primary means for light characterization for modeling purposes. The procedure employed is only applicable to clear sky conditions, so no runs on cloudy or overcast days were modeled in this study. The radiometer data was used as a cross-check to assure that the light conditions were not changing abruptly between the times spectral measurements were made.

As discussed by Jeffries (1988), the USPECTRA solar light model is designed to calculate ground-level solar spectra given relevant parameters such as time of day, day of year, total ozone column, atmospheric aerosol parameters, and extraterrestrial solar fluxes. It can be used either to calculate spherically integrated actinic fluxes for calculation of photolysis rates or to predict global or diffuse spectra as measured by the LiCor spectrometer. Some of the inputs to the program, such as the time of day or day of year, are known, others, such as the extraterrestrial fluxes, are assumed not to be variable and are provided with the model, while other inputs, such as the ozone column and the aerosol parameters, are uncertain or variable. The most sensitive of the uncertain inputs were adjusted, using a non-linear optimization algorithm, to fit the global and diffuse Licor spectra taken during the run, while for the less 
sensitive parameters the defaults used by Jeffries (1988) for "summer conditions" were used in all calculations. Although moderately good fits of adjusted model calculation to Licor spectra could obtained by adjusting only the parameters in the JSPECTRA model, for best fits to the data three separate parameters were added to scale the overall intensity as a function of wavelength. These consisted of scaling factors for the intensities at 300,500 , and $800 \mathrm{~nm}$; the scaling factors for other wavelengths were obtained by linear interpolation of these. With the set of parameters we used, these scaling factors were consistently $0.7,1$, and 1.1 at these three wavelengths, respectively. An example showing the comparison obtained between the adjusted model calculation and the global and diffuse LiCor spectra is shown on Figure 7.

The results of the optimization of the JSPECTRA input parameters could then be used to calculate spherically integrated actinic fluxes for the times the LiCor spectra were taken. The calculated spherically integrated fluxes were not sensitive to the specific set of JSPECTRA parameters optimized, as long as the model could closely simulate the direct and diffuse LiCor data. If the run was carried out on a clear day, the parameters affecting light fluxes might reasonably be assumed not to change abruptly with time. In this case, the values of the adjusted parameters for times between those where Licor data were taken could be estimated by linear interpolation of the optimized values. Based on this assumption, parameters were estimated at each 20 minute interval during the run, from which actinic fluxes for those times were calculated. The fact that this assumption is not valid for cloudy days is not a significant limitation because the JSPECTRA model was not designed to calculate solar fluxes for those conditions in any case. For this reason, only data from clear day runs were characterized for modeling purposes. The few runs carried out on days with unfavorable weather are not discussed.

The JSPECTRA program, with its time-varying inputs derived as discussed above, could also be used to calculate how the data from the UV and broadband radiometers should vary with time. Thus, while this method does not directly utilize these data in the photolysis rate calculations, they can be used as a check on the appropriateness of the model's interpolations. Typical results are included on Figure 7, which shows plots of observed and calculated radiometer data vs. time for run OTC-274. In general, the model gave somewhat better predictions of the time profiles of the broadband data than the UV data. This can be attributed to the fact that the spectral response of UV radiometers such as those employed in this study are not particularly well characterized, and the JSPECTRA model uses a highly idealized representation in this regard.

The above procedure predicts light spectra outside the chamber, but the relevant quantities are the light spectra inside the Teflon reaction bag. Jeffries et al. (1989) measured light reflection and transmission through 2 mil and $5 \mathrm{mil}$ FEP Teflon film as a function of wavelength and the incidence angle of the light beam, and developed a parameterized model to fit these data. Although 


\section{Spectral Data for $1300 \mathrm{hrs}$}

\section{Experimental (Global)}

- - Experimental (Shaded)

......... Model Calculation (Global and Shaded)

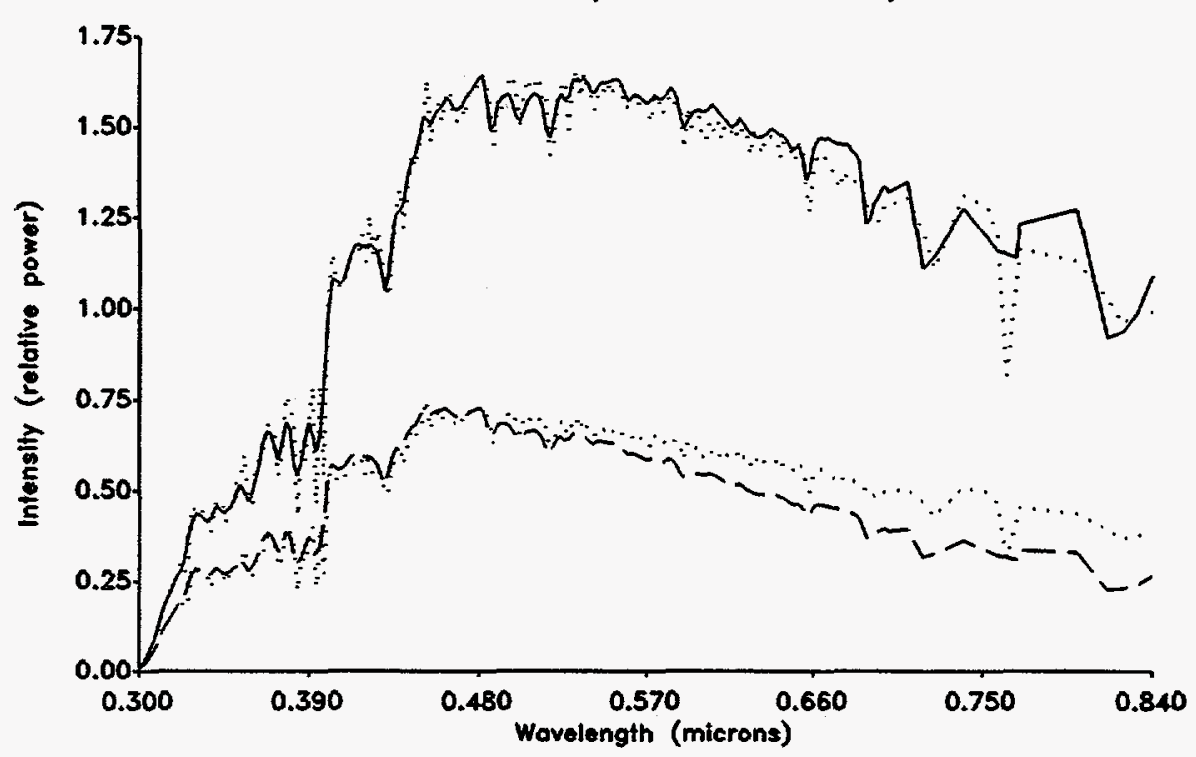

UV Radiometer Data

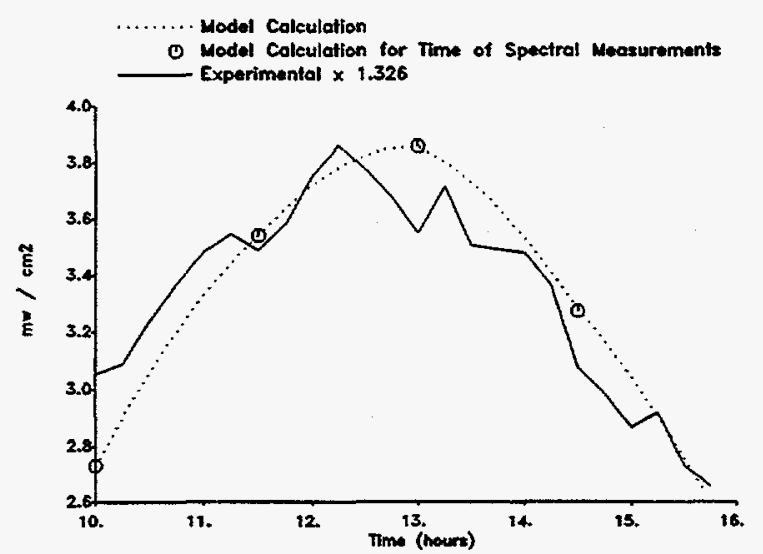

Broadband Radiometer Data

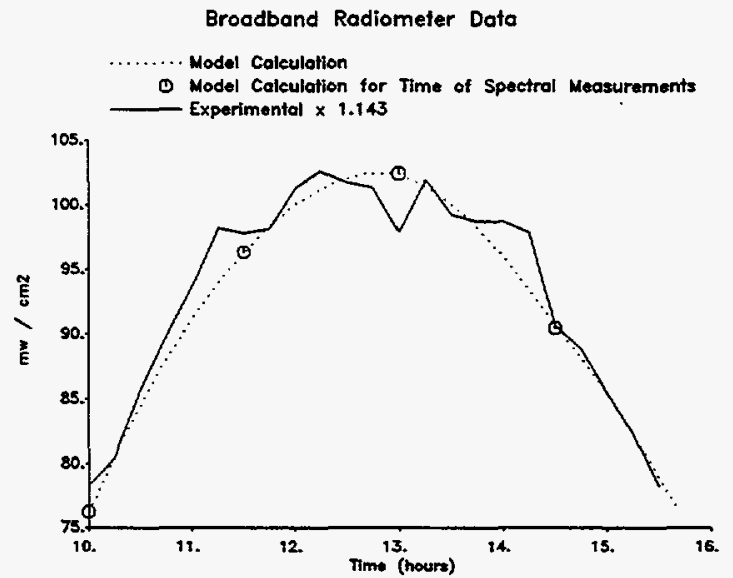

Figure 7. Examples of fits of adjusted solar light model to light characterization data for two outdoor chamber runs. Top plots: fits to direct and diffuse spectral data. Bottom plots: fits to changes with time in the data from the UV and broadband radiometers. 
this model includes a term for absorption, the fraction of light absorbed is small (less than $1 \%$ for 2-mil film) and is neglected in our model. Thus only loss due to reflection on the outer chamber walls, or enhancement due to reflection on the inner walls, are considered. The OTC can be thought of as a transparent bag suspended in space, with light entering it from all directions. If the effect of the presence of the bag on the light coming in from the bottom is neglected, it can be shown that the light enhancement by the reflections from inside the bag just makes up for the light lost due to the reflection when it enters the bag, with the result being that the intensity (and spectrum) inside the bag should be exactly the same as outside. The principle behind this is exactly the same as the principle behind the arguments given by zafonte et al. (1977) when they concluded that reflections off quartz tubes do not affect results of actinometry measurements using such tubes. Consistent with this is the fact that no large differences were observed when $\mathrm{NO}_{2}$ actinometry measurements were made inside and outside the OTC on the same days (see Results).

The assumption that the presence of the OTC does not affect light coming from the bottom is not totally valid because the reaction bag is sufficiently close to the ground that all the light coming from the bottom has first passed through the bag, and was thus attenuated by the first reflection from the top. An approximate correction for this was made based on assuming the top and the bottom of the chamber are flat planes of film parallel to the surface, and that the albedo of the carpet under the chamber is the same as the general albedo which is the default in the JSPECTRA model. Parameterized fits to 2-mil FEP Teflon transmission data provided by Jeffries (private communication) were used to calculate the transmissions and reflectance through the chamber walls. This is a fairly small correction, causing the predicted in-chamber photolysis rates to be $\sim 4 \%$ lower than those calculated for outside.

The in-chamber actinic fluxes calculated for every 20 minutes during the run were used as input into model when simulating the run. The model then calculated the photolysis rates for these periods using the absorption cross sections and quantum yields for the various reactions. The photolysis rates were updated at each time step in the simulation, with the model deriving the photolysis rates for intermediate times between these 20 minute intervals by linear interpolation.

This method was evaluated by conducting actinometry experiments both inside and outside the reaction bag, as discussed elsewhere in this report. Comparisons of the predictions of this model with $\mathrm{NO}_{2}$ actinometry measurements made in and around the OTC indicate that predicted photolysis rates are $\sim 7 \%$ 10w, both inside and outside the chamber. Thus, a factor of 1.07 correction was applied to all photolysis rates calculated by this method when modeling OTC runs. This is discussed in more detail in section $\mathrm{V}-\mathrm{C}$. 


\section{Chamber Effects Model and Parameters}

Modeling environmental chamber experiments requires an appropriate representation of wall and contaminant effects. These include heterogeneous reactions on the walls, wall adsorption of reactants, contaminant offgasing, and contamination of injected $\mathrm{NO}_{\mathrm{x}}$ with HONO. Table 2 shows the reactions and the parameterization in the wall effects model used when modeling these experiments, and Table 3 shows the values of the parameters which were used. This parameterization is the same as used when evaluating the RADM2 (Carter and Lurmann, 1990) and the SAPRC-90 (Carter and Lurmann, 1991) mechanisms, though the values given on Table 3 are in some cases different than those used previously.

Table 3 also includes a brief explanation of how all the parameters were derived. In some cases, parameter values were changed as a result of modeling runs for this work. The most important example of this is the derivation of the temperature-dependent radical source parameters for the Teflon chambers, which is discussed in more detail in section $V-D$.

$\mathbf{D}$

Representation of other Run Conditions

The other run conditions which need to be specified when simulating a chamber experiment are the initial reactant concentrations, temperature, humidity, dilution, and (when applicable) subsequent reactant injections or other operations. In the case of the runs modeled in this work, all reactants were present initially, and there were no subsequent injections or other operations after the irradiation began. The initial reactant concentrations were based on the measured values - experiments where these were unknown or highly uncertain are not modeled in this work. The methods for representing the other conditions are summarized below.

Temperature: The temperature used when modeling the experiments was based on fitting the temperature data to a series of line segments (usually two for indoor runs - one to represent the relatively rapid increase in temperature during the first 15 minutes of the run, the other to represent any small trend in temperature later), as recommended when modeling SAPRC chamber runs (Carter et al., 1995a). The temperature in the model simulation changed linearly between the times defining the end points of these segments. Note that this differs slightly from our previous procedure of using a constant temperature (based on the average during the run) when modeling indoor chamber runs.

Humidity: The water concentrations used when modeling the EC and ITC are given by Carter et al. (1995a). All the EC and ITC experiments modeled in this work were carried out at $\sim 50 \% \mathrm{RH}$, which correspond to a $\mathrm{H}_{2} \mathrm{O}$ concentration of $\sim 2$ $\mathrm{x} 10^{4} \mathrm{ppm}$ at the normal temperature of these runs.

Unhumidified air was used for the ETC, OTC, and most of the DTC experiments because it minimizes chamber effects and improves reproducibility. Measurements made previously indicate the unhumidified output of the SAPRC pure air system 
Table 2. Reactions and parameters used to represent chamber wall processes and contaminant effects.

Parameter Representation in Model [b] Description

[a]

Rate Constants for Dark Wall Reactions

$\mathrm{k}(\mathrm{O} 3 \mathrm{~W}) \quad \mathrm{O}_{3}=$ (loss of $\mathrm{O}_{3}$ )

$\mathrm{k}(\mathrm{N} 25 \mathrm{I}) \quad \mathrm{N}_{2} \mathrm{O}_{5}=$ (wall $\mathrm{NO}_{x}$ )

$\mathrm{k}$ (N25S) $\quad \mathrm{N}_{2} \mathrm{O}_{5}+\mathrm{H}_{2} \mathrm{O}=$ (wall $\mathrm{NO}_{x}$ )

$\mathrm{k}$ (NO2W) $\mathrm{NO}_{2}=\# y_{\text {HoNo }}$ HONO $+\# 1-y_{\text {HoNo }}$ (wall $\mathrm{NO}_{x}$ ) $\mathrm{NO}_{2}$ Hydrolysis

Rate Constants used to Represent Contaminant Offgasing effects

$k(\mathrm{XSHC}) \quad \mathrm{HO} .=\mathrm{HO}_{2}$.

Background reactivity

Rate Constants for Light Induced Wall Reactions

RS-I $\times k_{1} \quad \mathrm{HV}=\mathrm{HO}$.

RS-S X k $\mathrm{k}_{1} \quad \mathrm{NO}_{2}+\mathrm{HV}=\# .5$ HONO $+\# .5$ (wall $\left.\mathrm{NO}_{x}\right)$

$\mathrm{E}-\mathrm{NO} 2 \times \mathrm{k}_{1} \quad \mathrm{HV}=\mathrm{NO}_{2}+\#-1$ (wall $\mathrm{NO}_{x}$ )

$\mathrm{E}-\mathrm{HOHO} \times \mathrm{k}_{1}$ HV $=$ HONO $+\#-1$ (waIl $\left.\mathrm{NO}_{x}\right)$

Ozone Dark decay

$\mathrm{N}_{2} \mathrm{O}_{5}$ Hydrolysis

Other Parameters

YHowO HONO yield in $\mathrm{NO}_{2}$ hydrolysis reaction

Fovo Fraction of initial $\mathrm{NO}_{2}$ converted to initial HONO prior to irriadiation

[a] If a reaction is shown in the right column, the parameter, or the parameter multiplied by $k_{1}$, is the rate constant for the reaction. $k_{1}$ is the $\mathrm{NO}_{2}$ photolysis rate.

[b] "\#" used to indicate product coefficient.

was too low to measure reliable, or $5 \% \mathrm{RH}$ or less. For modeling these runs, we assume the humidity is $25 \%$, which corresponds to approximately $2000 \mathrm{ppm}$ of $\mathrm{H}_{2} \mathrm{O}$.

For runs DTC061 and DTC062, the air was humidified by injecting water vapor prior to injecting the other reactants, and humidity was measured to be approximately $50 \% \mathrm{RH}$. $\mathrm{A}_{2} \mathrm{O}$ concentration of $2 \times 10^{4}$ ppm was used when modeling these runs.

Dilution: The dilution rates used in simulating the EC experiments was $1.8 \%$ per hour, based on typical sampling rates in this chamber (Carter et al., 1995a). Dilution was assumed to be negligible when simulating the ITC runs. For the ETC, DTC, XTC, and OTC runs, the dilution rates were derived based on measured rates of decay of slowly reacting relative to more rapidly reacting species which react only with $\mathrm{OH}$ radicals, as discussed elsewhere (Carter et al., 1993a, 1995a,b). While dilution can be an important factor when analyzing some types of results 
Table 3 .

Values of chamber wall and contaminant effects parameters used when modeling runs in this work.

\begin{tabular}{|c|c|c|}
\hline Parm. ${ }^{a}$ & Cham. ${ }^{b}$ & Value \\
\hline \multirow[t]{5}{*}{$k(03 W)$} & EC & $1.1 \times 10^{-3} \mathrm{~min}^{-2}$ \\
\hline & ITC & $1.5 \times 10^{-4} \mathrm{~min}^{-1}$ \\
\hline & ETC (bag2) & $1.22 \times 10^{-4} \mathrm{~min}^{-1}$ \\
\hline & отс & $1.67 \times 10^{-4} \mathrm{~min}^{-1}$ \\
\hline & Other TC & $1.5 \times 10^{-4} \mathrm{~min}^{-1}$ \\
\hline \multirow[t]{2}{*}{$\begin{array}{l}k(N 25 I) \\
k(N 25 S)\end{array}$} & EC & $\begin{array}{l}4.65 \times 10^{-3} \mathrm{~min}^{-2} \\
2.22 \times 10^{-6}-\mathrm{k}_{\mathrm{g}} \mathrm{ppm}^{-1} \mathrm{~min}\end{array}$ \\
\hline & All TC & $\begin{array}{l}2.8 \times 10^{-3} \mathrm{~min}^{-1} \\
1.5 \times 10^{-6}-\mathrm{k}_{\mathrm{g}}\end{array}$ \\
\hline \multirow{2}{*}{$\begin{array}{l}k \text { (NO2W), } \\
y_{\text {ноко }}\end{array}$} & EC & $2.8 \times 10^{-4} \mathrm{~min}^{-1}, 0.5$ \\
\hline & aII-TC & $1.6 \times 10^{-4} \mathrm{~min}^{-1}, 0.2$ \\
\hline \multirow[t]{2}{*}{$k(X S H C)$} & EC & 0.0 \\
\hline & aIl-TC & $250 \min ^{-1}$ \\
\hline $\begin{array}{l}\text { RS }-I, \\
\text { RS-S }\end{array}$ & EC & $0.293 \mathrm{ppb}, 1.62 \times 10^{-3}$ \\
\hline & ITC & $0.08 \mathrm{ppb}, 0$ \\
\hline
\end{tabular}

Discussion

Based on $\mathrm{O}_{3}$ decay experiments as discussed by carter et al. (1995a).

Based on $\mathrm{O}_{3}$ decay experiments as discussed by Carter et al. (1995a).

Based on $\mathrm{O}_{3}$ decay runs ETC410, ETC456 in this bag.

As used by Carter and Lurmann (1990, 1991) for previous SAPRC OTC runs.

Limited data available indicate that value used for ITC is not inappropriate.

Based on the $\mathrm{N}_{2} \mathrm{O}_{5}$ decay rate measurements in the $\mathrm{EC}$ reported by Tuazon et al. (1983). See carter et al. (1995a). $\mathrm{k}_{\mathrm{g}}$ is the rate constant for the gas-phase $\mathrm{N}_{2} \mathrm{O}_{5}$ hydrolysis used in the mechanism.

Based on the $\mathrm{N}_{2} \mathrm{O}_{5}$ decay rate measurements in the ETC reported by Tuazon et al. (1983). Assumed to be the same for all Teflon chambers. See above.

Based on dark $\mathrm{NO}_{2}$ decay and HONO formation measured in the EC by Pitts et al. (1984).

Based on dark $\mathrm{NO}_{2}$ decay and HONO formation measured in the ETC by Pitts et al. (1984). Assumed to be the same in all Teflon bag chambers, as discussed by Carter et al. (1995a).

As assumed in previous mechanism evaluations (Carter and Lurmann, 1990, 1991). See Carter et al., 1995a).

As given by carter et al. (1994). Estimated by modeling several ITC pure air irradiations. Consistent with simulations of pure air runs in the ETC. (Not an important parameter affecting model predictions except for pure air or $\mathrm{NO}_{\mathrm{x}}$-air runs.)

This work - see Section V.D.1. Standard assignment used in previous mechanism evaluations were adjusted downward by 25 은.

This work - see section V.D.1. Derived by modeling nbutane - NO experiments. Significantly lower than previous assignments which were derived from tracer $\mathrm{NO}_{x}$ - air experiments as discussed by Carter et al. (1982).

DTC 50\%RH $0.08 \mathrm{ppb}, 0$

dry $\mathrm{TC}$ $3.70 \times 10^{9} e^{-18.99 / 89} \mathrm{ppb}$,

Assumed to be the same as in the ITC, where $50 \%$ air was also used. Tracer - NO run DTC061 are fit by a much higher radical source, which is analogous to the situation with the ITC. See Section V.D.1.

This work - see Section V.D.2. R=0.0019872 kcal ${ }^{\circ} \mathrm{K}^{-2}$ mol $^{-2}$, and $T$ is the temperature in ${ }^{\circ} \mathrm{K}$. Derived based on modeling n-butane - $\mathrm{NO}_{x}$ - air irradiations in the DTC, XTC, and OTC. Temperature dependence is necessary to fit the OTC experiments.

As given by Carter et al. (1995a). Fits PAN yields in acetaldehyde-air run EC253.

As given by Carter et al. (1995a). Reasonably consistent with model simulations of acetaldehyde air runs in the ITC.

Based on simulations of acetaldehyde - air run ETC319. Within the range of variability of values which fit modeling of pure air runs. 
Table 3 (continued)

\begin{tabular}{|c|c|c|c|}
\hline Parm . & Cham. & Value & Discussion \\
\hline \multirow[t]{3}{*}{ E-NO2 } & $\operatorname{ETC}(\operatorname{bag} 2)$ & $0.04 \mathrm{ppb}$ & $\begin{array}{l}\text { Based on model simulations of acetaldehyde - air runs } \\
\text { in this bag. }\end{array}$ \\
\hline & DTC & $0.03 \mathrm{ppb}$ & $\begin{array}{l}\text { Based on model simulations of pure air run DTC049. } \\
\text { Consistent with ETC value. }\end{array}$ \\
\hline & XTC, OTC & $0.03 \mathrm{ppb}$ & $\begin{array}{l}\text { Assumed to be the same as used for ETC (bagl) and DTC } \\
\text { runs. }\end{array}$ \\
\hline \multirow[t]{3}{*}{$\mathrm{f}_{\text {HONO }}$} & EC & 0.07 & $\begin{array}{l}\text { As given by Carter et al. (1995a) and used in the } \\
\text { mechanism evaluation studies of Carter and Iurmann } \\
\text { (1990, 1991). Based on analysis of tracer - NO } \mathrm{N}_{\mathrm{x}} \text { runs } \\
\text { in the EC (Carter et al. 1982). }\end{array}$ \\
\hline & ITC & 0 & 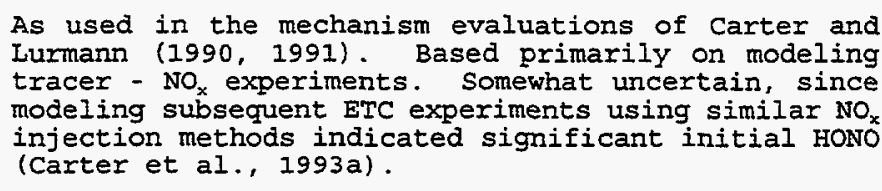 \\
\hline & $\begin{array}{l}\text { ETC, DTC, } \\
\text { XTC, OTC }\end{array}$ & 0 & $\begin{array}{l}\text { All these experiments employed } \mathrm{NO}_{x} \text { injection proce- } \\
\text { dures designed to remove HoNo contamination. Model } \\
\text { simulations of runs discussed by Carter et al. (1993a) } \\
\text { indicated that this procedure successfully removes } \\
\text { HONO. }\end{array}$ \\
\hline
\end{tabular}

a See Table 2 for definition of parameters

- Chamber code "all-TC means all Teflon bag chambers, i.e., ITC, ETC, XTC, DTC, and OTC. ETC (bag1) refers to ETC runs with the reaction bag used for runs prior to ETC357. ETC (bag2) refers to ETC runs with the reaction bag used after ETC372.

- Not applicable to ETC runs prior to ETC090, where there was definite indication of HoNo contamination. These runs were not modeled in this work.

of incremental reactivity experiments (Carter et al., 1993a, 1995b), it is not a sensitive factor in the types of experimental vs model comparisons discussed in this work. 


\section{RESULTS AND DISCUSSION}

A.

Summary of New Experiments

Table 4 give chronological listings of all the new ETC, DTC, XTC, and OTC experiments which are relevant to this report. These include experiments used to determine effects of chamber and light source on mechanism evaluations, together with the characterization used to derive the chamber-dependent parameters for the model simulations, or to evaluate the performance of the xenon arc light source. Not listed are a number of incremental reactivity experiments whose results are discussed in detail elsewhere (Carter et al., 1995b), though selected base case experiments used in those studies are included on the listing because they are also modeled in this work. The chronology of the experimental studies is briefly summarized below.

The first experiments were carried out in the ETC chamber used in our previous studies of incremental reactivities (Carter et al., 1993a). A new reaction bag was installed, and a series of characterization and control runs were conducted. This includes several replicates of the standard "minisurrogate" experiment in the previous phase. The results of the latter were within the normal range, as discussed later. Several single-compound runs were conducted for comparison with the data base of previous experiments and the new experiments in the other chambers. A number of runs were then carried out for other programs. Following these, and several additional characterization runs, a series of "ethylene surrogate" incremental reactivity runs were carried out, whose results are discussed elsewhere (Carter et al., 1995b). These consisted of ethylene - $\mathrm{NO}_{x}$ "base case" runs and ethylene - $\mathrm{NO}_{\mathrm{x}}$ runs with a test voC added. The base case runs are included on the list because they were modeled as part of study.

Around the same time the ethylene surrogate experiments were being conducted in the ETC, the construction of the Dividable Teflon Chamber (DTC) was completed, and actinometry and other characterization experiments were conducted in it. Most of the experiments in the DTC consisted of incremental reactivity experiments whose results are discussed in detail elsewhere (Carter et al., 1995b). These runs involved $\mathrm{NO}_{\mathrm{x}}$-air irradiations, at two different $\mathrm{NO}_{\mathrm{x}}$ levels, of an 8-component ROG surrogate consisting of n-butane, n-octane, ethylene, propene, trans-2-butene, toluene, m-xylene, and formaldehyde, simultaneously with irradiations of the same mixture with a test VOC added. The high and low $\mathrm{NO}_{x}$ base case surrogate - $\mathrm{NO}_{x}$ experiments are also modeled as part of this study, though not all the individual runs are listed explicitly in Table 4 (see Carter et al., [1995b] for a complete listing).

Following the reactivity experiments, various single compound - $\mathrm{NO}_{\mathrm{x}}$ experiments were carried out for the purpose of mechanism evaluation and 
Table 4. Listing of new environmental chamber experiments relevant to this report. [a]

Run Date Description and Comments

ETC Experiments

$\begin{array}{ll} & 4 / 22 / 92 \\ 370 & 4 / 23 / 92 \\ 371 & 4 / 23 / 92 \\ 372 & 4 / 27 / 92 \\ 373 & 4 / 28 / 92 \\ 374 & 5 / 12 / 92 \\ 375 & 5 / 18 / 92 \\ 376 & 5 / 19 / 92 \\ 377 & 5 / 20 / 92 \\ 378 & 5 / 21 / 92 \\ 379 & 5 / 22 / 92 \\ 380 & 5 / 26 / 92 \\ 381 & 5 / 27 / 92 \\ 382 & 5 / 28 / 92 \\ 383 & 5 / 2 / 92 \\ 384 & 6 / 3 / 92 \\ 385 & 5 / 8 / 92 \\ 440 & 10 / 1 / 92 \\ 441 & 10 / 2 / 92 \\ 448 & \\ 458 & 11 / 9 / 92 \\ 461 & 11 / 13 / 92 \\ 462 & 11 / 13 / 92 \\ 466 & 11 / 23 / 92 \\ 467 & 11 / 25 / 92 \\ 469 & 12 / 2 / 92 \\ 473 & 12 / 8 / 92 \\ 475 & 12 / 14 / 92 \\ 476 & 12 / 15 / 92 \\ 479 & 12 / 18 / 92 \\ 482 & 1 / 5 / 93 \\ 485 & 1 / 8 / 93 \\ 486 & 1 / 11 / 93 \\ 502 & 2 / 5 / 93 \\ 4 & \\ 743\end{array}$

DTC Experiments

$\begin{array}{ll} & 1 / 4 / 93 \\ 001 & 1 / 21 / 93 \\ 002 & 1 / 22 / 93 \\ 003 & 1 / 27 / 93 \\ 004 & 1 / 28 / 93 \\ 005 & 1 / 29 / 93 \\ 006 & 2 / 11 / 93 \\ & \\ 014 & 3 / 12 / 23 \\ 025 & 4 / 1 / 93 \\ 026 & 4 / 6 / 93 \\ 027 & 4 / 7 / 93 \\ 028 & 4 / 8 / 93 \\ 029 & 4 / 9 / 93 \\ 041 & 5 / 3 / 93 \\ 042 & 5 / 5 / 93 \\ 043 & 5 / 6 / 93 \\ 049 & 5 / 17 / 93 \\ 052 & 5 / 25 / 93 \\ 054 & 5 / 28 / 93 \\ 055 & 6 / 1 / 93 \\ 058 & 6 / 7 / 93 \\ 059 & 6 / 8 / 93 \\ 060 & 6 / 9 / 93 \\ 061 & 6 / 10 / 93 \\ 062 & 6 / 11 / 93 \\ 063 & 7 / 14 / 93 \\ 064 & 7 / 15 / 93 \\ 071 & 7 / 27 / 93 \\ 072 & 7 / 28 / 93 \\ 073 & 7 / 29 / 93 \\ 074 & 7 / 30 / 93 \\ 076 & 8 / 4 / 93 \\ & \\ 075\end{array}$

New reaction bag installed.

Pure-air irradiation

Ozone decay (result in normal range)

Standard phase I Mini-Surrogate

Standard Phase I Mini-Surrogate

Pure-air irradiation

Propene-NO

Standard Phase I Mini-Surrogate

Ethene-NO

Formaldehyde - $\mathrm{NO}_{x}$

Formaldehyde-air

Tracer-No

Ethene-NO

Acetaldehyde-air

Standard Phase I Mini-Surrogate

Standard Phase I Mini-Surrogate

Formaldehyde-air

Propene - NO

Formaldehyde - NO,

$\mathrm{NO}_{2}$ Actinometry

(runs for other programs, or full surrogate test runs)

Pure air Irradiation

$\mathrm{NO}_{2}$ Actinometry

Tracer - NO

Ethene - NO $\mathrm{N}_{\mathrm{x}}[\mathrm{b}]$

Ethene - No,

Ethene - NO

Ethene - NO

Propene - NO

Ethene - NOx

Ethene - NOx

Ethene - NO,

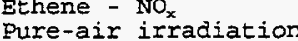

Pure-air irrad

Ethene - NOx

New reaction bags bags installed.

$\mathrm{NO}_{2}$ Actinometry.

Pure air photolysis.

$\mathrm{O}_{3}$ decay.

pure air photolysis

$\mathrm{NO}_{2}$ Actinometry.

$\mathrm{NO}_{2}$ Actinometry

Ethene-NO $\mathrm{NO}_{\mathrm{x}}$ side eq. test.

Preliminiary surrogate experiments and injection and analysis tests

First run in a series of high No surrogate incremental reactivity experiments. Base case on one side, added voc on the other.

last mun in this series.

Propene-NO,

Low NO $\mathrm{Nu}_{x}$ surogate side equivalency test.

High NO $\mathrm{Nu}_{x}$ surogate incremental reactivity experiment

First run in a series of low $\mathrm{NO}_{x}$ surrogate incremental reactivity experiments.

Last run in this series

Toluene + $\mathrm{NO}_{x}$

Ethene - $\mathrm{NO}_{x}$ (side $\mathrm{B}$ )

Pure Air Irradiation (Temperature control test)

Propene - $\mathrm{NO}_{x}$ (A); isobutene - $\mathrm{NO}_{z}$ (B)

propene - $\mathrm{NO}_{x}(\mathrm{~A})$

Acetaldehyde - $\mathrm{NO}_{x}(\mathrm{~B})$

$\mathrm{n}$-butane - $\mathrm{NO}_{\mathrm{x}}$

tracer - NO

propene - NO

propene - $\mathrm{NO}_{\mathrm{x}}(50 \% \mathrm{RH})$

tracer - $\mathrm{NO}_{\mathrm{x}}(50 \% \mathrm{RH})$

Propene - NO

First run in a sexies of high or low No, surrogate incremental reactivity experiments.

Last run in this series

Ethene - NO $\mathrm{N}_{\mathrm{x}}$ (B)

m-XYlene - $\mathrm{NO}_{\mathrm{x}}$ (A)

Biacetyl Irriadiation

m-Xylene - $\mathrm{NO}_{x}(\mathrm{~B})$ 
Table 4 (continued)

Run Date Description and Comments

xTC Experiments

$\begin{array}{ll}077 & 8 / 9 / 93 \\ 078 & 8 / 13 / 93 \\ 079 & 8 / 19 / 93 \\ 080 & 8 / 20 / 93 \\ 081 & 8 / 23 / 93 \\ 082 & 8 / 24 / 93 \\ 083 & 8 / 25 / 93 \\ 084 & 8 / 26 / 93 \\ 085 & 8 / 27 / 93 \\ 086 & 8 / 30 / 93 \\ 091 & 9 / 14 / 93 \\ 092 & 9 / 15 / 93 \\ 096 & 9 / 22 / 93 \\ 097 & 9 / 23 / 93 \\ 098 & 9 / 24 / 93 \\ 103 & 10 / 11 / 93 \\ 104 & 10 / 12 / 93 \\ 105 & 10 / 14 / 93 \\ 106 & 10 / 15 / 93 \\ 107 & 10 / 18 / 93 \\ 109 & 10 / 22 / 93 \\ 111 & 10 / 27 / 93 \\ 112 & 10 / 28 / 93 \\ 113 & 11 / 4 / 93 \\ 114 & 11 / 8 / 93 \\ 115 & 11 / 9 / 93 \\ 116 & 11 / 10 / 93 \\ 117 & 11 / 11 / 93 \\ 118 & 11 / 12 / 93 \\ 119 & 11 / 15 / 93 \\ 122 & 11 / 19 / 93 \\ & \\ 112 & 019\end{array}$

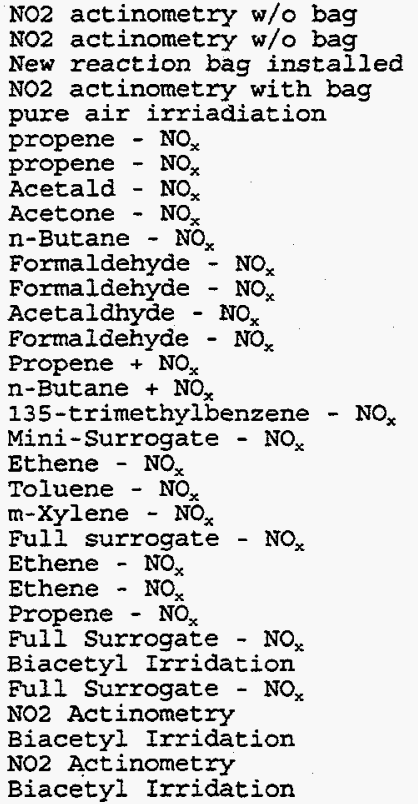

oTC Experiments

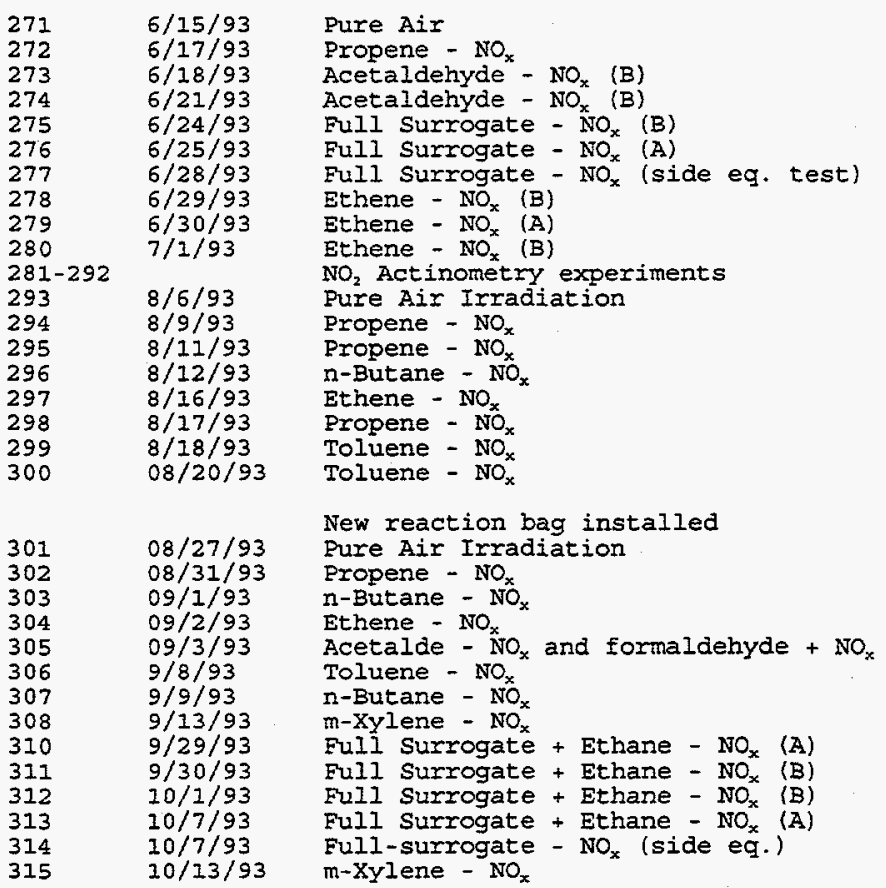

[a] Gaps in run numbers, or runs in the DTC or OTC chamber side not indicated, are runs with acetone (Carter et al., 1993a) or incremental reactivity experiments (Carter et. al.. 1995b) which are reported elsewhere, or runs with biogenic compounds for which the report is in preparation.

[b] These and the following ethene - $\mathrm{NO}_{x}$ runs are used as the base case in a series of "ethene surrogate" incremental reactivity experiments (Carter et al., 1995b). 
comparison with runs in other chambers, together with additional characterization runs, and experiments with biogenic VoCs added which are beyond the scope of this report. The runs for this project included a propene - $\mathrm{NO}_{x}$ and a tracer - $\mathrm{NO}_{x}$ run to determine how humidity affects mechanism evaluation results. In these runs, the air was humidified to $\sim 50 \% \mathrm{RH}$ by injecting water vapor after the pure air fill and prior to reactant injections. The propene - $\mathrm{NO}_{x}$ run was used for mechanism evaluation, and the tracer - $\mathrm{NO}_{x}$ run was to characterize the chamber radical source under humidified conditions.

The xenon arc light source was then installed in the DTC chamber enclosure, with the resulting chamber being designated the XTC. (The XTC run numbers continue on the sequence of DTC numbers.) Actinometry experiments were conducted prior to and after the installation of the new reaction bag. A series of single compound and selected surrogate - $\mathrm{NO}_{x}$ irradiations were then conducted for comparison with other experiments for the purpose of this light source sensitivity study. The single compounds were chosen to be of the major types of Vocs for which there are comparable evaluation data in other types of chambers, and the surrogates were used extensively in our previous reactivity studies (Carter et al., 1993a, 1995b). During these experiments, the performance of the light source was monitored by conducting periodic $\mathrm{NO}_{2}$ actinometry measurements and by measuring the spectrum and intensity of the lights during each experiment. The performance of the light source is discussed in the following section.

In the summer and fall of 1993, simultaneously with the latter DTC and XTC runs, a series of outdoor chamber (OTC) experiments were carried out. Generally, the procedure was to conduct OTC runs when the weather was favorable, and DTC or XTC runs when it was not. This permitted a much larger number of all types of runs to be conducted than would otherwise have occurred. This was made possible because of the SCAOMD-funded modular building was used to house the analytical equipment and indoor chambers immediately adjacent to the outdoor chamber site. The OTC runs listed on Table 4 consisted primarily of a series of single compound and selected surrogate - $\mathrm{NO}_{\mathrm{x}}$ irradiations for comparison with other experiments for the purpose of this light source sensitivity study. As with the XTC, the single compounds were chosen to be of the major types of vocs for which there are comparable evaluation data in other types of chambers, and the surrogates were used extensively in our reactivity studies (Carter et al., 1993a, 1995b). In addition to these, a number of experiments were carried out to assess acetone's reactivity, whose results are discussed in detail elsewhere (Carter et al., 1993b). The base case experiments and the added ethane reactivity runs are included on the list in Table 4 and are modeled in this study as part of the assessment of the light source sensitivity in the simulations of surrogate runs.

The indoor chamber experiments listed on Table 4 have been included in the current version of the SARRC documented environmental chamber data base for evaluating photochemical mechanisms (Carter et al., 1994a). As indicated previously, this data base also includes the EC, ITC and ETC runs previously 
carried out at SAPRC which may be useful for mechanism evaluation. The outdoor chamber experiments are not included in the current documented data base; they may be included in subsequent releases.

The results of these experiments are discussed in the following sections. Section $B$ discusses the performance of the xenon arc light source which was developed for this study, and section $C$ discusses the results of the evaluation of the light model used to calculate photolysis rates when modeling the outdoor chamber runs. Section $D$ discusses the results of model simulations of the characterization experiments which are sensitive to the chamber-dependent radical source, which is an important parameter affecting mechanism evaluation results, and how they may be affected by chamber. Finally, section E discusses the results of the model simulations of the various types of mechanism evaluation experiments carried out in this and previous studies, to assess how differences in light source and chamber affect mechanism evaluation results.

\section{B. Xenon Arc Light Evaluation Results}

1. Light Intensity

All the XTC experiments were run with a $4 \mathrm{kw}$ power setting, which is lower than the $\sim 6 \mathrm{kw}$ maximum. A lower than maximum setting was used to minimize the deterioration rate of the lamps and extent the lamp life. The light intensity and uniformity system was measured by $\mathrm{NO}_{2}$ actinometry. Three sets of actinometry experiments were conducted: (1) quartz tube actinometry measurements at various positions in the XTC area before the reaction bag was installed; (2) several quartz tube actinometry and one $\mathrm{NO}, \mathrm{NO}_{2}, \mathrm{O}_{3}$ steady state actinometry experiment inside the reaction bag at various times interdispersed with the experimental runs, and (3) an extensive series of quartz actinometry measurements at various positions in the chamber several months after the experiments were completed.

The results of the first two sets of actinometry experiments, which were carried out immediately prior to or during the experimental runs, are summarized in Table 5, and a plot of the actinometry results measured inside the reaction bag was installed is shown in Figure 8 . The initial results gave an $\mathrm{NO}_{2}$ photolysis rate of $0.32 \mathrm{~min}^{-1}$ in the center position, which was within the desired specifications of the system as discussed in section II. The light intensity was $20 \%$ lower when measured in the reaction bag, averaging $0.256 \pm 0.012$ $\min ^{-1}$. The measurement using the steady state method agreed with the quartz tube methods within the variability of the determination. The later actinometry experiments tended to indicate a slight decrease in light intensity with time, though one experiment, XTC119, had a light intensity which was slightly higher than the initially measured values.

A more precise indication of the relative changes in the light intensity was obtained from the Li-1800 spectral measurements made during the course of the 
Table 5. Summary of results of $\mathrm{NO}_{2}$ actinometry experiments in the Xenon Teflon Chamber.

\begin{tabular}{lllll}
\hline Run & Date & $\mathrm{k}_{1}\left(\mathrm{~min}^{-1}\right)$ & Conditions & Position \\
\hline 077 & $8 / 9 / 93$ & 0.331 & no bag & center \\
078 & $8 / 13 / 93$ & 0.327 & no bag & upper \\
078 & $8 / 13 / 93$ & 0.322 & no bag & center \\
078 & $8 / 13 / 93$ & 0.313 & no bag & low \\
078 & $8 / 13 / 93$ & 0.323 & no bag & upper \\
078 & $8 / 13 / 93$ & 0.317 & no bag & center \\
078 & $8 / 13 / 93$ & 0.310 & no bag & low \\
078 & $8 / 13 / 93$ & 0.310 & no bag & low \\
& & & & \\
079 & $8 / 19 / 93$ & 0.257 & In bag & center \\
079 & $8 / 19 / 93$ & 0.261 & In bag & center \\
079 & $8 / 19 / 93$ & 0.271 & In bag & center \\
089 & $9 / 3 / 93$ & 0.246 & In bag & center \\
100 & $10 / 1 / 93$ & 0.247 & In bag & center \\
117 & $11 / 11 / 93$ & 0.250 & In bag & center \\
119 & $11 / 15 / 93$ & 0.272 & In bag & center \\
124 & $12 / 1 / 93$ & 0.240 & Steady state method \\
\hline
\end{tabular}

experimental runs. Usually at least three such measurements were made during each run. The spectraradiometer was in the same location during all the runs, so the measured spectral intensities give a good indication of the relative light intensities during the run. These spectral intensities can be converted to quantities proportional to $\mathrm{NO}_{2}$ photolysis rates by integrating the products of these intensities with the $\mathrm{NO}_{2}$ absorption cross sections and quantum yields. These $\mathrm{NO}_{2}$ photolysis rates are then placed on an absolute basis using the results of the quartz tube or steady state actinometry experiments. This was done by fitting the Li-1800-calculated $\mathrm{NO}_{2}$ photolysis rates to a linear function of the XTC run number to determine the relative change in photolysis rate with time, and by using a constant factor adjusted to minimize the difference between the Li1800-calculated values and the results of the absolute actinometry determinations. The apparently anomalous run XTC119 was not used in determining this factor. The resulting adjusted $\mathrm{Li}-1800$-calculated photolysis rates are shown on Figure 8 , where it can be seen that they agree well with the trend indicated by the actinometry results, except for the apparently anomalous run XTC119, whose result was high by $\sim 10 \%$. These data indicate a $\sim 6 \%$ decline in the $\mathrm{NO}_{2}$ photolysis rate during the course of these experiments.

The $\mathrm{NO}_{2}$ photolysis rate used for modeling the XTC runs was derived from the linear fit to the Li-1800-calculated photolysis rates, adjusted to agree with the 


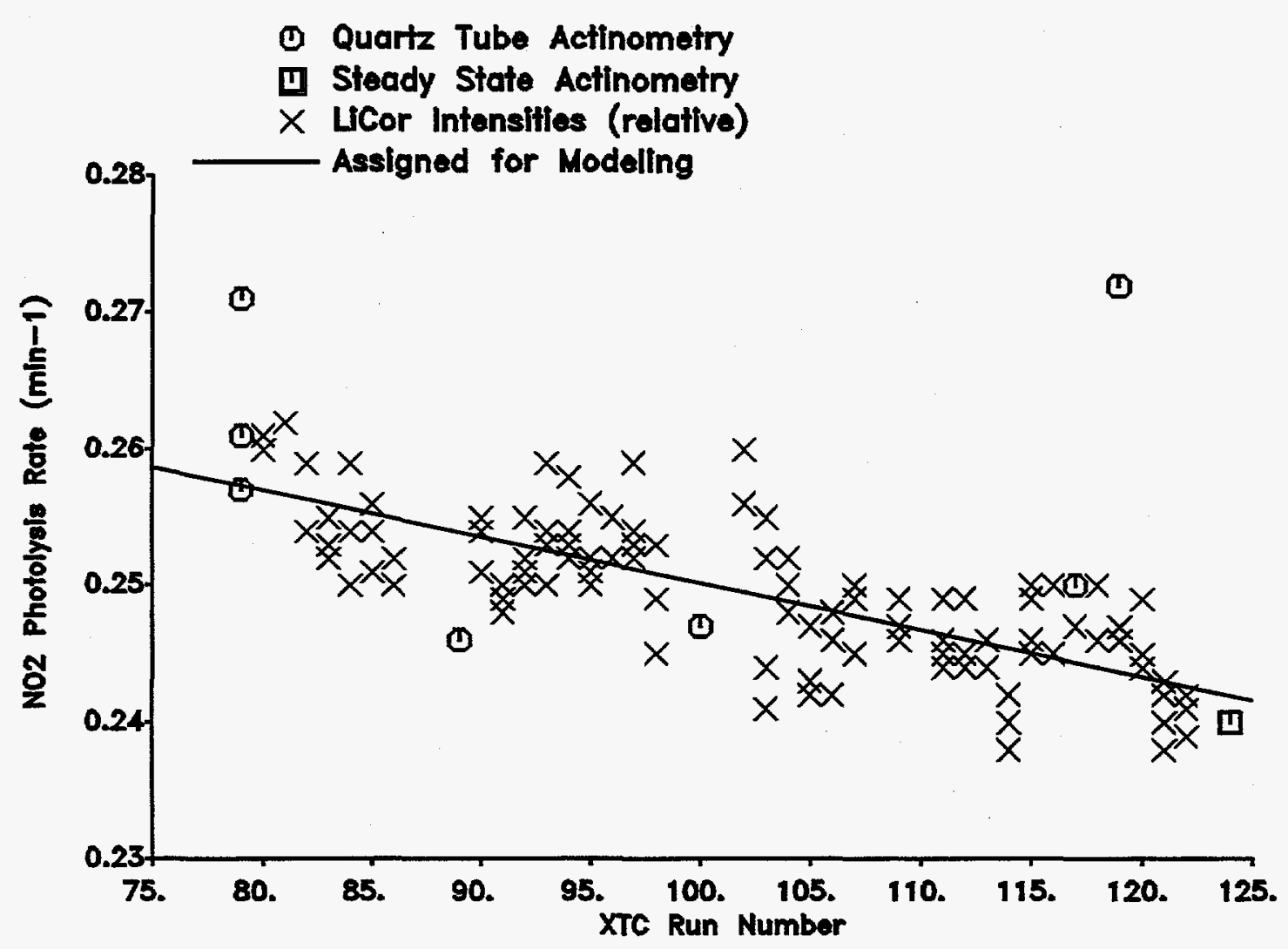

Figure 8. Plots of $\mathrm{NO}_{2}$ photolysis rates in the XTC chamber against XTC run number.

actinometry results as indicated above. The line used for these assignments is also shown on Figure 8 .

\section{Iight Uniformity}

The uniformity of the light intensity in the XTC was measured on two different occasions. When the chamber was first constructed, the $\mathrm{NO}_{2}$ photolysis rate was measured with the quartz tube in central, upper, and lower position in the area where the reaction bag was to be located. The results, given in Table 5 , indicate a $\sim 2 \%$ higher intensity in the upper position and a $\sim 3 \%$ lower intensity in the lower position. A more extensive series of relative light intensity measurements in the XTC chamber area was made several months after the last experiment for this program, after the reaction bag was removed. The results of these light uniformity measurements are given in Figure 9, which shows the $\mathrm{NO}_{2}$ photolysis rates, relative to the average, in 24 locations in the chamber enclosure. The results show that the light uniformity is within $\pm 12 \%$ of the average, with the highest intensities being in the center and upper level on the 
Floor Level (22")

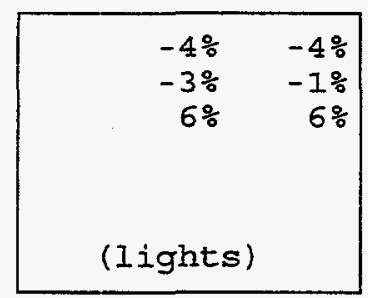

Mid Level (43")

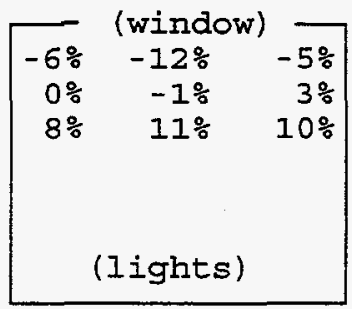

Upper Level (65")

\begin{tabular}{|rrr|}
\hline $3 \%$ & $2 \%$ & $2 \%$ \\
$7 \%$ & $7 \%$ & $7 \%$ \\
$10 \%$ & $12 \%$ & $9 \%$ \\
& & \\
& & \\
& & \\
& & \\
\end{tabular}

Figure 9. Summary of results of light uniformity measurements in the XTC. Values shown are the percentages by which the $\mathrm{NO}_{2}$ photolysis rates in various locations differ from the average for all locations.

side closest to the lights, and the lowest intensities being immediately in front of the sampling window.

\section{Light Spectrum}

Representative plots of XTC light spectra compared to the solar spectra are shown on Figure 10, where they are compared with solar spectra for zenith angles of $0^{\circ}$ and $60^{\circ}$, respectively. The spectra shown are all normalized to give the same $\mathrm{NO}_{2}$ photolysis rate. The spectra are as expected based on the xenon arc spectra we examined when evaluating alternative light sources, as discussed in section II. Thus, the XTC light source performed as expected in this regard.

As discussed above, the intensity of the XTC lights were found to decline gradually with time during the course of the experiments for this program. The rate of decline was found to be wavelength-dependent, as shown on Figure 11A, which shows a plot of the ratio of an XTC spectrum taken around the end of the program to one taken initially. The decrease in intensity can be seen to be minor for wavelengths above $400 \mathrm{~nm}$, but becomes increasingly important for wavelengths lower than that. This is probably due to solarization of the pyrex filters, which were not changed during the course of the program. The manufacturer recommends changing the spectral filter periodically to maintain approximately constant UV intensity.

Unlike the $\mathrm{NO}_{2}$ photolysis rate, whose decrease in intensity with time (shown on Figure 8) was approximately linear, the decline in intensity at the shortest wavelength was nonlinear, increasing more rapidly when the lights were new. This is shown on Figure 11B, which gives a plot of the absolute intensity at the shortest wavelength measured by the LiCor (300 nm) against XTC run number. Thus the spectrum, if not the overall intensity, tends to become more stable as the lamps age. 

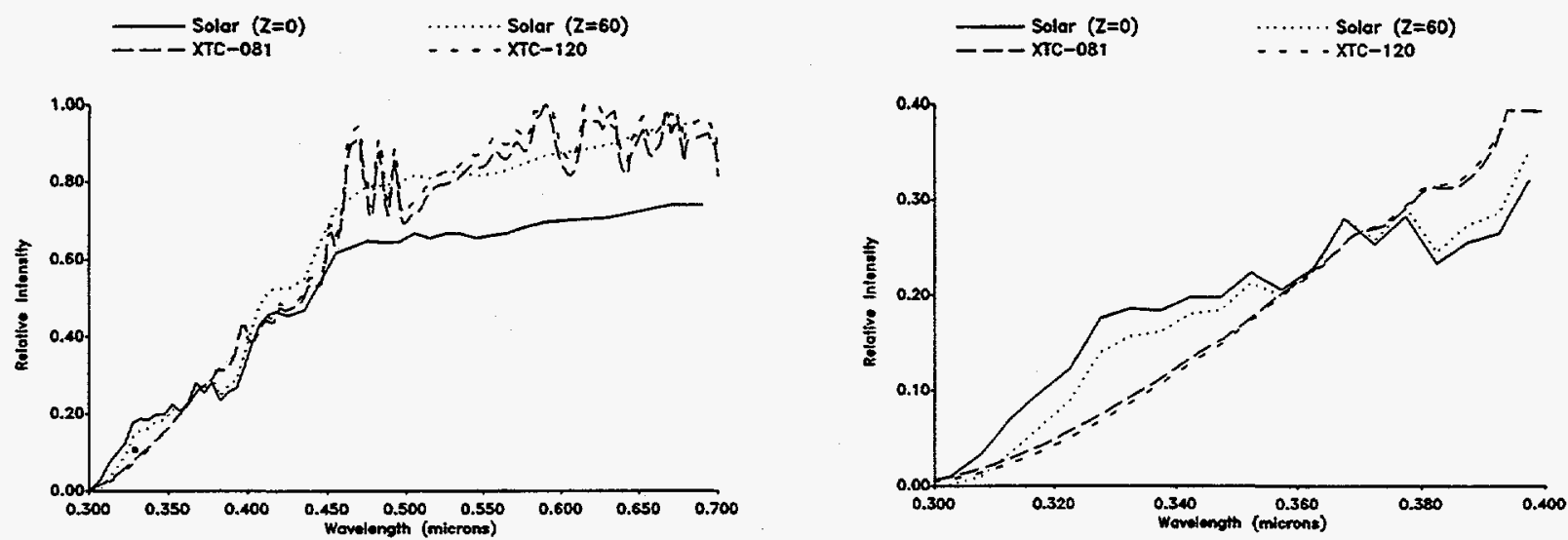

Figure 10. Representative XTC spectra compared with solar spectra for zenith angles of $0^{\circ}$ and $60^{\circ}$. The spectra are all normalized to give the same $\mathrm{NO}_{2}$ photolysis rate.
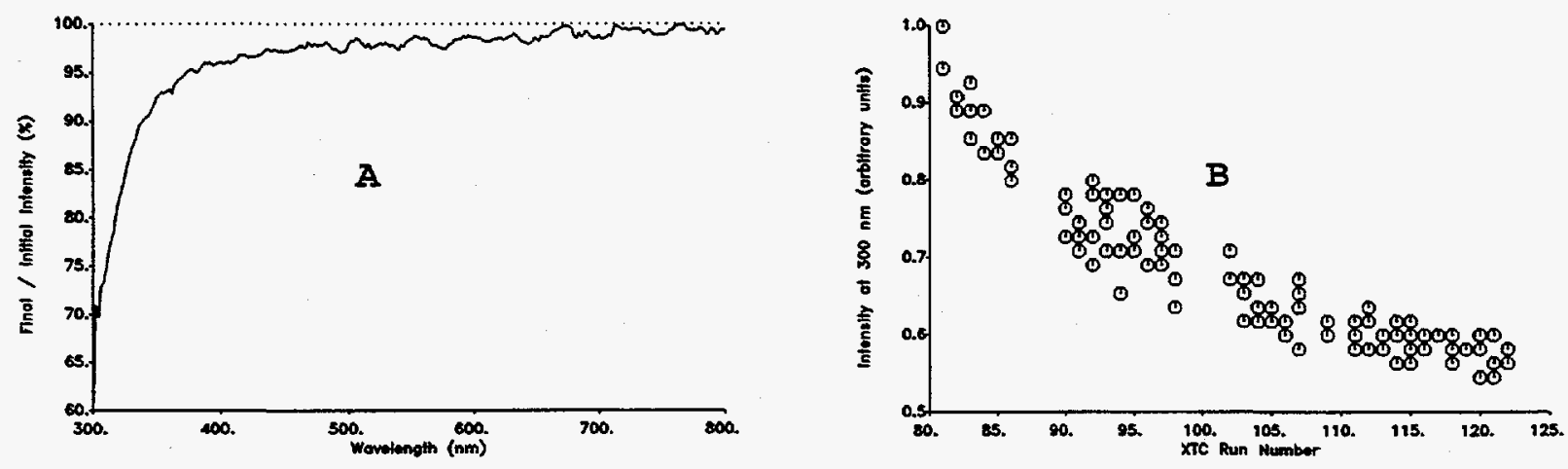

Figure 11. (A) Ratio of spectrum of run XTC120 relative to that of run XTC081 against wavelength, showing the decline of spectral intensity as a function of wavelength during the experiments for this program. Plot of relative intensity at $300 \mathrm{~nm}$ against XTC run number.

As discussed in section II, the relevant factor when evaluating Iight source spectra for chamber runs is the ratios of photolysis rate constants when the light source is used. Table 6 shows how the photolysis rate constant ratios, relative to that for $\mathrm{NO}_{2}$, derived from the spectra of the blacklight and XTC chamber, differ from those for ambient sunlight. The photolysis reactions are ordered by increasing wavelength region to which they are sensitive, and the XTC rate constant ratios are given both for the beginning (run XTC081) and near the end (XTC120) of the experiments for this program. The XTC light source can be seen to give as good a correspondence to solar rate constant ratios as can be expected for an artificial light source. The change in photolysis rate ratios caused by the decline in the relative ov intensity had a relatively minor effect 
Table 6. Calculated ratios of photolysis rate constants relative to $\mathrm{NO}_{2}$ for the XTC or blacklight chambers, relative to ratios calculated for solar zenith angles of $0^{\circ}$ and $60^{\circ}$.

\begin{tabular}{|c|c|c|c|c|c|c|}
\hline Photolysis Process & Black & $\begin{array}{r}100 \\
\text { Iights }\end{array}$ & $\begin{array}{r}\mathrm{k}\left(\mathrm{NO}_{2}\right) \\
\mathrm{XTC}\end{array}$ & $\begin{array}{l}]^{\text {XTC }} / \\
081\end{array}$ & $\left.\left.\mathrm{O}_{2}\right)\right]_{\mathrm{XTC}}^{\mathrm{SOl}}$ & \\
\hline & $/ Z=0$ & $/ \bar{Z}=40$ & $/ Z=0$ & $/ Z=40$ & $/ Z=0$ & $/ Z=40$ \\
\hline $\mathrm{O}_{3} \rightarrow \mathrm{O}^{1} \mathrm{D}$ & 32 & 116 & 71 & 262 & 51 & 189 \\
\hline $\mathrm{CH}_{3} \mathrm{CHO} \rightarrow$ Products & 36 & 79 & 54 & 119 & 42 & 93 \\
\hline $\mathrm{CH}_{3} \mathrm{COCH}_{3} \rightarrow$ Products & 41 & 95 & 61 & 142 & 46 & 109 \\
\hline Higher Ketones $\rightarrow$ Products & 45 & 86 & 51 & 97 & 41 & 79 \\
\hline Higher Aldehydes $\rightarrow$ Products & 45 & 86 & 51 & 97 & 41 & 78 \\
\hline $\mathrm{HCHO} \rightarrow \mathrm{H}+\mathrm{HCO}$ & 49 & 77 & 46 & 73 & 39 & 62 \\
\hline $\mathrm{H}_{2} \mathrm{O}_{2} \rightarrow 2 \mathrm{OH}$ & 91 & 133 & 53 & 77 & 46 & 68 \\
\hline $\mathrm{CH}_{3} \mathrm{OOH}$ (absorpt.) & 97 & 139 & 54 & 77 & 48 & 68 \\
\hline $\mathrm{HCHO} \rightarrow \mathrm{H}_{2}+\mathrm{CO}$ & 120 & 151 & 54 & 67 & 49 & 62 \\
\hline Acrolein (absorpt.) & 158 & 183 & 68 & 79 & 65 & 75 \\
\hline Benzaldehyde $\rightarrow$ Products & 155 & 173 & 75 & 84 & 73 & 82 \\
\hline HONO $\rightarrow \mathrm{OH}+\mathrm{NO}$ & 154 & 160 & 89 & 92 & 88 & 91 \\
\hline $\mathrm{NO} 2 \rightarrow \mathrm{NO}+\mathrm{O}^{3} \mathrm{P}$ & 100 & 100 & 100 & 100 & 100 & 100 \\
\hline $\mathrm{CH}_{3} \mathrm{COCHO} \rightarrow$ Products & 15 & 13 & 103 & 91 & 105 & 93 \\
\hline HCOCHO $\rightarrow$ Products & 11 & 9 & 104 & 90 & 107 & 93 \\
\hline $\mathrm{NO}_{3} \rightarrow \mathrm{NO}_{2}+\mathrm{O}^{3} \mathrm{P}$ & 2 & 1 & 128 & 103 & 133 & 107 \\
\hline $\mathrm{O}_{3} \rightarrow \mathrm{O}_{2}+\mathrm{O}^{3} \mathrm{P}$ & 10 & 8 & 121 & 104 & 125 & 107 \\
\hline $\mathrm{NO}_{3} \rightarrow \mathrm{NO}+\mathrm{O}_{2}$ & 0 & 0 & 134 & 107 & 140 & 112 \\
\hline
\end{tabular}

on most photolysis rate ratios except for the reactions most sensitive to the UV, where the ageing of the lights caused slightly a improved correspondence to solar photolysis rate constant ratios. Because of this, and the increased stability in the relative UV intensity with time (as shown in Figure 11B), it appears that well aged lamps are actually better for environmental chamber applications than new or newly conditioned ones.

\section{Outdoor Chamber Light Model Evaluation Results}

As discussed in section IV.B.2, as part of this work a new method was developed for deriving photolysis rates for outdoor chamber experiments. This method, which is based on modeling direct and diffuse solar spectral measurements, was evaluated by measuring $\mathrm{NO}_{2}$ photolysis rates, both inside and outside the OTC, using the quartz tube actinometry method. The $\mathrm{NO}_{2}$ photolysis rate measurements were made in three locations: (1) adjacent to the chamber over a similar indoor/outdoor carpet as used under the chamber ("outside"); (2) in the same location as the OTC reaction bag but with the bag removed ("bag area"); and (3) inside the chamber ("inside"). Spectral measurements were made simultaneousIy with the actinometry experiments, and the results were used to derive out-of- 
chamber and in-chamber photolysis rates using the same light model and fitting procedures as used when deriving photolysis rates for modeling OTC runs.

The results of the actinometry experiments and the corresponding calculated $k_{\text {ro2 }}$ values from the spectral measurements and the light model are summarized on Table 7, and are plotted against each other on Figure 12 . Figure 12 also shows the best fit lines (forced through zero) through the data, with the dotted lines showing the effects of $\pm 5 \%$ variations in the slope. It can be seen that almost all of the points are within $\pm 5 \%$ of the best fit line. The "inside OTC" data are plotted to indicate data from the separate experiments, with the consecutive points in the same run being connected by dashed lines to indicate how they vary with time.

The results of this evaluation indicate that there is a good correlation between the experimental and calculated $\mathrm{NO}_{2}$ photolysis rates, but that the model overpredicts the measured $\mathrm{NO}_{2}$ photolysis rate by $7.3 \pm 0.7 \%$ inside the chamber, and by slightly more ( $10 \%$ ) outside. This discrepancy might be due to the standard urban default albedos (Jeffries 1988) used in the model being too low for this location. The model uses the assumed albedos (in part) when calculating the spherically integrated light fluxes from the horizontal fluxes which are actually measured. However, given the assumptions concerning albedos and other uncertainties, the results can be considered to be reasonably good agreement.

Since these data indicate that the OTC light model underpredicts in-chamber photolysis rates by $7.3 \%$, the calculated photolysis rates are increased by a factor of 1.073 when modeling OTC runs for this study.

D. Evaluation of Chamber Radical Source Assignments

It is now well recognized that the chamber-dependent radical source is an important factor which must be taken into account when evaluating mechanisms using environmental chamber data (Carter et al., 1982; Carter and Lurmann, 1991, and references therein). This can be particularly important when assessing the effect of chamber differences in mechanism evaluation results, especially if the magnitude of the radical source differs among chambers, or if it is assumed to be different when in fact it is not. For this reason, it is important when assessing mechanism performance that the magnitude of the radical source in the different chambers be derived in a consistent manner. Otherwise, inappropriate radical source assignments may cause differences in evaluation results among chambers which are due only to this effect, or (worse) inappropriate radical source assignments may mask problems with the mechanism or the model for other chamber or light source effects.

As indicated on Table 2 in section IV.C, chamber-dependent radical sources are represented in the model by the following two parameterized "reactions": 
Table 7. Results of $\mathrm{NO}_{2}$ actinometry experiments in the outdoor chamber.

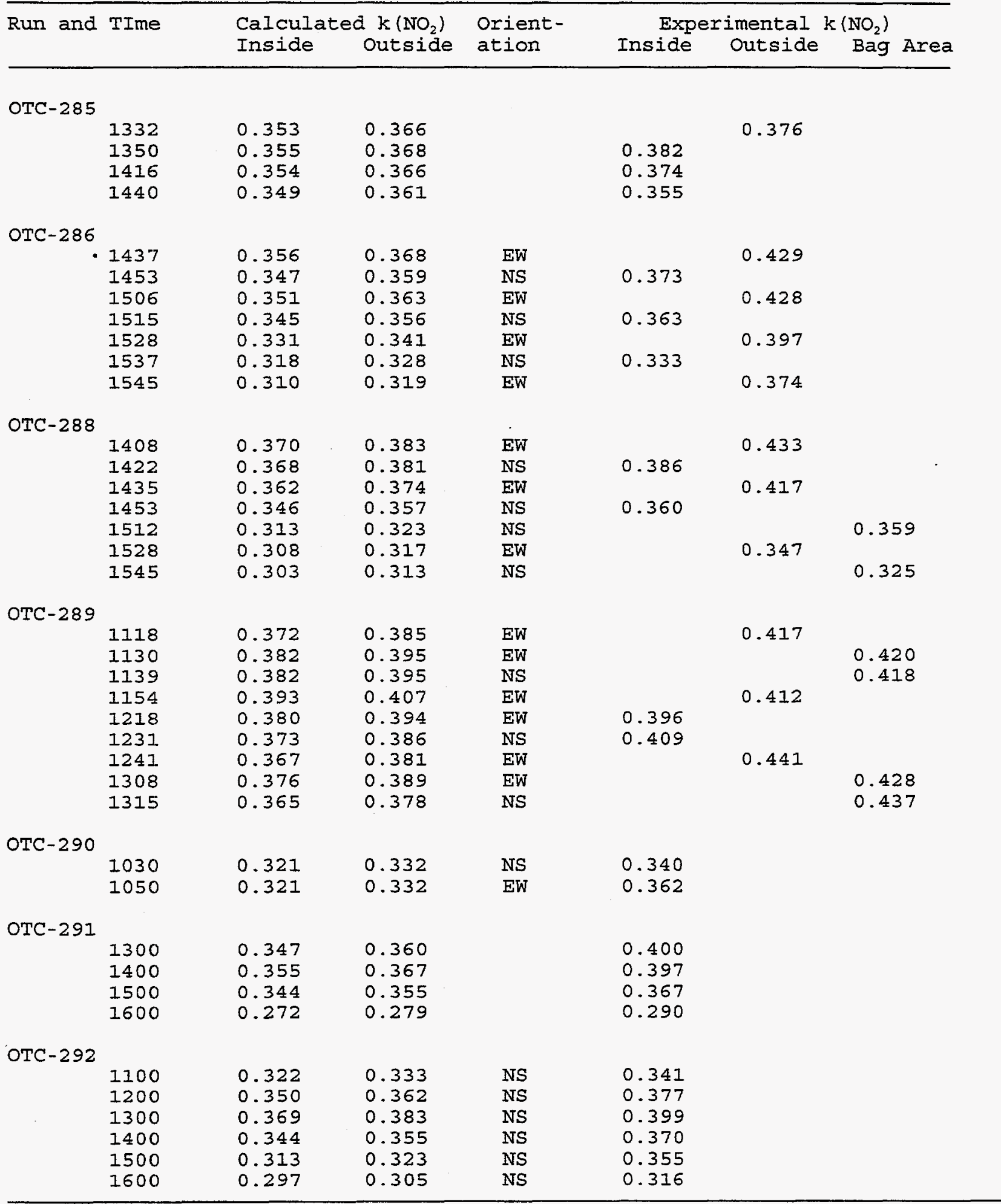



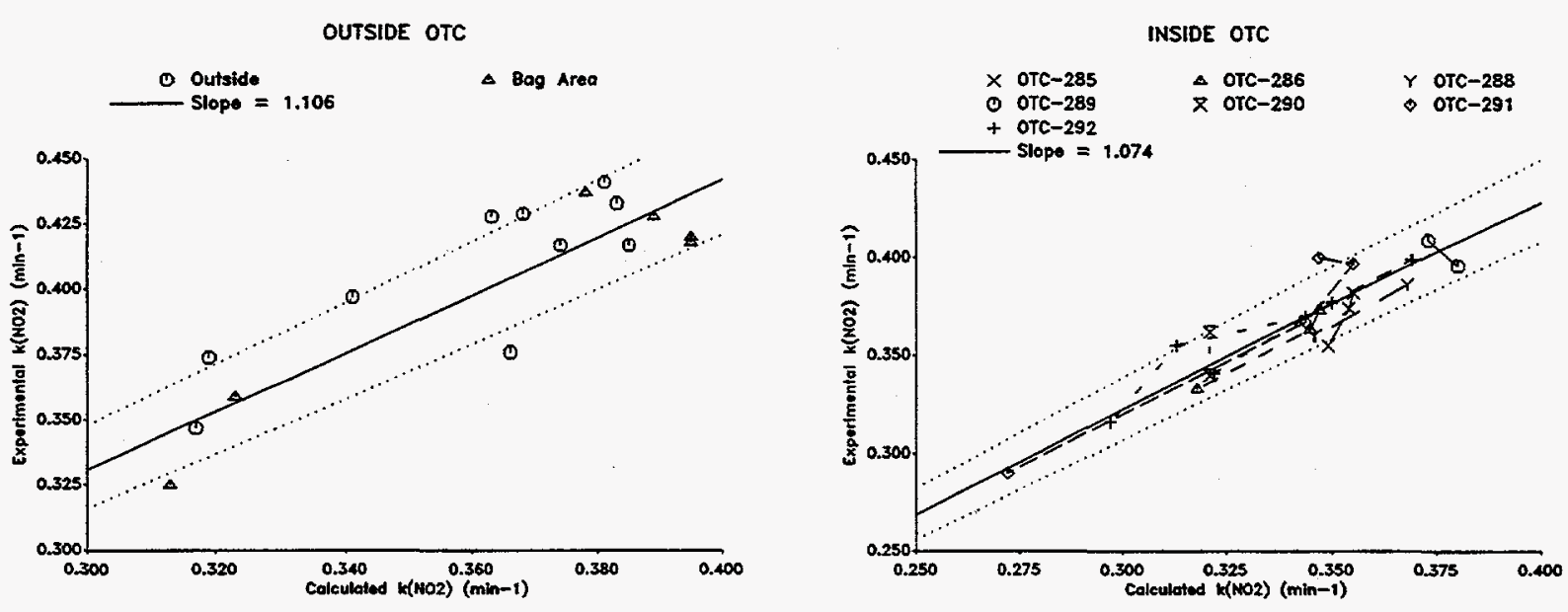

Figure 12. Plots of experimental vs calculated $\mathrm{NO}_{2}$ photolysis rates measured in or around the Outside Teflon Chamber.

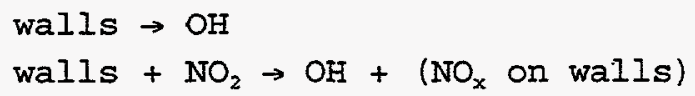

where $k_{1}$ is the $\mathrm{NO}_{2}$ photolysis rate and RS-I and RS-S are the NO $\mathrm{N}_{\mathrm{x}}$-independent and $\mathrm{NO}_{\mathrm{x}}$-dependent radical source parameters. The values for these two parameters are adjusted for the particular chamber and chamber conditions as discussed below.

In our previous evaluations of the SAPRC-90 (Carter and Lurmann, 1991) and the RADM-2 (Carter and Lurmann 1990) mechanisms, the magnitudes RS-I and RS-S were derived using analyses of radical tracer - $\mathrm{NO}_{x}$ - air runs as described by Carter et al. (1982). These analyses involve computing the $\mathrm{OH}$ radical concentration from decay rates of trace levels of propene or isobutene in $\mathrm{NO}_{x}$ air irradiations, and assuming that the major radical sink is the reaction of $O H$ with $\mathrm{NO}_{2}$, and thus equating the magnitude to the radical source to the rate of that reaction. These analyses indicated that the radical source in the EC tended to increase with temperature and humidity, but for the temperature and humidity range of most experiments, RS-I $=0.39 \mathrm{ppb}$ and RS-S $2.16 \times 10^{-3}$. Experiments in the ITC indicated no discernable $\mathrm{NO}_{2}$ dependence in that chamber, so RS-S = 0 was assumed when modeling all experiments in the ITC and other Teflon bag experiments. The value of RS-I indicated by the analyses of the tracer - $\mathrm{NO}_{\mathrm{x}}$ runs was found to vary with the reaction bag employed, ranging from 0.15 to $0.6 \mathrm{ppb}$

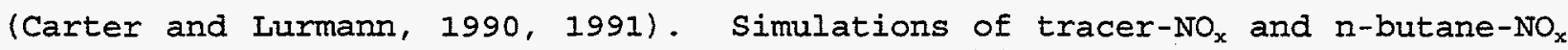
runs in the ETC were best fit using lower radical source parameter than those used for the ITC, as would be expected since dry air is used in the ETC while the ITC runs used humidified $(\sim 50 \% \mathrm{RH})$ air. In our previous model simulations of ETC runs (Carter et al., 1993a), a low RS-I value of only $0.02 \mathrm{ppb}$ was used in the simulations of the experiments after ETC-90 (where the $\mathrm{NO}_{2}$ injection procedure was modified to eliminate HONO contamination in the NO source). This was based 
on simulations of a single tracer - $\mathrm{NO}_{x}$ experiment, but is reasonably consistent with results of other ETC experiments which are sensitive to the radical source, as discussed below.

An alternative methods for deriving the radical source are to simulate rates of $\mathrm{NO}$ decay and $\mathrm{O}_{3}$ formation observed in $\mathrm{CO}-\mathrm{NO}_{x}$ - air or alkane - $\mathrm{NO}_{x}$-air experiments. These compounds have insignificant radical sources in their mechanisms, so the reactions causing No oxidation and ozone formation in these systems are initiated almost entirely by radicals formed from the chamber radical source. Thus model simulations of these runs are highly sensitive to this parameter. Although use of $\mathrm{CO}-\mathrm{NO}_{x}$ runs might be preferable because of the simpler chemistry $C O$, there are relatively few such runs in the SAPRC chamber data base. Also, Jeffries (private communication) has observed some evidence that there may be anomalous chamber effects involving $\mathrm{CO}$ in the UNC outdoor chamber - though we see no evidence for such problems in the limited number of CO runs in SAPRC chambers. N-butane - NO $\mathrm{N}_{x}$ runs provides a better alternative for the SAPRC data base because there is a much larger number of such runs, and because the atmospheric chemistry of n-butane, though not as simple as that of CO, is quite well characterized (Atkinson, 1990, and references therein).

For this study, we evaluated the existing radical source assignments for the EC and ITC for consistency with the butane and $\mathrm{CO}$ - $\mathrm{NO}_{\mathrm{x}}$ experiments in those chambers. Based on the results of this evaluation, we concluded that the use of the tracer - $\mathrm{NO}_{\mathrm{x}}$-air experiments may be giving inappropriately high radical sources, especially in the ITC, and that use of n-butane - NO $\mathrm{N}_{x}$ air is a more reliable and consistent method for deriving the radical source. This is then used as the basis for deriving the radical sources for the other chambers modeled in this study. This evaluation of the previous radical source assignments, and the new radical source assignments used in this study, are discussed below.

\section{Re-Evaluation of Previous Radical Source Assignments}

ITC. Figure 13 shows the performance of the current chemical mechanism in simulating ozone formation and No oxidation in all the ITC n-butane, ethene, and propene runs in the SAPRC mechanism evaluation data base (Carter et al., 1995a), where the model used the radical source assignments based on the tracer - $\mathrm{NO}_{\mathbf{x}}$ data. These radical source assignments are the same as used SAPRC-90 and RADM-2 mechanism evaluations (Carter and Lurmann, 1990, 1991). Model performance is measured by the ability of the model to simulate $d\left(\mathrm{O}_{3}-\mathrm{NO}\right)$, which is defined as the change in $\left(\left[\mathrm{O}_{3}\right]-[\mathrm{NO}]\right)$, or the sum of amount of $\mathrm{O}_{3}$ formed + NO oxidized. This is a more useful means for evaluating model performance than assessing simulations of $\mathrm{O}_{3}$ alone because as discussed elsewhere (Johnson, 1983; Carter and Atkinson, 1987; Carter and Lurmann, 1990, 1991), the consumption of NO and the formation of $\mathrm{O}_{3}$ are the results of the same chemical processes. Thus the quantity $d\left(\mathrm{O}_{3}-\mathrm{NO}\right)$ provides useful reactivity information both under high No as well as high $\mathrm{O}_{3}$ conditions. 

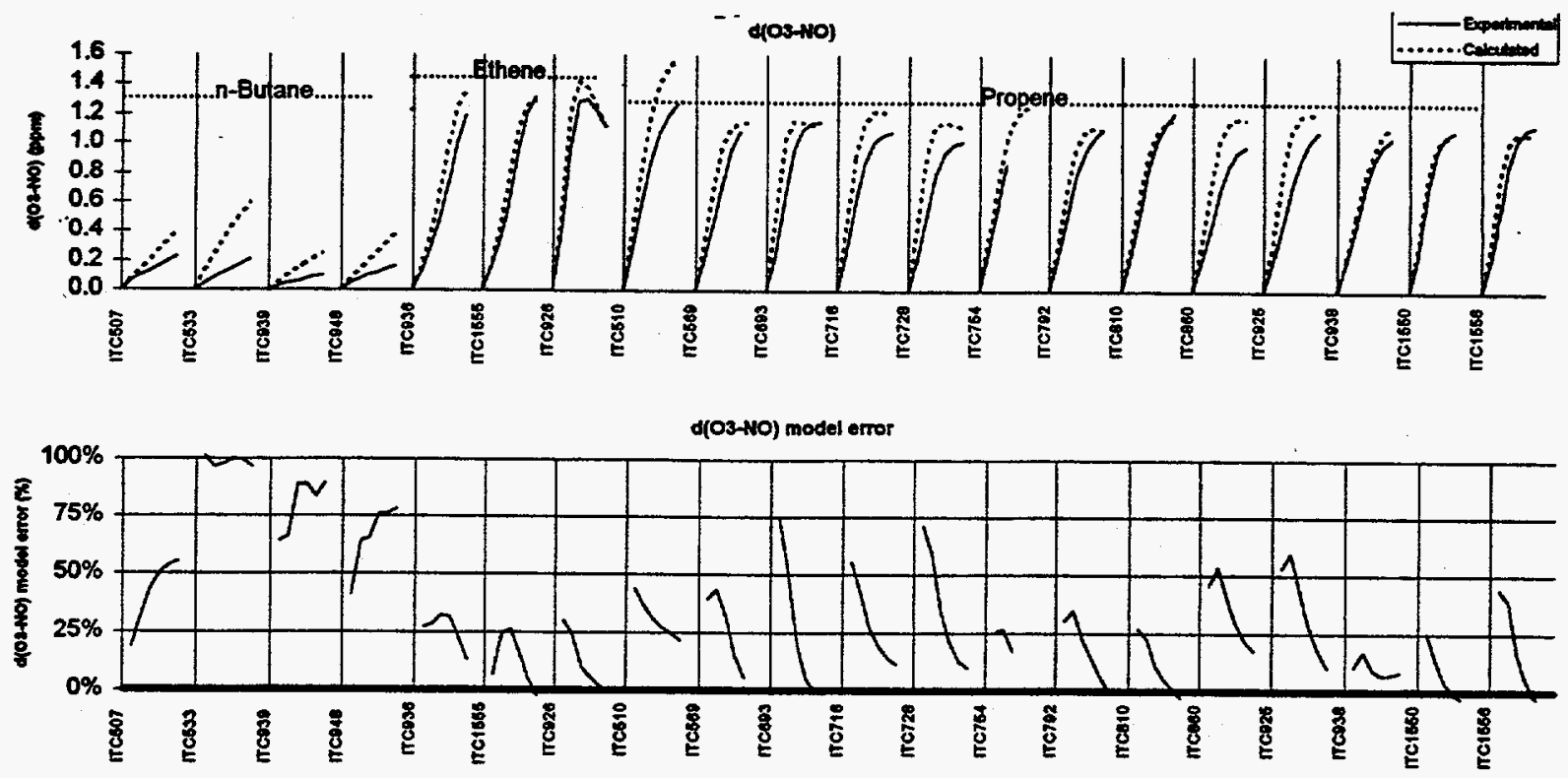

Figure 13. Results of model simulations of $d\left(\mathrm{O}_{3}-\mathrm{NO}\right)$ of the $\mathrm{n}$-butane - $\mathrm{NO}_{\mathrm{x}}$, ethene - $\mathrm{NO}_{\mathrm{x}}$ and propene - $\mathrm{NO}_{x}$ experiments carried out in the SAPRC ITC, where the model used the radical source assignments used in the SAPRC-90 and RADM-2 mechanism evaluations. "Model error" is normalized bias (see text).
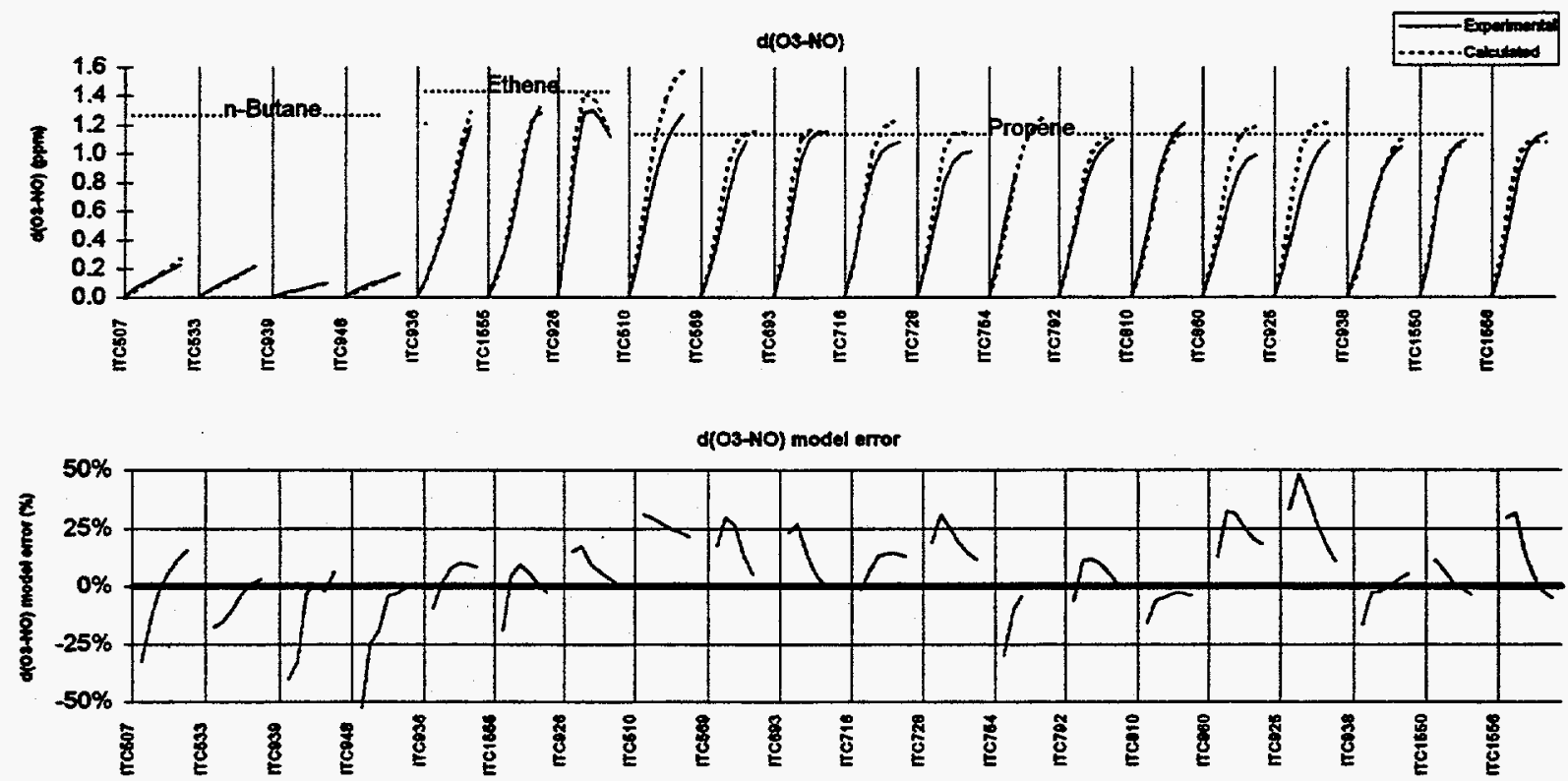

Figure 14. Results of model simulations of $d\left(\mathrm{O}_{3}-\mathrm{NO}\right)$ of the n-butane - $\mathrm{NO}_{x}$, ethene - $\mathrm{NO}_{\mathrm{x}}$ and propene - $\mathrm{NO}_{x}$ experiments carried out in the SAPRC ITC, where the model used the radical source assignments adjusted to fit the n-butane runs. 
The format for displaying model performance on Figure 13 will be used extensively throughout this report, so it is important that it be understood. The top plots show, for each of the experiments modeled, the concentration-time plots of the hourly $d\left(\mathrm{O}_{3}-\mathrm{NO}\right)$ values, with the solid lines being the experimental data and the dotted lines being the model calculation. The quantity "d( $\left.\mathrm{O}_{3}-\mathrm{NO}\right)$ " is defined as the change $\left[\mathrm{O}_{3}\right]-[\mathrm{NO}]$ during the course of the experiment, as discussed above. The bottom plots show the normalized bias" of the model calculation for each of the hourly $d\left(\mathrm{O}_{3}-\mathrm{NO}\right)$ values. Note that the " $\mathrm{x}$ " axis of the plots is time, with the plots for each experiment given immediately adjacent to each other. The experiments of a given type are usually ordered either by run number, $\mathrm{ROG} / \mathrm{NO}_{x}$ ratio, or temperature, depending on the context of the discussion. In the case of Figure 13, the experiments are ordered by run number, i.e., by date they were carried out.

Figure 13 shows that the model consistently overpredicts, by $50 \%$ to more than a factor of 2 , the rate of $d\left(\mathrm{O}_{3}-\mathrm{NO}\right)$ formation in the $n$-butane runs. This is a definite indication of the model using too high a chamber radical source, since, as discussed above, $n$-butane runs are highly sensitive to this parameter and are not considered to have an uncertain mechanism. Supporting evidence that the chamber radical source in the model is high comes from the simulations of the ethene and propene runs, which are also shown on Figure 13. These indicate a consistent positive bias for almost all the runs. Although the fits to the ethene and propene runs are definitive in this regard because they are less sensitive to chamber radical sources and also have mechanism uncertainties related to radical effects, it is perhaps significant that the bias is consistent and in the same direction as indicated by the modeling of the n-butane runs.

Figure 14 shows the results of the model simulations of the butane and alkene runs where the ITC radical source was adjusted downward so the model better fit the butane runs. The $d\left(\mathrm{O}_{3}-\mathrm{NO}\right)$ formation rate in the four ITC butane runs are fit reasonably well using a RS-I value of $0.08 \mathrm{ppb}$, which is from $50 \%$ to over $80 \%$ lower than the values derived from the tracer - No experiments. Figure 14 shows that in addition to the model giving much better fits to the highly sensitive n-butane runs, the bias in the simulations of the ethene and propene runs is significantly reduced or eliminated. It is also appears to us to be more reasonable to use a single value for the radical source parameter when modeling all ITC runs, rather than a set which varies by up to a factor of 4 depending on the reaction bag, as was the case previously. One would not expect such a large variation among reaction bags unless contamination effects were

"Normalized bias is defined as (calculation-experiment)/(average of calculation and experiment). This is used to provide a measure of model performance in a relative sense. This is referred to as "model error" on the figures and tables showing model performance. Note that normalized bias for $d\left(\mathrm{O}_{3}-\mathrm{NO}\right) \mathrm{reflect}$ model performance both in terms of $\mathrm{NO}$ oxidation and $\mathrm{O}_{3}$ formation, and provide a useful measure even in experiments where $O_{3}$ is low. 
important, in which case variation within a single bag (or old vs new) would also be expected.

Additional evidence for problems or inconsistencies with the tracer - $\mathrm{NO}_{\mathbf{x}}$ method for deriving the radial source for the ITC comes from the several tracer $\mathrm{NO}_{x}$ runs where $\sim 50 \mathrm{ppm}$ or more of $\mathrm{CO}$ was added after two hours of irradiation. Four such runs were carried out, all around the same time, and essentially the same results were obtained. An example is shown on Figure 15, which shows concentration - time plots of $\mathrm{d}\left(\mathrm{O}_{3}-\mathrm{NO}\right)$ and the propene and n-butane tracers in one such run, along with model calculations with the radical sources derived using the two different methods. It can be seen that the lower radical source which fits the $n$-butane runs gives the better fit to the $d\left(\mathrm{O}_{3}-\mathrm{NO}\right)$ data, while the higher radial source indicated by the tracer data gives the better fit to the propene tracer consumption rate.

It is unclear why the tracer - $\mathrm{NO}_{\mathrm{x}}$ runs tend to be fit by higher radical source values than the n-butane, $\mathrm{CO}$, and other runs. Dilution is not the problem, since this is corrected for in the analysis of the tracer- $\mathrm{NO}_{x}$ runs by using data from a more slowly reacting compound, usually propane or n-butane (Carter et al, 1982). (The fits of the models to the simulations of $n$-butane in the run shown in Figure 15 indicates that dilution is not a factor in that case.) There may be some heterogeneous loss process for the trace levels of propene which are affecting the results, or some background or other effects are occurring in the ITC tracer - NO ${ }_{x}$ runs which are not accounted for by the model. In any case, the results of modeling the $n$-butane and $c o$ runs tend to give consistent results, and tend to be supported by the results of modeling of the large numbers of propene and ethene runs. For this reason, we conclude that modeling rates of No consumption and $O_{3}$ formation in $n$-butane runs is to be a less uncertain way to derive radical input rates for Teflon chambers than analyzing or modeling tracer decay rates in $\mathrm{NO}_{x}$ - air irradiations. For this reason, modeling $n$-butane runs is the primary method for deriving radical input rates for the purpose of this study.

EC. The plots on the left side of Figure 16 show the results of the model simulations of the EC n-butane runs using the previous radical source assignments. It can be seen that, like the ITC, the model with the previous radical source assignments has a definite bias to overpredict $d\left(\mathrm{O}_{3}-\mathrm{NO}\right)$ in n-butane runs, though the bias is much less than is the case with the ITC. Reducing both RS-I and RS-S by $25 \%$ significantly reduces this bias, as is shown on the right hand plots, though the biases vary in the individual runs. The reduced parameter values were therefore used in the simulations of the other EC runs for this study. This relatively small change does not have a significant effect on the simulations of the alkene, aromatic, and surrogate runs discussed in the following section. 
9(O)-NO)

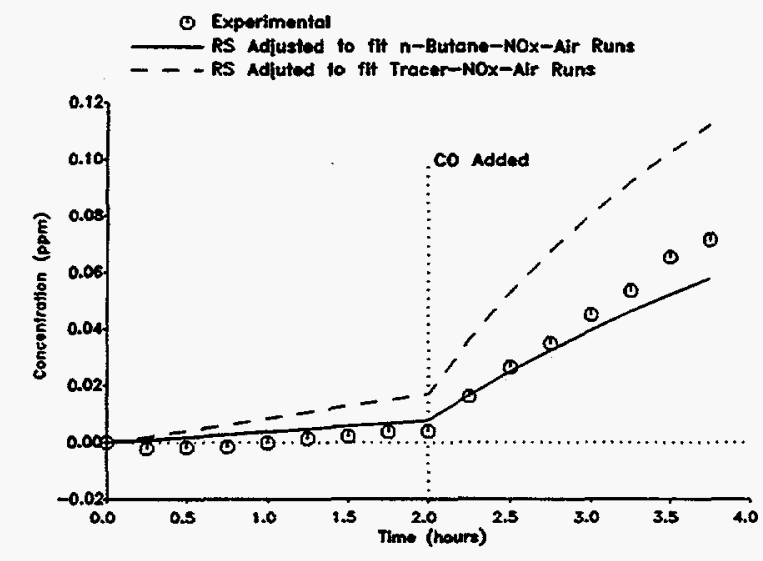

TRACERS

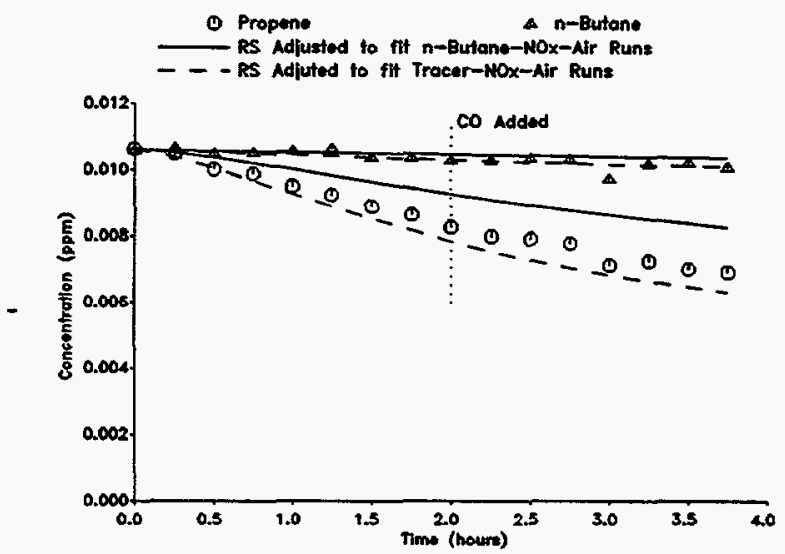

Figure 15. Experimental and calculated concentration - time profiles for $\mathrm{d}\left(\mathrm{O}_{3}-\mathrm{NO}\right)$ and propene and $\mathrm{n}$-butane tracers in the tracer - $\mathrm{NO}_{\mathbf{x}}+$ added CO experiment ITC625.

ETC. The radical source assignments used when modeling the ETC incremental experiments in our phase 1 study* (Carter et al., 1993) were based on model simulations of a single tracer - $\mathrm{NO}_{\mathbf{x}}$ run. This tracer - $\mathrm{NO}_{\mathrm{x}}$ run was $\mathrm{fit}$ by a relatively low RS-I of $0.2 \mathrm{ppb}$, which is a factor of 4 lower than that derived from modeling the $n$-butane - $\mathrm{NO}_{\mathrm{x}}$ runs in the ITC. A lower radical source in the ETC runs is not unexpected because ETC runs were carried out dry, while all the ITC runs were humidified to 50\% RH. Results of the tracer - No experiments in the EC indicated that the radical source tends to increase with humidity (Carter et al, 1982). Figure 17 shows the model performance in simulating the ETC $n-$ butane experiments carried out after the $\mathrm{NO}_{x}$ injection procedure was changed. Figure 17 shows that, unlike the case with the ITC, the n-butane runs are fit using the tracer-derived radical source without a significant bias, indicating reasonable consistency between the tracer-NO $\mathrm{NO}_{x}$ and butane - NO $\mathrm{Nata}_{x}$. This suggests that humidity may be playing a role in the inconsistency observed with the ITC runs.

Figure 17 also shows the model performance in simulating a selected subset of the many replicate standard "Set 3" mini-surrogate runs performed in the ETC as part of our phase I reactivity study (Carter et al., 1993a). The runs are given in order of increasing average temperature, which varied by almost $15^{\circ} \mathrm{C}$. These runs are of relevance in this context because the temperature variation might be affecting the magnitude of the radical source. Because of lack of

"In this work we will consider only those ETC runs carried out after the $\mathrm{NO}_{x}$ injection procedure was modified to eliminate apparent HoNo contamination, since the condition of the previous ETC runs are not comparable to those of the new experiments for this study. 

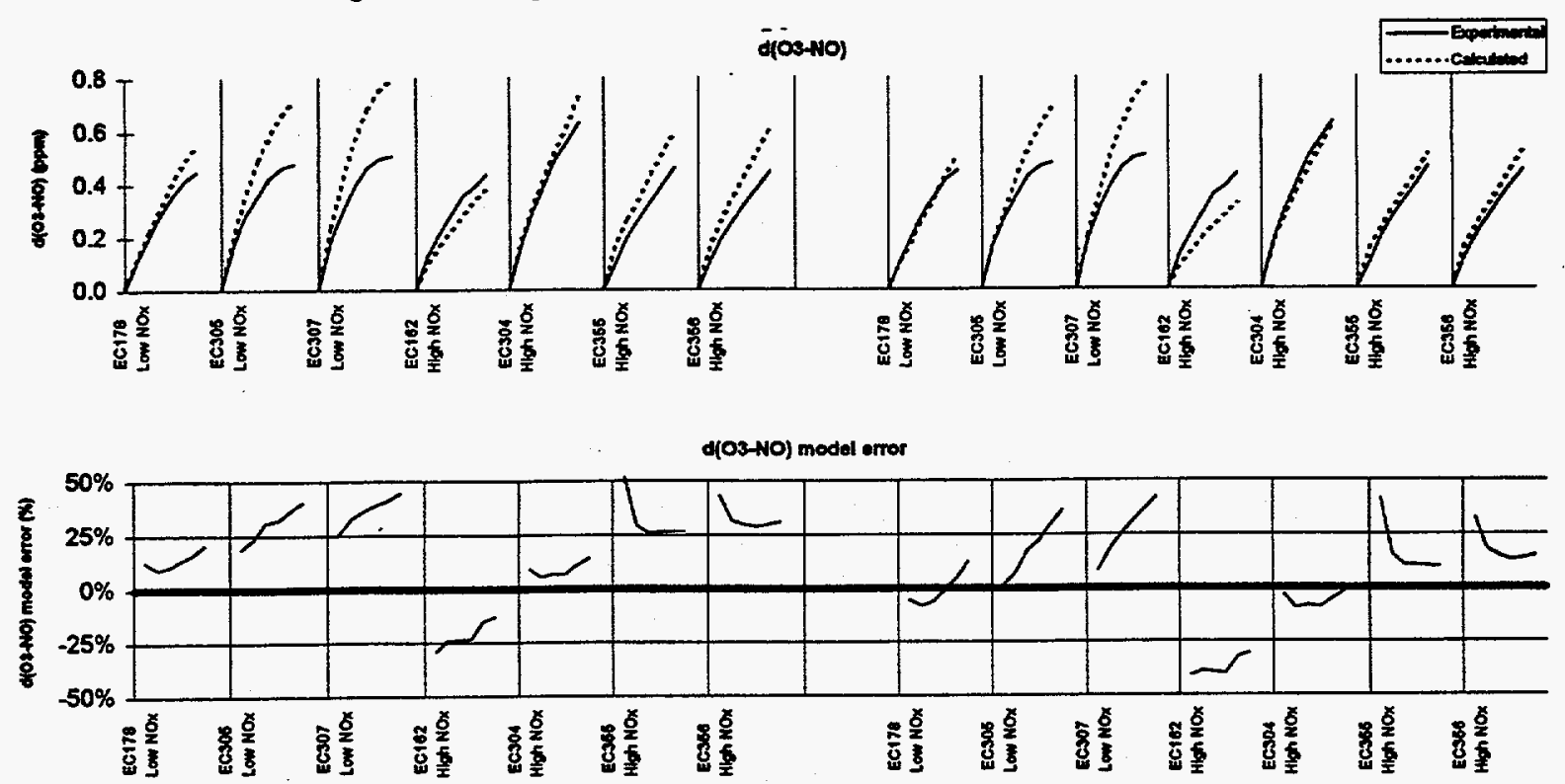

Figure 16. Results of model simulations of $d\left(\mathrm{O}_{3}-\mathrm{NO}\right)$ in the $\mathrm{EC} \mathrm{n}$-butane - $\mathrm{NO}_{x}$ runs using the previous and the adjusted radical source assignments.

butane - $\mathrm{NO}_{x}$ or tracer - $\mathrm{NO}_{x}$ data for such a wide temperature range, the previous ETC radical source assignment had no provision for such a temperature effect. The model performance in simulating the set 3 mini-surrogate runs, which are shown on Figure 17 in order of increasing average temperature, indicates a definite temperature trend in model bias, with the model overpredicting $d\left(\mathrm{O}_{3}-\mathrm{NO}\right)$ at the low temperature range and underpredicting it at the highest temperatures. This suggests that there may be a temperature effect in the ETC radical source. However, these data do not provide definitive evidence for this, since the temperature trend in the model bias may well be due to some other error in the mechanism, such as, for example, an unaccounted-for temperature effect in the uncertain portion of the m-xylene mechanism. Therefore, it would not be appropriate to adjust the radical source based on simulations of these surrogate runs. Fortunately, more direct evidence concerning temperature effects of the radical source was obtained in simulations of the $n$-butane experiments in the OTC, as is discussed in the following section.

\section{Radical Source Assignments for Dry Teflon Chamber Experiments}

One should expect the factors affecting the chamber radical sources to be similar in the ETC, DTC, XTC, and OTC because they all have the same type of chamber surface and most or all experiments carried out in them used dry air. The variables which differ are the size of the chamber, the temperature (which may vary from run to run), and the light source. We would not expect the size of the chamber to be a major factor in the case of these chambers, because the 

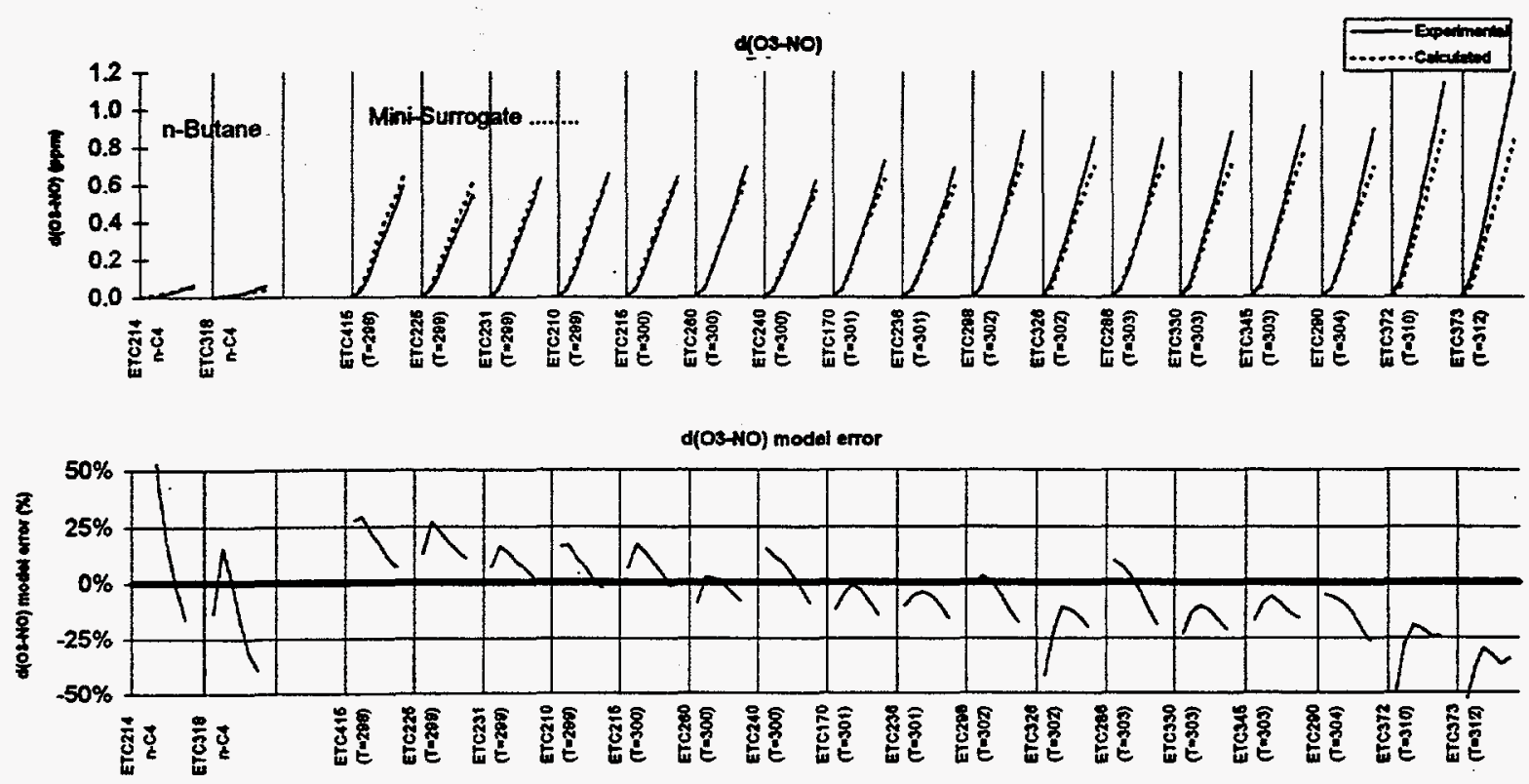

Figure 17. Results of model simulations of $d\left(\mathrm{O}_{3}-\mathrm{NO}\right)$ in ETC n-butane - $\mathrm{NO}_{x}$ and in selected Set 3 mini-surrogate - NO $_{x}$ experiments using the radical source assignment of Carter et. al (1993a). The mini-surrogate runs are ordered by temperature.

DTC and ETC are comparable in volume, and although the OTC is larger, during most of the OTC experiments the reaction bag is partially deflated, and thus has comparable or even larger surface/volume than the ETC or DTC chambers. The UNC outdoor chamber, which is also constructed of FEP Teflon film, is much larger in volume than any of the SAPRC chambers, but the radical source in that chamber is comparable to or somewhat larger than that in the ITC (Carter and Lurmann, 1990, 1991). Thus the factors which need to be considered is the temperature and the light source.

For reasons discussed above, we consider modeling $\mathrm{n}$-butane - $\mathrm{NO}_{\mathrm{x}}$ or $\mathrm{CO}$ NO $_{x}$ experiments the most reliable means for deriving the magnitude of the chamber radical source in Teflon bag experiments. Table 8 lists all the n-butane runs carried out in these chambers under conditions applicable to the runs modeled in this study, and gives the value of the RS-I parameter which was found to give the best fits to the $d\left(\mathrm{O}_{3}-\mathrm{NO}\right)$ data in each. It can be seen that the radical sources are much higher in the OTC than in the other chambers. This could be attributed to the different light source or the higher temperatures. However, there is no significant differences between radical sources in the DTC and the XTC runs, which have comparable temperatures but different light sources. As discussed previously, the solar light spectrum applicable to the OTC is much more like that of the XTC than the DTC. This indicates that the nature of the light source is 
Table 8. Summary of radical source values which best fit data in model simulations of ETC, DTC, XTC, and OTC $n$-butane experiments.

\begin{tabular}{lcccc}
\hline Run & $\begin{array}{c}\text { NOx } \\
(\mathrm{ppm})\end{array}$ & $\begin{array}{c}\text { n-Butane } \\
(\mathrm{ppm})\end{array}$ & $\begin{array}{c}\text { Avg } \mathrm{T} \\
(\mathrm{K})\end{array}$ & $\begin{array}{c}\text { Best Fit } \\
\text { RS-I } \\
(\mathrm{ppb})\end{array}$ \\
\hline ETC214 & 0.49 & 3.93 & 299.4 & 0.03 \\
ETC318 & 0.52 & 4.22 & 298.3 & 0.02 \\
DTC058A & 0.24 & 3.68 & 300.9 & 0.07 \\
DTC058B & 0.24 & 3.78 & 300.9 & 0.06 \\
& & & & \\
XTC085 & 0.55 & 3.80 & 298.5 & 0.08 \\
XTC098 & 0.57 & 4.06 & 302.5 & 0.07 \\
OTC296A & 0.53 & 4.47 & 310.3 & 0.16 \\
OTC296B & 0.52 & 4.98 & 310.3 & 0.12 \\
OTC303A & 0.54 & 3.85 & 313.4 & 0.25 \\
OTC303B & 0.52 & 3.78 & 313.4 & 0.20 \\
OTC307A & 0.46 & 3.66 & 318.6 & 0.35 \\
OTC307B & 0.48 & 3.70 & 318.6 & 0.30 \\
& & & & \\
\hline
\end{tabular}

not an important factor affecting the chamber radical source, but that the temperature is clearly very important.

Temperature dependencies of rates of elementary reactions are generally given in terms of Arrhenius plots, where the log of the rate constant is plotted against $1 / R T$, where $R$ is the gas constant. The slope then gives the activation energy of the reaction. Although the radical source is almost certainly not an elementary process, the Arrhenius relationship suggests a possible parameterization for the temperature dependence. Figure 18 shows an Arrhenius plot for the radical sources for the $n$-butane runs. It can be seen that the Arrhenius parameterization works fairly well in predicting how the radical sources in the various chambers depend on temperature, though the radical sources in the ETC are somewhat lower than expected based on those in the DTC and XTC. The data for the DTC, XTC, and OTC are reasonably well fit by

$$
\text { RS-IDTC, XTC, OTC }=3.70 \times 10^{9} \mathrm{e}^{-18.99 / \mathrm{RT}}
$$

Where RS-I is in ppb, $R=0.0019872 \mathrm{kcal}^{\circ} \mathrm{K}^{-1} \mathrm{~mol}^{-1}$, and $\mathrm{T}$ is the temperature in ${ }^{\circ} \mathrm{K}$. This suggests that whatever process(es) are responsible for the radical source in these chambers, the rate determining step has an activation energy of $\sim 20$ $\mathrm{kcal} / \mathrm{mole}$. However, this expression overestimates, by a factor of $\sim 2$, the radical sources in the two n-butane experiments in the ETC. 

O ETC
$\triangle$ DTC
ए XTC
$\diamond$ OTC
Used for Modeling

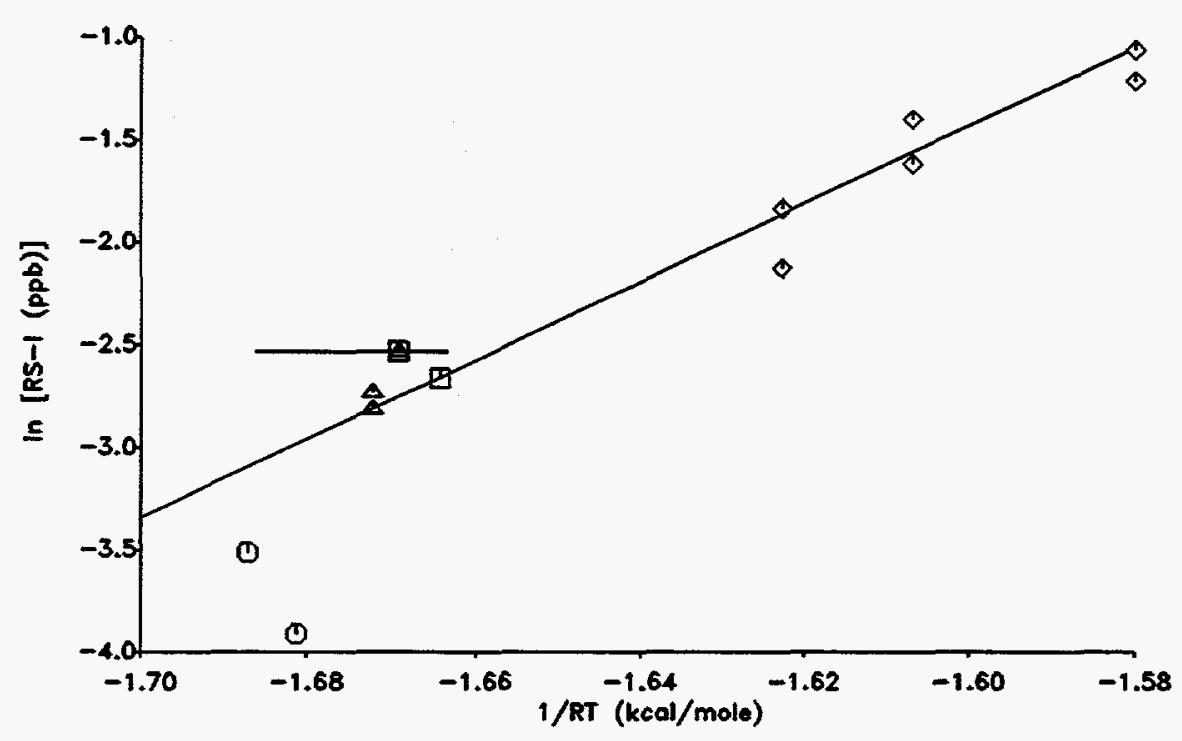

Figure 18. Arrhenius plot showing the temperature dependence of radical source input parameters which fit the ETC, DTC, XTC, and OTC n-butane runs.

Based on the fits to the n-butane experiments, Equation (IV) is used for modeling the all the SAPRC Teflon chamber experiments where dry air was used. Figure 19 shows the performance of the model with this radical source assignment in simulating the $\mathrm{n}$-butane runs in these chambers. As expected from Figure 18, the model gives acceptable fits to the runs in the DTC, XTC, and OTC, but somewhat overpredicts the rate of $d\left(\mathrm{O}_{3}-\mathrm{NO}\right)$ formation in the ETC runs. This was nevertheless used when modeling the ETC runs for consistency with the other chambers with the same surface type and humidity, and because the fits for the ETC are based only on two experiments. Thus, although this radical source assignment gives a consistent chamber model for all these chambers which is consistent with the results of most of the n-butane experiments, it may be causing overpredictions of $d\left(\mathrm{O}_{3}-\mathrm{NO}\right)$ formation rates in ETC experiments which are sensitive to this parameter. This possibility should be taken into account when comparing results of simulations of ETC experiments with simulations of experiments in the other chambers.

\section{E. Effect of Iight Source and Chamber on Mechanism Evaluation Results}

Table 9 summarizes the types of environmental chamber experiments used for assessing the dependence of light source and chamber on mechanism evaluation results, and Table 10 summarizes selected conditions and results of for each experiment. The listed runs include most of the new experiments listed on Table 

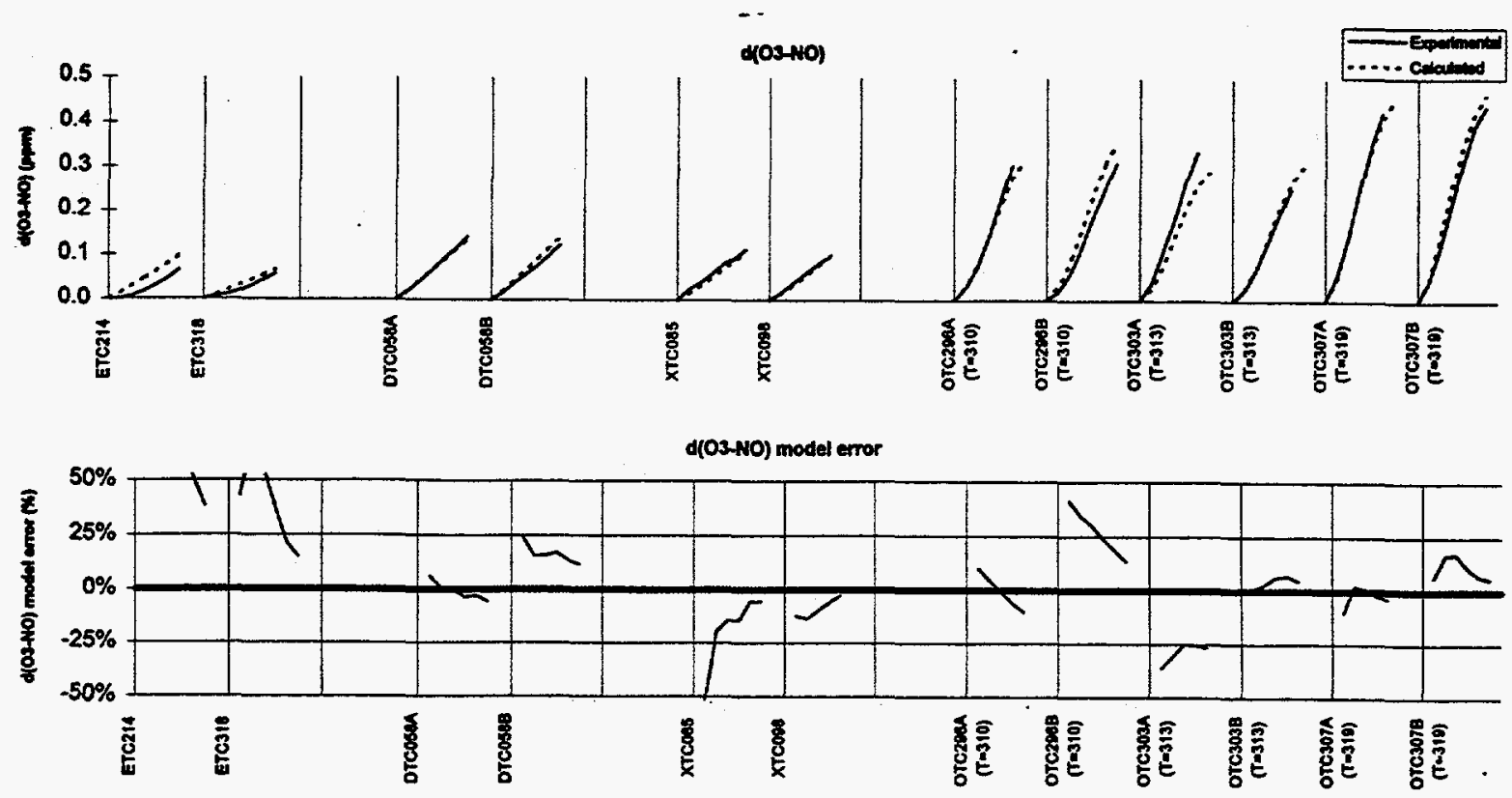

Figure 19. Results of model simulations of the ETC, DTC, XTC, and OTC n-butane - $\mathrm{NO}_{\mathrm{x}}$ experiments using the radical source assignment given in Equation (IV). The OTC runs are ordered by temperature.

4 (other than characterization rins) together with selected comparable EC and ITC experiments in the existing SAPRC mechanism evaluation data base (Carter et al., 1995a). The n-butane runs used for assessing the chamber radical source (discussed in the previous section) are also included.

Although the environmental chamber data can be used to evaluate many aspects of model performance, in this work we will consider only the model's ability to simulate ozone formation and No oxidation. The ability to simulate other aspects of reactivity, such as rates of VOC decay and formation of formaldehyde, PAN and other major products are also important, but if a mechanism cannot simulate ozone formation and No oxidation, then it is obviously not acceptable for vOC reactivity assessment modeling. As discussed above, ozone formation + NO oxidation, or $\mathrm{d}\left(\mathrm{O}_{3}-\mathrm{NO}\right)$, is a more useful means for assessing model performance under a wide variety of conditions than simulations of $\mathrm{O}_{3}$ alone.

Table 10 gives the experimental and calculated hourly $d\left(\mathrm{O}_{3}-\mathrm{NO}\right)$ for all the selected mechanism evaluation experiments, together with the normalized bias in the model simulations. The calculations all used the updated SAPRC chemical mechanism discussed in section IV.A, and used the light characterization and other run conditions inputs derived as discussed in sections IV.B - IV.D, adjusted or corrected as discussed above. These results are discussed below for various types of experiments. 
Table 9. Summary of types of chamber runs used to assess the effects of chamber and light source on mechanism evaluation results.

\begin{tabular}{lccccccc}
\hline Chamber & ITC & ETC & DTC & DTC & EC & XTC & OTC \\
Light Source $^{\mathrm{a}}$ & BL & BL & BL & BL & Xen & Xen & Sun \\
Humidity $^{b}$ & Wet & Dry & Dry & Wet & Wet & Dry & Dry \\
Surface & TF & TF & TF & TF & TCA & TF & TF \\
\hline
\end{tabular}

\section{Run Type}

Formaldehyde

Acetaldehyde

Ethene

Propene

Toluene

m-Xylene

135-Trimethylbenzene

High $\mathrm{NO}_{x}$ Mini-Surrogate ${ }^{d}$

other Mini-Surrogate

$\mathrm{High} \mathrm{NO}_{x} \mathrm{Full}$ surrogate

other Full surrogate
Number of Experiments Modeled
2

13

2

1

3

10

$\begin{array}{clll} & 4 & 3 & 2 \\ & 2 & 2 & 4 \\ & 2 & 3 & 7 \\ & 6 & 4 & 6 \\ & 5 & 4 & 6 \\ & 9 & 1 & 4 \\ & 2 & 1 & \\ & 2 & 1 & \\ & & & 1\end{array}$

20

13
1

$6^{\mathrm{f}}$

1

a $\mathrm{BL}=$ blacklights; Xen = xenon arc; Sun = sunlight

b Wet $=\sim 50 \% \mathrm{RH} ;$ Dry $=55 \% \mathrm{RH}$

c $T F=2$ mil thick FEP Teflon film; TCA = Teflon coated aluminum with quartz end windows.

a "High $\mathrm{NO}_{x}$ " refers to experiments which simulate maximum reactivity conditions. "True" ozone maximum not reached at end of run.

- Representative subset of the $>50$ ETC mini-surrogate runs which were modeled. subset chosen to represent the range of temperatures and $\mathrm{d}\left(\mathrm{O}_{3}\right.$-NO) model exrors observed in the full set.

f Includes runs with added ethane. The ethane is calculated to have only a small effect on the results.

1. Formaldehyde and Acetaldehyde

A limited number of acetaldehyde - $\mathrm{NO}_{x}$ and/or formaldehyde - $\mathrm{NO}_{x}$ experiments were carried out in each of the chambers. Figure 20 shows the model performance in simulating these runs. The model performance is generally good, with the error being less than $25 \%$ error in almost all cases. There is no bias in the simulations of the xenon arc (EC and XTC) or outdoor chamber (OTC) experiments, though there is some variability in formaldehyde simulations. There may be a slight positive bias in the simulation of the blacklight chamber experiments, but this is based on a very limited number of runs, and the bias is within the variability of the simulations of the other runs. Thus there does notappear to be a significant light source or chamber effect in the simulations of these aldehyde runs. 
Table 10. Summary of conditions and experimental and calculated d $\left(\mathrm{O}_{3}-\mathrm{NO}\right)$ results for all environmental chamber experiments modeled for this program.

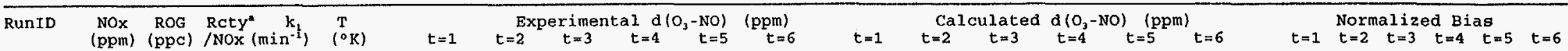
n-Butane

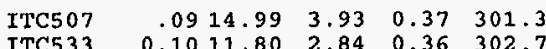
$\begin{array}{llllll}\text { ITC533 } & 0.1011 .80 & 2.84 & 0.36 & 302.7\end{array}$

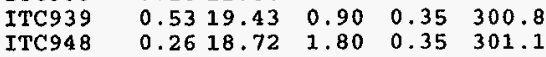
$\begin{array}{llllll}\text { ETC214 } & 0.49 & 15.71 & 0.80 & 0.35 & 299.4\end{array}$

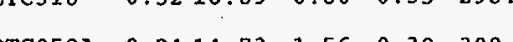
$\begin{array}{llllll}\text { DTC058A } & 0.24 & 14.73 & 1.56 & 0.39 & 300.9 \\ \text { DTC058B } & 0.24 & 15.13 & 1.61 & 0.39 & 300.9\end{array}$ $\begin{array}{lllllll}X T C 085 & 0.55 & 15.18 & 0.71 & 0.26 & 298 .\end{array}$ $\begin{array}{llllll}\text { XTC098 } & 0.5716 .23 & 0.74 & 0.25 & 302 .\end{array}$ $\begin{array}{llrllll}\text { EC178 } & 0.10 & 9.99 & 2.16 & 0.34 & 303.7\end{array}$ $\begin{array}{llllll}\mathrm{EC} 307 & 0.11 & 28.48 & 5.76 & 0.41 & 301.9\end{array}$ $\begin{array}{llllll}\text { EC162 } & 0.5410 .29 & 0.41 & 0.34 & 300.8\end{array}$ $\begin{array}{llllll}\text { EC304 } & 0.5118 .41 & 0.85 & 0.40 & 302.0\end{array}$ $\begin{array}{lllll}\text { EC355 } & 0.5016 .80 & 0.82 & 0.35 & 302.3 \\ \text { EC356 } & 0.5017 .30 & 0.86 & 0.35 & 302.2\end{array}$

$\begin{array}{llllll}\text { OTC296A- } & 0.5317 .87 & 0.86 & 0.00 & 310.3\end{array}$ $\begin{array}{llllll}0 \text { TC296B } & 0.52 & 19.92 & 0.99 & 0.00 & 310.3\end{array}$ $\begin{array}{lllllll}\text { OTC303A } & 0.54 & 15.40 & 0.75 & 0.00 & 313.4\end{array}$ $\begin{array}{llllll}\text { OTC303B } & 0.52 & 15.14 & 0.75 & 0.00 & 313.4\end{array}$ $\begin{array}{llllll}\text { OTC307A } & 0.4614 .64 & 0.82 & 0.00 & 318 .\end{array}$ $\begin{array}{llllll}0 \text { TC307B } & 0.48 & 14.80 & 0.80 & 0.00 & 318.6\end{array}$ Formaldehyde

$\begin{array}{llllll}\text { ETC378 } & 0.24 & 0.22 & 0.35 & 0.35 & 301.1 \\ \text { ETC441 } & 0.27 & 0.50 & 0.61 & 0.35 & 300.7\end{array}$ $\begin{array}{lllllll}\text { EC389 } & 4.75 & 9.53 & 0.72 & 0.37 & 301.3\end{array}$ $\begin{array}{llllll}\text { EC391 } & 5.40 & 18.06 & 1.23 & 0.37 & 301.6\end{array}$ $\begin{array}{llllll}8 C 392 & 11.37 & 9.95 & 0.31 & 0.37 & 301.6\end{array}$

$\begin{array}{lllllll}\text { XTC086 } & 0.16 & 1.68 & 1.32 & 0.26 & 298.7\end{array}$ $\begin{array}{llllll}\text { XTC096 } & 0.17 & 1.65 & 1.58 & 0.26 & 301.8 \\ \text { XTC091 } & 0.15 & 1.73 & 1.79 & 0.26 & 299.8\end{array}$ $\begin{array}{lllll}\text { OTC270A } & 0.53 & 0.56 & 1.79\end{array}$

306.5 Acetaldehyde

$\begin{array}{llllll}\text { DTC055B } & 0.14 & 3.30 & 5.44 & 0.39 & 301.0\end{array}$ $\begin{array}{llllll}\text { EC164 } & 0.54 & 0.68 & 0.38 & 0.35 & 304.5 \\ \text { EC254 } & 0.11 & 0.98 & 2.66 & 0.29 & 303.0\end{array}$ $\begin{array}{lllllll}\mathrm{xTC} 083 & 0.25 & 2.63 & 2.52 & 0.26 & 300.5\end{array}$ $\begin{array}{lllllll}0.060 & 0.098 & 0.127 & 0.158 & 0.191 & 0.226\end{array}$ $\begin{array}{lllllll}0.042 & 0.081 & 0.114 & 0.143 & 0.174 & 0.208\end{array}$ $\begin{array}{llllll}0.024 & 0.047 & 0.053 & 0.068 & 0.088 & 0.096 \\ 0.048 & 0.071 & 0.100 & 0.115 & 0.142 & 0.166\end{array}$ $\begin{array}{lllllll}0.001 & 0.006 & 0.017 & 0.031 & 0.047 & 0.066\end{array}$ $\begin{array}{lllllll}0.006 & 0.010 & 0.018 & 0.030 & 0.045 & 0.059\end{array}$ $\begin{array}{lllllll}0.020 & 0.044 & 0.067 & 0.093 & 0.115 & 0.142 \\ 0.017 & 0.039 & 0.059 & 0.078 & 0.101 & 0.124\end{array}$ $\begin{array}{lllllll}0.024 & 0.039 & 0.059 & 0.081 & 0.094 & 0.114\end{array}$

$\begin{array}{lllllll}0.108 & 0.201 & 0.286 & 0.357 & 0.416 & 0.446\end{array}$ $\begin{array}{llllll}0.165 & 0.279 & 0.356 & 0.429 & 0.461 & 0.475\end{array}$ $\begin{array}{lllllll}0.181 & 0.301 & 0.394 & 0.458 & 0.491 & 0.455 \\ 0.129 & 0.210 & & 0.355 & 0.388 & 0.435\end{array}$ $\begin{array}{lllllll}0.169 & 0.294 & 0.393 & 0.491 & 0.563 & 0.631 \\ 0.098 & 0.195 & 0.271 & 0.333 & 0.396 & 0.458\end{array}$ $\begin{array}{llllll}0.098 & 0.196 & 0.271 & 0.333 & 0.396 & 0.458\end{array}$ $\begin{array}{llllll}0.028 & 0.075 & 0.143 & 0.225 & 0.306\end{array}$ $\begin{array}{lllllll}0.021 & 0.059 & 0.115 & 0.186 & 0.306 & 0.313\end{array}$ $\begin{array}{lllll}0.038 & & 0.181 & 0.267 & 0.338 \\ 0.025 & 0.073 & 0.130 & 0.195 & 0.255\end{array}$ $\begin{array}{lllll}0.025 & 0.073 & 0.130 & 0.195 & 0.255 \\ 0.057 & 0.0140 & 0.251 & 0.354 & 0.429\end{array}$ $\begin{array}{lllllll}0.057 & 0.140 & 0.251 & 0.354 & 0.429 & \\ 0.050 & 0.125 & 0.220 & 0.320 & 0.397 & 0.443\end{array}$

$\begin{array}{lllllll}0.032 & 0.054 & 0.073 & 0.086 & 0.098 & 0.105 \\ 0.110 & 0.173 & 0.212 & 0.238 & 0.256 & 0.271\end{array}$ $\begin{array}{lllll}1.979 & 2.258 & 2.379 & 2.515\end{array}$

$\begin{array}{lllll}.583 & 5.590 & 6.361 & 6.497 & 6.402\end{array}$

$\begin{array}{llllll}2.223 & 2.540 & 2.650 & 2.699 & 2.738 & 2.750\end{array}$

$\begin{array}{llllll}0.140 & 0.229 & 0.300 & 0.357 & 0.409 & 0.453\end{array}$ $\begin{array}{llllll}0.130 & 0.210 & 0.267 & 0.309 & 0.341 & 0.363 \\ 0.125 & 0.216 & 0.287 & 0.344 & 0.395 & \end{array}$

$\begin{array}{lllll}0.184 & 0.293 & 0.350 & 0.381 & 0.395\end{array}$ $\begin{array}{llllll}0.316 & 0.535 & 0.696 & 0.801 & 0.858\end{array}$

$\begin{array}{llllll}0.106 & 0.182 & 0.253 & 0.316 & 0.378 & 0.434\end{array}$ $\begin{array}{lllllll}0.136 & 0.231 & 0.294 & 0.346 & 0.380 & 0.409\end{array}$ $\begin{array}{lllllll}0.098 & 0.160 & 0.215 & 0.263 & 0.305 & 0.33\end{array}$ $\begin{array}{llllll}0.143 & 0.238 & 0.305 & 0.370 & 0.430 & 0.488\end{array}$ $\begin{array}{llllll}0.043 & 0.084 & 0.125 & 0.168 & 0.215 & 0.264\end{array}$ $\begin{array}{llllll}0.035 & 0.069 & 0.103 & 0.138 & 0.176 & 0.215\end{array}$ $\begin{array}{llllll}0.016 & 0.034 & 0.051 & 0.069 & 0.086 & 0.103 \\ 0.027 & 0.055 & 0.083 & 0.110 & 0.137 & 0.165\end{array}$ $\begin{array}{lllllll}0.014 & 0.030 & 0.046 & 0.063 & 0.080 & 0.097\end{array}$ $\begin{array}{lllllll}0.009 & 0.020 & 0.032 & 0.044 & 0.056 & 0.068\end{array}$ $\begin{array}{llllll}0.021 & 0.044 & 0.067 & 0.089 & 0.112 & 0.134 \\ 0.022 & 0.046 & 0.069 & 0.093 & 0.116 & 0.139\end{array}$ $\begin{array}{lllllll}0.014 & 0.032 & 0.051 & 0.070 & 0.089 & 0.108\end{array}$ $\begin{array}{lllllll}0.014 & 0.032 & 0.052 & 0.071 & 0.092 & 0.112\end{array}$ $\begin{array}{lllllll}0.102 & 0.185 & 0.269 & 0.354 & 0.436 & 0.507\end{array}$ $\begin{array}{lllllll}0.167 & 0.301 & 0.424 & 0.533 & 0.622 & 0.688\end{array}$ $\begin{array}{llllll}0.197 & 0.360 & 0.506 & 0.626 & 0.715 & 0.772\end{array}$ $\begin{array}{llllll}0.085 & 0.142 & 0.191 & 0.237 & 0.280 & 0.321 \\ 0.163 & 0.268 & 0.361 & 0.449 & 0.534 & 0.619\end{array}$ $\begin{array}{lllllll}0.150 & 0.229 & 0.302 & 0.371 & 0.438 & 0.506\end{array}$ $\begin{array}{lllllll}0.153 & 0.235 & 0.309 & 0.380 & 0.449 & 0.518\end{array}$

$\begin{array}{lllllll}0.031 & 0.078 & 0.142 & 0.212 & 0.276 & 0.317\end{array}$ $\begin{array}{lllllll}0.032 & 0.084 & 0.156 & 0.236 & 0.310 & 0.358\end{array}$ $\begin{array}{llllll}0.026 & 0.077 & 0.141 & 0.207 & 0.259 & 0.292 \\ 0.025 & 0.075 & 0.139 & 0.209 & 0.267 & 0.305\end{array}$ $\begin{array}{llllll}0.025 & 0.075 & 0.139 & 0.209 & 0.267 & 0.305 \\ 0.051 & 0.143 & 0.254 & 0.347 & 0.415 & 0.457\end{array}$ $\begin{array}{llllll}0.051 & 0.143 & 0.254 & 0.347 & 0.415 & 0.457 \\ 0.053 & 0.148 & 0.262 & 0.357 & 0.426 & 0.468\end{array}$

$\begin{array}{lllllll}0.048 & 0.075 & 0.092 & 0.104 & 0.112 & 0.118 \\ 0.126 & 0.181 & 0.213 & 0.234 & 0.249 & 0.260\end{array}$ $\begin{array}{lllll}2.222 & 2.675 & 2.820 & 2.886\end{array}$

$\begin{array}{lllll}4.426 & 5.462 & 6.292 & 6.568 & 6.482\end{array}$

$\begin{array}{llllll}2.180 & 2.685 & 2.856 & 2.940 & 2.992 & 3.030\end{array}$

$\begin{array}{llllll}0.126 & 0.207 & 0.270 & 0.323 & 0.368 & 0.406\end{array}$ $\begin{array}{lllllllll}0.162 & 0.249 & 0.270 & 0.323 & 0.368 & 0.406\end{array}$ $\begin{array}{llllllllll}0.178 & 0.290 & 0.375 & 0.440 & 0.491 & 0.530\end{array}$ $\begin{array}{lllllll}0.173 & 0.262 & 0.305 & 0.329 & 0.341 & 0.345\end{array}$ $\begin{array}{lllllll}0.309 & 0.507 & 0.644 & 0.724 & 0.765 & 0.780\end{array}$

$\begin{array}{lllllll}0.135 & 0.225 & 0.308 & 0.386 & 0.459 & 0.518\end{array}$ $\begin{array}{lllllll}0.117 & 0.205 & 0.270 & 0.324 & 0.372 & 0.409\end{array}$ $\begin{array}{lllllll}0.107 & 0.173 & 0.229 & 0.280 & 0.327 & 0.368\end{array}$ $\begin{array}{llllll}0.160 & 0.250 & 0.318 & 0.379 & 0.438 & 0.494\end{array}$

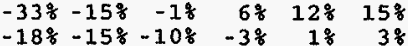

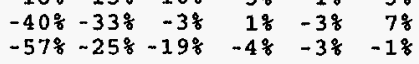
$173 \% 133 \% \quad 92 \% \quad 68 \% \quad 52 \% \quad 38 \%$ 43\% 688 558 $37 \% 218158$ $\begin{array}{rrrrrr}6 \% & 1 \% & 0 \% & -4 \% & -3 \% & -6 \% \\ 25 \% & 16 \% & 16 \% & 17 \% & 14 \% & 12 \%\end{array}$ $-51 \%-19 \%-15 \%-14 \%-5 \%$
$-12 \%-14 \%-10 \%$ $-128-148-108-6 \frac{8}{8}-38$

$\begin{array}{rrrrrr}-6 \% & -8 \% & -6 \% & -1 \% & 5 \% & 13 \% \\ 1 \% & 7 \% & 18 \% & 22 \% & 30 \% & 37 \%\end{array}$ $\begin{array}{llllll}1 \% & 78 \% & 25 \% & 31 \% & 37 \% & 42 \%\end{array}$

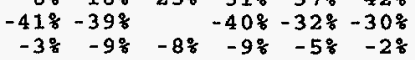
$42 \% \quad 16 \% \quad 11 \% \quad 11 \% \quad 108 \quad 10 \%$ $10 \%$ - $-18-10 \%$ $\begin{array}{rrrrr}10 \% & 4 \% & -1 \% & -6 \% & -10 \% \\ 42 \% & 34 \% & 30 \% & 24 \% & \\ -36 \% & & -25 \% & -25 \% & -27 \%\end{array}$

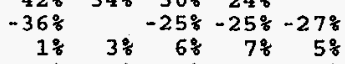
$\begin{array}{rrrrr}-10 \% & 2 \% & 1 \% & -28 & -38 \\ 6 \% & 17 \% & 17 \% & 11 \% & 7 \%\end{array}$

$\begin{array}{rrrrrr}39 \% & 32 \% & 23 \% & 19 \% & 13 \% & 11 \% \\ 14 \% & 4 \% & 0 \% & -2 \% & -3 \% & -4 \%\end{array}$ $\begin{array}{rrrrrr}12 \% & 17 \% & 17 \% & 14 \% & \\ -3 \% & -2 \% & -1 \% & 1 \% & 1 \%\end{array}$ $\begin{array}{rrrrrr}-3 \% & -2 \% & -1 \% & 1 \% & 1 \% & \\ 1 \% & 4 \% & 6 \% & 8 \% & & \\ -2 \% & 6 \% & 7 \% & 9 \% & 9 \% & 10 \%\end{array}$

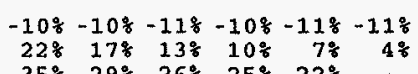
$\begin{array}{lllll}35 \% & 29 \% & 26 \% & 25 \% & 22 \%\end{array}$

$-6 \%-11 \%-14 \%-15 \%-15 \%$
$-2 \%-5 \%-8 \%-10 \%-11 \%$

$24 \% \quad 21 \% \quad 19 \% \quad 20 \% \quad 19 \% \quad 18 \%$ $\begin{array}{rrrrrr}-158 & -12 \% & -9 \% & -7 \% & -2 \% & 0 \% \\ 9 \% & 8 \% & 6 \% & 6 \% & 7 \% & 8 \%\end{array}$ $\begin{array}{llllll}11 \% & 5 \% & 4 \% & 3 \% & 2 \% & 1 \%\end{array}$ 
Table 10 (continued)

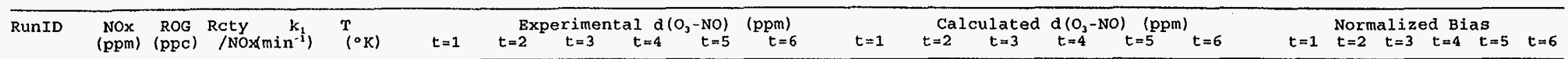

$\begin{array}{llllllllllll}\mathrm{XTC092} & 0.25 & 3.32 & 2.76 & 0.26 & 301: 0 & 0.116 & 0.200 & 0.260 & 0.312 & 0.363 & 0.412\end{array}$

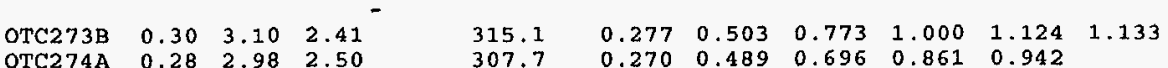
$\begin{array}{llll}\text { OTC274A } & 0.28 & 2.98 & 2.50\end{array}$ $\begin{array}{llll}0 T C 317 \mathrm{~B} & 0.26 & 3.98 & 2.50 \\ 0 \mathrm{TC} & 0.32 & 3.06\end{array}$

307.7

315.8

then

$\begin{array}{llllll}\operatorname{ETC220} & 0.51 & 1.22 & 0.39 & 0.35 & 299.4 \\ \text { ETC467 } & 0.52 & 2.98 & 0.91 & 0.35 & 300.3\end{array}$ $\begin{array}{llllll}\text { ETC439 } & 0.66 & 3.91 & 0.95 & 0.35 & 300.1\end{array}$ $\begin{array}{llllll}\text { ETC439 } & 0.66 & 3.91 & 0.95 & 0.35 & 300.1 \\ \text { ETC466 } & 0.41 & 3.00 & 1.17 & 0.35 & 300.3\end{array}$ $\begin{array}{lllllll}\text { ETC502 } & 0.43 & 3.45 & 1.29 & 0.35 & 300.3\end{array}$ $\begin{array}{llllll}\text { ETC505 } & 0.40 & 3.29 & 1.33 & 0.35 & 300.3\end{array}$ $\begin{array}{llllll}\text { ETC4 } 76 & 0.43 & 3.42 & 1.27 & 0.35 & 300.4\end{array}$ $\begin{array}{llllll}\text { ETC4 82 } & 0.41 & 3.20 & 1.25 & 0.35 & 300.5 \\ \text { ETC479 } & 0.42 & 3.57 & 1.37 & 0.35 & 300.6\end{array}$ $\begin{array}{llllll}\text { ETC4 86 } & 0.44 & 3.18 & 1.16 & 0.35 & 300.7\end{array}$ $\begin{array}{llllll}\text { TC469 } & 0.46 & 3.60 & 1.27 & 0.35 & 300.7\end{array}$ $\begin{array}{lllllll}\text { ETC464 } & 0.38 & 3.01 & 1.29 & 0.35 & 301.0\end{array}$ $\begin{array}{lllllll}\text { ETC381 } & 0.52 & 4.12 & 1.29 & 0.35 & 301.0\end{array}$ $\begin{array}{llllll}\text { ETC4 } 97 & 0.45 & 3.54 & 1.26 & 0.35 & 301.2\end{array}$ $\begin{array}{lllllll}E T C 471 & 0.45 & 3.61 & 1.28 & 0.35 & 301.6\end{array}$ $\begin{array}{lllllll}\text { ETC221 } & 0.51 & 8.09 & 2.55 & 0.35 & 299.4\end{array}$

$\begin{array}{lllllll}\text { DTC043A } & 0.47 & 3.95 & 1.18 & 0.39 & 300.3\end{array}$ $\begin{array}{lllllll}\text { DTC072B } & 0.47 & 4.33 & 1.19 & 0.39 & 301.9\end{array}$ $\begin{array}{lllllll}\text { DTC047A } & 0.48 & 4.53 & 1.22 & 0.39 & 300.7\end{array}$ $\begin{array}{lllllll}\text { DTC051A } & 0.48 & 4.55 & 1.23 & 0.39 & 301.3\end{array}$

$\begin{array}{llllll}\text { DTC0 46B } & 0.17 & 4.44 & 3.37 & 0.19 & 300.0\end{array}$ $\begin{array}{llllll}\text { DTC041B } & 0.17 & 4.08 & 3.41 & 0.39 & 300.2\end{array}$ $\begin{array}{llllll}\text { DTC0 } 8 B & 0.17 & 4.55 & 3.49 & 0.39 & 301.1\end{array}$ $\begin{array}{llllll}\text { DTC044B } & 0.16 & 4.19 & 3.56 & 0.39 & 300.4\end{array}$

$\begin{array}{llllll}\text { ITC936 } & 0.52 & 3.88 & 1.22 & 0.35 & 301.0\end{array}$ $\begin{array}{llllll}\text { ITC1555 } & 0.45 & 4.19 & 1.51 & 0.35 & 300.8 \\ \text { ITC926 } & 0.53 & 7.88 & 2.42 & 0.35 & 301.0\end{array}$

$\begin{array}{llllll}\text { EC285 } & 1.01 & 3.90 & 0.62 & 0.38 & 302.3\end{array}$ $\begin{array}{llllll}E C 142 & 0.49 & 1.90 & 0.63 & 0.31 & 300.9\end{array}$ $\begin{array}{llllll}\text { EC286 } & 0.97 & 7.52 & 1.25 & 0.38 & 302.4\end{array}$ $\begin{array}{llllll}\text { EC156 } & 0.47 & 3.99 & 1.37 & 0.33 & 301.1 \\ \text { EC287 } & 0.54 & 7.99 & 2.38 & 0.37 & 302.1\end{array}$ $\begin{array}{llllll}\text { XTC112 } & 0.52 & 6.24 & 1.68 & 0.25 & 301.5 \\ \text { XTC105 } & 0.24 & 4.54 & 2.50 & 0.25 & 300.9\end{array}$ $\begin{array}{llll}\text { OTC2 } 788 & 0.46 & 2.43 & 0.53\end{array}$ $\begin{array}{llll}\text { OTC2 } 97 \mathrm{~A} & 0.63 & 2.93 & 0.59\end{array}$ OTC304A $0.60 \quad 2.84 \quad 0.61$

312.7 308.6 $\begin{array}{lllll}0.270 & 0.489 & 0.696 & 0.861 & 0.942 \\ 0.130 & 0.274 & 0.403 & 0.470 & 0.503\end{array}$ $\begin{array}{llllll}0.313 & 0.580 & 0.862 & 1.040 & 1.112\end{array}$

$\begin{array}{lllllll}0.016 & 0.045 & 0.079 & 0.116 & 0.159 & 0.202\end{array}$ $\begin{array}{lllllll}0.065 & 0.169 & 0.282 & 0.413 & 0.550 & 0.732\end{array}$ $\begin{array}{llllll}0.100 & 0.264 & 0.448 & 0.662 & 0.969 & 1.303 \\ 0.085 & 0.217 & 0.370 & 0.554 & 0.818 & 1.080\end{array}$ $\begin{array}{lllll}0.072 & 0.195 & 0.345 & & 0.994\end{array}$ $\begin{array}{llllll}0.102 & 0.226 & 0.379 & 0.591 & 0.851 & 1.080\end{array}$ $\begin{array}{llllll}0.063 & 0.195 & 0.333 & 0.522 & 0.774 & 1.043\end{array}$ $\begin{array}{lllllll}0.113 & 0.247 & 0.401 & 0.614 & 0.884 & 1.13\end{array}$ $\begin{array}{lllllll}0.084 & 0.219 & 0.379 & 0.592 & 0.887 & 1.150\end{array}$ $\begin{array}{lllllll}0.104 & 0.245 & 0.423 & 0.660 & 0.980 & 1.236\end{array}$ $\begin{array}{llllllll}0.082 & 0.226 & 0.392 & 0.632 & 0.923 & 1.133\end{array}$ $\begin{array}{llllll}0.122 & 0.327 & 0.585 & 0.951 & 1.319 & 1.506\end{array}$ $\begin{array}{llllll}0.086 & 0.218 & 0.384 & 0.612 & 0.921 & 1.184\end{array}$ $\begin{array}{lllllll}0.095 & 0.248 & 0.436 & 0.700 & 1.019 & 1.268\end{array}$ $\begin{array}{lllll}0.329 & 0.980 & 1.395 & 1.505 & 1.499\end{array}$

$\begin{array}{lllllll}0.063 & 0.174 & 0.318 & 0.485 & 0.712 & 1.009\end{array}$ $\begin{array}{lllllll}0.067 & 0.180 & 0.326 & 0.492 & 0.718 & 1.022\end{array}$ $\begin{array}{lllllll}0.067 & 0.190 & 0.348 & 0.537 & 0.805 & 1.126\end{array}$ $\begin{array}{lllllll}0.078 & 0.204 & 0.360 & 0.550 & 0.816 & 1.126\end{array}$ $\begin{array}{lllllll}0.032 & 0.096 & 0.200 & 0.361 & 0.500 & 0.578\end{array}$ $\begin{array}{llllll}0.087 & 0.304 & 0.614 & 0.793 & 0.865 & 0.879\end{array}$ $\begin{array}{llllll}0.099 & 0.352 & 0.661 & 0.822 & 0.879 & 0.885\end{array}$ $\begin{array}{lllllll}0.094 & 0.335 & 0.638 & 0.796 & 0.857 & 0.863\end{array}$

$\begin{array}{lllllll}0.126 & 0.287 & 0.464 & 0.701 & 0.982 & 1.191\end{array}$ $\begin{array}{llllll}0.165 & 0.333 & 0.587 & 0.938 & 1.203 & 1.320 \\ 0.383 & 0.943 & 1.282 & 1.299 & 1.224 & 1.116\end{array}$ $\begin{array}{lllllll}0.356 & 0.661 & 0.914 & 1.147 & 1.415 & 1.648\end{array}$ $\begin{array}{lllllll}0.214 & 0.395 & 0.584 & 0.799 & 1.012 & 1.648\end{array}$ $\begin{array}{llllll}0.496 & 1.086 & 1.446 & 1.446 & 1.344 & 1.230\end{array}$ $\begin{array}{llllll}0.546 & 1.102 & 1.423 & 1.385 & 1.287 & 1.173 \\ 0.854 & 1.367 & 1.299 & 1.156 & 1.041 & 0.966\end{array}$ $\begin{array}{lllllll}0.083 & 0.242 & 0.464 & 0.743 & 1.101 & 1.336\end{array}$ $\begin{array}{llllll}0.041 & 0.119 & 0.239 & 0.379 & 0.518 & 0.619\end{array}$ $\begin{array}{llllll}0.052 & 0.184 & 0.402 & 0.629 & 0.855\end{array}$ $\begin{array}{lllllll}0.074 & 0.201 & 0.346 & 0.537 & 0.887 & 1.150\end{array}$ $\begin{array}{lllllll}0.063 & 0.196 & 0.416 & 0.714 & 0.905 & 0.989\end{array}$ $\begin{array}{llllll}0.126 & 0.210 & 0.274 & 0.333 & 0.389 & 0.445\end{array}$ $\begin{array}{lllllll}0.289 & 0.528 & 0.818 & 1.082 & 1.214 & 1.233\end{array}$ $\begin{array}{lllllll}0.218 & 0.396 & 0.573 & 0.743 & 0.876 & 0.939\end{array}$ $\begin{array}{llllll}0.301 & 0.574 & 0.393 & 1.462 & 0.495 & 0.492\end{array}$

$\begin{array}{lllllll}0.018 & 0.044 & 0.075 & 0.109 & 0.144 & 0.179\end{array}$ $\begin{array}{lllllll}0.070 & 0.185 & 0.311 & 0.438 & 0.575 & 0.731\end{array}$ $\begin{array}{llllllll}0.080 & 0.209 & 0.396 & 0.566 & 0.762 & 0.996\end{array}$ $\begin{array}{llllllll}0.096 & 0.252 & 0.431 & 0.653 & 0.920 & 1.161\end{array}$ $\begin{array}{llllll}0.089 & 0.234 & 0.405 & 0.622 & 0.882 & 1.112\end{array}$ $\begin{array}{llllll}0.097 & 0.248 & 0.424 & 0.643 & 0.904 & 1.143\end{array}$ $\begin{array}{lllllll}0.092 & 0.240 & 0.404 & 0.600 & 0.837 & 1.073\end{array}$ $\begin{array}{llllll}0.106 & 0.278 & 0.478 & 0.732 & 1.018 & 1.233\end{array}$ $\begin{array}{lllllll}0.086 & 0.2274 & 0.381 & 0.732 & 1.018 & 1.233\end{array}$ $\begin{array}{lllllll}0.114 & 0.294 & 0.463 & 0.696 & 0.974 & 1.221\end{array}$ $\begin{array}{lllllll}0.087 & 0.225 & 0.384 & 0.578 & 0.813 & 1.036\end{array}$ $\begin{array}{lllllll}0.132 & 0.342 & 0.575 & 0.864 & 1.287 & 1.424\end{array}$ $\begin{array}{llllll}0.100 & 0.260 & 0.445 & 0.677 & 0.955 & 1.201\end{array}$ $\begin{array}{llllll}0.110 & 0.286 & 0.483 & 0.728 & 1.014 & 1.251 \\ 0.427 & 1.095 & 1.518 & 1.576 & 1.494 & 1.360\end{array}$ $\begin{array}{lllllll}0.087 & 0.235 & 0.401 & 0.591 & 0.824 & 1.088\end{array}$ $\begin{array}{llllll}0.087 & 0.235 & 0.401 & 0.591 & 0.824 & 1.088 \\ 0.097 & 0.250 & 0.414 & 0.598 & 0.819 & 1.062\end{array}$ $\begin{array}{lllllll}0.095 & 0.256 & 0.437 & 0.647 & 0.906 & 1.181\end{array}$ $\begin{array}{lllllll}0.095 & 0.256 & 0.437 & 0.647 & 0.906 & 1.181 \\ 0.095 & 0.255 & 0.436 & 0.648 & 0.912 & 1.194\end{array}$ $\begin{array}{lllllll}0.054 & 0.156 & 0.305 & 0.479 & 0.599 & 0.661\end{array}$ $\begin{array}{llllll}.158 & 0.468 & 0.758 & 0.889 & 0.922 & 0.904\end{array}$ $\begin{array}{lllllll}0.168 & 0.494 & 0.778 & 0.899 & 0.924 & 0.900\end{array}$ $\begin{array}{lllllll}0.172 & 0.507 & 0.778 & 0.888 & 0.909 & 0.883\end{array}$

$\begin{array}{lllllll}0.114 & 0.291 & 0.502 & 0.774 & 1.080 & 1.290\end{array}$ $\begin{array}{lllllll}0.136 & 0.350 & 0.645 & 0.995 & 1.220 & 1.285 \\ 0.445 & 1.121 & 1.412 & 1.391 & 1.272 & 1.133\end{array}$ $\begin{array}{lllllll}0.360 & 0.676 & 0.960 & 1.253 & 1.567 & 1.817\end{array}$ $\begin{array}{llllll}0.151 & 0.267 & 0.377 & 0.487 & 0.602 & 0.722\end{array}$ $\begin{array}{llllll}0.813 & 1.591 & 2.034 & 2.001 & 1.835 & 1.666 \\ 0.332 & 0.636 & 0.971 & 1.208 & 1.275 & 1.250\end{array}$ $\begin{array}{llllll}0.339 & 0.653 & 0.991 & 1.212 & 1.272 & 1.249 \\ 0.986 & 1.525 & 1.516 & 1.371 & 1.219 & 1.205\end{array}$ $\begin{array}{lllllll}0.087 & 0.254 \cdot 0.454 & 0.693 & 0.986 & 1.235\end{array}$ $\begin{array}{lllllll}0.064 & 0.185 & 0.346 & 0.559 & 0.751 & 0.862\end{array}$ $\begin{array}{lllllll}0.029 & 0.092 & 0.188 & 0.288 & 0.375 & 0.444\end{array}$ $\begin{array}{llllll}0.029 & 0.092 & 0.183 & 0.288 & 0.375 & 0.444 \\ 0.053 & 0.177 & 0.235 & 0.380 & 0.522 & 0.632 \\ & 0.346 & 0.503 & 0.629 & 0.738\end{array}$ $\begin{array}{llllll}8 \% & 5 \% & 5 \% & 6 \% & 7 \% & 8 \%\end{array}$ $4 \% \quad 5 \% \quad 6 \% \quad 8 \% \quad 8 \% \quad 8 \%$

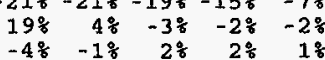

$12 \%-2 \%-5 \%-7 \%-10 \%-12 \%$ $\begin{array}{rrrrrr}8 \% & 9 \% & 10 \% & 6 \% & 4 \% & 0 \% \\ -7 \% & -11 \% & -12 \% & -16 \% & -24 \% & -27 \%\end{array}$ $-7 \frac{8}{6}-4 \%-5 \%-7 \%-13 \%-14 \%$ $-14 \frac{8}{8} \quad 4 \% \quad 7 \% \quad 5 \% \quad 4 \% \quad 3 \%$ $42 \% \quad 24 \% \quad 24 \% \quad 21 \% \quad 15 \% \quad 98$

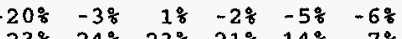
$23 \% \quad 24 \% \quad 23 \% \quad 21 \% \quad 14 \% \quad 7 \%$ 228 24\% 208 19\% $14 \%$

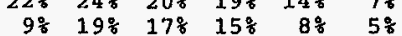
$5 \% \quad 0 \%-2 \%-98-138-11 \%$ $8 \% \quad 4 \%-2 \%-10 \%-11 \%-6 \%$ $15 \% \quad 18 \% \quad 15 \% \quad 10 \% \quad 4 \% \quad 1 \%$ 15\% $14 \% \quad 10 \% \quad 4 \% \quad 0 \%-1$ $\begin{array}{llllll}32 \% & 30 \% & 23 \% & 20 \% & 15 \% & 8 \% \\ 37 \% & 33 \% & 24 \% & 19 \% & 13 \% & 4 \%\end{array}$ $\begin{array}{llllll}35 \% & 30 \% & 23 \% & 19 \% & 12 \% & 5 \% \\ 20 \% & 22 \% & 19 \% & 16 \% & 11 \% & 6 \% \\ 29 \% & 28 \% & 22 \% & 19 \% & 12 \% & 6 \%\end{array}$ $\begin{array}{llllll}51 \% & 48 \% & 42 \% & 28 \% & 18 \% & 13 \%\end{array}$ $\begin{array}{llllll}58 \% & 42 \% & 21 \% & 11 \% & 6 \% & 38\end{array}$ $\begin{array}{llllll}52 \% & 34 \% & 16 \% & 9 \% & 5 \% & 2 \% \\ 61 \% & 41 \% & 18 \% & 9 \% & 4 \% & 0 \%\end{array}$ $\begin{array}{llllll}-10 \% & 1 \% & 8 \% & 10 \% & 10 \% & 8 \%\end{array}$ $\begin{array}{rrrrrr}-19 \% & 5 \% & 9 \% & 6 \% & 1 \% & -3 \% \\ 15 \% & 17 \% & 10 \% & 7 \% & 4 \% & 2 \%\end{array}$

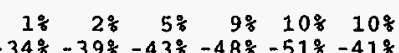
$-74-39 \%-43 \%-48 \%-51 \%-41$

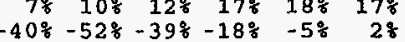

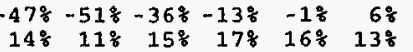

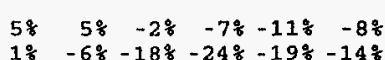
$-35 \%-26 \%-24 \%-27 \%-32 \%-33 \%$ $-448-448-468-458-498$
$2 \%-48-158-228-30 \%$ 
Table 10 (continued)

\begin{tabular}{|c|c|c|c|c|c|c|c|c|c|c|c|c|c|c|c|c|c|c|c|c|c|c|c|}
\hline \multirow[t]{2}{*}{ RunID } & \multirow{2}{*}{$\begin{array}{c}\text { Nox } \\
\text { (ppm) }\end{array}$} & \multirow{2}{*}{$\begin{array}{c}\text { ROG } \\
\text { (ppc) }\end{array}$} & \multirow{2}{*}{$\begin{array}{l}\text { Rety } \\
\text { /Nox } m\end{array}$} & \multirow{2}{*}{$\min ^{k_{1}}$} & \multirow{2}{*}{ 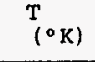 } & \multirow{2}{*}{$t=1$} & \multicolumn{4}{|c|}{ tal } & \multirow{2}{*}{$\underset{t=6}{(p p m)}$} & \multirow[b]{2}{*}{$t=1$} & \multicolumn{5}{|c|}{$d(0,-N C$} & \multicolumn{6}{|c|}{ maliz } \\
\hline & & & & & & & $t=2$ & $t=3$ & $t=c$ & $t=5$ & & & $t=2$ & $t=$ & $t=4$ & $t=5$ & $t=6$ & $t=1$ & & & & & $t=6$ \\
\hline $\mathrm{rC2} 79 \mathrm{~A}$ & .53 & 3.19 & 0.70 & & 313.4 & .067 & 0.229 & .494 & 0.869 & 1.190 & & .059 & 0.173 & 0.336 & 0.519 & 0.702 & 0.849 & $-13 \%$ & $-28 \%$ & $-38 \%$ & $-50 \%$ & $-52 \%$ & \\
\hline $280 \mathrm{~B}$ & 54 & 3.34 & 0.73 & & 311.9 & .071 & .229 & .477 & 0.821 & 1.139 & & & & 0.371 & & 0.679 & & $11 \%$ & 0 & $5 \%$ & & & \\
\hline OTC297B & 0.28 & 2.88 & 31.3 & & 308.6 & .058 & .239 & 0.572 & & 1.097 & 1.108 & .055 & 0.202 & 0.448 & .786 & 1.019 & 1.088 & $-6 i$ & $-17 \%$ & $-24 \%$ & & $-7 \%$ & $-2 \%$ \\
\hline OTC304B & 0.23 & 2.78 & $3 \quad 1.54$ & & 315.6 & 0.044 & & 0.561 & 0.905 & 1.027 & & 0.111 & 0.356 & 0.711 & 0.942 & 1.019 & 1.030 & $87 \%$ & & $24 \%$ & $4 \%$ & $-1 \%$ & \\
\hline \multicolumn{24}{|l|}{ Propene } \\
\hline ITC510 & 0.59 & 2.85 & & 0.53 & 301.5 & 0.246 & 0.573 & 0.870 & 1.069 & 1.191 & 1.270 & 0.336 & 0.770 & 1.142 & 1.372 & 1.508 & 1.571 & $31 \%$ & $29 \%$ & $27 \%$ & $25 \%$ & $23 \%$ & $21 \%$ \\
\hline ITC569 & 0.48 & 2.81 & & 0.36 & 298.8 & 0.192 & 0.435 & 0.715 & 0.960 & 1.087 & & 0.229 & 0.587 & 0.930 & 1.091 & 1.146 & 1.151 & $17 \%$ & $30 \%$ & $268^{\circ}$ & $13 \%$ & 58 & 210 \\
\hline ITC693 & 0.48 & 3.20 & & 0.35 & 301.0 & 0.239 & 0.616 & 0.955 & 1.099 & 1.146 & 1.151 & .302 & 0.808 & 1.098 & 1.161 & 1.154 & 1.146 & $23 \%$ & $27 \%$ & $14 \frac{8}{6}$ & $5 \%$ & $1 \%$ & $0 \%$ \\
\hline ITC716 & 0.53 & 3.03 & & 0.35 & 300.1 & 0.251 & 0.588 & 0.869 & 1.005 & 1.056 & 1.079 & 0.247 & 0.628 & 0.993 & 1.160 & 1.219 & 1,224 & $-2 \div$ & $7 \%$ & $13 \%$ & $14 \%$ & $24 \%$ & $13 \%$ \\
\hline ITC728 & 0.49 & 3.05 & & 0.35 & 299.2 & .221 & 0.507 & 0.794 & 0.938 & 0.996 & 1.010 & 0.267 & 0.693 & 1.023 & 1.134 & 1.147 & 1.133 & 198 & $31 \%$ & $25 \%$ & $19 \%$ & $14 \%$ & $11 \%$ \\
\hline ITC754 & 0.57 & 2.84 & & 0.35 & 299.3 & .275 & 0.557 & 0.863 & & & & .203 & 0.499 & 0.827 & 1.053 & 1.177 & 1. & $-30 \%$ & $-11 \%$ & $-4 \%$ & 5 & & \\
\hline ITC792 & 0.50 & 2.85 & & 0.35 & 296.4 & 0.240 & 0.504 & 0.789 & 0.953 & 1.046 & 1.103 & 0.224 & 0.562 & 0.886 & 1.047 & 1.105 & 1.108 & $-7 \%$ & $11 \%$ & $12 \%$ & $9 \%$ & $5 \%$ & $0 \%$ \\
\hline ITC810 & 0.52 & 2.70 & & 0.35 & 297.9 & 0.232 & 0.517 & 0.840 & 1.037 & 1.149 & 1.217 & .198 & 0.485 & 0.799 & 1.005 & 1.114 & 1.165 & $-16 \%$ & $-6 \frac{8}{8}$ & -58 & $-3 \frac{8}{8}$ & $-3 \frac{1}{8}$ & -48 \\
\hline ITC8 & 0.52 & 2.93 & & 0.35 & 298.4 & .204 & 0.419 & 0.677 & 0.855 & 0.952 & 0.987 & 0.231 & 0.580 & 0.926 & 1.102 & 1.172 & 1.183 & $12 \%$ & $32 \%$ & $31 \%$ & 258 & 218 & $18 \frac{8}{8}$ \\
\hline ITC925 & 0.56 & 3.17 & & 0.35 & 301.9 & 0.199 & 0.447 & 0.714 & 0.902 & 1.017 & 1.092 & 0.278 & 0.735 & 1.058 & 1.181 & 1.214 & 1.215 & $33 \%$ & $49 \%$ & $39 \%$ & $27 \%$ & $18 \%$ & $11 \%$ \\
\hline $\operatorname{ITC} 938$ & 0.54 & 2.42 & & 0.35 & 301.0 & 0.196 & 0.427 & 0.714 & 0.897 & 0.995 & 1.047 & 0.166 & 0.415 & 0.696 & 0.899 & 1.027 & 1.110 & $-17 \%$ & $-3 \frac{8}{6}$ & $-3 \%$ & $0 \%$ & $3 \%$ & $6 \%$ \\
\hline ITC1550 & 0.49 & 2.95 & & 0.35 & 301.3 & 0.261 & 0.697 & 0.967 & 1.063 & 1.096 & & 0.293 & 0.749 & 0.982 & 1.051 & 1.055 & & $12 \%$ & $7 \%$ & $2 \%$ & $-1 \%$ & $-4 \%$ & \\
\hline ITC1556 & 0.49 & 2.98 & & 0.35 & 300.6 & 0.207 & 0.529 & 0.868 & 1.035 & 1.113 & 1.139 & 0.278 & 0.728 & 0.997 & 1.079 & 1.086 & 1.079 & 298 & $32 \%$ & $14 \%$ & $4 \%$ & $-2 \%$ & -58 \\
\hline $\mathrm{TC2} 16$ & 0.51 & 3.99 & & 0.35 & 299.0 & 200 & 0.618 & 1.053 & 1.181 & 1.199 & 1.187 & .237 & 0.620 & .975 & 1.134 & 1.184 & 1. & $17 \%$ & $0 \%$ & $-8 \%$ & $5-4 \%$ & $-1 \frac{8}{6}$ & $-1 z$ \\
\hline ETC321 & 0.44 & 3.99 & & 0.35 & 298 & .149 & 0.478 & 0.964 & 1.142 & 1.174 & 1.165 & 258 & 0.697 & 26 & 1.118 & 1.110 & 1. & $53 \%$ & $37 \%$ & $6 \%$ & $-2 z$ & $-6 \frac{8}{8}$ & $-7 \frac{1}{6}$ \\
\hline ETC440 & 0.60 & 3.51 & & 0.35 & 299.7 & 0.178 & 0.510 & 0.977 & 1.226 & 1.310 & 1.329 & 0.264 & 0.683 & 1.093 & 1.276 & 1.337 & 1.335 & $39 \%$ & $29 \%$ & $11 \%$ & $4 \%$ & $2 \%$ & $0 \%$ \\
\hline TC061A & 0.50 & 3.36 & & .39 & 301. & 193 & 0.517 & 0.941 & 1.128 & 1.176 & 1.169 & .207 & 0.531 & 0.878 & 1.084 & 1.183 & 1,215 & 7움 & 3\% & $-7 \frac{\%}{6}$ & $-4 \%$ & $1 \%$ & $4 \%$ \\
\hline & 0 & & & 39 & 30 & & & 24 & & 1.187 & & & 04 & & & 1.212 & & $22 \%$ & 20 & $5:$ & $1 \%$ & $2 \%$ & $3 \%$ \\
\hline DTCO & 0.49 & 3.50 & & 0.39 & 301.8 & 0.300 & 0.996 & 1.237 & 1.259 & 1.242 & 1.248 & 0.371 & 0.975 & 1.218 & 1.237 & 1.216 & 1.210 & $21 \%$ & $-2 \frac{8}{6}$ & $-2 \%$ & $-2 \%$ & $-2 \frac{6}{6}$ & -38 \\
\hline DTCO & 0.49 & 3.53 & & 0.39 & 301.8 & 0.310 & 0.977 & 1.243 & 1.269 & 1.255 & 1.245 & 0.375 & 0.986 & 1.228 & 1.247 & 1.227 & 1.221 & $19 \%$ & 18 & $-1 \%$ & $-2 \frac{8}{8}$ & $-2 \frac{8}{8}$ & $-2 \%$ \\
\hline DTC060B & 0.51 & 3.60 & & 0.39 & 301.4 & 0.173 & 0.521 & 0.988 & 1.179 & & & .221 & 0.587 & 0.971 & 1.181 & 1.277 & & $24 \%$ & $12 \%$ & $-2 \frac{8}{8}$ & $0 \%$ & & \\
\hline DTC & 0.48 & 3.53 & & 0.39 & 301.2 & 0.190 & & 1.095 & 1.181 & 1.204 & 1191 & .223 & 0.606 & 0.975 & 1.154 & 1.222 & 1.232 & $16 \%$ & & $-12 \%$ & $-2 \%$ & $1:$ & 38 \\
\hline DTC063B & 0.48 & 3.57 & & 0.39 & 301.2 & 0.186 & & 1.150 & 1.185 & 1.209 & 1.200 & 0.229 & 0.625 & 0.995 & 1.166 & 1.225 & 1.232 & $21 \%$ & & $-14 \%$ & $-2 \%$ & $1 \%$ & $3 \%$ \\
\hline $\operatorname{EC} 216$ & 0.52 & 1.51 & 88 & .43 & 300 & 292 & 0.498 & 0.648 & 0.765 & 0.861 & 0.9 & .303 & 0.525 & 0.702 & 0.836 & 0.936 & 1.009 & $4 \%$ & $5 \%$ & $8 \%$ & $9 \%$ & $8 \%$ & $8 \%$ \\
\hline & & & & & & & & & & & & & & & & & & $-9 \%$ & $-5 \%$ & 48 & $10 \%$ & $12 \%$ & $15 \%$ \\
\hline $\mathrm{EC}$ & 0.52 & 1.62 & 12 & 0.35 & 301 & 219 & 0.395 & 0.526 & 0.631 & 0.715 & & 6 & 0.483 & 0. & 0.783 & 0.880 & 0.953 & 238 & $20 \%$ & $22 \%$ & $22 \%$ & $21 \%$ & $20 \%$ \\
\hline $\mathrm{EC} 23$ & 0.50 & 1.64 & .25 & 0.29 & 301.8 & 176 & 0.345 & 0.461 & 0.548 & 0.618 & 0. & .242 & 0.426 & 0.583 & 0.707 & 0.797 & 0.862 & $31 \%$ & $21 \%$ & $23 \%$ & $25 \%$ & $25 \%$ & $25 \%$ \\
\hline EC278 & 0.50 & 3.05 & 6.12 & 0.36 & 301.8 & 0.471 & 0.856 & 0.989 & 0.967 & 0.941 & 0.928 & 0.624 & 1.034 & 1.120 & 1.090 & 1.054 & 1.033 & $28 \%$ & 198 & 128 & 128 & 118 & 118 \\
\hline XTC081 & 0.56 & 4.21 & 7.55 & 0.26 & 298 & .154 & 0.426 & 0.905 & 1.221 & 1.315 & & 136 & 89 & 46 & & 56 & & $-13 \%$ & $-9 \frac{8}{6}$ & -198 & $-16 \%$ & -128 & $-10 \%$ \\
\hline & & & & & & & & & & & & & & & & & & -8 & & & & & $-12 \%$ \\
\hline & 0. & 4.63 & 8.25 & 0.26 & & 0.144 & 0.422 & 0 & 1. & & & & & & & & & $0 \%$ & 18 & $-6 \%$ & $-7 \frac{8}{6}$ & $-7 \%$ & $-7 \%$ \\
\hline XTC113 & 0.53 & 4.57 & 8.57 & 0.25 & 301.6 & 0.144 & 0.441 & 0.949 & 1.183 & 1.231 & 1.23 & 0.145 & 0.406 & 0.785 & 1.042 & 1.114 & 1.122 & $1 \%$ & $-8 \%$ & $-19 \%$ & -13 & -108 & -98 \\
\hline OT & 0 & 4 & 7 & & 3 & 0.498 & 1 & 1 & 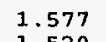 & 1 & 1.576 & 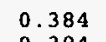 & 1 & 1 & 1 & 1 & 1 & $-26 \%$ & $-20 \%$ & -78 & $-5 \%$ & $-4 \%$ & $-4 \frac{2}{8}$ \\
\hline & 0 & & 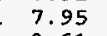 & & & & & & & & & & 1 & & & & & & $-12 \%$ & -38 & $-1 \%$ & 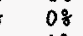 & \\
\hline OTC298A & 0.58 & 5.01 & 8.61 & & 310.6 & 0.446 & 1.363 & 1.518 & 1.555 & 1.525 & 1.533 & 0.372 & 1.207 & 1.507 & 1.565 & 1.593 & 1.585 & $-18 \%$ & $-12 \frac{8}{8}$ & $-1 \%$ & $1 \%$ & 48 & $3 \%$ \\
\hline OTC298B & 0.57 & 5.16 & 8.99 & & 310.6 & 0.334 & 1.210 & 1.436 & 1.509 & 1.546 & & 0.414 & 1.274 & 1.498 & 1.549 & 1.582 & 1.580 & $21 \%$ & $5 \%$ & $4 \frac{8}{8}$ & $3 \%$ & 28 & \\
\hline OTC295B & 0.52 & 5.62 & 10.81 & & 312 & 0.349 & 1.236 & 1.394 & 1.445 & 1.470 & & 0.665 & 1.359 & 1.423 & 1.489 & 1.521 & 1.516 & $62 \%$ & 98 & $2 \%$ & $3 \%$ & $3 \%$ & \\
\hline OTC2 $95 \mathrm{~A}$ & 0.54 & 6.64 & 12.42 & & 312.5 & 0.463 & 1.352 & 1.483 & 1.542 & 1.559 & & 0.654 & 1.381 & 1.443 & 1.490 & 1.516 & 1.514 & $34 \%$ & $2 \%$ & $-3 \frac{6}{6}$ & $-3 \frac{8}{8}$ & -38 & \\
\hline Toluene & & & & & & & & & & & & & & & & & & & & & & & \\
\hline ITC5 34 & & & & & & & 0 & & 0 & 0.824 & & & & & 7 & 0.909 & & 98 & $9 \%$ & $3 \%$ & $\%$ & $10 \%$ & \\
\hline & & & .74 & 35 & .0 & 238 & 0.592 & 850 & 0.833 & & & 0.142 & 0.482 & .733 & 0.851 & & & 50 & 200 & & $2 \%$ & & \\
\hline
\end{tabular}


Table 10 (continued)

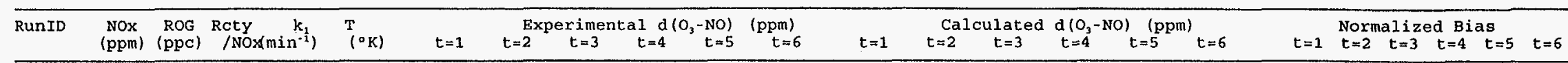

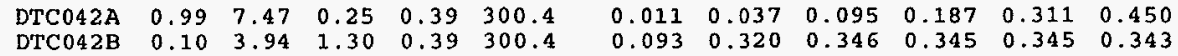

$\begin{array}{llllll}\text { EC340 } & 0.49 & 3.76 & 0.25 & 0.36 & 302.0\end{array}$

$\begin{array}{llllll}E C 269 & 0.48 & 3.96 & 0.26 & 0.34 & 301.7\end{array}$

$\begin{array}{lllllll}\text { EC327 } & 0.49 & 4.01 & 0.26 & 0.41 & 302.3\end{array}$

$\begin{array}{llllll}\mathrm{EC} 270 & 0.47 & 5.50 & 0.44 & 0.35 & 301.9\end{array}$

$\begin{array}{lllllll}5 & 0.49 & 7.49 & 0.50 & 0.40 & 302.0\end{array}$

$\begin{array}{lllllll}8 \mathrm{C} 266 & 0.44 & 8.37 & 0.62 & 0.34 & 301.7\end{array}$

$\begin{array}{llllll}E C 273 & 0.11 & 4.11 & 1.19 & 0.40 & 302.5\end{array}$

$\begin{array}{lllllll}\text { EC2 } 71 & 0.21 & 8.02 & 1.21 & 0.35 & 301.9\end{array}$

$\begin{array}{llllll}\text { XTC106 } & 0.25 & 14.49 & 1.93 & 0.25 & 300.8\end{array}$

$\begin{array}{llll}\text { OTC300A } & 0.52 & 3.59 & 0.22\end{array}$

$\begin{array}{llll}0 \text { TC299B } & 0.50 & 3.56 & 0.23\end{array}$

$\begin{array}{lll}2 & 7.99 & 0.50 \\ .52 & 3.57 & 0.52\end{array}$

$\begin{array}{llll}\text { OTC306A } & 0.5017 .18 \quad 1.12\end{array}$

311.9
311.8
318.6

311.9

311.8
318.6

\section{m-Xylene}

$\begin{array}{llllll}\text { ITC702 } & 0.50 & 4.42 & 1.00 & 0.35 & 300.8\end{array}$

$\begin{array}{lllllll}\operatorname{ETC} 222 & 0.48 & 4.11 & 0.97 & 0.35 & 299.6\end{array}$

$\begin{array}{lllllll}\text { DTC073A } & 0.48 & 1.28 & 0.23 & 0.39 & 301.5\end{array}$

$\begin{array}{lllllll}\text { DTC076B } & 0.48 & 1.41 & 0.26 & 0.39 & 301.9\end{array}$

$\begin{array}{lllllll}\text { EC344 } & 0.78 & 3.89 & 0.57 & 0.36 & 302.1 \\ \text { EC345 } & 0.31 & 3.84 & 1.38 & 0.35 & 302.0\end{array}$

$\begin{array}{llllll}\text { XTC107 } & 0.23 & 3.45 & 1.31 & 0.25 & 300.9\end{array}$

$\begin{array}{lllll}0 \text { OTC315A } & 0.47 & 2.46 & 0.53\end{array}$

$\begin{array}{llll}0 \mathrm{TC} 315 \mathrm{~B} & 0.47 & 1.62 & 0.33\end{array}$

TC308B $0.19 \quad 1.65 \quad 0.83$

303.9

303.9

1,3,5-Trimethylbenzene

$\begin{array}{llllll}\text { ITC709 } & 0.97 & 4.47 & 1.13 & 0.35 & 300.7\end{array}$ $\begin{array}{llllll}\text { ITC706 } & 0.47 & 2.49 & 1.31 & 0.35 & 300.2 \\ \text { ITC703 } & 0.49 & 5.02 & 2.49 & 0.35 & 301.2\end{array}$

$\begin{array}{lllllll}\text { EC903 } & 1.01 & 4.91 & 1.19 & 0.27 & 301.8\end{array}$

$\begin{array}{llllll}\operatorname{XTC103} & 0.50 & 3.02 & 1.34 & 0.26 & 301.2\end{array}$

Mint-Surrogate (High Nox)

$\begin{array}{lllllll}\text { ETC415 } & 0.53 & 4.71 & 0.79 & 0.35 & 298.4\end{array}$ $\begin{array}{llllll}\text { ETC225 } & 0.50 & 4.40 & 0.80 & 0.35 & 298.7\end{array}$ $\begin{array}{llllll}0.176 & 0.346 & 0.469 & 0.569 & 0.682\end{array}$ $\begin{array}{lllllll}0.155 & 0.318 & 0.423 & 0.509 & 0.596 & 0.687\end{array}$ $\begin{array}{lllllll}0.147 & 0.329 & 0.460 & 0.571 & 0.681 & 0.755\end{array}$ $\begin{array}{lllllll}0.250 & 0.441 & 0.566 & 0.674 & 0.771 & 0.779\end{array}$ $\begin{array}{lllll}0.450 & 0.737 & 0.808 & 0.770 & 0.7\end{array}$

$\begin{array}{lllllll}0.237 & 0.521 & 0.748 & 0.783 & 0.756 & 0.727\end{array}$ $\begin{array}{lllllll}0.290 & 0.300 & 0.293 & 0.289 & 0.289 & 0.279\end{array}$ $\begin{array}{lllllll}0.399 & 0.468 & 0.439 & 0.421 & 0.410 & 0.400\end{array}$

$\begin{array}{llllll}0.149 & 0.573 & 0.602 & 0.579 & 0.557\end{array}$

$\begin{array}{llllll}0.034 & 0.140 & 0.345 & 0.538 & 0.687\end{array}$

$\begin{array}{llllll}0.021 & 0.140 & 0.377 & 0.368 & 0.496 & \\ 0.072 & 0.484 & 0.960 & 1.012 & 0.960 & 0.898\end{array}$

$\begin{array}{lllll}0.042 & 0.268 & 0.551 & 0.612 & 0.603\end{array}$

$\begin{array}{lllll}0.097 & 0.558 & 0.987 & 0.984 & 0.933 \\ 0.420 & 0.951 & 0.931 & 0.872 & 0.814\end{array}$

$0.462 \quad 0.856 \quad 1.007 \quad 1.009$

$\begin{array}{lllllll}0.182 & 0.656 & 0.959 & 1.034 & 1.020 & 1.004\end{array}$

$\begin{array}{llllllll}0.021 & 0.100 & 0.214 & 0.310 & 0.380 & 0.433\end{array}$

$\begin{array}{lllllll}0.699 & 1.052 & 1.172 & 1.133 & 1.109 & 1.089\end{array}$ $\begin{array}{lllllll}0.625 & 0.610 & 0.587 & 0.571 & 0.565 & 0.563\end{array}$

$\begin{array}{llllll}0.194 & 0.547 & 0.658 & 0.657 & 0.653\end{array}$

$\begin{array}{llllll}0.078 & 0.476 & 0.763 & 0.930 & 0.991\end{array}$

$\begin{array}{lllll}0.025 & 0.145 & 0.372 & 0.507 & 0.593 \\ 0.046 & 0.265 & 0.464 & 0.578 & 0.651\end{array}$

$\begin{array}{lllllll}0.103 & 0.394 & 0.572 & 0.635 & 0.664\end{array}$

$\begin{array}{llllll}0.718 & 1.076 & 1.261 & 1.391 & 1.490 & 1.542\end{array}$ $\begin{array}{llll}0.446 & 0.698 & 0.851 & 0.941 \\ 0.820 & 1.074 & 1.064 & 1.055\end{array}$

$\begin{array}{llllll}0.861 & 1.108 & 1.238 & 1.274 & 1.247 & 1.238\end{array}$

$\begin{array}{llllll}0.303 & 0.772 & 0.992 & 1.067 & 1.081 & 1.085\end{array}$

$\begin{array}{llllll}0.032 & 0.120 & 0.248 & 0.366 & 0.483 & 0.596\end{array}$ $\begin{array}{lllllll}0.035 & 0.113 & 0.225 & 0.337 & 0.441 & 0.547\end{array}$ $\begin{array}{llllllllllll}0.011 & 0.037 & 0.095 & 0.187 & 0.311 & 0.450 & 0.016 & 0.071 & 0.182 & 0.323 & 0.450 & 0.548 \\ 0.093 & 0.320 & 0.346 & 0.345 & 0.345 & 0.343 & 0.184 & 0.332 & 0.346 & 0.356 & 0.364 & 0.371\end{array}$ $\begin{array}{lllll}0.108 & 0.245 & 0.362 & 0.452 & 0.526\end{array}$

$\begin{array}{llllll}0.110 & 0.257 & 0.380 & 0.471 & 0.545 & 0.617\end{array}$ $\begin{array}{lllllll}0.131 & 0.288 & 0.412 & 0.507 & 0.595 & 0.693 \\ 0.229 & 0.416 & 0.536 & 0.637 & 0.739 & 0.785\end{array}$ $\begin{array}{lllllll}0.229 & 0.416 & 0.536 & 0.637 & 0.739 & 0.785\end{array}$ $\begin{array}{lllllll}0.254 & 0.505 & 0.699 & 0.781 & & \end{array}$ $\begin{array}{lllllll}0.254 & 0.502 & 0.690 & 0.776 & 0.762 & 0.752\end{array}$ $\begin{array}{lllllll}0.215 & 0.360 & 0.373 & 0.379 & 0.384 & 0.389 \\ 0.282 & 0.499 & 0.516 & 0.507 & 0.504 & 0.504\end{array}$ $\begin{array}{lllllll}0.077 & 0.276 & 0.450 & 0.541 & 0.540 & 0.539\end{array}$ $\begin{array}{lllllll}0.024 & 0.111 & 0.259 & 0.398 & 0.497 & 0.566\end{array}$ $\begin{array}{llllll}0.017 & 0.077 & 0.197 & 0.325 & 0.421 & 0.482 \\ 0.129 & 0.515 & 0.905 & 0.980 & 0.960 & 0.935 \\ 0.053 & 0.222 & 0.424 & 0.551 & 0.565 & 0.562\end{array}$ $\begin{array}{lllllll}0.053 & 0.222 & 0.424 & 0.551 & 0.566 & 0.562\end{array}$ $\begin{array}{llllll}0.058 & 0.326 & 0.636 & 0.896 & 0.916 & 0.904 \\ 0.421 & 0.948 & 0.970 & 0.944 & 0.912 & 0.885\end{array}$

$\begin{array}{llll}0.438 & 0.833 & 0.918 & 0.921\end{array}$

$\begin{array}{lllllll}0.338 & 0.718 & 0.864 & 0.860 & 0.862 & 0.865\end{array}$ $\begin{array}{lllllll}0.026 & 0.125 & 0.239 & 0.315 & 0.363 & 0.395\end{array}$ $\begin{array}{lllllll}0.462 & 0.656 & 0.635 & 0.623 & 0.618 & 0.616\end{array}$ $\begin{array}{lllllll}0.061 & 0.246 & 0.393 & 0.520 & 0.560 & 0.563\end{array}$ $\begin{array}{lllllll}0.039 & 0.273 & 0.486 & 0.618 & 0.702 & 0.724\end{array}$ $\begin{array}{lllllll}0.017 & 0.107 & 0.262 & 0.379 & 0.441 & 0.458 \\ 0.019 & 0.124 & 0.317 & 0.453 & 0.537 & 0.591\end{array}$ $\begin{array}{lllllll}0.072 & 0.272 & 0.450 & 0.515 & 0.532 & 0.539\end{array}$

$\begin{array}{llllll}0.742 & 1.157 & 1.401 & 1.534 & 1.589 & 1.614\end{array}$ $\begin{array}{lllll}0.458 & 0.717 & 0.847 & 0.888 \\ 0.818 & 0.919 & 0.916 & 0.919\end{array}$

$\begin{array}{llllll}0.697 & 1.007 & 1.215 & 1.355 & 1.397 & 1.394 \\ 0.433 & 0.639 & 0.772 & 0.827 & 0.837 & 0.848\end{array}$

$\begin{array}{lllllll}0.056 & 0.195 & 0.346 & 0.469 & 0.574 & 0.679\end{array}$ $\begin{array}{lllllll}0.052 & 0.179 & 0.318 & 0.436 & 0.542 & 0.650\end{array}$ $\begin{array}{lllllllll}0.482 & 0.808 & 1.031 & 1.187 & 1.205 & 1.190\end{array}$ $\begin{array}{llllll}0.213 & 0.543 & 0.721 & 0.852 & 0.895 & 0.905\end{array}$ $\begin{array}{rrrrrr}36 \% & 63 \% & 63 \% & 53 \% & 37 \% & 20 \% \\ 66 \% & 4 \% & 0 \% & 3 \% & 5 \% & 8 \%\end{array}$ $-488-34 \%-26 \%-23 \%-26 \%$ $-34 \%-21 \%-11 \%-8 \%-9 \%-11 \%$

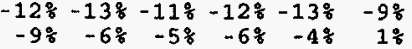

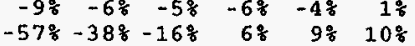
$6 \%-4 \%-11 \%-1 \%$ $\begin{array}{rrrrrr}7 \% & -4 \% & -8 \% & -1 \% & 1 \% & 3 \% \\ -30 \% & 18 \% & 24 \% & 27 \% & 28 \% & 33 \%\end{array}$

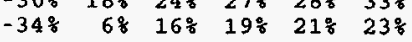
$-648-708-29 \%-7 \%-3 \%$

$-33 \%-24 \%-29 \%-30 \%-32 \%$ $\begin{array}{r}-23 \% \\ 57 \%\end{array} 6 \frac{-34 \%}{-6 \%}-13 \%-16 \%$ $238-198-268-10 \%-6 \%$

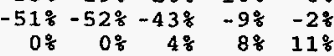

$-5 \%-3 \%-9 \%-9 \%$ $60 \% \quad 9 \%-10 \%-18 \%-17 \%-15 \%$ $\begin{array}{rllllr}22 \% & 22 \% & 11 \% & 2 \% & -4 \% & -9 \% \\ 97 \% & 71 \% & 43 \% & 23 \% & 11 \% & 3 \%\end{array}$

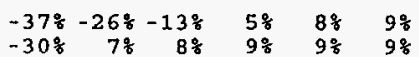
$-104 \%-76 \%-51 \%-23 \%-15 \%$ $-67 \%-54 \%-44 \%-40 \%-34 \%$ $-37 \%-30 \%-35 \%-29 \%-29 \%$ $-368-37 \%-24 \div-21 \%-228$ $\begin{array}{rrrrrr}38 & 7 \% & 11 \% & 10 \% & 6 \% & 5 \% \\ 38 & 3 \% & 0 \% & -6 \% & -8 \% & -7 \% \\ 0 \% & -168 & -15 \% & -14 \% & & \end{array}$

$\begin{array}{rrrrrr}-21 \% & -10 \% & -2 \% & 6 \% & 11 \% & 12 \% \\ -12 \% & -48 & 0 \% & 11 \% & 12 \% & 29 \%\end{array}$ $-35 \%-35 \%-32 \%-22 \%-19 \%-18 \%$

$\begin{array}{llllll}55 \% & 48 \% & 33 \% & 25 \% & 17 \% & 13 \%\end{array}$ 
Table 10 (continued)

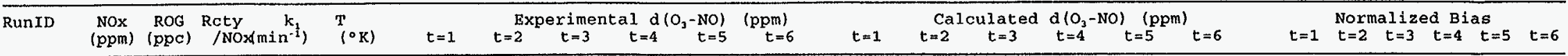

$\begin{array}{llllll}\text { ETC231 } & 0.50 & 4.72 & 0.83 & 0.35 & 299.1 \\ \text { ETC210 } & 0.50 & 4.78 & 0.82 & 0.35 & 299.3\end{array}$ $\begin{array}{llllll}\text { ETC210 } & 0.50 & 4.78 & 0.82 & 0.35 & 299.3 \\ \text { ETC215 } & 0.48 & 4.59 & 0.80 & 0.35 & 299.7\end{array}$ $\begin{array}{llllll}\text { ETC215 } & 0.48 & 4.59 & 0.80 & 0.35 & 299.7 \\ \text { ETC260 } & 0.49 & 4.60 & 0.84 & 0.35 & 300.0\end{array}$ $\begin{array}{llllll}\operatorname{ETC240} & 0.48 & 4.18 & 0.78 & 0.35 & 300.2\end{array}$ $\begin{array}{lllllll}\text { ETC170 } & 0.51 & 4.54 & 0.78 & 0.35 & 300.9 \\ \text { ETC236 } & 0.50 & 4.31 & 0.77 & 0.35 & 301.3\end{array}$ $\begin{array}{llllll}\operatorname{ETC2} 98 & 0.49 & 4.46 & 0.82 & 0.35 & 301.9\end{array}$ $\begin{array}{lllllll}\text { ETC326 } & 0.53 & 4.66 & 0.79 & 0.35 & 302.4\end{array}$ $\begin{array}{llllll}\text { ETC286 } & 0.48 & 4.28 & 0.80 & 0.35 & 302.6\end{array}$ \begin{tabular}{lllllll}
\hline $1 C 330$ & 0.50 & 4.59 & 0.83 & 0.35 & 302.8
\end{tabular} ETC345 $0.52 \quad 4.850 .840 .35303$. $\begin{array}{llllll}0.48 & 4.72 & 0.89 & 0.35 & 3030\end{array}$ $\begin{array}{llllll}\text { ETC373 } & 0.48 & 4.72 & 0.89 & 0.35 & 310.1 \\ & 0.56 & 4.71 & 0.77 & 0.35 & 312.3\end{array}$

$\begin{array}{llllll}\text { xTC104 } & 0.51 & 3.83 & 0.65 & 0.25 & 301.2\end{array}$ Min1-Surrogate (Low NOx)

$\begin{array}{llllll}\text { ETC403 } & 0.15 & 3.41 & 2.02 & 0.35 & 298.9\end{array}$ $\begin{array}{llllll}\text { ETC405 } & 0.13 & 3.68 & 2.44 & 0.35 & 298.9 \\ \text { ETC395 } & 0.14 & 3.91 & 2.41 & 0.35 & 299.0\end{array}$ $\begin{array}{llllll}\text { ETC392 } & 0.15 & 3.65 & 2.10 & 0.35 & 299.5\end{array}$ $\begin{array}{llllll}\text { ETC390 } & 0.14 & 3.92 & 2.38 & 0.35 & 299.7\end{array}$ $\begin{array}{lllllll} & 0.15 & 3.73 & 2.24 & 0.35 & 29.7\end{array}$ $\begin{array}{lllll}0.15 & 3.93 & 2.35 & 0.35 & 299.7\end{array}$ $\begin{array}{llllll}\text { ETC388 } & 0.15 & 3.78 & 2.27 & 0.35 & 300.8\end{array}$ Fullsurrogate $\begin{array}{llllll}\text { DTC011B } & 0.52 & 3.78 & 0.74 & 0.39 & 300.7 \\ \text { DTC011A } & 0.52 & 3.91 & 0.75 & 0.39 & 300.7\end{array}$ $\begin{array}{llllll}\text { DTC069B } & 0.48 & 3.65 & 0.76 & 0.39 & 301.5\end{array}$ $\begin{array}{lllllll}\text { DTC 068A } & 0.48 & 3.80 & 0.78 & 0.39 & 301 .\end{array}$ $\begin{array}{lllllll}\text { DTC022A } & 0.50 & 4.01 & 0.79 & 0.39 & 300.3\end{array}$ $\begin{array}{llllll}D T C 016 \mathrm{~B} & 0.48 & 3.92 & 0.80 & 0.39 & 300.2\end{array}$ $\begin{array}{llllll}\text { DTC017B } & 0.48 & 3.94 & 0.80 & 0.39 & 300.1\end{array}$ $\begin{array}{lllllll} & 0.48 & 3.94 & 0.80 & 0.39 & 300.1\end{array}$

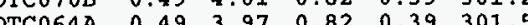
$\begin{array}{lllllll}\text { DTC014B } & 0.48 & 3.99 & 0.82 & 0.39 & 300.6\end{array}$ $\begin{array}{llllll}\text { DTC065B } & 0.48 & 3.95 & 0.83 & 0.39 & 301.3\end{array}$ $\begin{array}{lllllll}\text { DTC021A } & 0.49 & 4.15 & 0.84 & 0.39 & 300.1\end{array}$ $\begin{array}{lllllll}\text { DTC028B } & 0.49 & 4.11 & 0.85 & 0.39 & 300.9\end{array}$ $\begin{array}{llllll}\text { DTC018B } & 0.48 & 4.23 & 0.85 & 0.39 & 300.6\end{array}$ $\begin{array}{llllllll}\text { DTCO13B } & 0.45 & 4.00 & 0.87 & 0.39 & 300.6\end{array}$

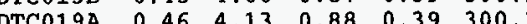
$\begin{array}{llllllll}D T C 013 A & 0.45 & 4.11 & 0.89 & 0.39 & 300.3\end{array}$ $\begin{array}{llllll}\text { DTC025B } & 0.47 & 4.19 & 0.90 & 0.39 & 301.7\end{array}$

$\begin{array}{llllll}\text { DTC066A } & 0.17 & 3.80 & 2.16 & 0.39 & 301.6 \\ \text { DTC071A } & 0.18 & 3.97 & 2.18 & 0.39 & 301.7\end{array}$ $\begin{array}{llllll}0.039 & 0.134 & 0.264 & 0.388 & 0.502 & 0.633\end{array}$ $\begin{array}{llllll}0.034 & 0.131 & 0.271 & 0.398 & 0.531 & 0.661 \\ 0.036 & 0.131 & 0.264 & 0.388 & 0.508 & 0.643\end{array}$ $\begin{array}{lllllll}0.044 & 0.145 & 0.281 & 0.411 & 0.546 & 0.696\end{array}$ $\begin{array}{lllllll}0.030 & 0.116 & 0.234 & 0.356 & 0.480 & 0.621\end{array}$ $\begin{array}{lllllll}0.044 & 0.156 & 0.292 & 0.429 & 0.572 & 0.724 \\ 0.040 & 0.143 & 0.277 & 0.407 & 0.539 & 0.693\end{array}$ $\begin{array}{llllll}0.045 & 0.180 & 0.348 & 0.511 & 0.688 & 0.88\end{array}$ $\begin{array}{lllllll}0.068 & 0.213 & 0.370 & 0.524 & 0.680 & 0.854\end{array}$ $\begin{array}{llllll}0.037 & 0.152 & 0.308 & 0.462 & 0.641 & 0.842\end{array}$ $\begin{array}{lllllllll}0.058 & 0.210 & 0.387 & 0.558 & 0.731 & 0.912\end{array}$ $\begin{array}{lllllll}0.042 & 0.169 & 0.340 & 0.505 & 0.693 & 0.902\end{array}$ $\begin{array}{lllllll}0.089 & 0.274 & 0.465 & 0.672 & 0.907 & 0.902\end{array}$ $\begin{array}{lllllll}0.089 & 0.274 & 0.465 & 0.672 & 0.993 & 0.902 \\ 0.088 & 0.278 & 0.491 & 0.724 & 0.976 & 1.195\end{array}$

$\begin{array}{lllllll}0.029 & 0.107 & 0.233 & 0.365 & 0.479 & 0.575\end{array}$

$0.049 \quad 0.189$ $\begin{array}{lll}0.499 & 0.583 & 0.619\end{array}$ $\begin{array}{lllllll}0.053 & 0.213 & 0.393 & 0.527 & 0.590 & 0.613\end{array}$ $\begin{array}{llllll}0.058 & 0.236 & 0.437 & 0.573 & 0.637 & 0.656 \\ 0.061 & 0.235 & 0.439 & 0.582 & 0.652 & 0.675\end{array}$ $\begin{array}{llllll}0.043 & 0.225 & 0.424 & 0.555 & 0.616 & 0.63\end{array}$ $\begin{array}{lllllll}0.058 & 0.230 & 0.421 & 0.544 & 0.516 & 0.637 \\ 0.062 & 0.225 & 0.405 & 0.556 & 0.636 & 0.6773\end{array}$ $\begin{array}{lllllll}0.042 & 0.200 & 0.387 & 0.527 & 0.590 & 0.597\end{array}$ $\begin{array}{lllllll}0.058 & 0.211 & 0.390 & 0.521 & 0.591 & 0.618 \\ 0.067 & 0.253 & 0.452 & 0.576 & 0.631 & 0.646\end{array}$

$\begin{array}{lllllll}0.184 & 0.388 & 0.513 & 0.607 & 0.694 & 0.780\end{array}$ $\begin{array}{lllll}0.184 & 0.388 & 0.513 & 0.607 & 0.694 \\ 0.177 & 0.380 & 0.506 & 0.598 & 0.681\end{array}$ $\begin{array}{lllllll}0.175 & 0.370 & 0.490 & 0.583 & 0.671 & 0.750\end{array}$ $\begin{array}{lllllll}0.155 & 0.340 & 0.464 & 0.555 & 0.638 & 0.722\end{array}$ $\begin{array}{lllllll}0.193 & 0.400 & 0.519 & 0.612 & 0.693 & 0.771 \\ 0.197 & 0.404 & 0.524 & 0.618 & 0.702 & 0.783\end{array}$ $\begin{array}{lllllll}0.195 & 0.398 & 0.518 & 0.610 & 0.695 & 0.779\end{array}$ $\begin{array}{llllll}0.195 & 0.398 & 0.518 & 0.610 & 0.695 & 0.779 \\ 0.205 & 0.407 & 0.530 & 0.629 & 0.724 & 0.816\end{array}$ $\begin{array}{lllllll}0.179 & 0.474 & 0.494 & 0.580 & 0.661 & 0.740 \\ 0.176 & 0.381 & 0.507 & 0.598 & 0.683 & 0.765\end{array}$ $\begin{array}{lllllll}0.176 & 0.381 & 0.507 & 0.598 & 0.683 & 0.765 \\ 0.205 & 0.409 & 0.528 & 0.623 & 0.716 & 0.803\end{array}$ $\begin{array}{lllllll}0.169 & 0.368 & 0.491 & 0.582 & 0.667 & 0.749\end{array}$ $\begin{array}{lllllll}0.201 & 0.407 & 0.524 & 0.610 & 0.693 & 0.772\end{array}$ $\begin{array}{llllll}0.179 & 0.385 & 0.512 & 0.611 & 0.704 & 0.799\end{array}$ $\begin{array}{lllllll}0.230 & 0.437 & 0.557 & 0.655 & 0.747 & 0.837\end{array}$ $\begin{array}{lllllll}0.208 & 0.406 & 0.525 & 0.620 & 0.716 & \end{array}$ $\begin{array}{llllll}0.190 & 0.392 & 0.509 & 0.602 & 0.688 & 0.771\end{array}$ $\begin{array}{lllllll}0.199 & 0.400 & 0.512 & 0.606 & 0.699 & 0.787 \\ 0.198 & 0.402 & 0.528 & 0.635 & 0.743 & 0.848\end{array}$ $\begin{array}{lllllll}0.318 & 0.490 & 0.567 & 0.594 & 0.599 & 0.600\end{array}$ $\begin{array}{lllllll}0.319 & 0.490 & 0.568 & 0.597 & 0.603 & 0.606\end{array}$ $\begin{array}{lllllll}0.055 & 0.190 & 0.336 & 0.459 & 0.573 & 0.692\end{array}$ $\begin{array}{llllllll}0.053 & 0.187 & 0.336 & 0.450 & 0.573 & 0.692 & 0.573\end{array}$ $\begin{array}{llllllll}0.052 & 0.179 & 0.322 & 0.447 & 0.565 & 0.695\end{array}$ $\begin{array}{llllllll}0.048 & 0.163 & 0.295 & 0.408 & 0.511 & 0.618\end{array}$ $\begin{array}{lllllll}0.054 & 0.188 & 0.335 & 0.458 & 0.570 & 0.684\end{array}$ $\begin{array}{lllllll}0.051 & 0.174 & 0.312 & 0.430 & 0.538 & 0.650\end{array}$ $\begin{array}{llllllll}0.056 & 0.174 & 0.312 & 0.430 & 0.538 & 0.650\end{array}$ $\begin{array}{lllllll}0.068 & 0.227 & 0.389 & 0.522 & 0.645 & 0.775\end{array}$ $\begin{array}{llllll}0.060 & 0.210 & 0.366 & 0.498 & 0.630 & 0.772\end{array}$ $\begin{array}{llllllll}0.074 & 0.249 & 0.423 & 0.567 & 0.710 & 0.7963\end{array}$ $\begin{array}{lllllll}0.061 & 0.210 & 0.367 & 0.500 & 0.632 & 0.776\end{array}$ $\begin{array}{llllll}0.110 & 0.324 & 0.515 & 0.704 & 0.906 & 1.100 \\ 0.097 & 0.303 & 0.497 & 0.678 & 0.876 & 1.084\end{array}$

$\begin{array}{lllllll}0.021 & 0.066 & 0.136 & 0.222 & 0.308 & 0.387\end{array}$

$\begin{array}{lllllll}0.088 & 0.242 & 0.411 & 0.549 & 0.615 & 0.635\end{array}$ $\begin{array}{lllllll}0.108 & 0.286 & 0.466 & 0.567 & 0.601 & 0.604\end{array}$ $\begin{array}{lllllll}0.108 & 0.291 & 0.477 & 0.583 & 0.617 & 0.618 \\ 0.092 & 0.249 & 0.423 & 0.570 & 0.648 & 0.677\end{array}$ $\begin{array}{llllll}0.092 & 0.249 & 0.423 & 0.570 & 0.648 & 0.677 \\ 0.110 & 0.294 & 0.481 & 0.588 & 0.624 & 0.627\end{array}$ $\begin{array}{llllllll}0.120 & 0.313 & 0.504 & 0.614 & 0.651 & 0.653\end{array}$ $\begin{array}{lllllll}0.121 & 0.308 & 0.500 & 0.625 & 0.675 & 0.685\end{array}$ $\begin{array}{llllll}0.115 & 0.306 & 0.497 & 0.600 & 0.632 & 0.634\end{array}$ $\begin{array}{lllllll}0.089 & 0.237 & 0.394 & 0.531 & 0.609 & 0.642 \\ 0.112 & 0.298 & 0.488 & 0.601 & 0.642 & 0.650\end{array}$

$\begin{array}{lllllll}0.200 & 0.373 & 0.476 & 0.548 & 0.607 & 0.662\end{array}$ $\begin{array}{llllll}0.197 & 0.372 & 0.480 & 0.555 & 0.620 & 0.681\end{array}$ $\begin{array}{llllll}0.197 & 0.370 & 0.476 & 0.556 & 0.627 & 0.696\end{array}$ $\begin{array}{lllllll}0.199 & 0.371 & 0.477 & 0.557 & 0.632 & 0.707 \\ 0.210 & 0.389 & 0.496 & 0.573 & 0.641 & 0.706\end{array}$ $\begin{array}{llllll}0.210 & 0.389 & 0.496 & 0.573 & 0.641 & 0.706 \\ 0.200 & 0.371 & 0.473 & 0.545 & 0.605 & 0.661\end{array}$ $\begin{array}{lllllll}0.200 & 0.371 & 0.473 & 0.545 & 0.641 & 0.706 \\ 0.203 & 0.374 & 0.476 & 0.550 & 0.614 & 0.674\end{array}$ $\begin{array}{lllllll}0.218 & 0.400 & 0.509 & 0.591 & 0.665 & 0.737\end{array}$ $\begin{array}{lllllll}0.217 & 0.403 & 0.515 & 0.601 & 0.680 & 0.757\end{array}$ $\begin{array}{llllll}0.216 & 0.400 & 0.510 & 0.594 & 0.671 & 0.745\end{array}$ $\begin{array}{lllllll}0.209 & 0.385 & 0.490 & 0.566 & 0.633 & 0.695\end{array}$ $\begin{array}{lllllll}0.220 & 0.404 & 0.514 & 0.600 & 0.638 & 0.7956 \\ 0.230 & 0.411 & 0.518 & 0.599 & 0.672 & 0.741\end{array}$ $\begin{array}{lllllll}0.228 & 0.416 & 0.528 & 0.616 & 0.696 & 0.772\end{array}$ $\begin{array}{lllllll}0.220 & 0.405 & 0.513 & 0.595 & 0.667 & 0.735\end{array}$ $\begin{array}{lllllll}0.225 & 0.408 & 0.516 & 0.599 & 0.675 & 0.748\end{array}$ $\begin{array}{llllll}0.215 & 0.390 & 0.494 & 0.572 & 0.643 & 0.708\end{array}$ $\begin{array}{llllll}0.218 & 0.397 & 0.503 & 0.585 & 0.660 & 0.731\end{array}$ $\begin{array}{llllll}0.218 & 0.395 & 0.499 & 0.580 & 0.652 & 0.719 \\ 0.235 & 0.424 & 0.541 & 0.638 & 0.731 & 0.817\end{array}$ $\begin{array}{lllllllll}0.313 & 0.477 & 0.557 & 0.580 & 0.593 & 0.605\end{array}$ $\begin{array}{llllll}0.313 & 0.477 & 0.557 & 0.580 & 0.593 & 0.605 \\ 0.325 & 0.493 & 0.574 & 0.596 & 0.609 & 0.623\end{array}$
$35 \% \quad 35 \% \quad 24 \% \quad 17 \% \quad 13 \% \quad 9 \%$ $44 \% \quad 40 \%$ 27\% $18 \%$ 12\% $17 \%$ 21\% $14 \%$ 8\% $3 \frac{3 \%}{6 \%}$ $46 \% \quad 34 \% \quad 23 \% \quad 14 \% \quad 6 \%$ $\begin{array}{llllll}21 \% & 18 \% & 14 \% & 7 \% & 0 \% & -6 \% \\ 25 \% & 20 \% & 12 \% & 6 \% & 0 \% & -6 \%\end{array}$ $39 \% \quad 27 \%$ 14\% $5 \%-3 \% \quad-9 \%$ $\begin{array}{rrrrrr}0 \% & 6 \% & 5 \% & 0 \% & -5 \% & -10 \% \\ 48 \% & 32 \% & 17 \% & 8 \% & -2 \% & -9 \%\end{array}$ $\begin{array}{rrrrrr}48 \% & 32 \% & 17 \% & 8 \% & -28 & -9 \% \\ 22 \% & 15 \% & 6 \% & 0 \% & -5 \% & -10 \%\end{array}$

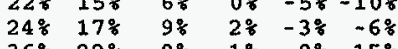
$36 \% \quad 22 \% \quad 8 \%-1 \%-9 \%-15 \%$ $\begin{array}{rrrrrr}21 \% & 17 \% & 10 \% & 5 \% & 0 \% & -4 \% \\ 10 \% & 9 \% & 1 \% & -7 \% & -11 \% & -10 \%\end{array}$ $-33 \div-48 \div-52 \%-49 \div-43 \%-39 \%$

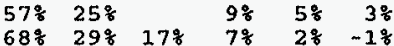
$60 \% 21 \% \quad 9 \% \quad 28-3 \frac{8}{6}-6 \%$ $\begin{array}{llllll}40 \% & 68 & -4 \% & -28 & -1 \% & 0 \% \\ 878 & 278 & 138 & 68 & 18 & -28\end{array}$ $\begin{array}{rrrrrr}70 \% & 30 \% & 18 \% & 12 \% & 18 \% & -2 \% \\ 60 \% & 10 \% & 8 \%\end{array}$ $93 \% \quad 428 \quad 25 \% \quad 13 \% \quad 7 \% \quad 6 \%$ $\begin{array}{rrrrrr}42 \% & 11 \% & 1 \% & 2 \% & 3 \% & 4 \% \\ 50 \% & 16 \% & 8 \% & 4 \% & 2 \% & 1 \%\end{array}$

$9 \%-4 \%-7 \%-10 \%-13 \%-16 \%$ $\begin{array}{llllll}11 \% & -28 & -58 & -78 & -98 & \\ 12 \% & 0 \% & -3 \% & -58 & -78 & -78\end{array}$ $25 \% \quad 98 \quad 38 \quad 080-18-28$

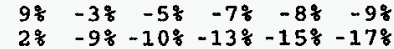

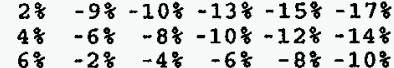
$19 \% \quad 8 \% \quad 4 \% \quad 4 \% \quad 3 \% \quad 2 \%$

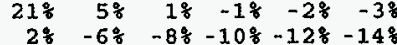
$26 \% \quad 98 \quad 5 \% \quad 3 \% \quad 28 \quad 1 \%$ $\begin{array}{rrrrrr}13 \% & 1 \% & -1 \frac{8}{6} & -2 \% & -38 & -4 \% \\ 24 \% & 8 \% & 3 \% & 1 \% & -18 & -3 \%\end{array}$

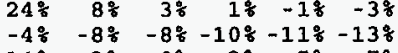
$148 \quad 38 \quad 0 \%-28-58-78$ $3 \%-4 \%-68-8 \%-118$ $14 \% \quad 18-1 \%-3 \%-4 \%-5 \%$ $\begin{array}{rrrrrr}14 \% & 18 & -38 & -3 \% & -48 & -58 \\ 17 \% & 5 \% & 2 \% & 1 \% & -2 \% & -4 \%\end{array}$ $\begin{array}{rrrrrr}-1 \% & -3 \% & -2 \% & -2 \% & -1 \% & 1 \% \\ 28 & 1 \% & 18 & 0 \% & 1 \% & 3 \%\end{array}$ 
Table 10 (continued)

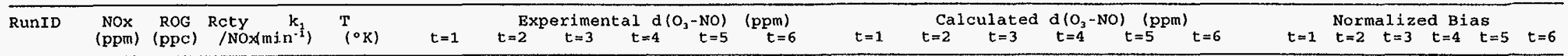

$\begin{array}{llllllllllll}\text { DTC067A } & 0.17 & 3.84 & 2.20 & 0.39 & 301.4 & 0.308 & 0.481 & 0.558 & 0.587 & 0.595 & 0.597\end{array}$ $\begin{array}{llllll}\text { DTCO38B } & 0.17 & 3.91 & 2.29 & 0.39 & 300.7\end{array}$ $\begin{array}{llllll}\text { DTC035B } & 0.17 & 3.98 & 2.36 & 0.39 & 300.6\end{array}$ DTC03 $0.18 \quad 4.35 \quad 2.380 .39 \quad 300.4$ DTC037A $0.17 \quad 4.25 \quad 2.43 \quad 0.39 \quad 300.6$ $\begin{array}{lllllll}\text { DTC032A } & 0.17 & 4.21 & 2.44 & 0.39 & 300.4\end{array}$ $\begin{array}{llllll}\text { DTC029B } & 0.17 & 4.27 & 2.46 & 0.39 & 301.0\end{array}$ $\begin{array}{lllllll}\text { DTC034A } & 0.16 & 3.96 & 2.46 & 0.39 & 300.9\end{array}$ $\begin{array}{lllll}0.17 & 4.15 & 2.46 & 0.39 & 300.3\end{array}$

$\begin{array}{llllll}\text { ITC885 } & 0.64 & 1.39 & 0.29 & 0.35 & 295.2 \\ \text { ITC881 } & 0.67 & 2.27 & 0.38 & 0.35 & 295.9\end{array}$

$\begin{array}{llllll}\text { ITC881 } & 0.67 & 2.27 & 0.38 & 0.35 & 295.9 \\ \text { ITC631 } & 0.32 & 1.05 & 0.42 & 0.35 & 299.6\end{array}$

$\begin{array}{llllll}\text { ITC635 } & 1.19 & 4.01 & 0.44 & 0.35 & 299.5 \\ \text { ITC88 } & 0.66 & 2.34 & 0.47 & 0.35 & 295.4\end{array}$

$\begin{array}{llllll}\operatorname{ITC880} & 0.66 & 2.34 & 0.47 & 0.35 & 295.4 \\ \operatorname{ITC} 873 & 0.37 & 1.20 & 0.51 & 0.35 & 295.9\end{array}$

$\begin{array}{llllll}\text { ITC873 } & 0.37 & 1.20 & 0.51 & 0.35 & 295.9 \\ \text { ITC874 } & 0.36 & 2.05 & 0.60 & 0.35 & 295.6\end{array}$

$\begin{array}{llllll}\text { ITC874 } & 0.36 & 2.05 & 0.60 & 0.35 & 295.6 \\ \text { ITC872 } & 0.36 & 2.12 & 0.68 & 0.35 & 297.2\end{array}$

$\begin{array}{lllllll}\text { ITC872 } & 0.36 & 2.12 & 0.68 & 0.35 & 295.6 \\ \text { ITC877 } & 0.38 & 2.53 & 0.70 & 0.35 & 295.6\end{array}$

$\begin{array}{llllll}\text { ITC871 } & 0.37 & 1.97 & 0.79 & 0.35 & 296.2\end{array}$

$\begin{array}{llllll}\text { ITC630 } & 0.31 & 1.93 & 0.79 & 0.35 & 298.3 \\ \text { ITC633 } & 0.61 & 3.94 & 0.82 & 0.35 & 298.7\end{array}$

$\begin{array}{lllllll}\text { ITC868 } & 0.37 & 2.49 & 1.07 & 0.35 & 296.4\end{array}$

$\begin{array}{llllll}\text { ITC688 } & 0.32 & 3.61 & 1.26 & 0.35 & 295.9 \\ \text { ITC637 } & 0.30 & 3.93 & 1.70 & 0.35 & 299.0\end{array}$

$\begin{array}{llllll}\text { ITC637 } & 0.30 & 3.93 & 1.70 & 0.35 & 299.0 \\ \text { ITC626 } & 0.29 & 4.07 & 1.74 & 0.35 & 296.0\end{array}$

$\begin{array}{llllll}\text { ITC626 } & 0.29 & 4.07 & 1.74 & 0.35 & 296.0 \\ \text { ITC891 } & 0.32 & 4.18 & 1.78 & 0.35 & 296.2\end{array}$

$\begin{array}{llllll}\text { ITC8 91 } & 0.32 & 4.18 & 1.78 & 0.35 & 296.2 \\ \text { ITC865 } & 0.31 & 4.51 & 2.04 & 0.35 & 296.0\end{array}$

$\begin{array}{llllll}\text { EC241 } & 0.47 & 4.97 & 0.86 & 0.28 & 302.3\end{array}$

$\begin{array}{llllll}E C 238 & 0.91 & 10.10 & 0.90 & 0.29 & 302.5\end{array}$

$\begin{array}{llllll}\text { EC246 } & 0.48 & 8.56 & 0.91 & 0.29 & 302.3 \\ \text { EC232 } & 0.48 & 9.31 & 0.97 & 0.29 & 301.8\end{array}$

$\begin{array}{llllll}\mathrm{EC} 232 & 0.48 & 9.31 & 0.97 & 0.29 & 301.8 \\ \mathrm{EC} 231 & 0.68 & 13.17 & 1.42 & 0.29 & 301.7\end{array}$

$\begin{array}{lllllll}E C 247 & 0.48 & 6.17 & 1.50 & 0.29 & 302.2\end{array}$

$\begin{array}{llllll}E C 245 & 0.94 & 12.86 & 1.57 & 0.29 & 302.2\end{array}$

$\begin{array}{llllll}\mathrm{EC} 242 & 0.46 & 12.83 & 3.18 & 0.29 & 302.1 \\ \mathrm{EC} 233 & 0.09 & 9.50 & 5.06 & 0.29 & 301.5\end{array}$

$\begin{array}{llllll}\text { XTC114 } & 0.48 & 4.70 & 1.04 & 0.25 & 301.0\end{array}$

$\begin{array}{llll}\text { OTC314A } & 0.58 & 4.62 & 0.75\end{array}$

$\begin{array}{llll}0 \text { TC314B } & 0.57 & 4.52 & 0.75 \\ 0 & 0.75\end{array}$

OTC313B 0.50

OTC311B 0.4

OTC312B 0.58

0.86
0.83
0.81

302.3
302.3
304.0

304.0

\begin{tabular}{ll} 
OTC310A $\quad 0.22$ \\
\hline
\end{tabular}

1.89

304.0
313.4

316.6

314.2 $\begin{array}{lllllll}0.338 & 0.507 & 0.573 & 0.593 & 0.603 & 0.606\end{array}$ $\begin{array}{lllllllll}0.3430 & 0.509 & 0.573 & 0.593 & 0.603 & 0.606\end{array}$ $\begin{array}{lllllll}0.368 & 0.539 & 0.569 & 0.590 & 0.596 & 0.598\end{array}$ $\begin{array}{llllll}0.343 & 0.514 & 0.583 & 0.605 & 0.610 & 0.612 \\ 0.334 & 0.505 & 0.577 & 0.599 & 0.604 & 0.608\end{array}$ $\begin{array}{lllllll}0.364 & 0.537 & 0.605 & 0.628 & 0.634 & 0.638 \\ 0.330 & 0.503 & 0.573 & 0.597 & 0.600 & 0.602\end{array}$ $\begin{array}{llllll}0.330 & 0.503 & 0.573 & 0.597 & 0.600 & 0.602 \\ 0.342 & 0.512 & 0.582 & 0.604 & 0.612 & 0.615\end{array}$ $\begin{array}{llllll}0.342 & 0.512 & 0.582 & 0.604 & 0.612 & 0.615 \\ 0.351 & 0.520 & 0.590 & 0.612 & 0.618 & 0.621\end{array}$

$\begin{array}{lllllll}0.028 & 0.056 & 0.081 & 0.108 & 0.133 & 0.158\end{array}$ $\begin{array}{lllllll}0.047 & 0.098 & 0.147 & 0.181 & 0.215 & 0.248\end{array}$ $\begin{array}{lllllll}0.038 & 0.077 & 0.106 & 0.120 & 0.153 & 0.170\end{array}$ $\begin{array}{llllll}0.068 & 0.129 & 0.185 & 0.233 & 0.279 & 0.312 \\ 0.051 & 0.100 & 0.152 & 0.197 & 0.239 & 0.277\end{array}$ $\begin{array}{llllll}0.051 & 0.100 & 0.152 & 0.197 & 0.239 & 0.277 \\ 0.059 & 0.119 & 0.162 & 0.199 & 0.239 & 0.274\end{array}$ $\begin{array}{llllll}0.059 & 0.119 & 0.162 & 0.199 & 0.239 & 0.274 \\ 0.057 & 0.114 & 0.160 & 0.210 & 0.246 & 0.275\end{array}$ $\begin{array}{lllllll}0.087 & 0.163 & 0.223 & 0.264 & 0.304 & 0.339\end{array}$ $\begin{array}{lllllll}0.093 & 0.162 & 0.227 & 0.266 & 0.309 & 0.340\end{array}$ $\begin{array}{lllllll}0.075 & 0.159 & 0.226 & 0.288 & 0.346 & 0.400\end{array}$ $\begin{array}{lllllll}0.068 & 0.128 & 0.181 & 0.223 & 0.269 & 0.308\end{array}$ $\begin{array}{llllll}0.083 & 0.170 & 0.246 & 0.314 & 0.371 & 0.421 \\ 0.150 & 0.275 & 0.388 & 0.470 & 0.549 & 0.611\end{array}$ $\begin{array}{llllll}0.150 & 0.276 & 0.388 & 0.470 & 0.549 & 0.611 \\ 0.088 & 0.194 & 0.292 & 0.395 & 0.488 & 0.568\end{array}$ $\begin{array}{lllllll}0.088 & 0.194 & 0.292 & 0.435 & 0.488 & 0.511 \\ 0.132 & 0.280 & 0.420 & 0.543 & 0.649 & 0.711\end{array}$ $\begin{array}{lllllll}0.124 & 0.262 & 0.394 & 0.525 & 0.6436 & 0.730\end{array}$ $\begin{array}{lllllll}0.126 & 0.309 & 0.483 & 0.638 & 0.745 & 0.808 \\ 0.126 & 0.298 & 0.476 & 0.621 & 0.730 & 0.796\end{array}$ $\begin{array}{llllll}0.173 & 0.337 & 0.454 & 0.562 & 0.660 & 0.759\end{array}$ $\begin{array}{llllll}0.346 & 0.612 & 0.811 & 0.968 & 1.128 & 1.279\end{array}$ $\begin{array}{llllllll}0.190 & 0.350 & 0.461 & 0.550 & 0.638 & 0.726\end{array}$ $\begin{array}{lllllll}0.390 & 0.368 & 0.500 & 0.596 & 0.6770 & 0.747\end{array}$ $\begin{array}{lllllll}0.433 & 0.768 & 0.975 & 1.002 & 0.958\end{array}$ $\begin{array}{llllll}0.773 & 1.364 & 1.585 & 1.512 & 1.396 & 1.332\end{array}$ $\begin{array}{llllll}0.430 & 0.738 & 0.944 & 1.005 & 0.979 & 0.936\end{array}$ $\begin{array}{llllll}0.895 & 1.020 & 0.915 & 0.834 & 0.789 & 0.767 \\ 0.239 & 0.356 & 0.403 & 0.413 & 0.411 & 0.409\end{array}$ $\begin{array}{lllllll}0.152 & 0.381 & 0.530 & 0.618 & 0.698 & 0.770\end{array}$ $\begin{array}{llllll}0.088 & 0.316 & 0.533 & 0.651 & 0.721\end{array}$ $\begin{array}{lllll}0.088 & 0.3168 & 0.533 & 0.651\end{array}$ $\begin{array}{llllll}0.143 & 0.419 & 0.620 & 0.757 & 0.842\end{array}$ $\begin{array}{llllll}0.137 & 0.407 & 0.615 & 0.770 & 0.880\end{array}$ $\begin{array}{lllllll}0.121 & 0.418 & 0.651 & 1.006 & 0.999\end{array}$

$\begin{array}{lllllll}0.298 & 0.570 & 0.704 & 0.747 & 0.741 & 0.726\end{array}$ $\begin{array}{llllll}0.316 & 0.480 & 0.553 & 0.573 & 0.585 & 0.596\end{array}$ $\begin{array}{llllll}0.329 & 0.488 & 0.551 & 0.567 & 0.577 & 0.586 \\ 0.337 & 0.494 & 0.556 & 0.572 & 0.582 & 0.592\end{array}$ $\begin{array}{llllll}0.340 & 0.496 & 0.551 & 0.563 & 0.572 & 0.580\end{array}$ $\begin{array}{lllllll}0.364 & 0.524 & 0.582 & 0.593 & 0.601 & 0.609\end{array}$ $\begin{array}{lllllll}0.359 & 0.517 & 0.571 & 0.582 & 0.591 & 0.600\end{array}$ $\begin{array}{llllll}0.359 & 0.517 & 0.565 & 0.574 & 0.583 & 0.591\end{array}$ $\begin{array}{llllll}0.363 & 0.522 & 0.571 & 0.582 & 0.592 & 0.601 \\ 0.347 & 0.501 & 0.556 & 0.572 & 0.582 & 0.591\end{array}$ $\begin{array}{llllll}0.347 & 0.501 & 0.556 & 0.571 & 0.582 & 0.591 \\ 0.352 & 0.506 & 0.552 & 0.562 & 0.570 & 0.579\end{array}$ $\begin{array}{llllll}0.352 & 0.506 & 0.552 & 0.562 & 0.570 & 0.579 \\ 0.368 & 0.523 & 0.566 & 0.577 & 0.587 & 0.596\end{array}$

$\begin{array}{lllllll}0.015 & 0.035 & 0.057 & 0.079 & 0.099 & 0.118\end{array}$ $\begin{array}{lllllll}0.045 & 0.093 & 0.133 & 0.165 & 0.191 & 0.212\end{array}$ $\begin{array}{llllll}0.017 & 0.044 & 0.073 & 0.099 & 0.122 & 0.143 \\ 0.043 & 0.114 & 0.193 & 0.266 & 0.329 & 0.381\end{array}$ $\begin{array}{lllllll}0.043 & 0.114 & 0.193 & 0.266 & 0.329 & 0.381 \\ 0.026 & 0.066 & 0.110 & 0.153 & 0.192 & 0.225\end{array}$ $\begin{array}{lllllll}0.026 & 0.066 & 0.110 & 0.153 & 0.192 & 0.225 \\ 0.021 & 0.052 & 0.084 & 0.114 & 0.141 & 0.165\end{array}$ $\begin{array}{llllll}0.021 & 0.052 & 0.084 & 0.114 & 0.141 & 0.165 \\ 0.022 & 0.054 & 0.087 & 0.119 & 0.148 & 0.174\end{array}$ $\begin{array}{llllll}0.074 & 0.142 & 0.194 & 0.236 & 0.270 & 0.299\end{array}$ $\begin{array}{lllllll}0.077 & 0.152 & 0.210 & 0.255 & 0.293 & 0.325\end{array}$ $\begin{array}{llllll}0.037 & 0.095 & 0.155 & 0.210 & 0.259 & 0.301\end{array}$ $\begin{array}{lllllll}0.039 & 0.106 & 0.174 & 0.234 & 0.286 & 0.333\end{array}$ $\begin{array}{llllll}0.052 & 0.174 & 0.291 & 0.393 & 0.478 & 0.553 \\ 0.052 & 0.133 & 0.217 & 0.296 & 0.369 & 0.435\end{array}$ $\begin{array}{lllllll}0.043 & 0.104 & 0.169 & 0.235 & 0.299 & 0.361\end{array}$ $\begin{array}{lllllll}0.105 & 0.292 & 0.485 & 0.653 & 0.776 & 0.854\end{array}$ $\begin{array}{llllll}0.107 & 0.298 & 0.493 & 0.658 & 0.773 & 0.838\end{array}$ $\begin{array}{lllllll}0.102 & 0.281 & 0.474 & 0.641 & 0.765 & 0.851 \\ 0.123 & 0.348 & 0.587 & 0.765 & 0.871 & 0.924\end{array}$ $\begin{array}{lllllll}0.200 & 0.366 & 0.497 & 0.614 & 0.728 & 0.834\end{array}$ $\begin{array}{lllllll}0.401 & 0.709 & 0.934 & 1.145 & 1.340 & 1.495\end{array}$ $\begin{array}{lllllll}0.191 & 0.340 & 0.459 & 0.559 & 0.654 & 0.746\end{array}$ $0.5280 .870 \quad 1.448 \quad 1.300 \quad 1.315 \quad 0.832$ $\begin{array}{llllll}0.458 & 0.760 & 0.977 & 1.047 & 1.024 & \end{array}$ $\begin{array}{llllll}0.909 & 1.419 & 1.634 & 1.565 & 1.427 & 1.326\end{array}$ $\begin{array}{lllllll}0.469 & 0.812 & 1.042 & 1.126 & 1.114 & 1.065\end{array}$ $\begin{array}{llllll}0.948 & 1.054 & 0.941 & 0.834 & 0.774 & 0.745 \\ 0.303 & 0.439 & 0.499 & 0.523 & 0.532 & 0.533\end{array}$ $\begin{array}{lllllll}0.123 & 0.290 & 0.425 & 0.515 & 0.587 & 0.655\end{array}$ $\begin{array}{lllllll}0.075 & 0.231 & 0.392 & 0.500 & 0.562 & 0.592\end{array}$ $\begin{array}{lllllll}0.074 & 0.228 & 0.392 & 0.505 & 0.574 & 0.606\end{array}$ $\begin{array}{lllllll}0.094 & 0.274 & 0.448 & 0.567 & 0.643 & 0.677\end{array}$ $\begin{array}{llllll}0.135 & 0.345 & 0.522 & 0.655 & 0.749 & 0.787 \\ 0.135 & 0.394 & 0.593 & 0.751 & 0.879 & 0.950\end{array}$ $\begin{array}{llllll}0.136 & 0.394 & 0.593 & 0.751 & 0.879 & 0.950 \\ 0.157 & 0.462 & 0.733 & 0.987 & 1.202 & 1.282\end{array}$ $\begin{array}{lllllll}0.286 & 0.582 & 0.764 & 0.835 & 0.852 & 0.846\end{array}$

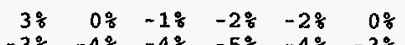
$\begin{array}{llllll}-3 \% & -4 \frac{8}{6} & -4 \% & -5 \% & -4 \% & -3 \% \\ -1 \% & -3 \% & -4 \% & -5 \% & -4 \% & -3 \%\end{array}$ $\begin{array}{rrrrrr}3 \% & -1 \% & -3 \frac{6}{6} & -5 \frac{8}{8} & -4 \% & -3 \% \\ -1 \% & -3 \% & -4 \% & & -5 \% & -3 \%\end{array}$

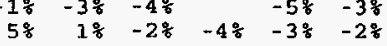
$0 \%-3 \%-6 \%-8 \%-7 \%-6 \%$

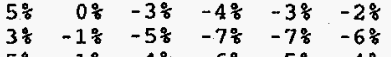
$-62 \%-46 \%-34 \%-31 \%-29 \%-29 \%$ $-4 \%-6 \%-10 \%-9 \%-12 \%-16 \%$ $-74 \%-54 \%-37 \%-19 \%-22 \%-18 \%$

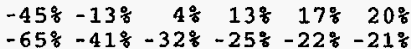
$-65 \%-41 \%-32 \%-25 \%-22 \%-21 \%$
$-95 \%-79 \%-64 \%-54 \%-51 \%-50 \%$ $-88 \%-72 \%-59 \%-56 \%-50 \%-45 \%$ $-16 \%-14 \%-14 \%-11 \%-12 \%-13 \%$

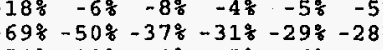
$-548-19 \%-4 \frac{8}{8} \quad 5 \% \quad 6 \% \quad 8 \%$ $-29 \% \quad 2 \% \quad 17 \% \quad 22 \% \quad 25 \% \quad 27 \%$ $-96 \%-70 \%-56 \%-45 \%-39 \%-34 \%$
$-68 \%-60 \%-53 \%-51 \%-48 \%-45 \%$ $-68 \%-60 \%-53 \%-51 \%-48 \%-45 \%$ $-15 \% 13 \% 22 \% \quad 22 \% 19 \% 18 \%$ $\begin{array}{rrrrrr}-15 \% & 13 \% & 22 \% & 22 \% & 19 \% & 14 \% \\ -21 \% & -9 \% & -2 \% & 0 \% & 3 \% & 5 \% \\ -3 \% & 15 \% & 21 \% & 21 \% & 18 \% & 15 \%\end{array}$ $\begin{array}{llllll}14 \% & 8 \% & 9 \% & 9 \% & 10 \% & 9 \%\end{array}$ $\begin{array}{llllll}158 & 15 \% & 14 \% & 17 \% & 17 \% & 16 \%\end{array}$ $\begin{array}{rrrrrr}0 \% & -3 \% & -18 & 2 \% & 3 \% & 3 \% \\ -6 \% & -6 \% & 0 \% & 4 \% & 8 \% & 11 \%\end{array}$ $\begin{array}{llllll}30 \% & 11 \% & 15 \% & 22 \% & 26 \% & 27 \%\end{array}$ $\begin{array}{rrrrr}30 \% & 11 \% & 0 \% & 4 \% & 7 \%\end{array}$ $16 \% \quad 4 \% \quad 3 \% \quad 3 \% \quad 2 \% \quad 0 \%$ $19 \%$

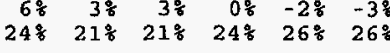
$-21 \%-27 \%-22 \%-18 \%-17 \%-16 \%$

$-16 \%-31 \%-31 \%-26 \%-25 \%$ $-3 \%-20 \%-25 \%-22 \%$
$-41 \%-42 \%-328-29 \%-27 \%$ $-18-16 \%-16 \%-16 \%-16 \%$
$12 \%-6 \%-98$
$0 \%-13 \%$ $12 \%-6 \%-98$
$0 \%-14 \%-15 \%-12 \%-6 \%$ $-4 \% \quad 2 \% \quad 8 \% \quad 11 \% \quad 14 \% \quad 15 \%$

* Rcty $=$ oH reactivity in propene equivalents. 
FORMALDEHYDE

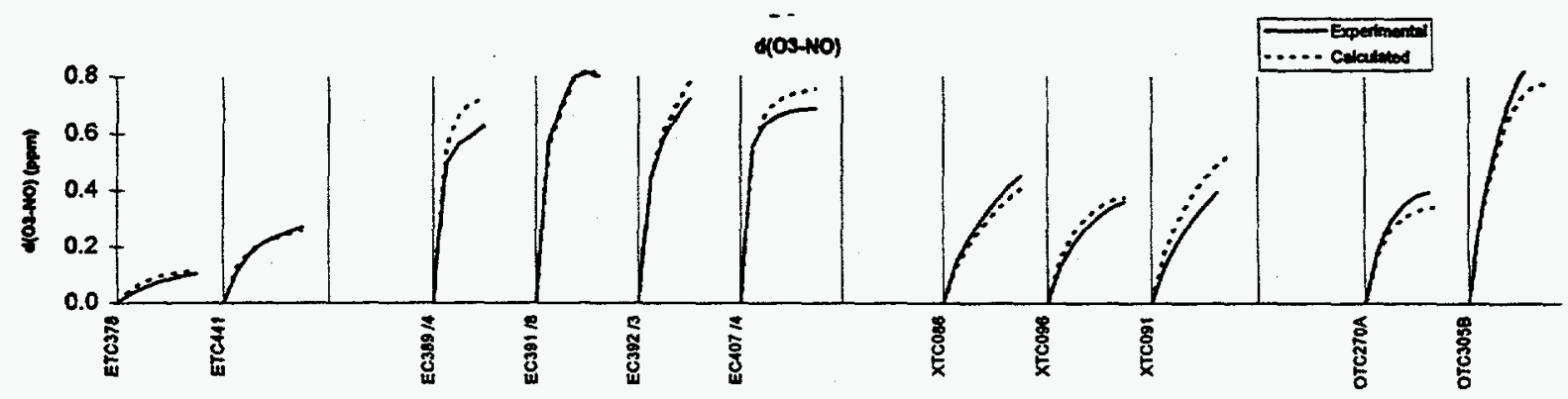

d $(03+\mathrm{NO}$ ) model error

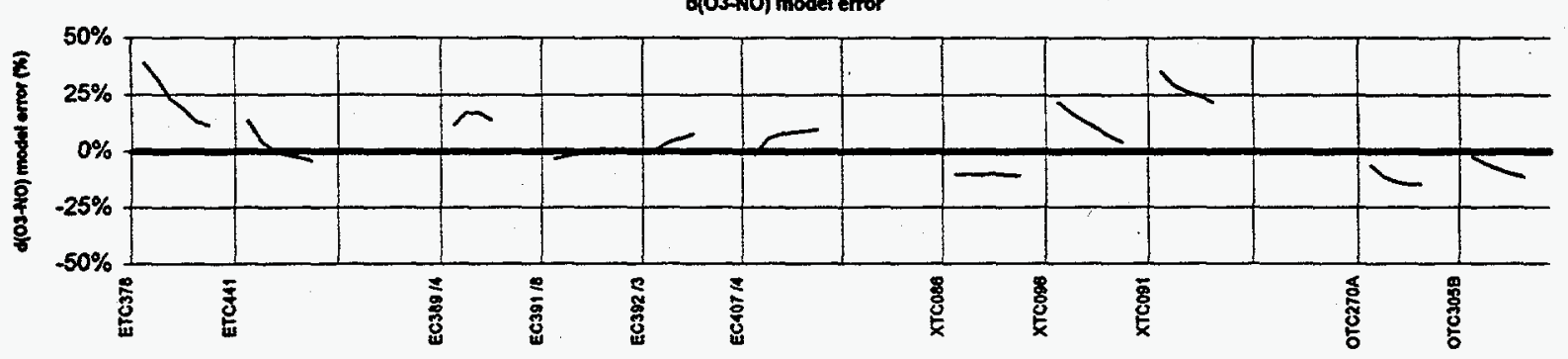

ACETALDEHYDE
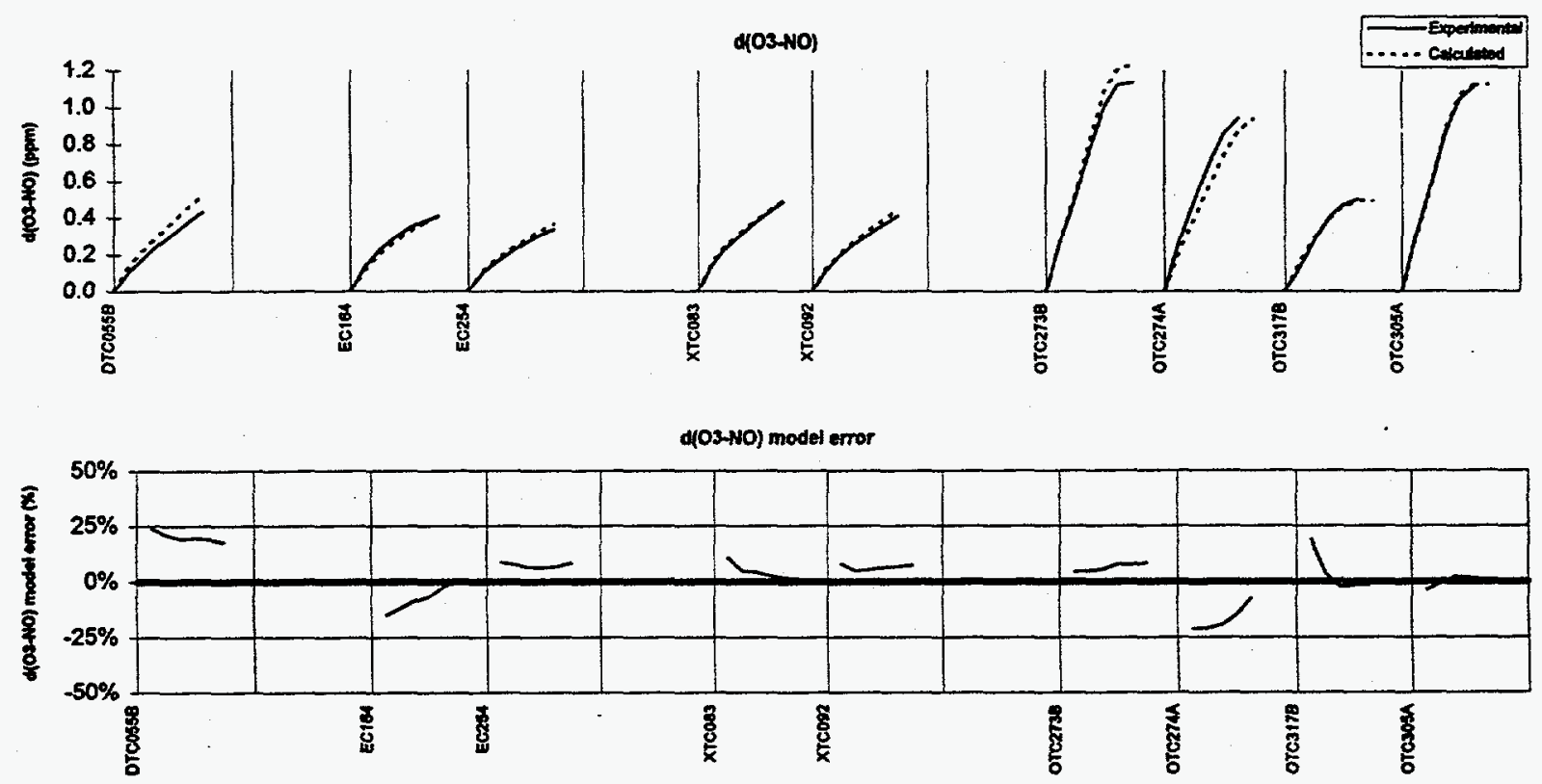
Figure 20. Results of model simulations of $\mathrm{d}\left(\mathrm{O}_{3}-\mathrm{NO}\right)$ in the formaldehyde - $\mathrm{NO}_{x}$
and the acetaldehyde - $\mathrm{NO}_{x}$ experiments. 
The consistency in the results between the EC and XTC experiments, which have similar light sources but different types of chamber walls, indicate that there is no apparent wall effect influencing the model performance for these compounds. Wall effects, particularly the chamber radical source, are probably not very important in affecting simulations of these compounds, since their photooxidation processes are driven primarily by their photolysis reactions. The EC formaldehyde experiments were carried out at approximately an order of magnitude higher formaldehyde and $\mathrm{NO}_{x}$ concentrations in the other chambers, which would also be expected to minimize chamber wall effects.

The lack of a significant light source effect on the model performance in simulating the formaldehyde and acetaldehyde experiments is important because both of these compounds are photoreactive, and their photolysis is a major factor determining their effect on $\mathrm{O}_{3}$ formation and No oxidation. The model apparently is properly taking into account the differences in the light source characteristics in the simulations of these experiments.

\section{Ethene}

Figure 21 shows the model performance in simulating the ethene experiments in the blacklight chambers, and Figure 22 shows the results of simulations of the xenon arc or blacklight chamber runs. A large number of experiments are shown for the ETC because ethene - $\mathrm{NO}_{\mathrm{x}}$ runs were used as the "base case" in a number of incremental reactivity experiments (Carter et al., 1995b). These replicate experiments are shown on the middle part of the plots on Figure 21 for the ETC runs, with the three runs at lower ethene/ $\mathrm{NO}_{x}$ ratios being to the left and the run at higher ethene/ $\mathrm{NO}_{x}$ being to the right. The DTC runs consist essentially of duplicates of a low and high $\mathrm{ROG} / \mathrm{NO}_{x}$ experiment. Other than these replicate experiments, which are listed in order they were carried out, the experiments from a given chamber are listed in order of increasing ethene/ $\mathrm{NO}_{\mathbf{x}}$ ratio.

Figures 21 and 22 show that model performance in simulating the ethene runs was variable and depended on the chamber. The simulations of the ETC and ITC runs generally gave fits to within $\pm 25 \%$, with no apparent consistent bias.

However, for the DTC, whose conditions should be essentially the same as the ETC, there appears to be a consistent bias towards overpredicting the initial No oxidation rates, though the final $\mathrm{O}_{3}$ yields are generally very well predicted. This difference between the may be due to the model using too high a radical source in the DTC simulations. However, the butane runs in the DTC indicate the that the model is using the appropriate radical source for that chamber, and the bias in the DTC ethene simulations is not completely eliminated if the lower radical source indicated by the ETC n-butane runs is used. The consistency in the model predictions between the $40 \% \mathrm{RH}$ ITC experiments and the drY ETC runs suggest that humidity is not affecting model performance. 
ETHENE (ETC)

(20s-no)
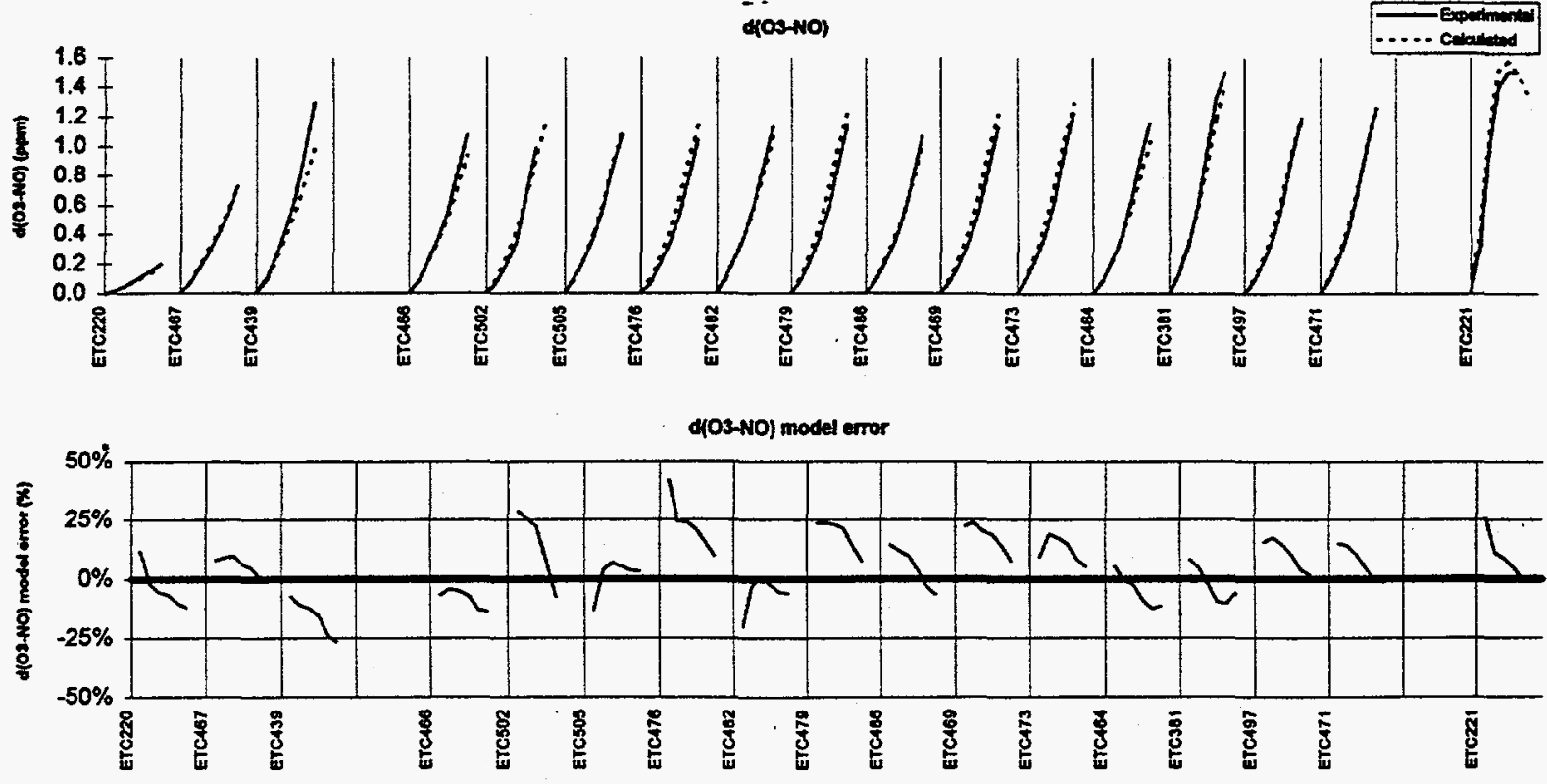

ETHENE (DTC, ITC)
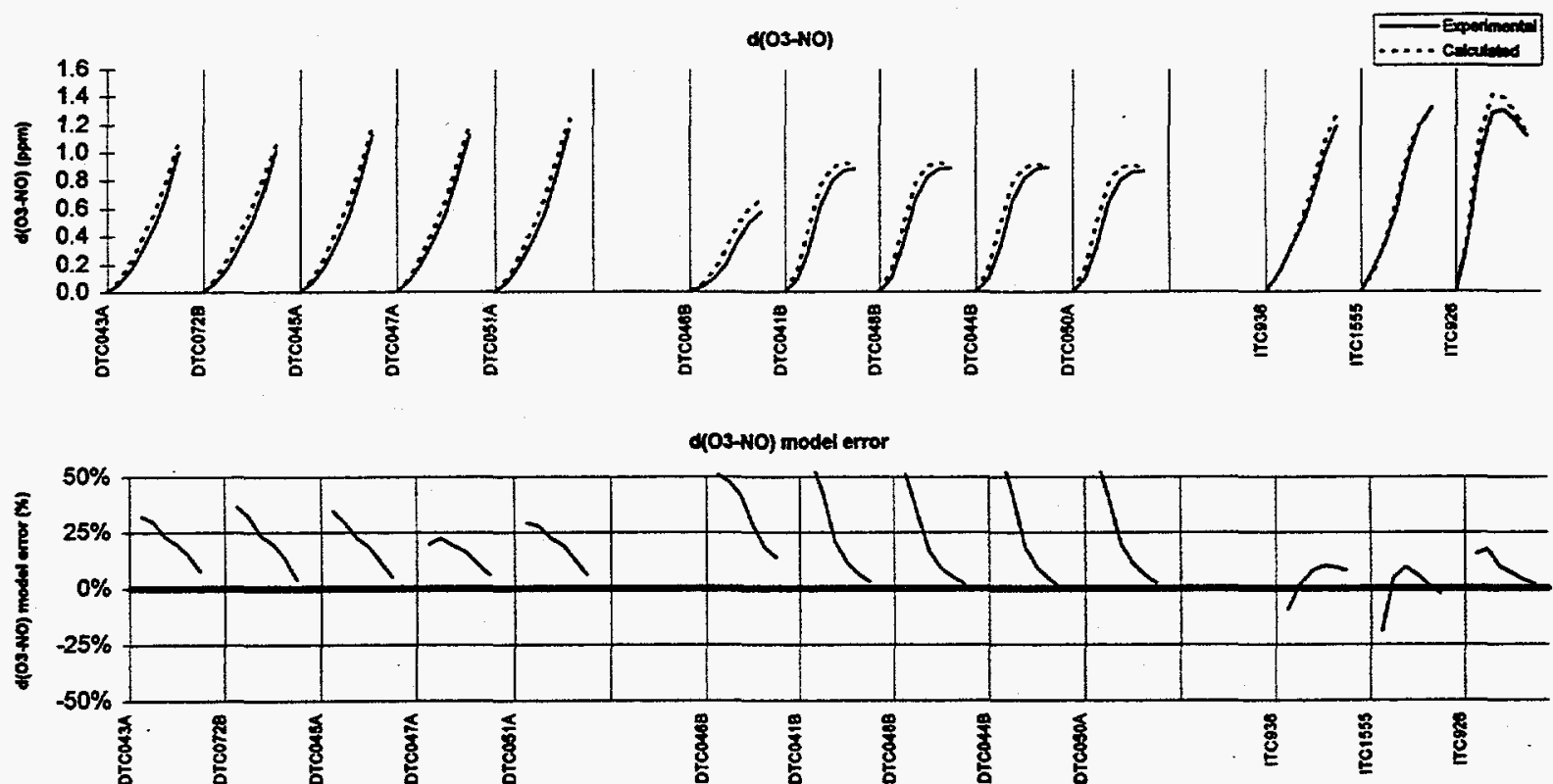

Figure 21. Results of model simulations of $\mathrm{d}\left(\mathrm{O}_{3}-\mathrm{NO}\right)$ in the ethene - $\mathrm{NO}_{\mathrm{x}}$ experiments carried out in the blacklight chambers. The runs are ordered by ROG/NO $\mathrm{NO}_{x}$ except for the 13 replicate ETC experiments (middle of top plot), which are ordered by temperature. 
ETHENE (EC, XTC, OTC)
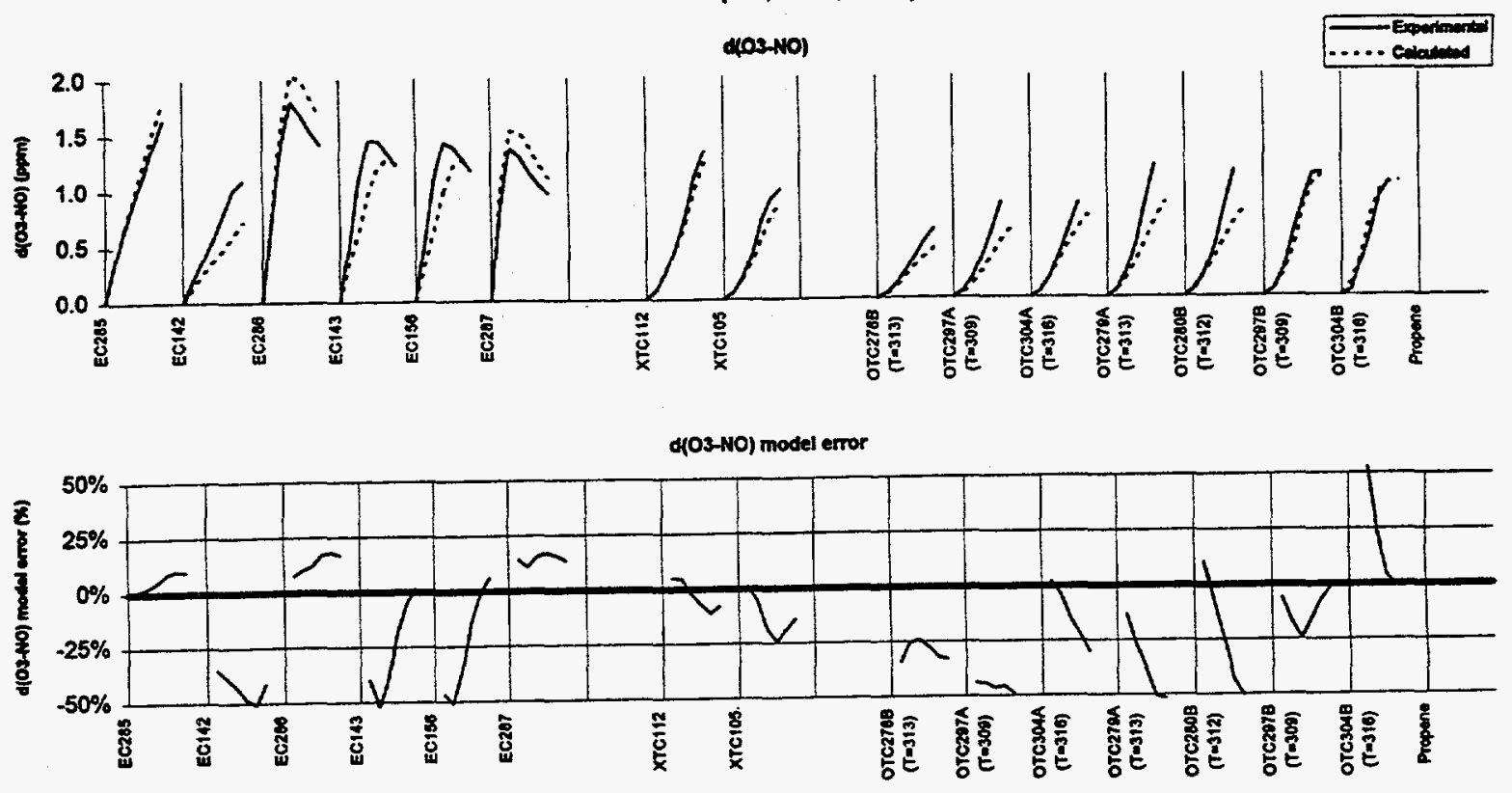

Figure 22. Results of model simulations of $\mathrm{d}\left(\mathrm{O}_{3}-\mathrm{NO}\right)$ in the ethene - $\mathrm{NO}_{x}$ experiment carried out in the xenon arc or outdoor chambers. Runs are ordered by $\mathrm{ROG} / \mathrm{NO}_{\mathrm{x}}$.

The model performance in simulating the ethene runs in the xenon arc and outdoor chambers is variable. The performance for the XTC runs is reasonably good, indicating that the model is properly accounting for the difference in light source in that chamber compared to the ETC. However, the model performance in simulating the EC runs, which use the same type of light source but have a different surface and $50 \% \mathrm{RH}$, is highly variable, with $250 \%$ underprediction in either $d\left(\mathrm{O}_{3}-\mathrm{NO}\right)$ formation rates of maximum $\mathrm{O}_{3}$ concentrations in half the experiments. The model performance is unsatisfactory for the outdoor runs, significantly underpredicting the $d\left(\mathrm{O}_{3}-\mathrm{NO}\right)$ formation rates in all the experiments except the two at the highest ethene/NO ratios. The reason for this variability in the EC and OTC results are unknown. There is no consistent temperature effect in the case of the OTC runs.

One possible cause for the observed variabilities could be dependence of model performance on reactant levels in the experiments. This might occur if there were a problem with the gas phase mechanism for ethene, or if the sensitivity to some uncertain or poorly characterized chamber for light source)effect were dependent on reactant levels. This possibility is examined in Figure 23, which shows plots of the $t=3 \mathrm{~d}\left(\mathrm{O}_{3}-\mathrm{NO}\right)$ normalized bias of the model prediction against initial $\mathrm{ROG} / \mathrm{NO}_{x}$. The figure suggests that the model bias may indeed depend on the ROG/NO${ }_{x}$ ratio, and that this might account for at least some of the chamber differences and variabilities. There is a tendency for the model to overpredict reactivity at the higher $R O G / N_{x}$ ratio and to unerpredict it at 


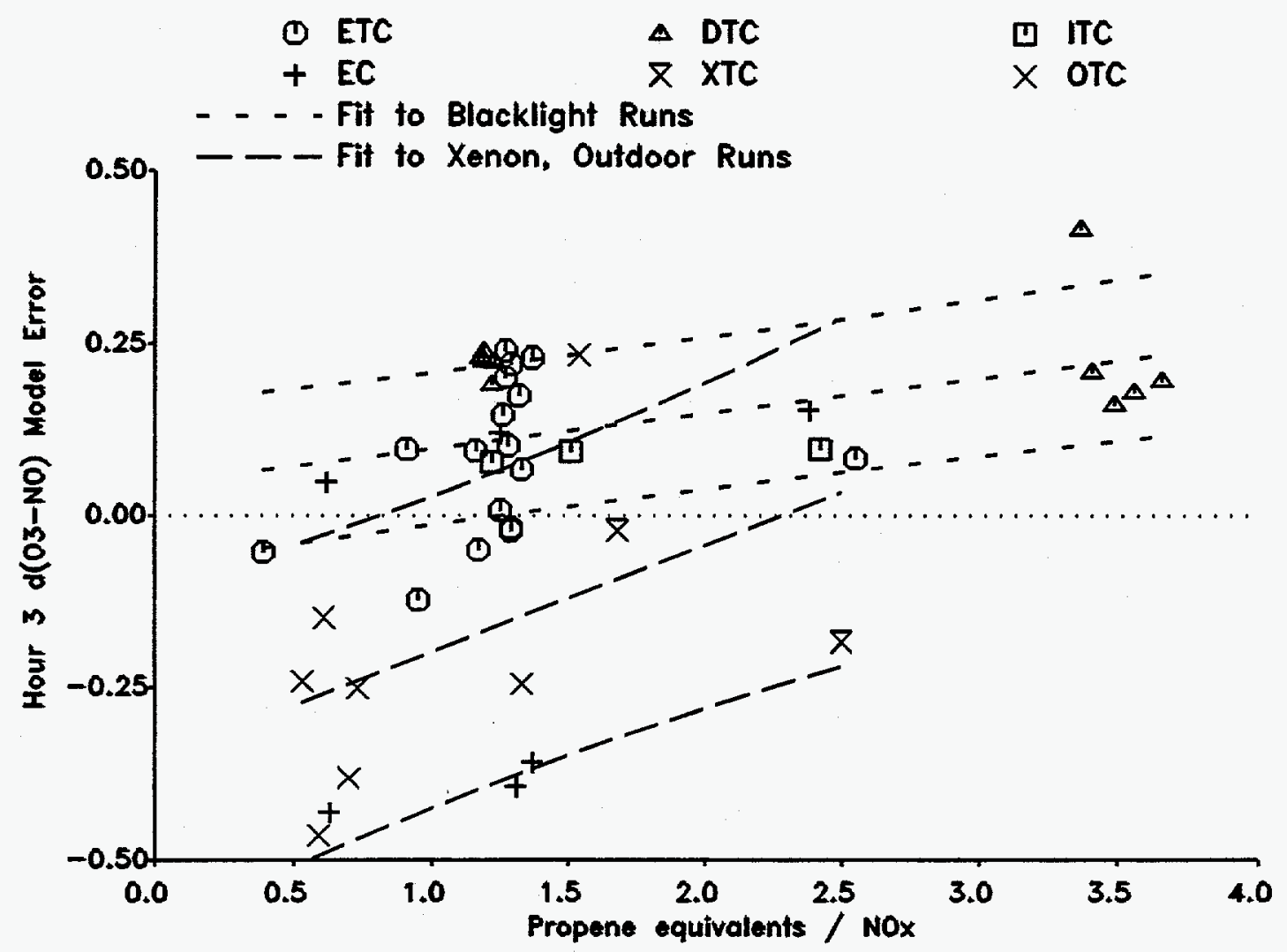

Figure 23. Plots of model bias for hour $3 \mathrm{~d}\left(\mathrm{O}_{3}-\mathrm{NO}\right)$ against initial $\mathrm{ROG} / \mathrm{NO}_{x}$ ratio for the ethene - $\mathrm{NO}_{x}$ experiments.

the low ratios. This might be the factor for the apparent positive bias for the DTC experiments, which include a large number of high ROG/NO $\mathrm{N}_{x}$ runs. The DTC experiments with similar $\mathrm{ROG} / \mathrm{NO}_{\mathrm{x}}$ ratios as the bulk of the ETC runs tend to have model biases consistent with these ETC runs. The OTC and EC runs where the model had negative bias tended to be at lower $\mathrm{ROG} / \mathrm{NO}_{\mathrm{x}}$ ratios.

Figure 23 also shows the least squares fit lines for the model biases as a function of $\mathrm{ROG} / \mathrm{NO}_{\mathrm{x}}$ ratio, along with the uncertainty ranges of the predictions of the linear regressions. Separate regressions were done for the blacklight chamber runs and the runs using xenon arcs or the outdoor chamber. (The xenon arc and outdoor chamber results are combined because there is no apparent significant difference.) These suggest a difference between the model performance for the blacklight chamber data compared to the data from the chambers using the xenon arc or solar light source. For all three types of lightsources the bias tends to increase with $\mathrm{ROG} / \mathrm{NO}_{x}$, but the bias appears to be generally positive for the blacklight runs, and generally negative, and more variable, with the other light sources. 
It should be noted that in general the sensitivity of model simulations to the chamber radical source increases with decreasing $\mathrm{ROG} / \mathrm{NO}_{\mathrm{x}}$ ratio. Therefore, uncertainties or inappropriate assignments of the chamber radical source may by a reason for the dependence of the bias on $\mathrm{ROG} / \mathrm{NO}_{\mathrm{x}}$. The type of trend shown on Figure 23 would be caused by the model using too low a radical source, which would have a greater tendency to cause underprediction at the low ratios. A runto-run variability in the radical source would cause an apparent variability in model performance at the low $\mathrm{ROG} / \mathrm{NO}_{x}$ ratios.

\section{Propene}

A relatively large number of replicate propene runs were carried out in the various chambers because they were used as controls to assess consistency of results. This provides a fairly good data base for inter-chamber comparisons. Figure 24 shows the model performance in the simulation of the propene - $\mathrm{NO}_{x}$ experiments in the blacklight chambers, and Figure 25 shows the results for the xenon arc and outdoor chamber runs.

The model performance in simulating the propene runs is somewhat more consistent than the simulations of the ethene runs, though there still are differences between the chambers. The model has consistent results in the simulations of the ETC and DTC runs, having relatively little bias or error except perhaps for a tendency to slightly overpredict the No oxidation rate in the first hour. There are more cases of negative bias in the simulations of the ITC experiments, though approximately half of the experiments are simulated reasonably well. In the case of the other light sources, the model seems to have a positive bias in the simulations of the EC runs, a negative bias in the XTC simulations, and no overall bias in simulating the outdoor runs. In most cases the biases are relatively small, being less than $25 \%$.

Figure 26 shows plots of the model bias in simulating the hour $3 \mathrm{~d}\left(\mathrm{O}_{3}-\mathrm{NO}\right)$ against $\mathrm{ROG} / \mathrm{NO}_{\mathrm{x}}$ for the propene runs. The data suggest that there may be a slight tendency for the bias to decrease as $\mathrm{ROG} / \mathrm{NO}_{x}$ increases, which is opposite the trend observed for the ethene experiments. However, this may be an artifact of the $\mathrm{ROG} / \mathrm{NO}_{\mathrm{x}}$ range for the runs in the different types of chambers. In contrast with the ethene runs, there does not appear to be any clear dependence of light source in model bias. The XTC experiments tend to have more negative biases than the runs in the other chambers, but this does not appear to be any suggestion of a light source effect on model performance, since the simulations of the EC runs tend to have the opposite bias. There may be a slight dependence of humidity, with the EC, ITC and the two humidified DTC runs having slightly more positive biases than the unhumidified DTC, ETC, and OTC runs.

\section{Aromatics}

The representation of uncertain aromatic reactions in the SAPRC mechanisms are based on model simulations of toluene, m-xylene and 1,3,5trimethylbenzene - $\mathrm{NO}_{x}$ experiments carried out in the EC and the ITC. For 
PROPENE (ITC)
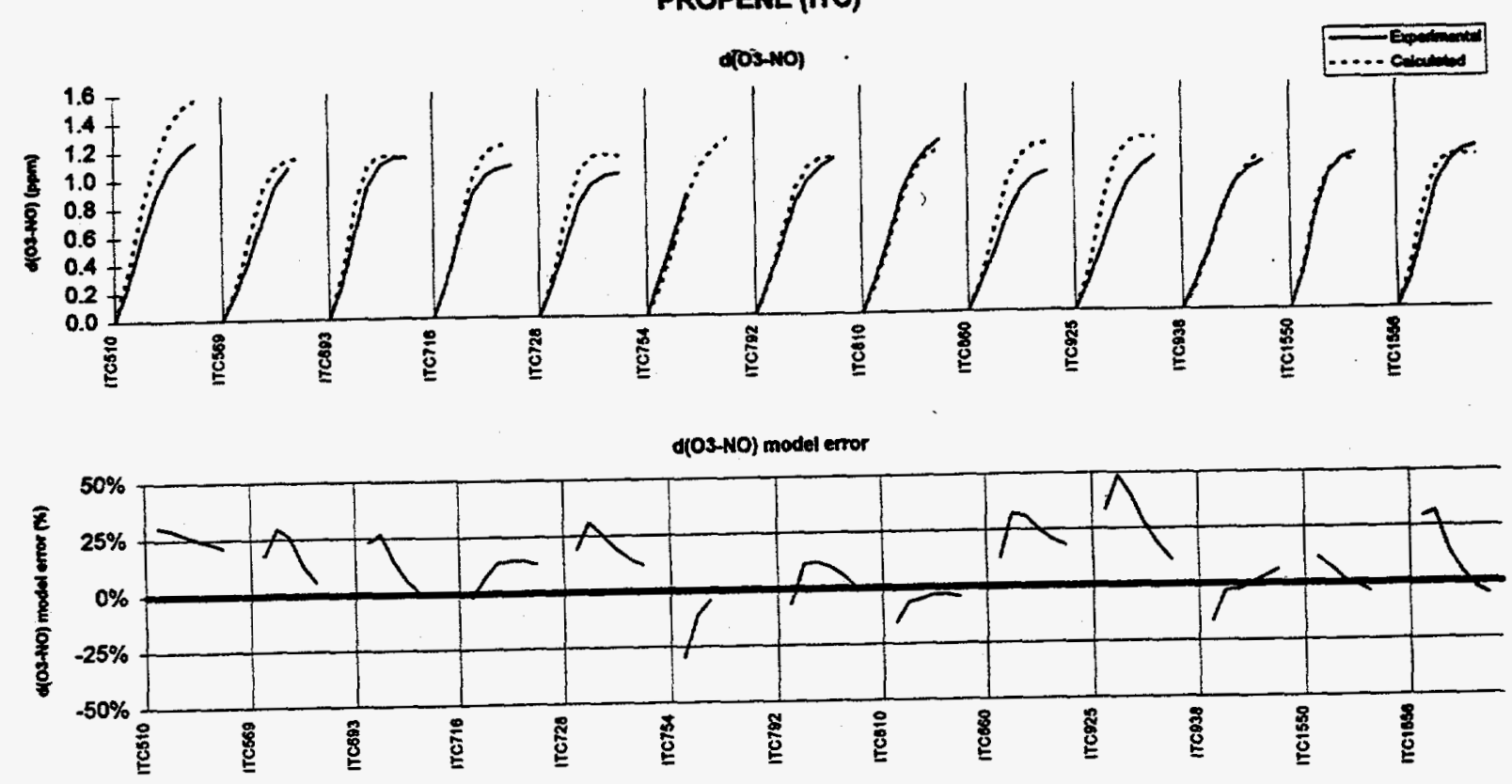

PROPENE (ETC, DTC)
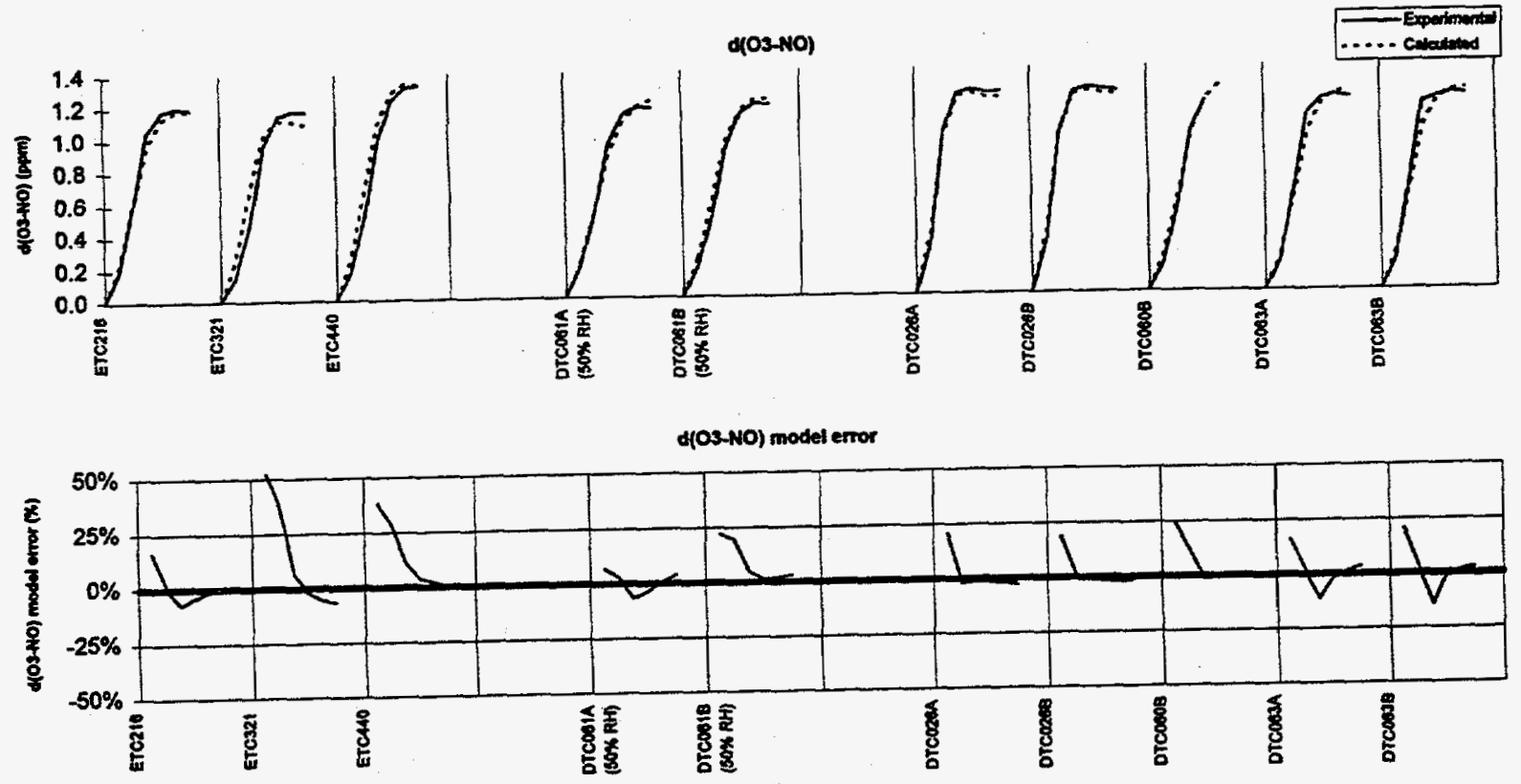

Figure 24. Results of model simulations of $d\left(\mathrm{O}_{3}-\mathrm{NO}\right)$ in the propene - $\mathrm{NO}_{x}$ experiments carried out in the blacklight chambers. Runs are ordered by experiment number. 

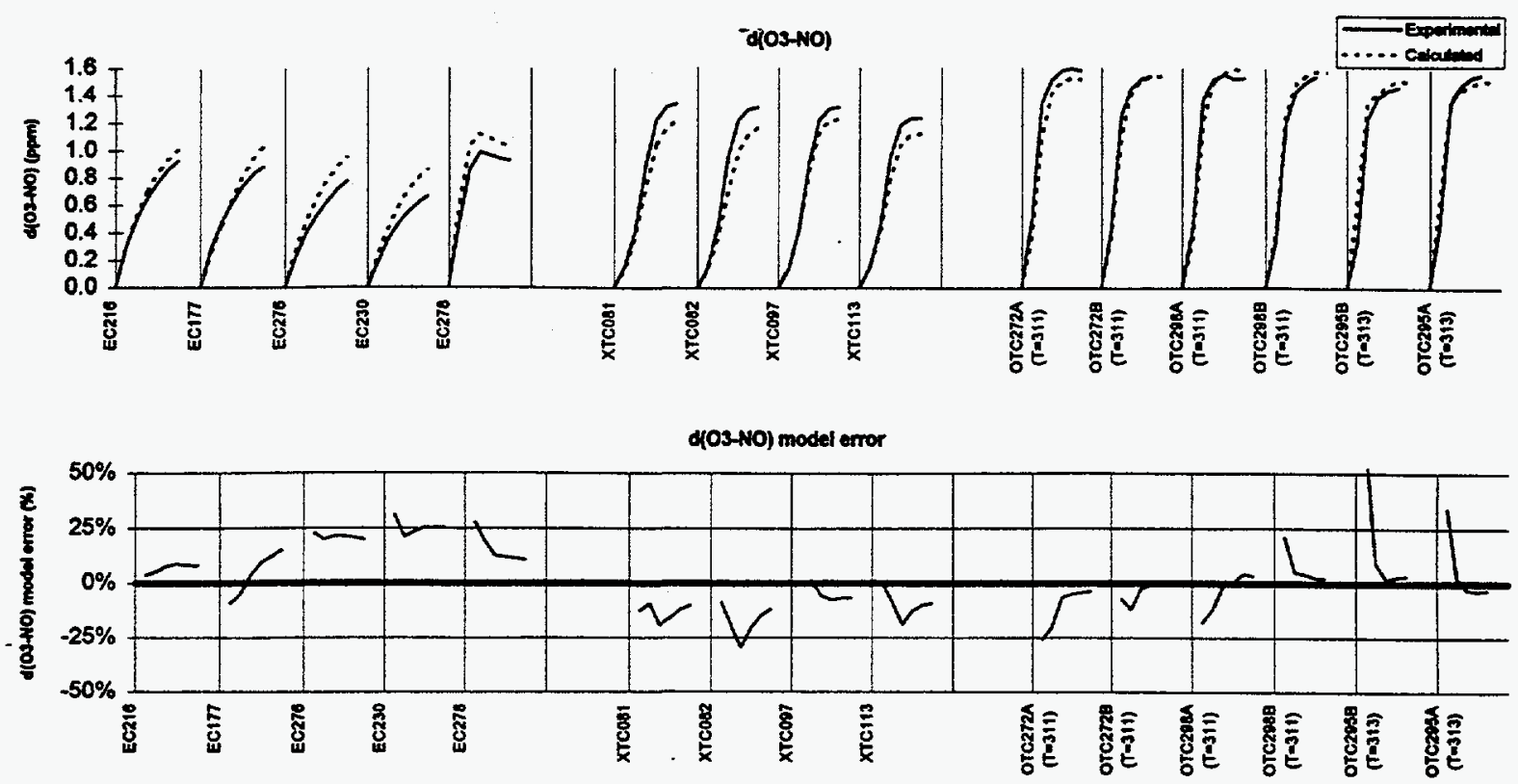

Figure 25. Results of model simulations of $d\left(\mathrm{O}_{3}-\mathrm{NO}\right)$ in the propene - $\mathrm{NO}_{x}$ experiment carried out in the xenon arc or outdoor chambers. Runs are ordered by $\mathrm{ROG} / \mathrm{NO}_{\mathrm{x}}$.

comparison with these important experiments, for this program we carried out comparable experiments with these compounds in the ETC or DTC, XTC and the OTC.

Toluene. Figure 27 shows the model performance in simulating $d\left(\mathrm{O}_{3}-\mathrm{NO}\right)$ in the toluene runs, and Figure 28 shows a plot of the model bias in simulating these runs against the toluene/ $\mathrm{NO}_{x}$ ratio. The OTC runs on Figure 27 are ordered by increasing temperature, while all other runs are ordered by ROG/NO ratio. Figure 28 shows that the model bias has a definite dependence on the $\mathrm{ROG} / \mathrm{NO}_{x}$ ratio, with the model tending to underpredict $\mathrm{d}\left(\mathrm{O}_{3}-\mathrm{NO}\right)$ at the low ratios, and (for the EC runs at least), overpredicting $O_{3}$ at the highest ratios. The exceptions to this are the one XTC run where the model underpredicted $d\left(\mathrm{O}_{3}-\mathrm{NO}\right)$ at high $\mathrm{ROG} / \mathrm{NO}_{x}$, and for the apparently anomalous low ROG/NO DTC run DTC042A, where the opposite bias was observed. The latter result may be due in part to the sensitivity of the lower $\mathrm{ROG} / \mathrm{NO}_{\mathrm{x}}$ experiments to the radical source; much better fits to run DTC024A are obtained if the model assumes the lower radical source indicated by the ETC $n$-butane - $\mathrm{NO}_{x}$ experiments (see above).

However, the discrepancies for the single XTC experiment, and the similar result for OTC299A are not significantly improved by reasonable variations of the radical source. The underprediction for the XTC run in particular is not consistent with the model performance for the other chambers, especially after the apparent effect of the $\mathrm{ROG} / \mathrm{NO}_{x}$ ratio is taken into account. Since the EC uses a similar light source as the XTC, this discrepancy does not clearly 


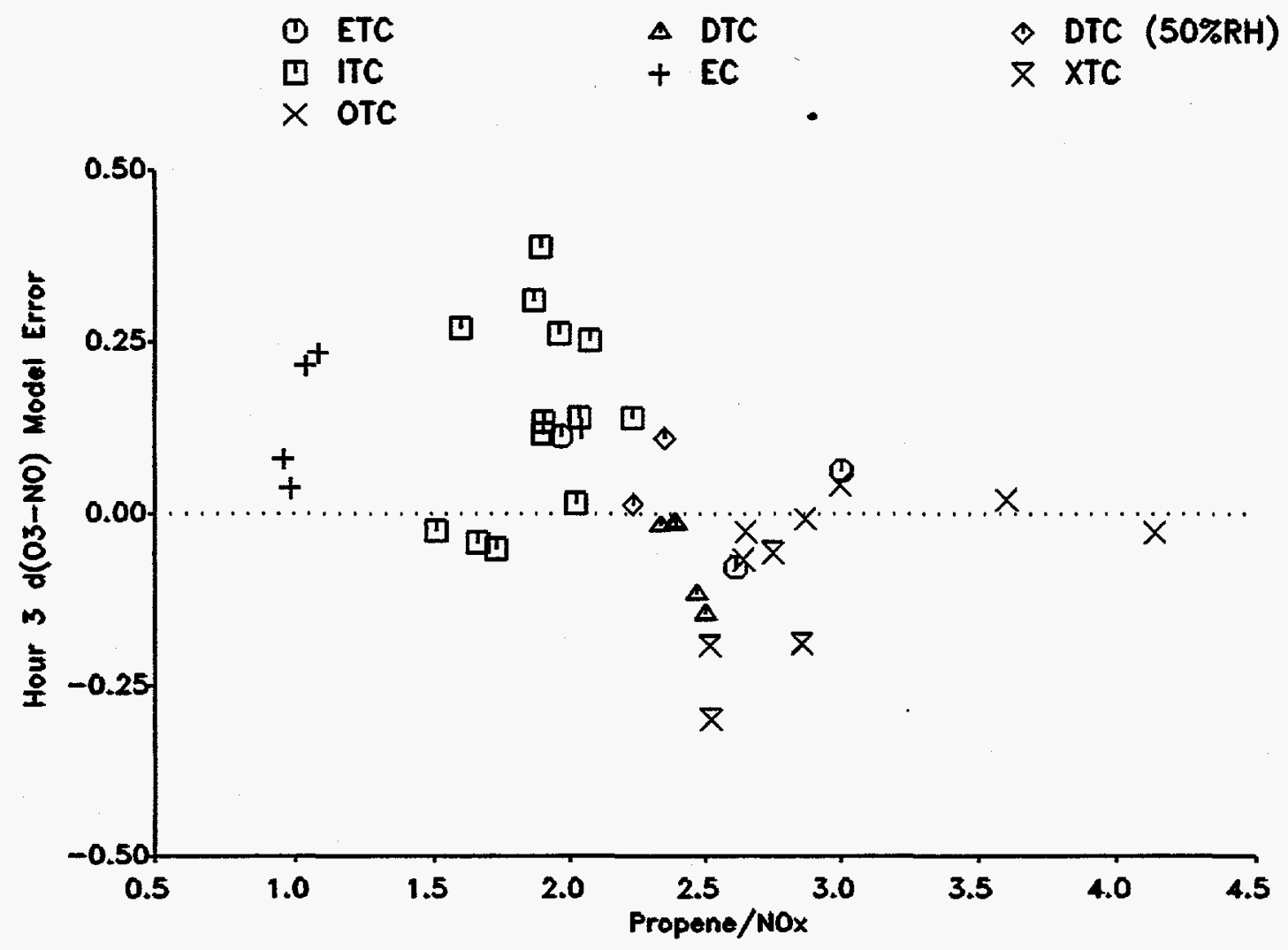

Figure 26. Plots of model bias for hour $3 \mathrm{~d}\left(\mathrm{O}_{3}-\mathrm{NO}\right)$ against initial $\mathrm{ROG} / \mathrm{NO}_{x}$ ratio for the propene - $\mathrm{NO}_{\mathrm{x}}$ experiments.

indicate a light source effect. Additional XTC toluene experiments would have been useful to assess whether that one run was run anomalous, or whether there is a problem in simulating toluene runs in that chamber.

m-xylene and 1,3,5-Trimethylbenzene. Figure 29 shows the model performance in simulating the m-xylene and 1,3,5-trimethylbenzene runs carried out in the various chambers, and Figure 30 gives a plot of the model biases against initial $\mathrm{ROG} / \mathrm{NO}_{\mathrm{x}}$. (The runs with 1,3,5-trimethylbenzene are indicated with a $" * \|$ on Figure 30). The model bias for these runs does not appear to have the same dependence on $\mathrm{ROG} / \mathrm{NO}_{\mathrm{x}}$ as the toluene runs. Like toluene, the model gives moderately good performance in simulating the ETC and ITC experiments, and the limited number of DTC or ETC experiments do not have significant or consistent discrepancies. The qualitative fits for the blacklight chamber or EC runs are generally consistent with the results for toluene, discussed above, and do not indicate large or consistent biases. As is also the case with toluene, the model underpredicts the $\mathrm{d}\left(\mathrm{O}_{3}-\mathrm{NO}\right)$ formation rate in the XTC by an amount which is outside the range of variability observed in the simulation of the blacklight 
TOLUENE (ITC, DTC, OTC)
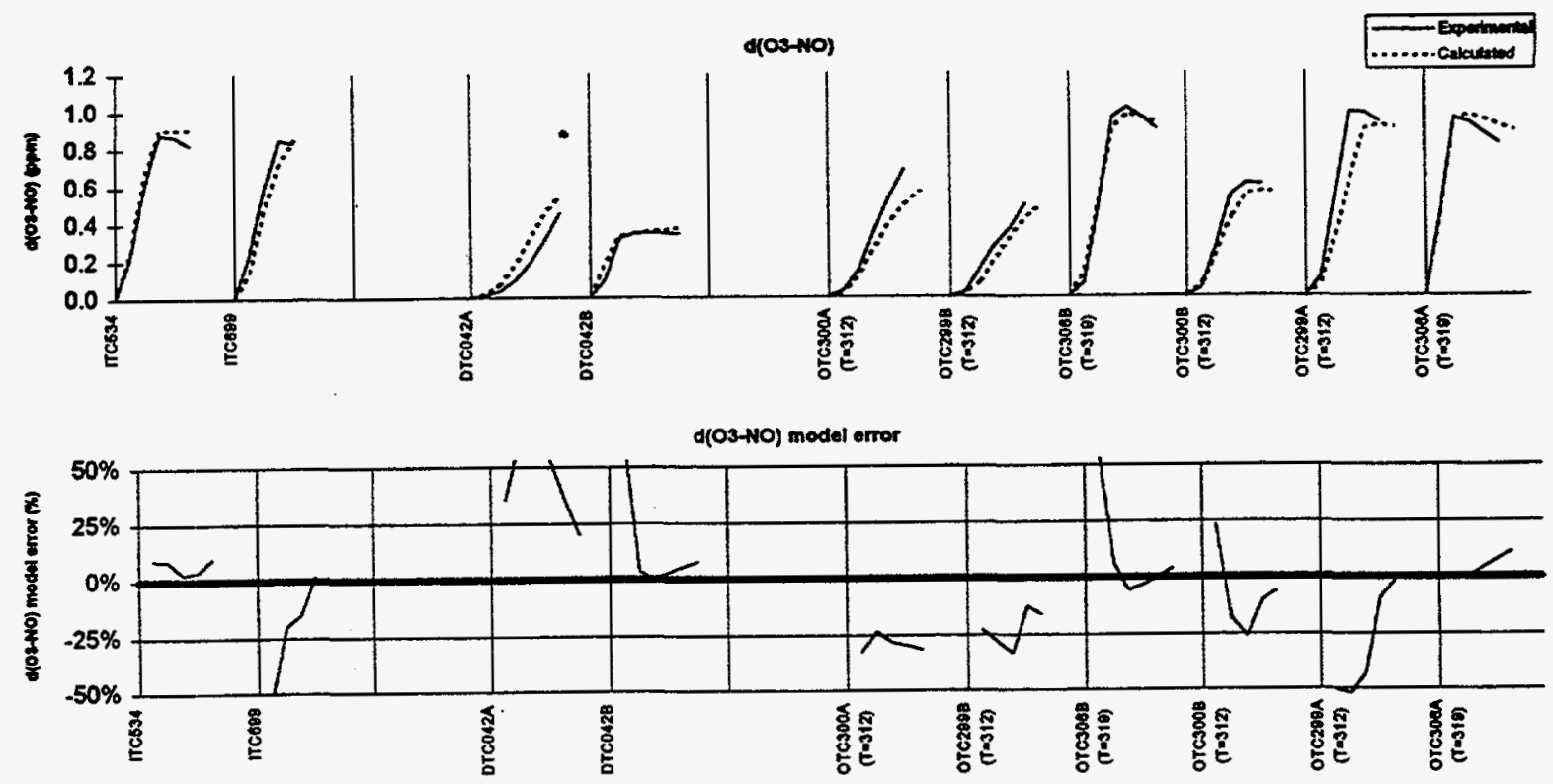

TOLUENE (XTC, EC)
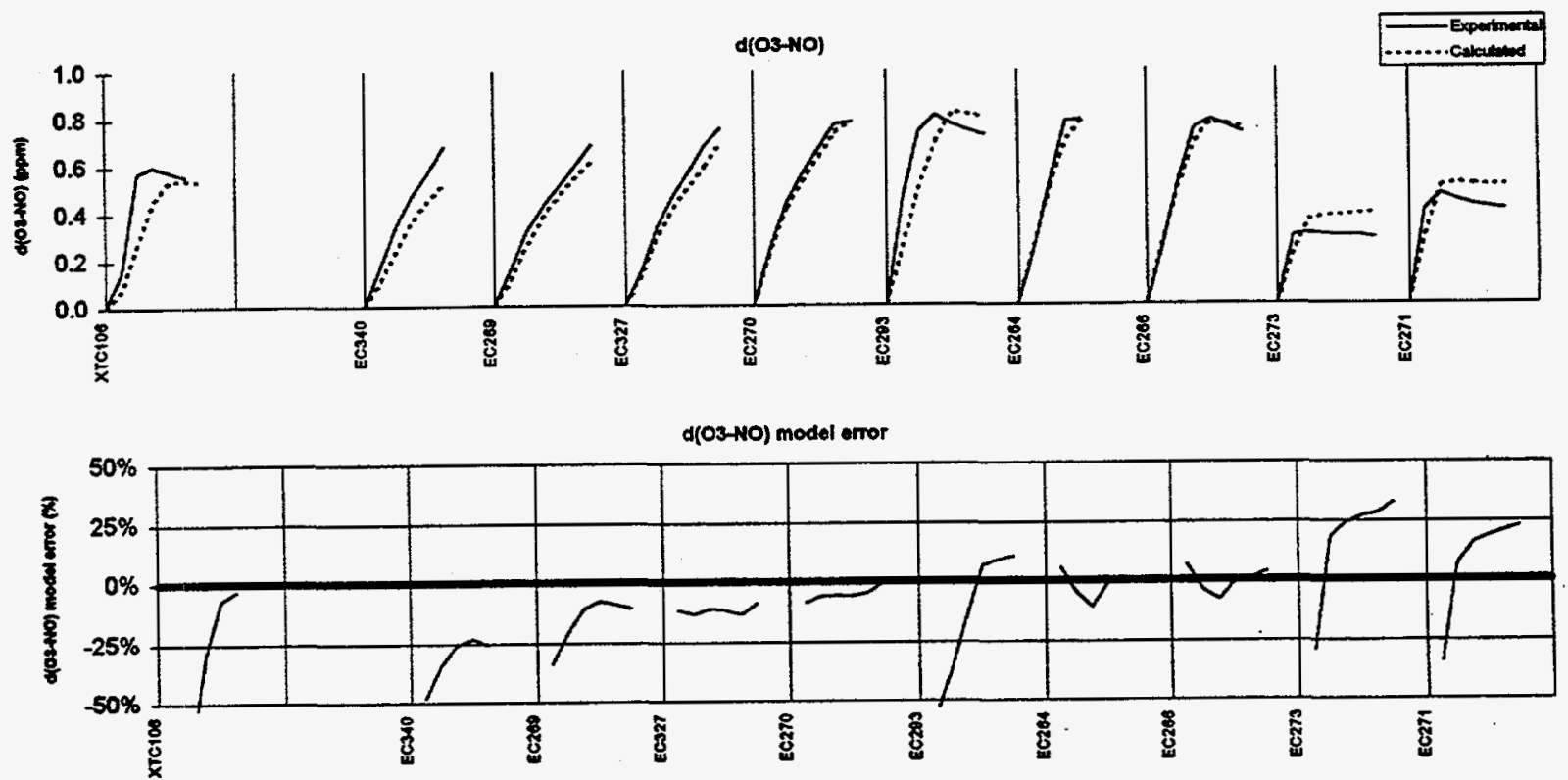

Figure 27. Results of model simulations of $d\left(\mathrm{O}_{3}-\mathrm{NO}\right)$ in the toluene - $\mathrm{NO}_{x}$ experiments. Runs are ordered by $\mathrm{ROG} / \mathrm{NO}_{\mathrm{x}}$. 

$\triangle$ DTC
ए ITC
$+E C$
又 XTC
$\times$ OTC

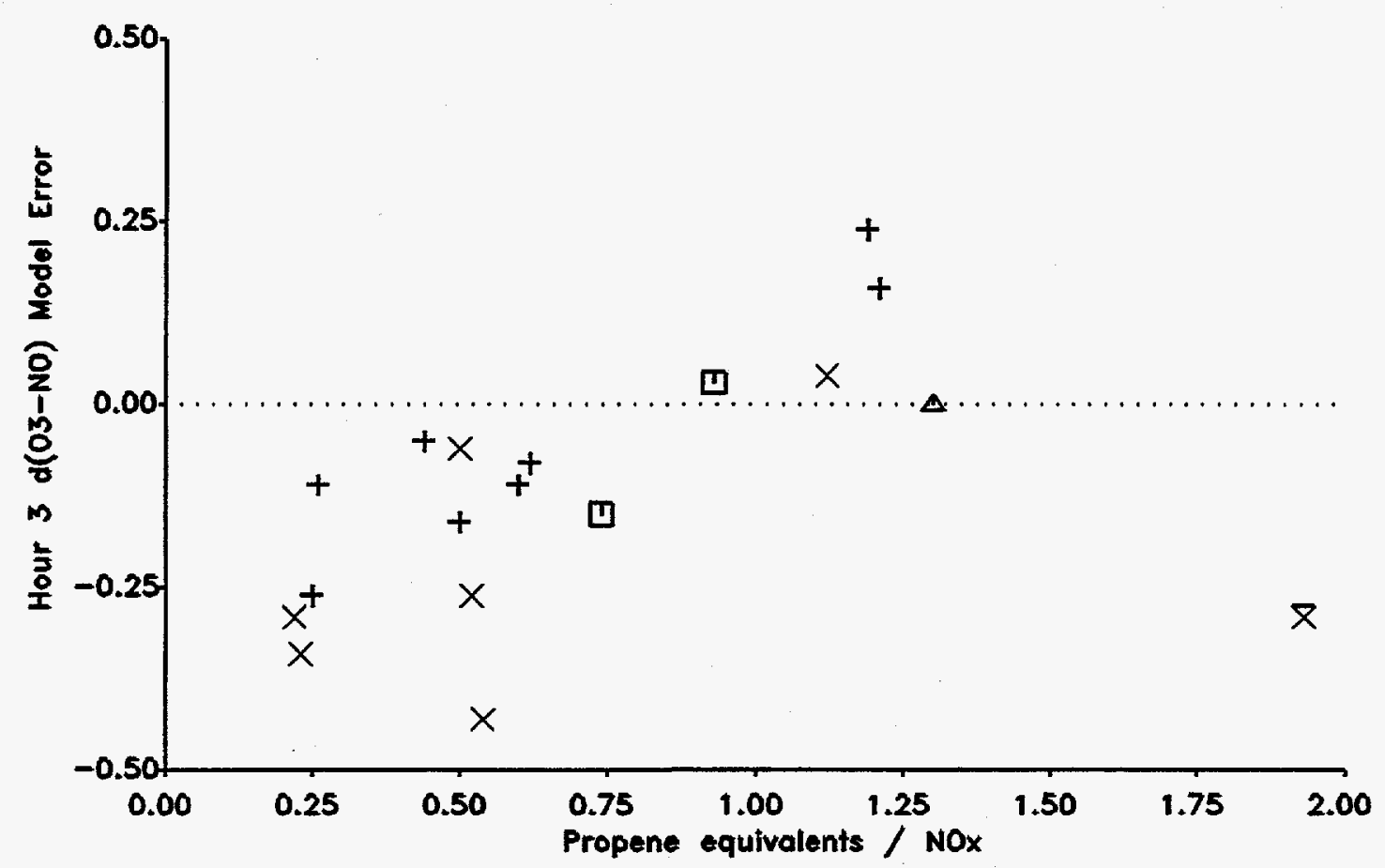

Figure 28. Plots of model bias for hour $3 \mathrm{~d}\left(\mathrm{O}_{3}-\mathrm{NO}\right)$ against initial $\mathrm{ROG} / \mathrm{NO}_{x} \mathrm{ratio}$ for the toluene - $\mathrm{NO}_{\mathrm{x}}$ experiments.

chamber or EC runs. Unlike toluene, where the model performance for the OTC runs was variable, the model consistently underpredicted $\mathrm{d}\left(\mathrm{O}_{3}-\mathrm{NO}\right)$ in the OTC m-xylene runs, with the underprediction being comparable to the results of the simulation of the m-xylene run in the XTC.

The model gives fair performance in simulating the EC and ITC aromatic experiments because as indicated above the unknown parameters in the aromatic mechanisms were adjusted based on simulations of these runs. However, the consistent tendency for the model to underpredict d $\left(\mathrm{O}_{3}-\mathrm{NO}\right)$ formation rates in all aromatic runs in the XTC, and most of the runs in the OTC, suggest that some chamber and/or light source effects are not being properly entirely taken into account in the aromatic simulations. This potentially significant result is supported by the results of the simulations of the surrogate experiments, discussed below. 

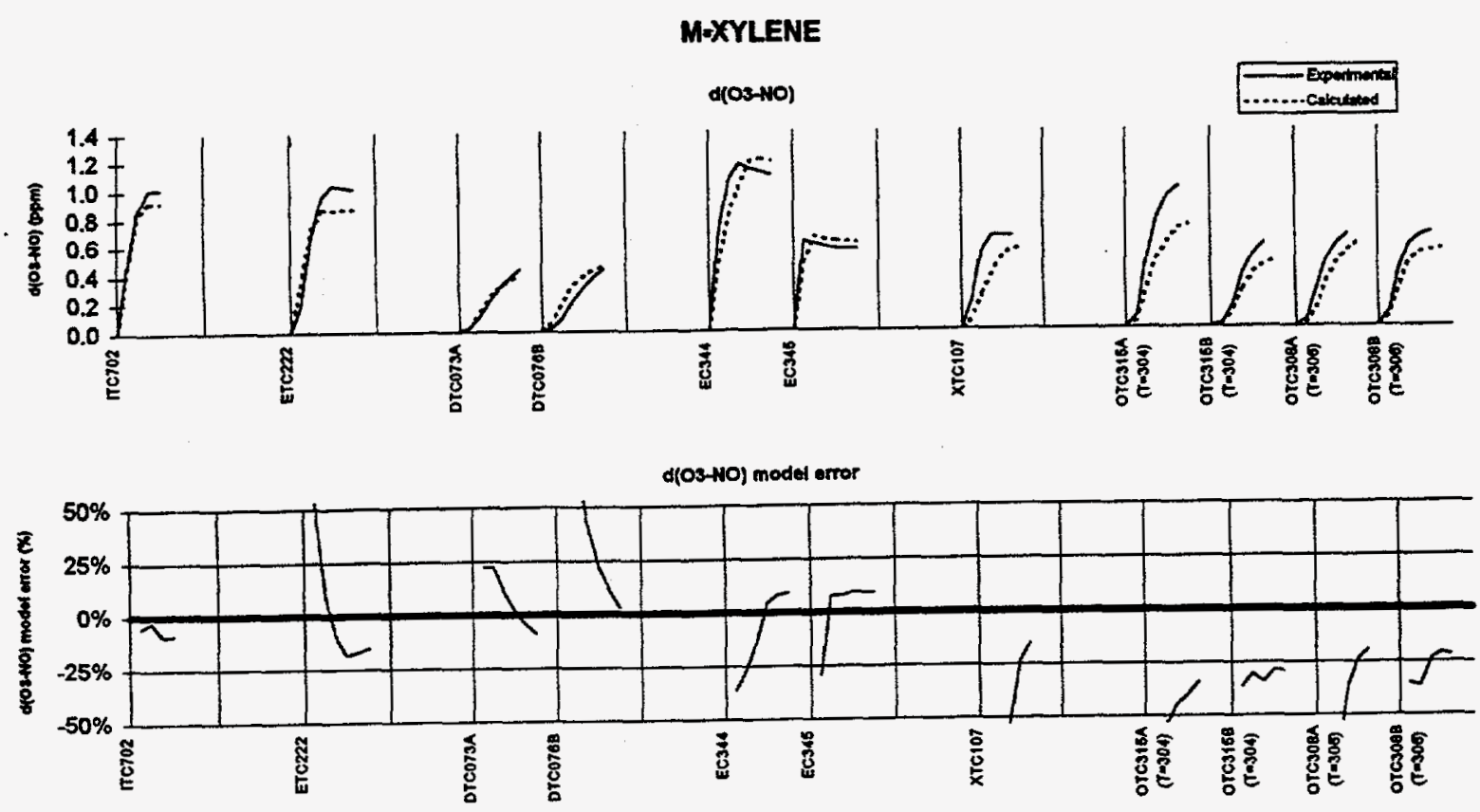

\section{1,3,5-TRIMETHYLBENZENE}
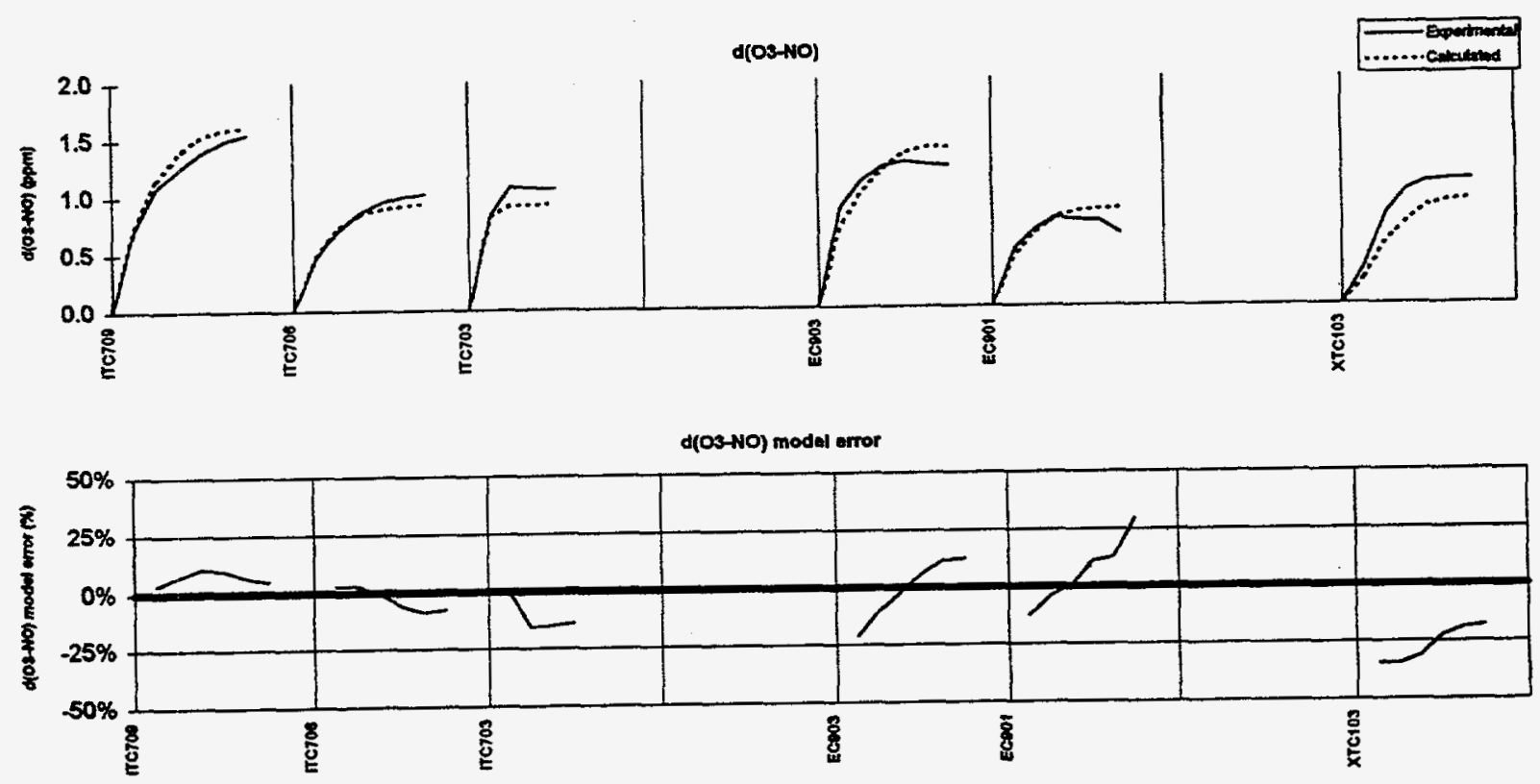

Figure 29. Results of model simulations of $\mathrm{d}\left(\mathrm{O}_{3}-\mathrm{NO}\right)$ in the m-xylene - $\mathrm{NO}_{x}$ and $1,3,5$-trimethylbenzene - $\mathrm{NO}_{x}$ experiments. Runs are ordered by $\mathrm{ROG} / \mathrm{NO}_{\mathrm{x}}$. 

(1) ETC
$+E C$
$\triangle$ DTC
ए ITC
X XTC
$\times$ OTC

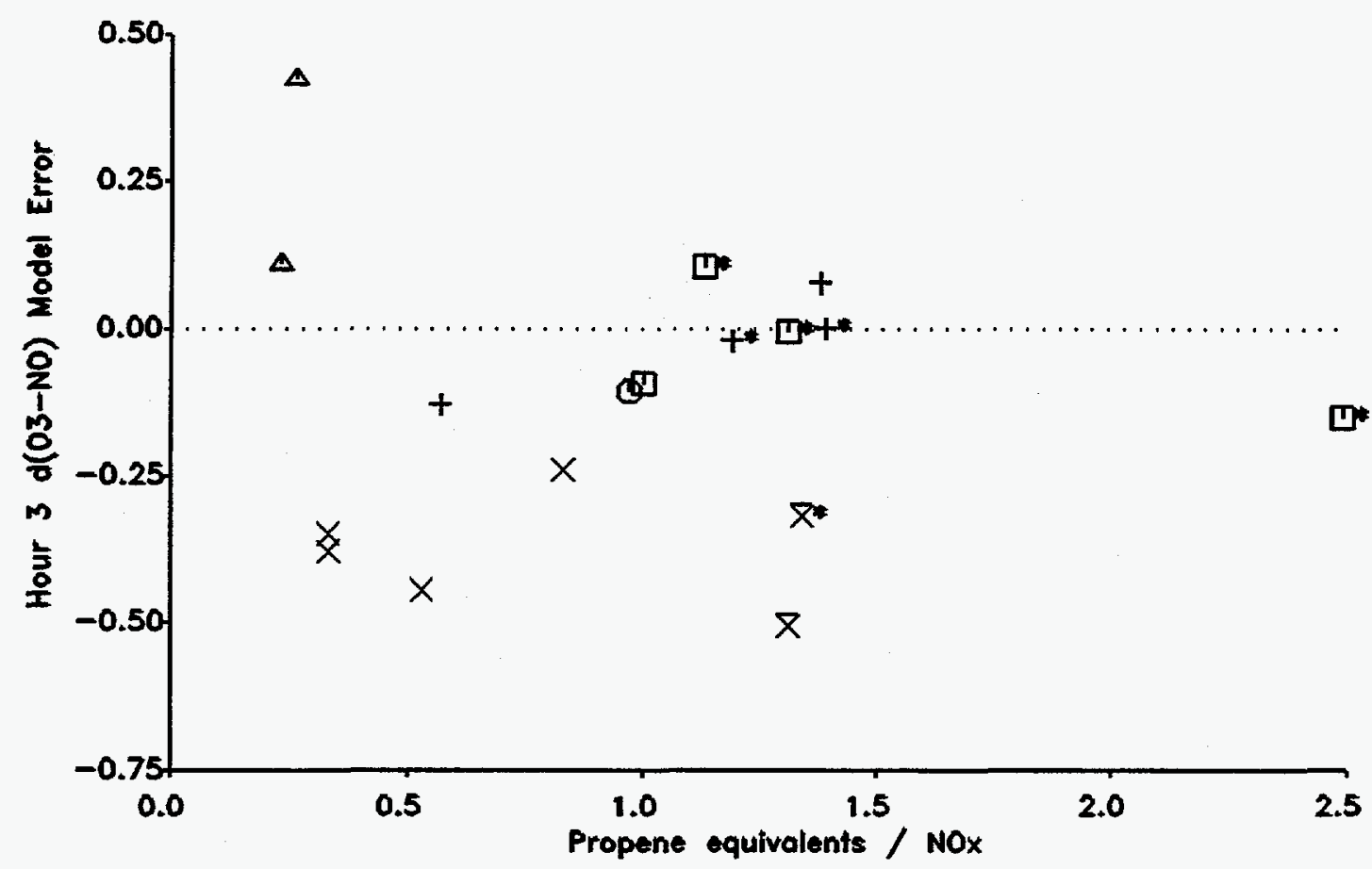

Figure 30. Plots of model bias for hour $3 \mathrm{~d}\left(\mathrm{O}_{3}-\mathrm{NO}\right)$ against initial $\mathrm{ROG} / \mathrm{NO}_{\mathrm{x}}$ ratio for the m-xylene - $\mathrm{NO}_{x}$ and 1,3,5-trimethylbenzene - $\mathrm{NO}_{x}$ experiments. The 1,3,5-trimethylbenzene experiments are indicated with a "*" after the plot symbol.

\section{Surrogate Experiments}

Surrogate - No experiments consist of simulations designed to represent ambient conditions. Reactive organic gas (ROG) surrogates of varying complexity can be used, but in general any surrogate contains at least one alkane, alkene, and aromatic, with relative proportions of each being based approximately on the relative abundances of these types of compounds in polluted urban atmospheres. The specific surrogates in the experiments modeled here are: (1) the "mini-surrogate" consisting of ethene, n-hexane, and m-xylene which were used as the base case runs for incremental reactivity studies at two $R O G / N O_{x}$ ratios in the ETC (Carter et al, 1993a; Carter et al., 1992); (2) an 8-component surrogate consisting of $n$-butane, n-octane, ethene, propene, trans-2-butene, toluene, m-xylene, and formaldehyde, which was used as the base case runs for incremental reactivity studies at two $\mathrm{ROG} / \mathrm{NO}_{\mathrm{x}}$ ratios in the DTC (Carter et al, 1995b) and for acetone reactivity studies in the oTC (Carter et al., 1993b); (3) a different 8-component surrogate consisting of $n$-butane, n-pentane, isoocatane, 
ethene, propene, isobutene, toluene, and $\mathrm{m}-x y l e n e$, which was used in a number of ITC experiments for mechanism evaluation at different $\mathrm{ROG} / \mathrm{NO}_{\mathrm{x}}$ ratios (Carter et al. 1984) and as base case experiments for evaluating methanol substitution effects (Carter et al., 1986); and (4) various 7-component surrogate mixtures consisting of n-butane, 2,3-dimethylbutane, ethene, propene, trans-2-butene, toluene, and m-xylene in various relative amounts which were used in $\mathrm{EC}$ experiments for mechanism evaluation (Pitts et al, 1979). For comparison with this data base, a mini-surrogate and an 8-component surrogate experiment was carried out in the XTC.

Figures 3I-33 show the model performance in simulating $d\left(\mathrm{O}_{3}-\mathrm{NO}\right)$ in the surrogate experiments in the various chambers, and Figure 34 shows a plot of the model bias against the $\mathrm{ROG} / \mathrm{NO}_{\mathrm{x}}$ ratio. The ETC and DTC runs on Figure 31 show the replicate low $\mathrm{ROG} / \mathrm{NO}_{\mathrm{x}}$ experiments on the left and the high $\mathrm{ROG} / \mathrm{NO}_{\mathrm{x}}$ experiments on the right, with the ETC runs sorted by increasing temperature. The ITC and ETC experiments on Figure 32 were carried out at various $\mathrm{ROG}$ and $\mathrm{NO}_{x}$ levels, and are ordered by increasing $\mathrm{ROG} / \mathrm{NO}_{x}$. The two XTC experiments on Figure 33 include the mini-surrogate run to the left and an 8-component surrogate to the right. The OTC experiments in the middle of Figure 34 are replicate $\mathrm{ROG} / \mathrm{NO}_{x}$ runs given in order of increasing temperature, and the OTC experiment on the right is a high $\mathrm{ROG} / \mathrm{NO}_{x}$ run.

Figures 31 and 32 show generally satisfactory and consistent results in the simulations of the surrogate runs in the ETC, DTC, and EC. Figure 31 shows that the model has a bias for overpredicting the $\mathrm{d}\left(\mathrm{O}_{3}\right.$-NO) formation rate in the early parts of the ETC experiments, with the bias becoming less at high temperatures. This may be due to a radical source effect, since using the lower radical source indicated by the ETC n-butane runs tends to reduce or eliminate this bias except at the lowest temperatures (see Figure 17, which shows the simulations of the ETC runs using the lower radical source). Given the uncertainty and variability in the radical source, and the differences in the types of surrogates modeled, the model performance can be considered to be reasonably good for this chamber. The simulations of the DTC surrogate experiments are highly consistent and uniformly good, though the model has a consistent (though extremely small) bias for overpredicting the initial No oxidation rate and underpredicting the final ozone yields. Figure 32 shows that the model performance is also good in simulating the EC surrogate runs, except for a few runs where there is a slight tendency to overpredict the maximum ozone yield. Note that these EC runs have variable surrogate compositions as well as varied ROG and NO ${ }_{x}$ levels (Pitts et al., 1979).

On the other hand, the model performance in simulating the ITC surrogate runs was variable and generally not as satisfactory. The model usually (though not always) has a bias towards underpredicting $d\left(\mathrm{O}_{3}-\mathrm{NO}\right)$ formation rates at low $\mathrm{ROG} / \mathrm{NO}_{x}$, and overpredicting $\mathrm{O}_{3}$ at high ratios. However, $20 \%$ of the runs, at various $\mathrm{ROG} / \mathrm{NO}_{\mathrm{x}}$ ratios, are well simulated by the model. The reason for the greater variability in the ITC runs is unclear, though it should be noted that 
REPRESENTATIVE MEN-SURROGATE (ETC)
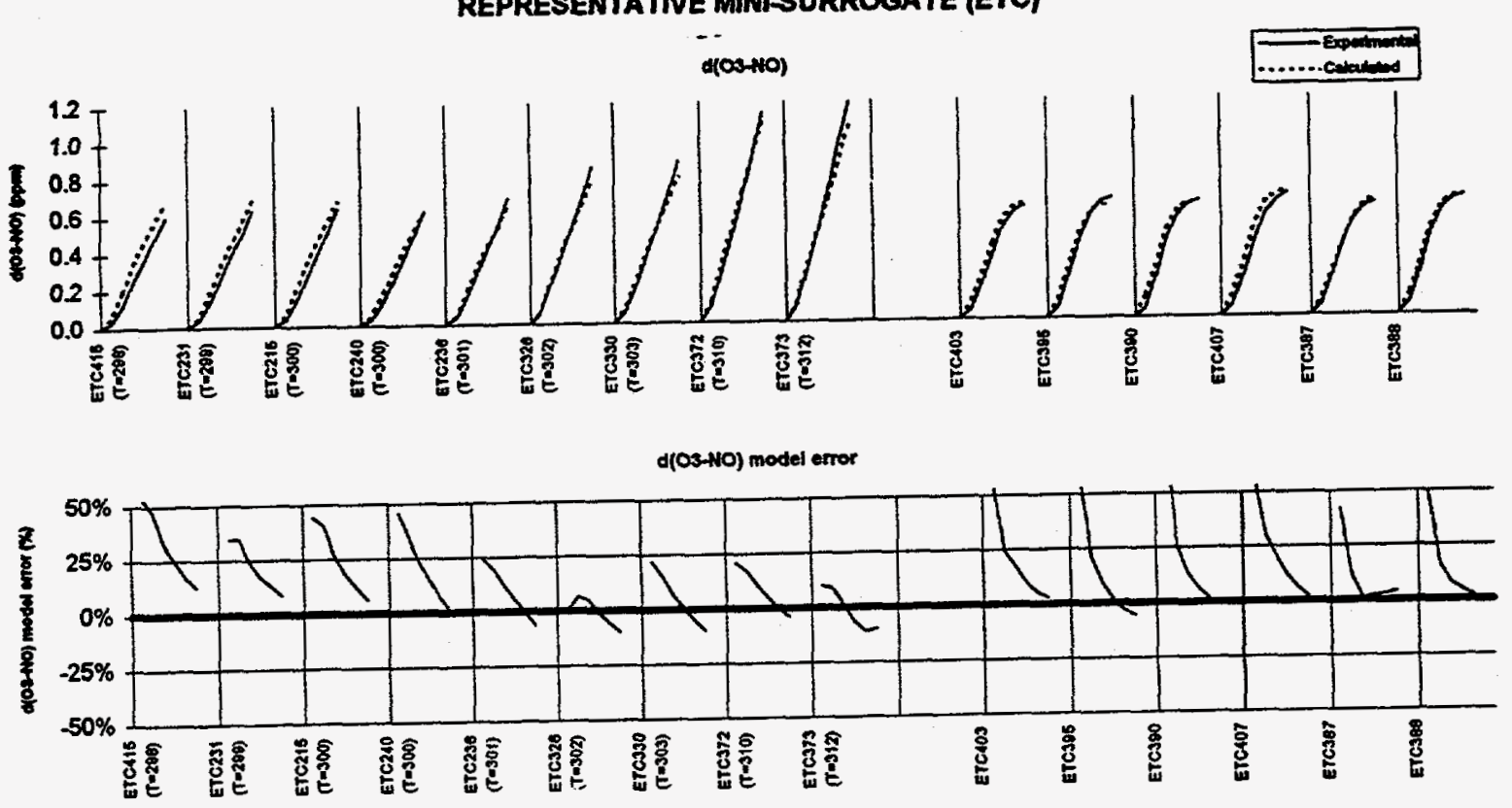

REPRESENTATIVE SURROGATE (DTC)
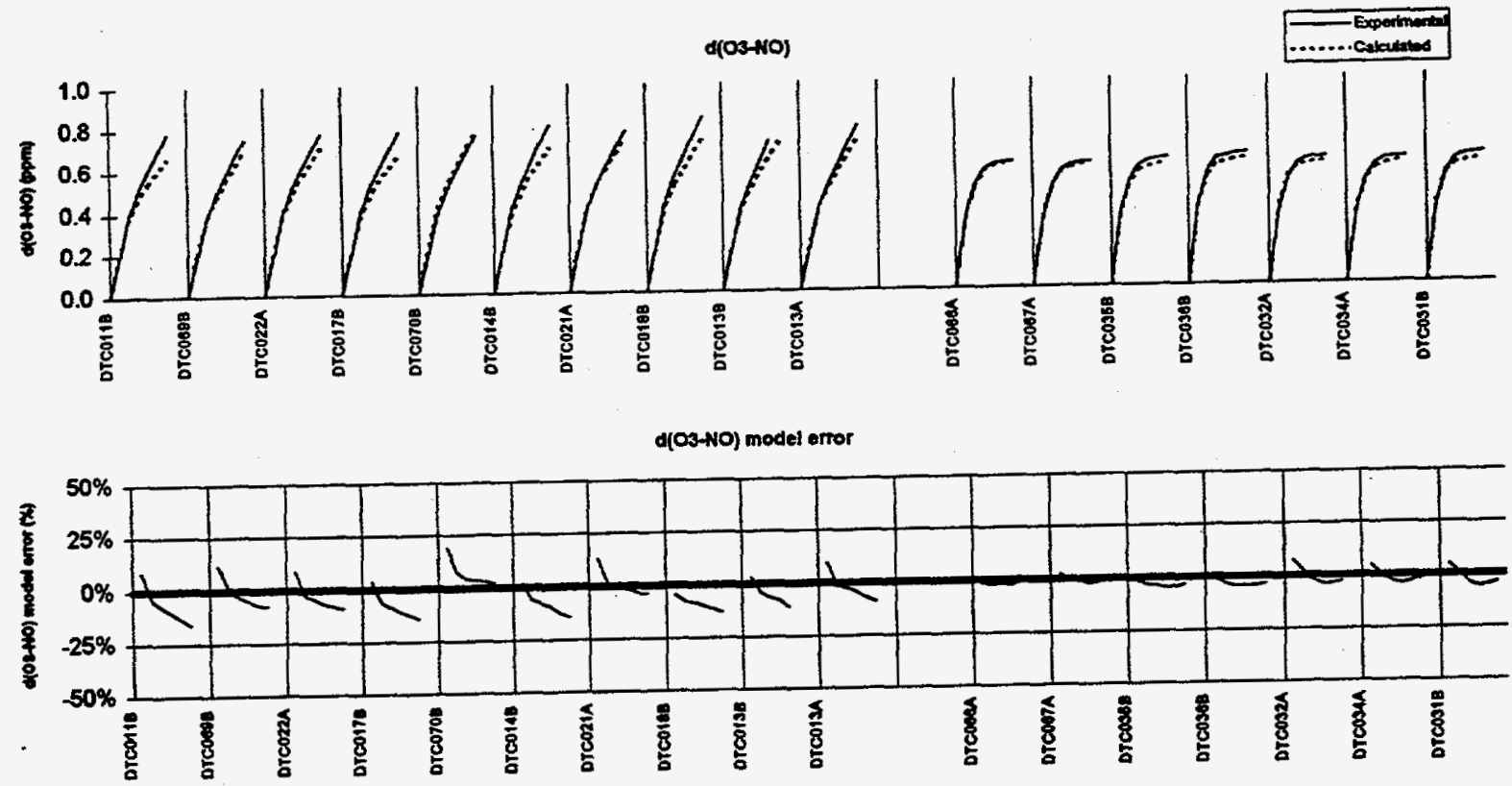

Figure 31. Results of model simulations of $\mathrm{d}\left(\mathrm{O}_{3}-\mathrm{NO}\right)$ in surrogate - $\mathrm{NO}_{x}$ experiments carried out in the ETC and the DTC. Runs are ordered by $R O G / N O_{x}$ except for the high $N_{x}$ ETC runs (top left set), which are ordered by temperature. 
SURROGATE (ITC)
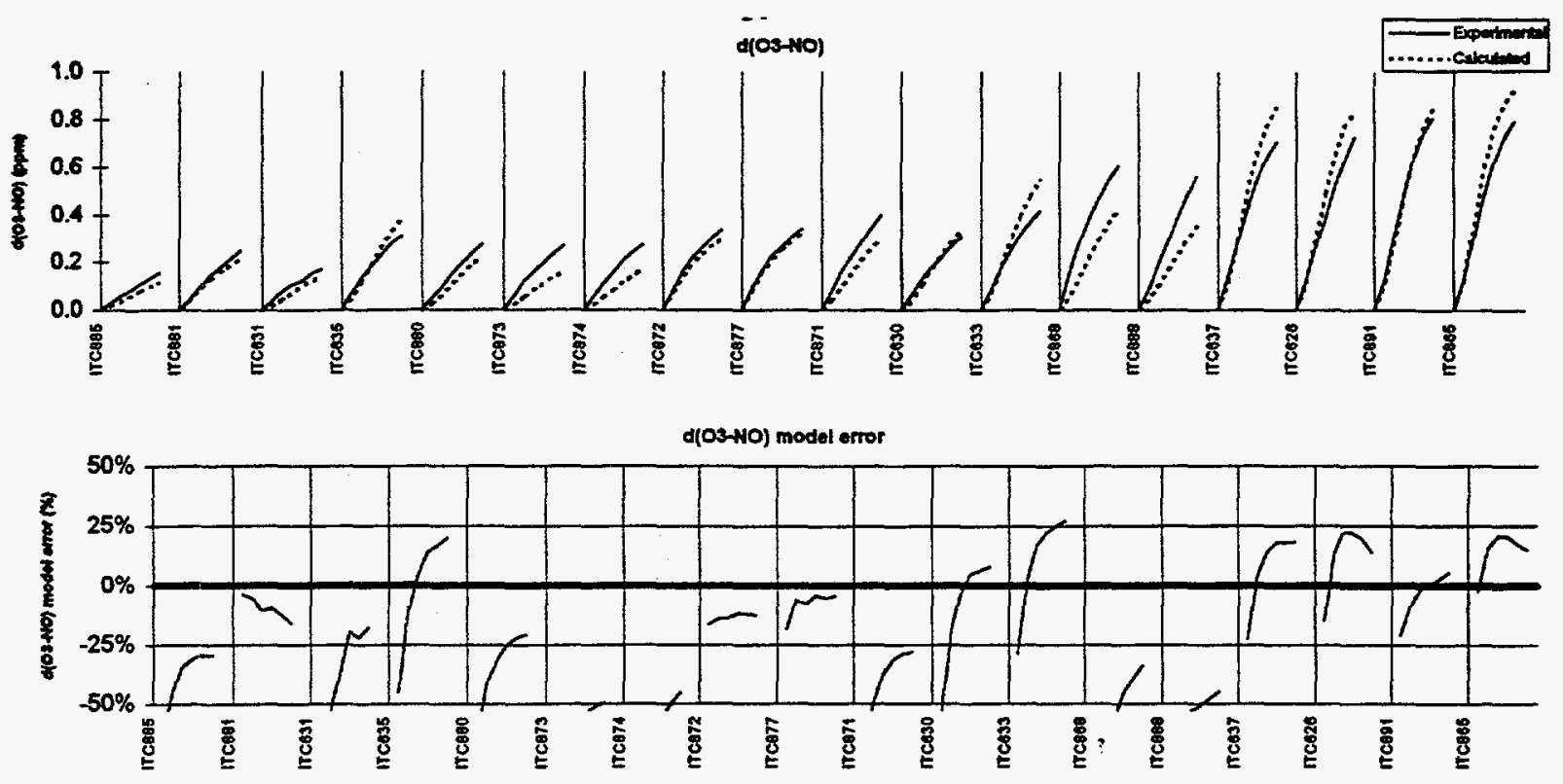

SURROGATE (EC)
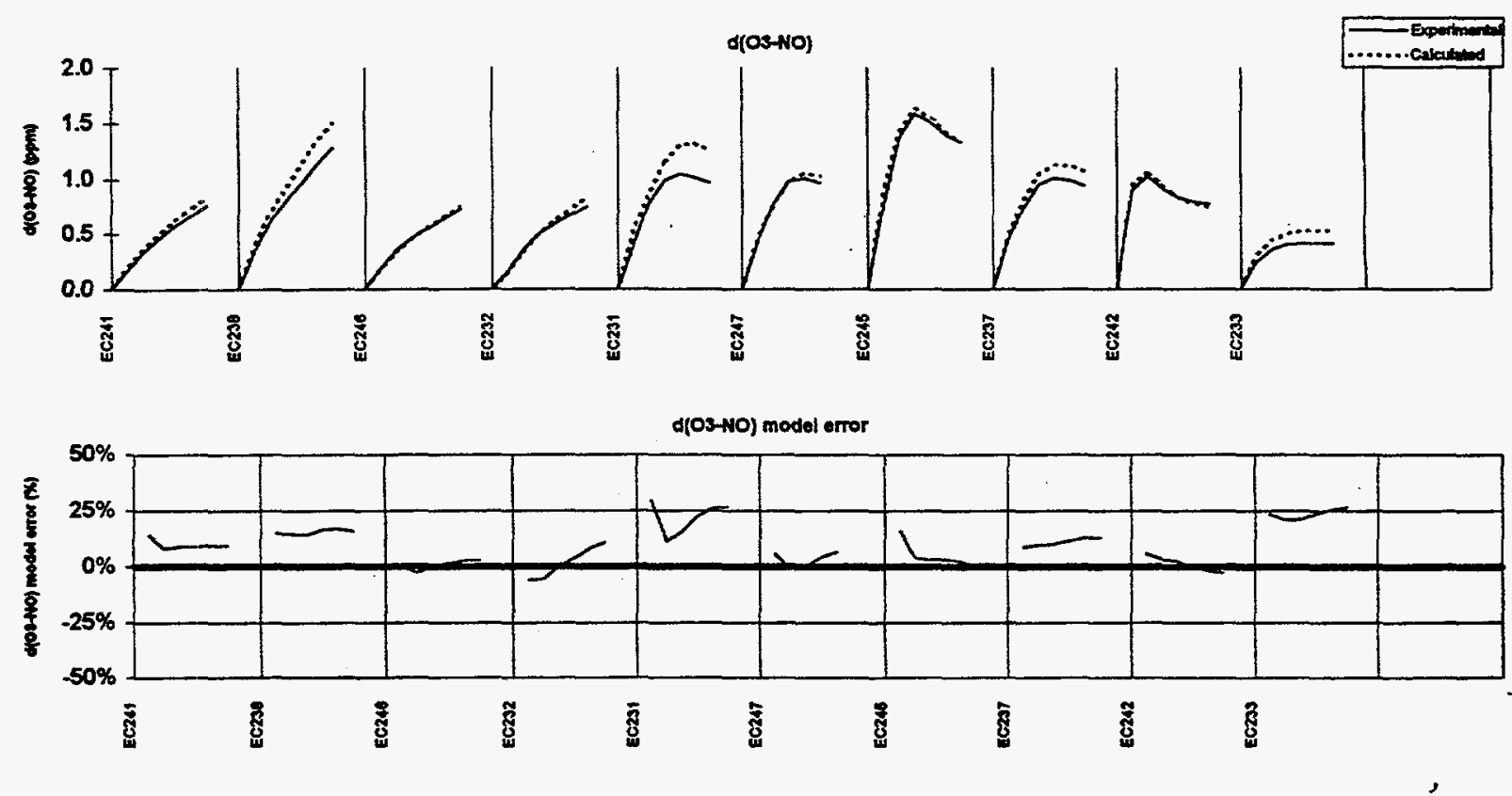

Figure 32. Results of model simulations of $\mathrm{d}\left(\mathrm{O}_{3}-\mathrm{NO}\right)$ in surrogate - $\mathrm{NO}_{x}$ experiments carried out in the ITC and the EC. Runs are ordered by 

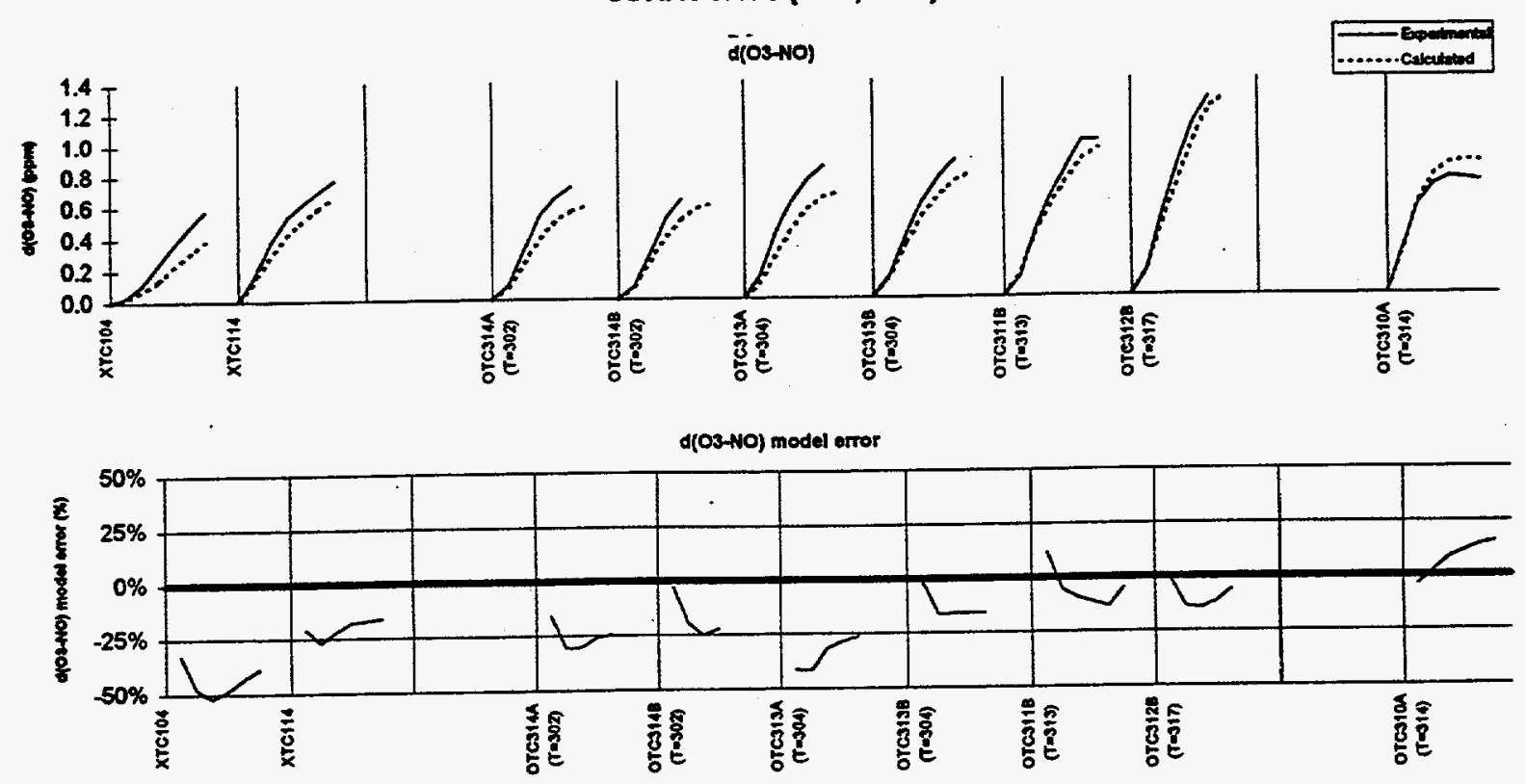

Figure 33. Results of model simulations of $d\left(\mathrm{O}_{3}-\mathrm{NO}\right)$ in surrogate - $\mathrm{NO}_{x}$ experiments carried out in the XTC and the OTC. OTC high NO ${ }_{x}$ runs (middle set) are ordered by temperature.

the model was also variable in the simulations of the propene runs in this chamber (though to a much lesser extent). The 8-component surrogate used in the ITC experiments lacked formaldehyde, which might make experiments using it more sensitive to variabilities in the radical source, compared to experiments with the 8-component surrogate used in the DTC, XTC and OTC, which includes this compound. (The mini-surrogate used in the ETC and the EC 7-component surrogate also do not have formaldehyde.) The bias towards underpredicting $\mathrm{d}\left(\mathrm{O}_{3}-\mathrm{NO}\right)$ at low $\mathrm{ROG} / \mathrm{NO}_{x}$ ratios is reduced if the higher radical sources indicated by the tracer $\mathrm{NO}_{x}$ experiments are assumed, though as discussed above these high radical sources are inconsistent with the $n$-butane - $\mathrm{NO}_{\mathbf{x}}$ runs, and cause biases in the simulations of the propene runs.

The results of the simulations of the XTC and OTC experiments, shown on Figure 33 , indicate that the model is biased towards underpredicting $d\left(\mathrm{O}_{3}-\mathrm{NO}\right)$ in the XTC and in the OTC runs at IOW ROG/NO $\mathrm{N}_{x}$ and moderate temperatures. This performance - bias towards underprediction in the XTC and OTC, but with good simulations of EC runs and generally satisfactory results in most of the blacklight chambers - is similar to what was observed in the aromatic experiments discussed above. Reasonable adjustment of the radical source does not eliminate this bias. Since aromatics are important components accounting for the overall reactivity of the surrogates, this suggests that problems with the aromatics mechanisms, or how the chamber and light source effects interact with the aromatics mechanisms, may be the cause for these results as well. 

(1) ETC
$\triangle$ DTC
D ITC
$+E C$
又 XTC
$\times$ OTC

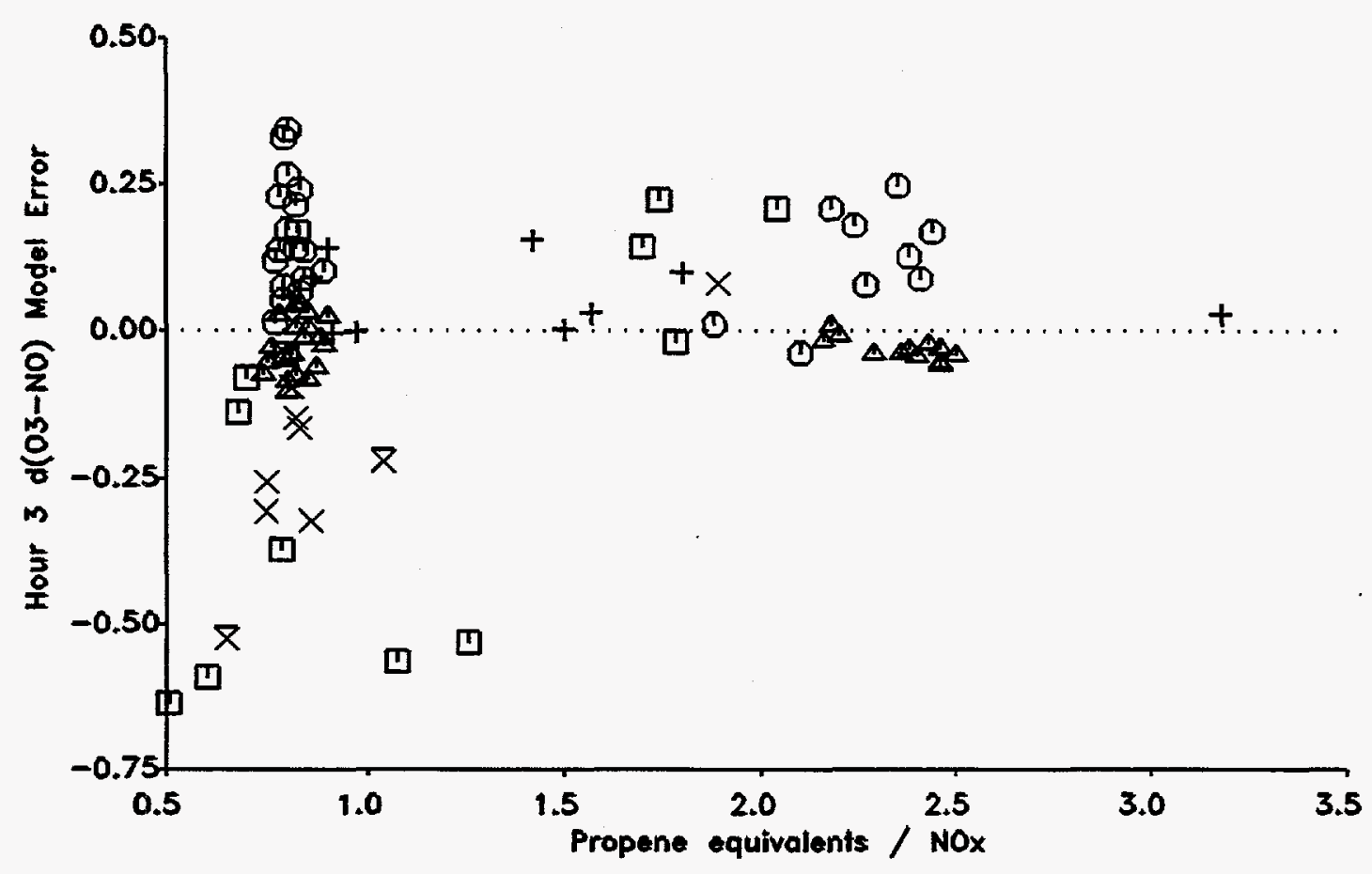

Figure 34. Plots of model bias for hour $3 \mathrm{~d}\left(\mathrm{O}_{3}-\mathrm{NO}\right)$ against initial $\mathrm{ROG} / \mathrm{NO}_{x}$ ratio for the surrogate - $\mathrm{NO}_{\mathbf{x}}$ experiments.

\section{UNC Outdoor Chamber Experiments}

Although modeling University of North Carolina outdoor chamber experiments is beyond the scope of this project, it is of interest to see whether the model performance in simulating these runs is comparable to the results observed in the outdoor chamber runs in this study. To assess this, we conducted model simulations of selected UNC propene - $\mathrm{NO}_{x}$ - air and surrogate mixture - $\mathrm{NO}_{x}$ - air in our present data base, using the chamber effects model used when evaluating the SAPRC-90 and RADM-2 mechanisms (Carter and Lurmann, 1990, 1991). The UNC radical source parameters for those runs were derived based on modeling n-butane runs, in a manner consistent with that employed for the SAPRC runs in this study. The runs modeled (not included in Table 10) consist of most of the propene and surrogate runs which have been used in our previous mechanism evaluations (Carter and Lurmann, 1990, 1991), with a few apparently anomalous runs removed. 
The model performance in simulating the UNC propene and surrogate runs is shown on Figure 35. The runs are given in order of increasing temperature. The variability in the model performance is somewhat greater than in most of the SAPRC runs; this may be due in part to the fact that the quality-assured data base of UNC runs is not yet available, but probably primarily due to the facts that humidity as well as temperature varies in these runs, and that runs with less than clear sky conditions are included. Nevertheless, it can be seen that, in contrast with the SAPRC OTC and XTC runs, the model has no consistent bias in simulating UNC chamber runs whose average temperatures in the range typical of SAPRC runs $\left(\sim 298^{\circ} \mathrm{K}\right.$ or greater). This makes the model performance for the UNC chamber comparable to that for the SAPRC EC, but inconsistent with the results for the XTC and OTC, where generally the model underpredicted $\mathrm{O}_{3}$. This could be a humidity effect, since the air in the UNC chamber runs is not dried, which is the case for the EC but not the OTC and XTC. However, the mechanism does not predict a significant humidity effect in the model simulations of these runs.

The model has a definite bias towards overpredicting $\mathrm{O}_{3}$ in the lower temperature runs. This is consistent with the results with the lowest temperature ETC mini-surrogate runs, as shown on Figure 31. The problem is not the radical source, since setting the radical source to zero does not significantly reduce the extent of underprediction. 
UNC Propene Runs
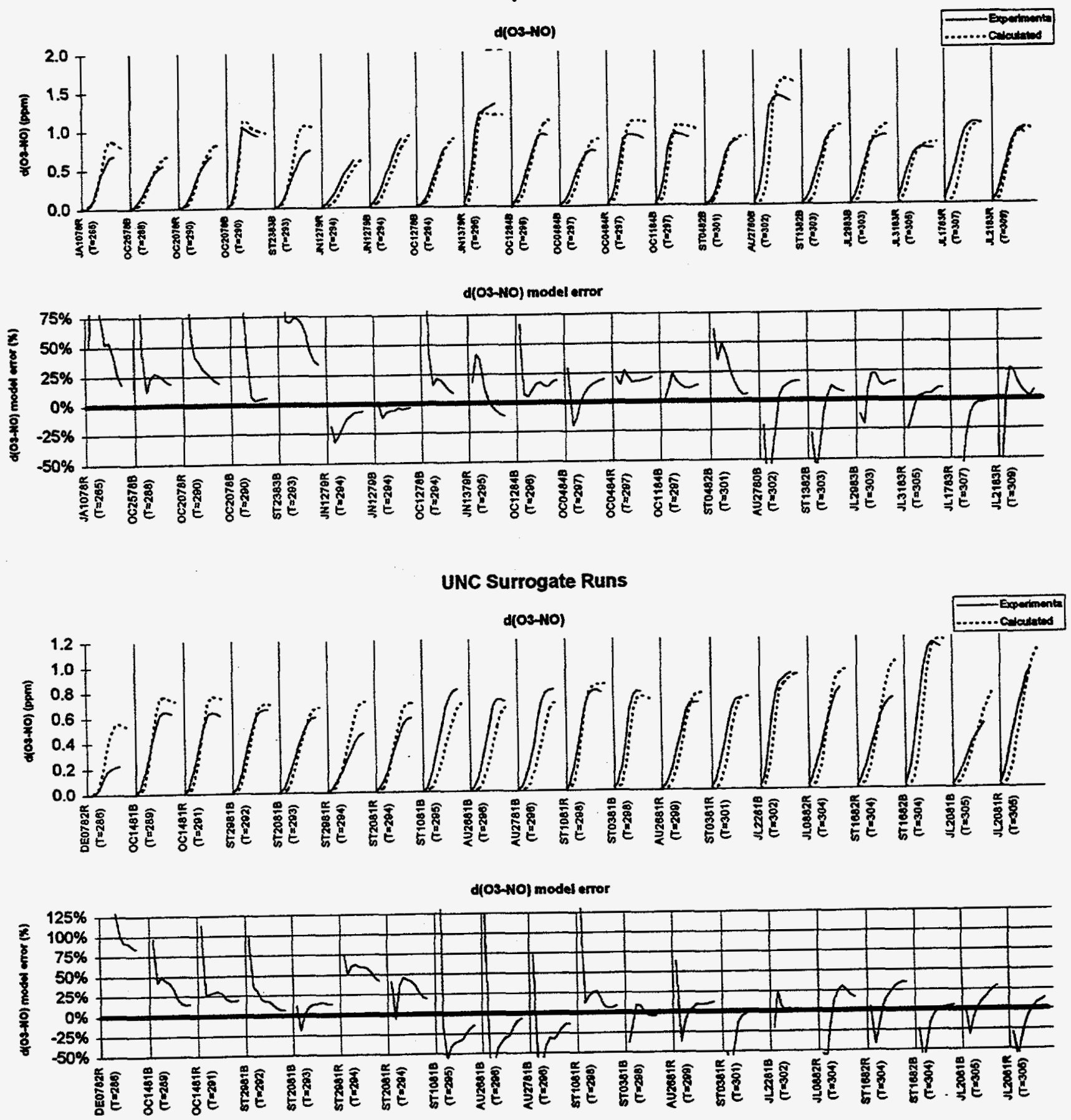

Figure 35. Results of model simulations of $\mathrm{d}\left(\mathrm{O}_{3}-\mathrm{NO}\right)$ in propene - $\mathrm{NO}_{x}$ and surrogate - $\mathrm{NO}_{x}$ experiments carried out in the uNC outdoor chamber. Runs are ordered by temperature. 


\section{CONCLUSIONS}

This study has provided useful information concerning the current status of chemical mechanism evaluation using environmental chamber data. To our knowledge, this is the first attempt to systematically evaluate the effect of changing the nature of the light source on the ability of a state-of-the-art chemical mechanism to simulate environmental chamber results. Although the results were not completely conclusive because of inconsistencies between new xenon arc chamber runs and previous runs in a different type of chamber using a similar light source, we believe that significant progress has been made. The conclusions which can be drawn from this work are summarized below.

Performance Evaluation of Alternative Light Sources. Xenon arc lights give a better representation of sunlight for use in indoor chamber experiments than the other alternatives which were examined. A commercially-available system consisting of four $6.5 \mathrm{~kW}$ xenon arc lights installed in a room with reflective surfaces and was found to give acceptable light intensity and uniformity for irradiating a 5000 -liter Teflon film chamber. The lights decline slowly in intensity with time, particularly in the UV portion of the spectrum. However, in terms of spectral stability and representativeness of ground-level sunlight in the far UV region the well-conditioned or aged xenon arc lights are actually more suitable for environmental chamber studies than newly conditioned ones. With power settings adjusted to give the appropriate $\mathrm{NO}_{2}$ photolysis rates, this light source can give rate constants for the other known atmospherically-relevant photolysis reactions which correspond to those of mid-day, clear sky sunlight to within a factor of 2 or better. This is as good as can reasonably be expected, especially since ratios of photolysis rates can vary by a factor of two or more in the atmosphere, depending on the solar zenith angle and other conditions. This is definitely superior to the performance of blacklights in this regard, since blacklights give significantly lower relative photolysis rates for $\alpha$ dicarbonyls (important products from aromatics) and $\mathrm{NO}_{3}$ radicals than expected for the atmosphere.

However, the match between xenon arc lights and sunlight is not exact, and outdoor chamber runs are still necessary to verify that we can accurately model the important photoreactive processes in the atmosphere. They are also necessary to verify the performance of the xenon arc system in simulating photochemical reactions in sunlight. To be useful for this, light spectrum for outdoor chamber runs must be much better characterized than has been the case in the past. An improved method for deriving outdoor chamber light spectra was developed to address this need. This is based on direct measurements of sunlight spectra during the runs, and utilizing a light model to correct for differences between the measured spectra and intensities and spectra and intensities in the chamber. The method gave good predictions of $\mathrm{NO}_{2}$ photolysis rates measured in and out of the chamber, though a $\sim 7 \%$ correction, presumably to account for albedo effects, 
had to be applied. Although only applicable for modeling runs carried out under clear sky conditions, we were able to carry out a sufficient number of outdoor runs under such conditions to provide a useful comparison with the xenon arc and other experiments.

The results of the outdoor chamber and xenon arc runs were generally consistent in terms of model performance when simulating comparable runs. With the possible exception of the outdoor chamber ethene runs, where inexplicably variable results were obtained, the types of runs which were simulated reasonably well in the XTC were also simulated reasonably well in the OTC. Where there were biases in the model performance results, they were generally the same for both chambers. This indicates that modeling runs using the xenon arc light source gives a good indication of how well the model will perform simulating runs using real sunlight, provided that other conditions are comparable. The consistency in the OTC and XTC results also provides validation for the light characterization method developed for the outdoor chamber.

Chamber Effects. Chamber effects represent a significant factor which must be taken into account when comparing data from different chambers. The differences in mechanism evaluation results between the SAPRC EC and the new XTC, which have essentially the same type of light source but quite different types of walls (and operated at different humidities), indicate the potential importance of chamber effects.

The most important known chamber effect is the chamber radical source. This can be a significant factor affecting model biases when assessing model performance using environmental chamber data. This is particularly important when looking for trends and biases on the order of $25-50 \%$, which is the case for most of the groups of runs modeled in this work. Uncertainties and variabilities in the radical source have the greatest effect under low ROG/NO conditions. Therefore, the sensitivity of the model simulations to this effect decreases as $\mathrm{ROG} / \mathrm{NO}_{\mathbf{x}}$ increases. This means that an inappropriate radical source assignment could cause apparent $\mathrm{ROG} / \mathrm{NO}_{x}$ dependencies in model biases. Because of this, and the uncertainties and variabilities in the radical source, we find that the that model performance generally improves as $\mathrm{ROG} / \mathrm{NO}_{x}$ increases.

The radical source assignments which have been used in previous mechanism evaluations are apparently too high, particularly for the SAPRC ITC. The tracerNO $_{x}$ runs used previously to derive radical source parameters for that chamber are inconsistent with results of $\mathrm{n}$-butane- $\mathrm{NO}_{\mathrm{x}}, \mathrm{CO}-\mathrm{NO}_{\mathrm{x}}$ and propene-NO $\mathrm{N}_{\mathrm{x}}$ runs. We conclude that the tracer- $\mathrm{NO}_{x}$ method for deriving radical source parameters is probably not reliable for Teflon chambers, though the reason for this is not known. There was a smaller apparent bias for previous radical source assignments in the EC, where the higher magnitude of the radical source makes deriving its values less uncertain. However, the radical sources in that chamber still had 
to be adjusted downward by $25 \%$ to eliminate bias in the model simulations of the n-butane runs.

This revision of our radical source assignments for the EC and ITC has implications concerning previous SAPRC mechanism evaluations. These high radical source assignments may be the reason that we found that the performance of the SAPRC-90 mechanism (Carter, 1990) in simulating these EC and ITC runs deteriorated when it was updated based on new laboratory data (Carter, 1993). The simulations using the SAPRC-90 mechanism fit the results of these runs without any apparent overall bias when the previous radical source assignments were used, though there was significant run-to-run variability (Carter and Lurmann, 1991). The updates made the mechanism slightly more "reactive", which resulted in it appearing to have a positive bias when simulating the same data set. The revised radical source assignments, which are based on considerations unrelated to the mechanism updates, remove this bias. This is indicated by the model performance of the updated mechanism, in this work, where no such overall positive bias is seen in simulations of the SAPRC EC and ITC runs. Thus, these new assignments indicate that a more "reactive" mechanism is more consistent with the data than indicated by model simulations using the previous radical source assignments, though the implications of this in terms of VOC reactivity simulations has not been fully assessed. This indicates the importance of appropriate and consistent radical source assignments when evaluating mechanisms using chamber data.

The chamber radical source has been known to be temperature dependent (Carter et al, 1992; Carter and Lurmann, 1990, 1991), and the results of this work provides additional support for this, and improved the data base necessary to quantify it. A single Arrhenius-type temperature dependence expression was found to fit the results of the $n$-butane runs carried out in all the Teflon film chambers where dry air was used, regardless of light source. This is based primarily on the $n$-butane runs in the outdoor chamber, where the average temperature ranged from $310-319 .{ }^{\circ} \mathrm{K}$, combined with the indoor runs where the temperature was typically $\sim 300^{\circ} \mathrm{K}$. The temperature dependence corresponds to an apparent activation energy of $20 \mathrm{kcal} / \mathrm{mole}$. The radical sources are higher in the SAPRC ITC because it uses humidified air, and higher yet in the SAPRC EC because of a different type of chamber surface as well as use of humidified air.

The dependence of the radical source on temperature explains some but not all of the temperature dependence observed in previous chamber runs. In particular, the parameterization based on the n-butane runs in the OTC and other chambers give good simulations of the replicate ETC mini-surrogate experiments (Carter et al, 1993) with average temperatures higher than $\sim 301^{\circ} \mathrm{K}$, but overpredict $\mathrm{O}_{3}$ formation in the runs at lower temperatures. A similar result is observed in the simulations of the propene and surrogate mixture - $\mathrm{NO}_{\mathrm{x}}$ runs in the UNC outdoor chamber. (Even assuming zero radical source causes overprediction in the lower temperature UNC runs.) It is probable that either the current gas-phase mechanisms are not accurate for lower temperature conditions, or that 
there is some low-temperature chamber artifact that is not currently recognized. More controlled experiments, both for chamber characterization and for mechanism evaluation, are needed for lower temperature conditions.

Effect of Chamber and Light Source on Mechanism Evaluations. The results of this study indicate no significant light source effect in the mechanisms evaluation results for runs which do not contain aromatics. The good performance in simulating the aldehyde runs in chambers with the different light sources is significant, since these compounds are photoreactive and experiments with them should be highly sensitive to the light source. The model is appropriately representing the differences in light spectra between blacklights, xenon arcs, and sunlight, at least for the photolysis reactions which are important in runs which do not contain aromatics.

There was variability in the model performance in the simulations of the propene and even more in the simulations of the ethene runs, in some of the chambers. In the case of propene the variability was greatest in the EC and ITC runs, which have different light sources but which both use humidified air. This may be a humidity effect because less variability was observed in the other chambers where dry air is used. In the case of ethene, the model performance in simulating runs in the EC and the OTC was highly variable and had no obvious dependence on $\mathrm{ROG} / \mathrm{NO}_{x}$ ratio or temperature. This is despite reasonably good performance in simulating the ethene runs in the blacklight chambers (both wet and dry) and in the limited number of XTC runs. The reason for this poor performance for ethene runs in these chambers is unclear, given the better model performance for propene and good performance for formaldehyde, the principal reactive product formed by ethene. There may be something in ethene's chemistry which is not being well represented in the model, though ethene has been thought to be the best understood of all the reactive vocs*. A more systematic study of humidity effects is necessary to investigate the reasons for the variability in the propene runs. More ethene runs in the $\mathrm{XTC}$, at variable $\mathrm{ROG} / \mathrm{NO}_{x}$ and temperatures, are needed to determine what experimental variables affect model performance for this important compound. Such experiments are being included in the next phase of our experimental chamber studies.

The model simulations of the aromatic and mixture runs in the various chambers suggests that there may be a problem either in the gas-phase mechanisms for aromatic compounds, or some chamber or humidity effect involving aromatics which has not been identified. The model gives fair to good performances in simulating the aromatic and mixture runs in the blacklight chambers and the EC - variabilities exist but at least no consistent biases are observed. The worst

*Jeffries et al. (1990) observed poor model performance in simulations of some UNC ethene runs, and speculated that this was due to uncertainties in the chemistry of glycolaldehyde, which is formed in $20 \%$ yield in the ethene $+\mathrm{OH}$ reaction. 
performance for these chambers is the mixture runs in the ITC, where run-to-run variability similar to (but slightly worse than) the variability in the propene runs in that chamber. The model simulations of mixture runs in the unc outdoor chamber also had no consistent biases except at the lower temperatures. On the other hand, the model has a consistent bias towards underpredicting ozone formation in aromatic or mixture runs in the XTC, and also usually underpredicted ozone formation in the OTC runs. This is not simply a light source effect because such biases are not seen in the EC or UNC experiments, and not simply a humidity effect since such biases are not seen in the DTC or ETC.

This result is difficult to understand unless there are compensating errors in the model involving both humidity and light source effects in the chambers where the unbiased fits are observed. It could be, for example, that humidity is affecting the yield of some of the photoreactive aromatic products whose relative photolysis rates are significantly different under blacklight irradiation than with solar or xenon arc lights. However, these conclusions are based on a very limited number of XTC and OTC runs, and on highly preliminary model simulations of the UNC data. We are planning to carry out an extensive series of additional aromatic experiments in the xenon arc chamber, and the study of the effects of humidity on these experiments, as part of the next phase of our experimental environmental chamber programs. 
100 


\section{REFERENCES}

Atkinson, R. (1990): "Gas-Phase Tropospheric Chemistry of Organic Compounds: A Review," Atmos. Environ., 24A, 1-24.

Atkinson, R. (1991) : "Kinetics and Mechanisms of the Gas-Phase Reactions of the $\mathrm{NO}_{3}$ Radical with Organic Compounds," J. Phys. Chem. Ref. Data, 20, 459-507.

Atkinson, R. (1994): "Gas-Phase Tropospheric Chemistry of Organic Compounds," J. Phys. Chem. Ref. Data, Monograph No. 2.

Atkinson, R. and S. M. Aschmann (1993): "OH Radical Production from the GasPhase Reactions of $\mathrm{O}_{3}$ with a Series of Alkenes under Atmospheric Conditions," Environ. Sci. Technol, 27, 1357-1363.

Beauchene, J. H., P. J. Bekowies, J. M. MCAfee, A. M. Winer, I. Zafonte and J. N. Pitts, Jr. (1973): "A Novel $20 \mathrm{KW}$ Solar Simulator Designed for Air Pollution Research," Proc. Seventh Conf. on Space Simulation, Paper No., 66, NASA Special Publication 335, pp 811-825.

Carter, W. P. L., P. S. Ripley, C. G. Smith, and J. N. Pitts, Jr. (1981): "Atmospheric Chemistry of Hydrocarbon Fuels: Vol I, Experiments, Results and Discussion," Final report to the U. S. Air Force, ESL-TR-81-53, November.

Carter, W. P. L., R. Atkinson, A. M. Winer, and J. N. Pitts, Jr. (1982): "Experimental Investigation of Chamber-Dependent Radical Sources, "Int. J. Chem. Kinet., 14, 1071.

Carter, W. P. L., Dodd, M. C., Long, W. D. and Atkinson, R. (1984): "Outdoor Chamber Study to Test Multi-Day Effects. Volume I: Results and Discussion," Final report, EPA-600/3-84-115.

Carter, W. P. L., W. D. Long, L. N. Parker, and M. C. Dodd (1986): "Effects of Methanol Fuel Substitution on Multi-Day Air Pollution Episodes, " Final Report on California Air Resources Board Contract No. A3-125-32, April.

Carter, W. P. I. and R. Atkinson (1987): "An Experimental Study of Incremental Hydrocarbon Reactivity," Environ. Sci. Technol., 211, 670-679

Carter, W. P. I., J. A. Pierce, I. I. Malkina, and D. Luo (1992): "Investigation of the Ozone Formation Potential of Selected Volatile Silicone Compounds," Final Report to Dow Corning Corporation, Midland, MI, November.

Carter, W. P. I. (1990): "A Detailed Mechanism for the Gas-Phase Atmospheric Reactions of Organic Compounds," Atm. Environ., 24A, 481-518.

Carter, W. P. L., and F. W. Lurmann (1990): "Evaluation of the RADM Gas-Phase Chemical Mechanism," Final Report, EPA-600/3-90-001.

Carter, W. P. L. and F. W. Lurmann (1991): "Evaluation of a Detailed Gas-Phase Atmospheric Reaction Mechanism using Environmental Chamber Data," Atm. Environ. 25A, 2771-2806.

Carter, W. P. L. and R. Walters (1992): "Design and Specification of a Light Source for Experimental Studies of Atmospheric Reactivities of volatile 
Organic Compounds," report to the National Renewable Energy Laboratory Contract No. XZ 2120751, August 15.

Carter, W. P. L., J. A. Pierce, I. L. Malkina, D. Luo and W. D. Long (1993a) : "Environmental Chamber Studies of Maximum Incremental Reactivities of Volatile Organic Compounds," Report to Coordinating Research Council, Project No. ME-9, California Air Resources Board Contract No. A032-0692; South Coast Air Quality Management District Conțract No. C91323, United States Environmental Protection Agency Cooperative Agreement No. CR814396-01-0, University Corporation for Atmospheric Research Contract No. 59166, and Dow Corning Corporation. April 1.

Carter, W. P. L, D. Luo, I. L. Malkina, and J. A. Pierce (1993b): "An Experimental and Modeling Study of the Photochemical Ozone Reactivity of Acetone," Final Report to Chemical Manufacturers Association Contract No. KET-ACE-CRC-2.0. December 10.

Carter, W. P. L., D. Luo, I. L. Malkina, and D. Fitz (1995a): "The University of California, Riverside Environmental Chamber Data Base for Evaluating Oxidant Mechanism. Indoor Chamber Experiments through 1993," Report submitted to the U. S. Environmental protection Agency, EPA/AREAL, Research Triangle Park, NC., March 20..

Carter, W. P. L., D. Luo, I. L. Malkina, and J. A. Pierce (1995b): "Environmental Chamber Studies of Atmospheric Reactivities of Volatile Organic Compounds. Effects of Varying ROG surrogate and $\mathrm{NO}_{x}$," Draft final report to Coordinating Research Council, Inc., Project ME-9, California Air Resources Board, Contract A032-0692, and South Coast Air Quality Management District, Contract C91323. March 24.

Dasgupta, P. K, Dong, S. and Hwang, H. (1988): "Continuous Liquid Phase Fluorometry Coupled to a Diffusion Scrubber for the Determination of Atmospheric Formaldehyde, Hydrogen Peroxide, and Sulfur Dioxide," Atmos. Environ. 22, 949-963.

Dasgupta, P.K, Dong, S. and Hwang, H. (1990): Aerosol Science and Technology 12, $98-104$

Dong, S. and Dasgupta, P. K. (1987): "Fast Fluorometric Flow Analysis of Formaldehyde," Environ. Sci. and Technol. 21, 581-588.

Dumdei, B. E. and R. J. O'Brien (1984): "Toluene Degradation Products in Simulated Atmospheric Conditions," Nature 311, 248-240.

Gardner, E. P., P. D. Sperry, and J. G. Calvert (1987): "Photodecomposition of Acrolein in $\mathrm{O}_{2}-\mathrm{N}_{2}$ Mixtures," J. Phys. Chem. 91, 1922.

Gery, M. W., G. Z. Whitten, and J. P. Killus (1988) : "Development and Testing of the CBM-IV For Urban and Regional Modeling,", EPA-600/3-88-012, January.

Jeffries, H. E., R. M. Kamens, K. G. Sexton, and A. A. Gerhardt (1982) : "Outdoor Smog Chamber Experiments to Test Photochemical Models", EPA-600/3-82-016a, April.

Jeffries, H. E., Sexton, K. G., Kamens, R. M. and Holleman, M. S. (1985a): "Outdoor Smog Chamber Experiments to Test Photochemical Models: Phase II, " Final Report, EPA-600/3-85-029.

Jeffries, H. E., Sexton, K. G., Morris, T. P., Jackson, H., Goodman, R. G., Kamens, R. M. and Holleman, M. S. (1985b): "Outdoor Smog Chamber Experiments Using Automobile Exhaust," Final Report, EPA-600/3-85-032. 
Jeffries, H. E., K. G. Sexton, and M. S. Holleman (1985C): "Outdoor Smog Chamber experiments: Reactivity of Methanol Exhaust", Final Report, EPA-600/3-85-009a, September

Jeffries, H. E., K. G. Sexton, J. R. Arnold, Y. Bai, J. L. Li, and R. Crouse (1990): "A Chamber and Modeling Study to Assess the Photochemistry of Formaldehyde," Report on EPA Cooperative Agreement CR-813964, Atmospheric Research and Exposure Assessment Laboratory, EPA, Research Triangle Park, NC.

Jeffries, H. E. (1988): Department of Environmental Science and Engineering, University of North Carolina, Chapel Hill, NC, diskette containing JSPECTRA code and input files. Main JSPECTRA source file dated June 22. Example input files dated November 10.

Jeffries, H. E. (1991): "UNC Solar Radiation Models," unpublished draft report for EPA Cooperative Agreements CR813107, CR813964 and CR815779". Undated.

Jeffries, H. E., M. W. Gery and W. P. I. Carter (1992a): "Protocol for Evaluating Oxidant Mechanisms for Urban and Regional Models," Report for U. S. Environmental Protection Agency Cooperative Agreement No. 815779, Atmospheric Research and Exposure Assessment Laboratory, Research Triangle Park, NC.

Jeffries, H. E. and K. G. Sexton (1992b) : "The Relative Ozone Forming Potential of Methanol-Fueled Vehicle Emissions and Gasoline-Fueled Vehicle Emissions in Outdoor Smog Chambers," Annual Report for the Coordinating Research Council Project No. ME-1, August 30.

Jeffries H. E., K. G. Sexton, J. R. Arnold, and T. L. Kale (1989): "Validation Testing of New Mechanisms with Outdoor Chamber Data. Volume 3: Calculation of Photochemical Reaction Photolysis Rates in the UNC Outdoor Chamber," Final Report, EPA-600/3-89-010c.

Johnson, G. M. (1983): "Factors Affecting oxidant Formation in Sydney Air," in "The Urban Atmosphere -- Sydney, a Case Study." Eds. J. N. Carras and G. M. Johnson (CSIRO, Melbourne), pp. 393-408.

Lurmann, F. W., W. P. L. Carter, and R. A. Coyner (1987): "A Surrogate Species Chemical Reaction Mechanism for Urban-Scale Air Quality Simulation Models. Volume I - Adaptation of the Mechanism," EPA-600/3-87-014a.

Meyrahn, H., J. Pauly, W. Schneider, and P. Warneck (1986): "Quantum Yields for the Photodissociation of Acetone in Air and an Estimate for the Life Time of Acetone in the Lower Troposphere," J. Atmos. Chem. 4, 277-291.

Peterson, J. T. (1976): "Calculated Actinic Fluxes (290-700 nm) for Air Pollution Photochemistry Applications", EPA-600/4-76-025, June.

Pitts, J. N., Jr., K. Darnall, W. P. L. Carter, A. M. Winer, and R. Atkinson (1979): "Mechanisms of Photochemical Reactions in Urban Air," EPA-600/ 3-79-110, November.

Pitts, J. N., Jr., E. Sanhueza, R. Atkinson, W. P. L. Carter, A. M. Winer, G. W. Harris, and C. N. Plum (1984): "An Investigation of the Dark Formation of Nitrous Acid in Environmental Chambers," Int. J. Chem. Kinet., 16, 919939.

Shepson, P. B., E. O. Edney, and E. W. Corse (1984): Ring Fragmentation Reactions in the photooxidations of Toluene and o-xylene," J. Phys. Chem, $88,4122-4126$. 
Stockwell, W. R., P. Middleton, J. S. Chang, and X. Tang (1990): "The Second Generation Regional Acid Deposition Model Chemical Mechanism for Regional Air Quality Modeling," J. Geophys. Res. 95, 16343- 16376.

Tuazon, E. C., R. Atkinson, C. N. Plum, A. M. Winer, and J. N. Pitts, Jr. (1983): "The Reaction of Gas-Phase $\mathrm{N}_{2} \mathrm{O}_{5}$ with Water Vapor, "Geophys. Res. Lett. 10, 953-956.

Winer, A. M., R. A. Graham, G. J. Doyle, P. J. Bekowies, J. M. McAfee, and J. N. Pitts, Jr. (1980): "An Evacuable Chamber and Solar Simulator Facility for the Study of Atmospheric Photochemistry, "Adv. Environ. Sci. Technol. I0, 461 .

Zafonte, L., P. L. Rieger, and J. R. Holmes (1977): "Nitrogen Dioxide Photolysis in the Los Angeles Atmosphere," Environ. Sci. Technol. 11, 483-487. 
Public reporting burden for this collection of information is estimated to average 1 hour per response, including the time for reviewing instructions, searching existing data sources, gathering and maintaining the data needed, and completing and reviewing the collection of information. Send comments regarding this burden estimate or any other aspect of this collection of information, including suggestions for reducing this burden, to Washington Headquarters Services, Directorate for Information Operations and Reports, 1215 Jefferson Davis Highway, Suite 1204, Artington, VA 22202-4302, and to the Office of Management and Budget, Paperwork Reduction Project (0704-0188), Washington, DC 20503.
1. AGENCY USE ONLY (Leave blank)

\section{REPORT DATE \\ May 1995}
3. REPORT TYPE AND DATES COVERED
Subcontract report

\section{TITLE AND SUBTITLE}

Environmental Chamber Studies of Atmospheric Reactivities of Volatile Organic Compounds: Effects of Varying

Chamber and Light Source

5. FUNDING NUMBERS

(C) XZ-2120751

(TA) FU522010

\section{AUTHOR(S)}

W. Carter, D. Luo, I. Malkina, and J. Pierce

\section{PERFORMING ORGANIZATION NAME(S) AND ADDRESS(ES)}

Statewide Air Pollution Research Center, and College of Engineering, Center for Environmental Research and

Technology, University of Califomia, Riverside, CA 92521

9. SPONSORING/MONITORING AGENCY NAME(S) AND ADDRESS(ES)

National Renewable Energy Laboratory

1617 Cole Boulevard

Golden, CO $80401-3393$

8. PERFORMING ORGANIZATION REPORT NUMBER

DE95009225

10. SPONSORINGMONITORING AGENCY REPORT NUMBER

NRELTP-425-7621

\section{SUPPLEMENTARY NOTES}

\section{2a. DISTRIBUTION/AVAILABILITY STATEMENT}

National Technical Information Service

U.S. Department of Commerce

5285 Port Royal Road

Springfield, VA 22161 12b. DISTRIBUTION CODE

$$
\text { UC } 1504
$$

\section{ABSTRACT (Maximum 200 words)}

An experimental and modeling study was conducted to assess how chemical mechanism evaluations using environmental chamber data are affected by the light source and other chamber characteristics. Experiments were also conducted in a new Teflon chamber constructed using new procedures to improve the light characterization, and in Tefion chambers using blacklights. These results and results of previous runs in other chambers, were compared with model predictions using an updated detailed chemical mechanism. This report presents the methodology and the results of this testing.

\section{SUBJECT TERMS}

Alternative fuels, atmospheric reactivity, volatile organic compounds, photochemical oxidant models

15. NUMBER OF PAGES

$$
123
$$

16. PRICE CODE

\section{SECURITY CLASSIFICATION OF REPORT}

\section{SECURITY CLASSIFICATION OF ABSTRACT}

20. LIMITATION OF ABSTRACT
Standard Form 298 (Rev. 2-89)

Prescribed by ANSI Std. Z39-18 